VIRGÍNIA LUCCHESE MASET

MODELO PARA ANÁLISE DO COMPORTAMENTO DE ESTACAS ESCAVADAS DE GRANDE DIÂMETRO COM FLUIDO ESTABILIZANTE NA BAIXADA SANTISTA, SUBMETIDAS A CARGAS AXIAIS 


\title{
MODELO PARA ANÁLISE DO COMPORTAMENTO DE ESTACAS ESCAVADAS DE GRANDE DIÂMETRO COM FLUIDO ESTABILIZANTE NA BAIXADA SANTISTA, SUBMETIDAS A CARGAS AXIAIS
}

\author{
Dissertação apresentada à Escola \\ Politécnica da Universidade de São \\ Paulo para obtenção do título de Mestre \\ em Ciências
}

Área de concentração:

Engenharia Geotécnica

Orientador: Prof. Dr. Faiçal Massad 
Autorizo a reprodução e divulgação total ou parcial deste trabalho, por qualquer meio convencional ou eletrônico, para fins de estudo e pesquisa, desde que citada a fonte.

\section{Catalogação-na-publicação}

Maset, Virgínia Lucchese

Modelo para análise do comportamento de estacas escavadas de grande diâmetro com fluido estabilizante na Baixada Santista submetidas a cargas axiais / V. L. Maset -- São Paulo, 2020.

$$
152 \mathrm{p} \text {. }
$$

Dissertação (Mestrado) - Escola Politécnica da Universidade de São Paulo. Departamento de Engenharia de Estruturas e Geotécnica.

1.Prova de carga estática 2.Instrumentação em profundidade 3.Estaca escavada de grande diâmetro 4.Baixada Santista I.Universidade de São Paulo. Escola Politécnica. Departamento de Engenharia de Estruturas e Geotécnica II.t. 


\section{AGRADECIMENTOS}

Aos meus pais, Márcia e Rubens, por todo o amor, cuidado, dedicação e incentivo ao longo de toda a minha vida.

À Jô, minha irmã, que sempre me viu como o seu exemplo, e hoje é o meu maior orgulho.

Ao Marco, meu marido, o amor da minha vida, por acreditar em mim incondicionalmente e me inspirar a ser uma pessoa melhor todos os dias.

Às mulheres da minha família, em especial à vó Luminda e à tia Áurea, por me ensinarem a ser uma mulher forte, independentemente das circunstâncias.

Às amigas - de infância, de Rio Preto, da Poli, da ZF -, pela amizade e apoio, além de algumas merecidas broncas.

À ZF \& Engenheiros Associados pelos dados das provas de carga estática e por todo o apoio para que este trabalho fosse finalizado.

Aos amigos da ZF, pela confiança, trocas de experiências e aprendizado ao longo desses últimos sete anos.

Ao prof. Faiçal Massad, pela gentileza, paciência, motivação e admirável sabedoria em todo o período da orientação.

Ao prof. Waldemar Hachich, por despertar em mim o amor pela Geotecnia.

Ao prof. Felipe Issa Kabbach Jr, pelas palavras de apoio e incentivo de que eu tanto precisava no momento, mesmo sem saber disso. 


\section{SUMÁRIO}

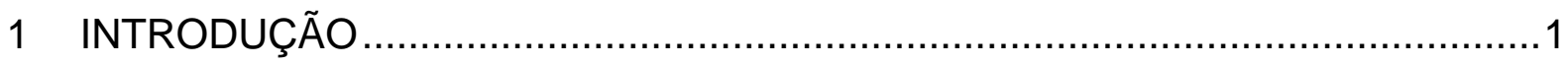

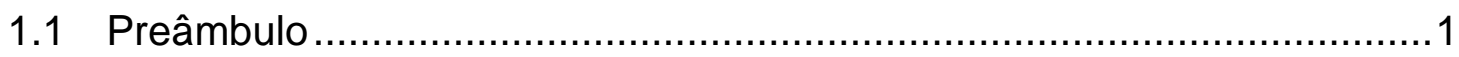

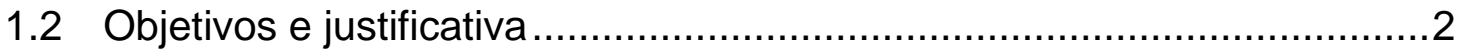

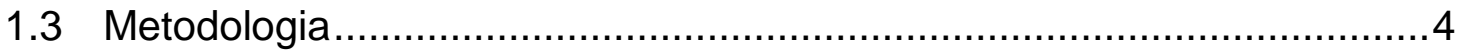

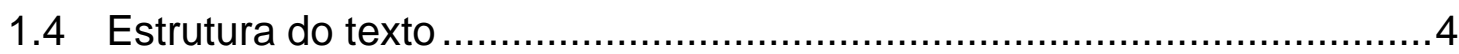

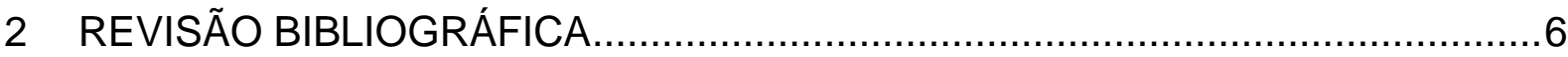

2.1 Histórico geológico, geotécnico e ocupacional da Baixada Santista ........6

2.2 Estacas escavadas de grande diâmetro com fluido estabilizante ...........16

2.3 Métodos semiempíricos de cálculo de capacidade de carga baseados em SPT. .24

2.3.1 Método de Décourt-Quaresma (1978) .....................................26

2.3.2 Método de Aoki-Velloso (1975) .................................................28

2.3.3 Método de Falconi e Perez (2008) …........................................30

2.4 Modelo matemático para análise de provas de carga .............................31

2.4.1 Modelo baseado nas Leis de Cambefort modificadas ...................31

2.4.2 Método de Coyle Reese (1966) ................................................

2.5 Provas de carga estática comuns e instrumentadas em profundidade ..38

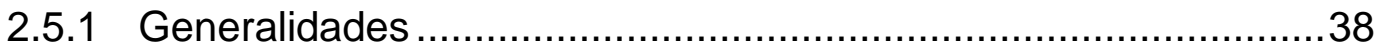

2.5.2 Técnicas de instrumentação em profundidade .............................44

2.5.3 Método do Módulo Tangente de Fellenius (1989) …....................47

2.6 Efeito "estaca T" da interface areia compacta-argila SFL .....................49

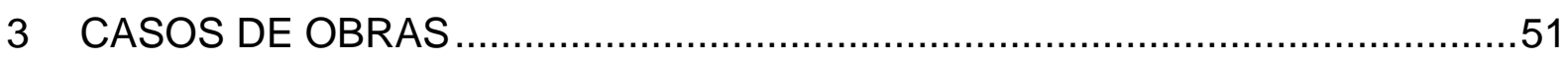

3.1 Características das obras e das estacas ensaiadas ………………......51

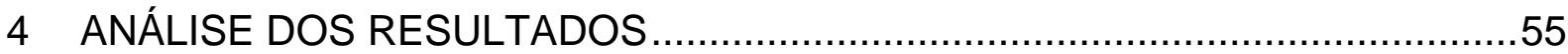

4.1 Detalhamento da metodologia de análise .........................................55

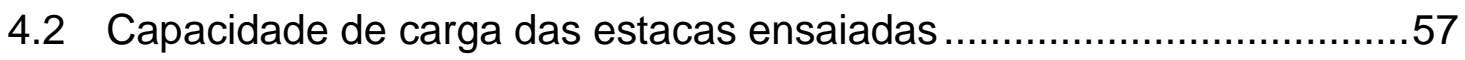

4.3 Provas de carga instrumentadas: parâmetros de Cambefort ..................61

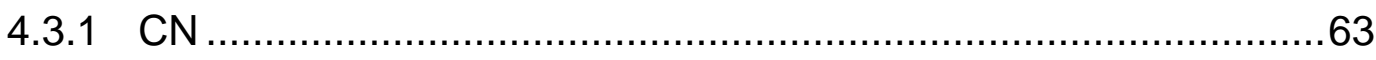

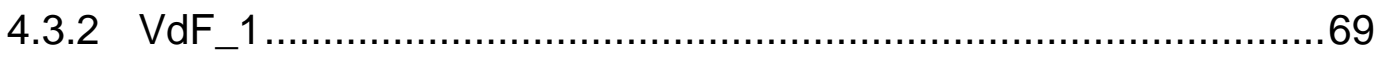

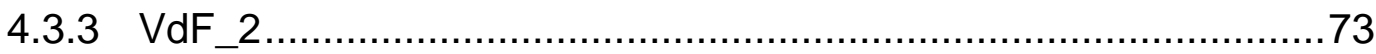

4.3.4 Corp_1 
4.3.5 Corp_2

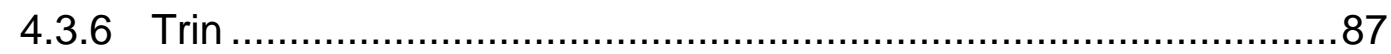

4.3.7 Resumo das análises das provas de carga instrumentadas ........92

4.4 Adaptação dos coeficientes do método Falconi-Perez (2008) para a sua utilização em estacas escavadas de grande diâmetro ........................................94

4.5 Modelo para determinação da curva $\mathrm{P}_{0}-\mathrm{y}_{0}$ de estacas escavadas de grande diâmetro com fluido estabilizante na Baixada Santista a partir dos dados das

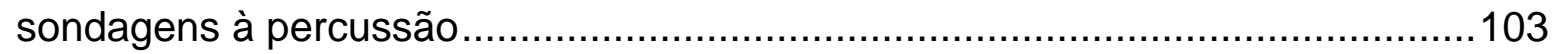

4.5.1 Aplicação do modelo utilizando os parâmetros determinados nos

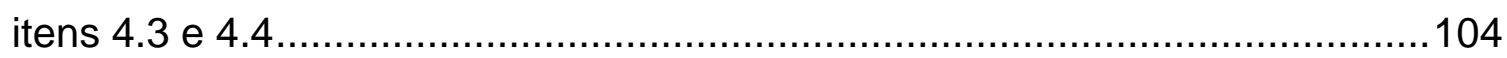

4.5.2 Aplicação do modelo com a adaptação dos parâmetros .............113

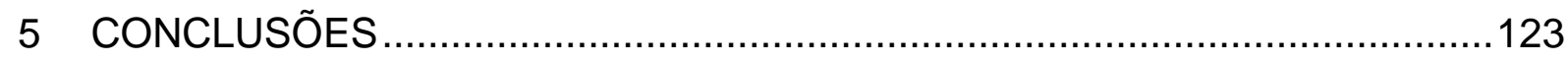

5.1 Sobre as estimativas de capacidade de carga por métodos semiempíricos 123

5.2 Sobre as análises das provas de carga instrumentadas em profundidade 123

5.3 Sobre o efeito "estaca T" 124

5.4 Sobre a adaptação dos coeficientes do método Falconi-Perez (2008) para estimar a capacidade de carga 124

5.5 Sobre o uso do método de Coyle-Reese (1966) para simular a curva carga-recalque do topo da estaca 125

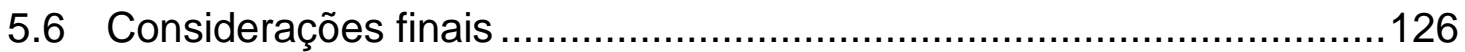

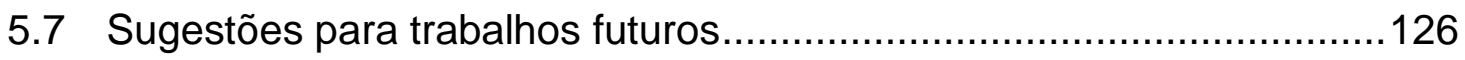

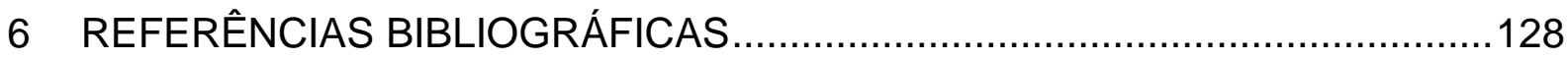

ANEXO I - DADOS DAS PROVAS DE CARGA ESTÁTICA ..................................133 


\section{RESUMO}

Para o caso específico de estacas escavadas de grande diâmetro com fluido estabilizante na Baixada Santista, existe a suspeita de que, quando dimensionadas por métodos semiempíricos consagrados com base no SPT, essas estacas estejam sendo superdimensionadas. Isso ocorre porque, nos solos da região, a história geológica e genética tem grande influência na capacidade de carga das fundações profundas, e essas características não necessariamente se refletem nos valores de SPT.

Dispõe-se nesse trabalho de 16 provas de carga estática, das quais 6 são instrumentadas em profundidade. Através dos dados das provas de carga, foi desenvolvido modelo matemático de previsão da curva carga-recalque no topo da estaca, com a utilização do método de Coyle-Reese (1966) e dos parâmetros de Cambefort (1964). O objetivo desse modelo é analisar o comportamento de estacas escavadas de grande diâmetro executadas na Baixada Santista, mais especificamente, em Santos e na Praia Grande, sob o ponto de vista de recalques admissíveis nas cargas de trabalho das estacas, em oposição à análise sob o ponto de vista de carga de ruptura.

Utilizando os resultados das provas de carga estática instrumentadas em profundidade, foi feita ainda uma análise com base em métodos semiempíricos de cálculo de capacidade de carga, em especial o método de Falconi-Perez (2008), e foi estudado como esses métodos podem ser aprimorados para refletirem de maneira mais realista o desempenho dessas estacas.

Observou-se que o modelo matemático desenvolvido pode ser aplicado para simular de maneira satisfatória o comportamento das estacas quando submetidas a um carregamento axial de compressão, principalmente do trecho inicial do carregamento até a carga de trabalho. Quanto à determinação da carga de ruptura, o modelo ainda precisa ser aprimorado, preferencialmente com a execução de ensaios que atinjam a ruptura geotécnica.

Palavras-Chave: prova de carga estática; instrumentação em profundidade; estaca escavada de grande diâmetro; Baixada Santista. 


\begin{abstract}
When analyzing large diameter bored piles with stabilizing fluid executed in the region of the Baixada Santista, in the coastal plain of the state of São Paulo, Brazil, there's a suspicion that, when calculated using the usual semi-empirical approaches, based on SPT results, these piles might be resulting longer than necessary. This probably occurs because the geological and genetic history of the typical soil layers of this region has great influence in the bearing capacity of the piles, and this history is not necessarily reflected in the SPT values of these soils.

In this work, 16 static load test results are presented, 6 of which were executed in instrumented piles. The data from the load tests were used to develop a mathematical model to predict the load-settlement curve at the top of the pile using the Coyle-Reese (1966) method and the Cambefort (1964) parameters. The goal for this model is to analyze the behavior of large diameter bored piles with stabilizing fluid executed in the Baixada Santista region (more specifically in the cities of Santos and Praia Grande), mainly their settlements under the usual working loads, in opposition to the usual approach of determining the failure load of the piles.

With the results from the static load tests in instrumented piles, an analysis based on semi-empirical load capacity calculation methods was conducted, with special focus on the Falconi-Perez (2008) method, studying whether these methods could be improved to reflect the behavior of the piles more realistically.

The mathematical model proposed was proven to simulate in a satisfactory way the behavior of piles when submitted to an axial compression load, especially on the beginning of the loading up to the usual working load. As for the failure load determination, the model still needs some improvement, more likely based on static load test results to be carried to failure.
\end{abstract}

Key-words: static load test; instrumented pile; large diameter bored pile; Baixada Santista. 


\section{LISTA DE FIGURAS}

Figura 1: esboço de corte geológico da Baixada Santista de acordo com conhecimento da década de 1950 (Vargas, 1999).

Figura 2: possíveis estádios da gênese das planícies sedimentares paulistas (Massad, 2009-a, apud Suguio e Martin, 1978).

Figura 3: perfil geológico sintético da orla praiana (Teixeira, 1994). .11

Figura 4: perfil geológico sintético da orla praiana (Massad, 2003, adaptado de Teixeira 1994). 11

Figura 5: perfil geológico sintético da orla praiana (Dias, 2010). 12

Figura 6: várias formas de desaprumos de edifícios em função da relatividade do tempo de construção (Teixeira, 1994).

Figura 7: método executivo para estaca escavada de grande diâmetro com fluido estabilizante (Brasfond, 2018) .18

Figura 8: colocação da camisa guia (acervo ZF, 2019) ..................................18

Figura 9: perfuração da estaca (acervo ZF, 2019). ........................................ 19

Figura 10: desarenação da lama bentonítica (acervo ZF, 2019). .........................19

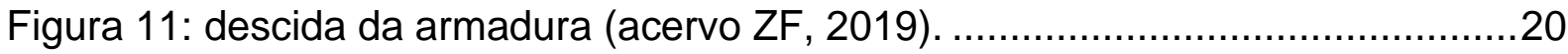

Figura 12: concretagem com tubo tremonha (acervo ZF, 2019). .........................20

Figura 13: canteiro de obras (acervo ZF, 2019)..........................................21

Figura 14: Leis de Cambefort (1964) modificadas por Cassan (1978) (extraída de

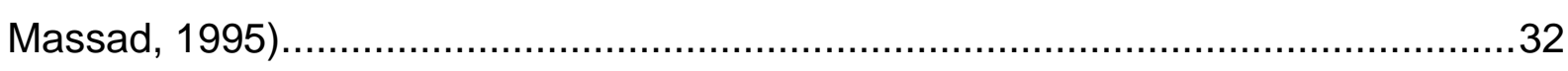

Figura 15: forças atuando em um elemento de estaca (adaptado de Massad, 1992).

Figura 16: curva carga-recalque teórica do topo da estaca (adaptado de Massad, 1992).

Figura 17: Relações de Cambefort modificadas para estacas escavadas submetidas ao primeiro carregamento (Massad, 1992). .36

Figura 18: Ilustração da aplicação do método de Coyle Reese (1966). 37

Figura 19: montagem de prova de carga estática com dois macacos hidráulicos em Santos (acervo ZF, 2019). 
Figura 20: detalhe dos dois macacos hidráulicos utilizados para aplicação de carga (acervo ZF, 2019).

Figura 21: detalhe do bloco de transferência de carga da estaca de reação para a viga (acervo ZF, 2019).

Figura 22: montagem de prova de carga estática com um macaco hidráulico em Santos (acervo ZF, 2019).

Figura 23: detalhe do macaco hidráulico e das vigas de referência com os deflectômetros (acervo ZF, 2019).

Figura 24: detalhe do bloco de transferência da estaca de reação para a viga e do deflectômetro (acervo ZF, 2019).

Figura 25: centralina hidráulica com motor elétrico e equipe de controle do ensaio (acervo ZF, 2019).

Figura 26: instrumentação em profundidade para prova de carga estática (Niyama et al, 2017). .44

Figura 27: Strain gages (acervo ZF, 2019)..... .46

Figura 28: painel e caixa seletora (acervo ZF, 2019). .46

Figura 29: curvas típicas de uma prova de carga instrumentada em estaca com módulo de elasticidade constante (metálica) (Fellenius, 1989)....

Figura 30: curvas típicas de prova de carga instrumentada em estaca com módulo de elasticidade que diminui com o aumento da tensão aplicada (concreto) (Fellenius, 1989).

Figura 31: exemplo de gráfico para obtenção do ES em ensaio com 5 níveis de instrumentação pelo método do Módulo Tangente de Fellenius (1989) adaptado por Massad (2009-b) (adaptado de Massad, 2009-b). 49

Figura 32: localização das obras nas cidades de Santos e Praia Grande/SP...... 52

Figura 33: localização das obras na cidade de Santos/SP. .52

Figura 34: capacidades de carga calculadas pelo método de Décourt-Quaresma (1978). .58

Figura 35: capacidades de carga calculadas pelo método de Aoki-Velloso (1975)...58 Figura 36: capacidades de carga calculadas pelo método de Falconi-Perez (2008).58 Figura 37: comparação entre a capacidade de carga calculada pelos métodos semiempíricos e a carga máxima atingida no ensaio, em kN. 60 
Figura 38: relação entre a capacidade de carga média calculada pelos três métodos semiempíricos e a carga máxima atingida no ensaio.

Figura 39: carga aplicada no topo da estaca em função da deformação média em cada nível de instrumentação para a prova de carga $\mathrm{CN}$.

Figura 40: diagramas de transferência de carga em profundidade para o ensaio $\mathrm{CN}$.

Figura 41: função de transferência de carga para o trecho topo - SG 01 do ensaio CN.

Figura 42: função de transferência de carga para o trecho SG 01-02 do ensaio CN.

Figura 43: função de transferência de carga para o trecho SG 02-05 do ensaio CN.

Figura 44: função de transferência de carga para o trecho SG 05-06 do ensaio CN.

Figura 45: função de transferência de carga para o

Figura 46: curva carga-recalque no topo da estaca obtida pelo método de CoyleReese (1966) para o ensaio CN.

Figura 47: carga aplicada no topo da estaca em função da deformação média em cada nível de instrumentação para a prova de carga VdF_1. .70

Figura 48: diagramas de transferência de carga para o ensaio VdF_1. .71

Figura 49: função de transferência de carga para o trecho topo - SG01 do ensaio VdF_1.

Figura 50: função de transferência de carga para o trecho SG01 - SG02 do ensaio $\mathrm{VdF}$ 1.

Figura 51: função de transferência de carga para o trecho SG02 - SG03 do ensaio VdF_1.

Figura 52: função de transferência de carga para o trecho SG03 - SG04 do ensaio VdF_1. .72

Figura 53: função de transferência de carga para o trecho SG04 - 05 do ensaio VdF_1.

Figura 54: função de transferência de carga para o trecho SG05 - 06 do ensaio VdF_1. 
Figura 55: carga aplicada no topo da estaca em função da deformação média em cada nível de instrumentação para a prova de carga VdF_2....................................75

Figura 56: diagramas de transferência de carga para o ensaio VdF_2 ...................76 Figura 57: função de transferência de carga para o trecho topo - SG01 do ensaio

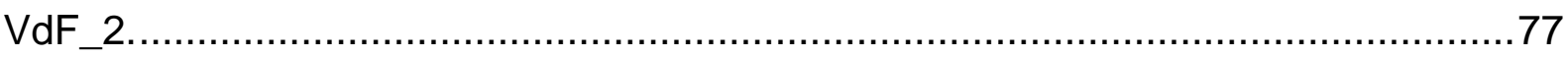

Figura 58: função de transferência de carga para o trecho SG01 - SG02 do ensaio $\mathrm{VdF} 2$

Figura 59: função de transferência de carga para o trecho SG02 - SG03 do ensaio $\mathrm{VdF} 2$.

Figura 60: função de transferência de carga para o trecho SG03 - SG04 do ensaio VdF_2.

Figura 61: função de transferência de carga para o trecho SG04 - 05 do ensaio VdF_2.

Figura 62: função de transferência de carga para o trecho SG05 - 06 do ensaio VdF_2.

Figura 63: curva carga-recalque no topo da estaca obtida pelo método de CoyleReese (1966) para o ensaio VdF_2.

Figura 64: carga aplicada no topo da estaca em função da deformação média em cada nível de instrumentação para a prova de carga Corp_1 80

Figura 65: diagramas de transferência de carga para o ensaio Corp_1. .82

Figura 66: função de transferência de carga para o trecho topo-SG01 do ensaio Corp_1.

Figura 67: função de transferência de carga para o trecho SG01-SG02 do ensaio Corp_1.

Figura 68: função de transferência de carga para o trecho SG02-SG03 do ensaio Corp_1.

Figura 69: função de transferência de carga para o trecho SG03-SG04 do ensaio Corp_1.

Figura 70: função de transferência de carga para o trecho SG04-05 do ensaio Corp_1.

Figura 71: função de transferência de carga para o trecho SG05-06 do ensaio Corp_1. 
Figura 72: função de transferência de carga para o .83

Figura 73: curva carga-recalque no topo da estaca obtida pelo método de CoyleReese (1966) para o ensaio Corp_1.

Figura 74: carga aplicada no topo da estaca em função da deformação média em cada nível de instrumentação para a prova de carga Corp_2.

Figura 75: carga aplicada no topo da estaca em função da deformação média em cada nível de instrumentação para a prova de carga Trin. .88

Figura 76: diagramas de transferência de carga em profundidade do ensaio Trin....89 Figura 77: função de transferência de carga para o trecho SG 01-02 do ensaio Trin.

Figura 78: função de transferência de carga para o trecho SG 02-03 do ensaio Trin.

Figura 79: função de transferência de carga para o trecho SG 03-04 do ensaio Trin.

Figura 80: função de transferência de carga para o trecho SG 04-P (ponta fictícia) do ensaio Trin.

Figura 81: curva carga-recalque no topo da estaca obtida pelo método de CoyleReese (1966) para o ensaio Trin.

Figura 82: comparação entre a carga máxima do ensaio e o atrito lateral estimado pelo método Falconi-Perez (2008).

Figura 83: atrito lateral nos trechos do ensaio $\mathrm{CN}$ medido e calculado pelo método Falconi-Perez (2008) com os coeficientes adaptados.

Figura 84: atrito lateral nos trechos do ensaio VdF_1 medido e calculado pelo método Falconi-Perez (2008) com os coeficientes adaptados. 96

Figura 85: atrito lateral nos trechos do ensaio VdF_2 medido e calculado pelo método Falconi-Perez (2008) com os coeficientes adaptados. 97

Figura 86: atrito lateral nos trechos do ensaio Corp_1 medido e calculado pelo método Falconi-Perez (2008) com os coeficientes adaptados. .97

Figura 87: atrito lateral nos trechos do ensaio Trin medido e calculado pelo método Falconi-Perez (2008) com os coeficientes adaptados. 
Figura 88: atrito lateral nos trechos do ensaio $\mathrm{CN}$ medido e calculado pelo método Falconi-Perez (2008) com os coeficientes adaptados e diferenciação da areia compacta superficial.

Figura 89: atrito lateral nos trechos do ensaio VdF_1 medido e calculado pelo método Falconi-Perez (2008) com os coeficientes adaptados e diferenciação da areia compacta superficial. 100

Figura 90: atrito lateral nos trechos do ensaio VdF_2 medido e calculado pelo método Falconi-Perez (2008) com os coeficientes adaptados e diferenciação da areia compacta superficial. 100

Figura 91: atrito lateral nos trechos do ensaio Corp_1 medido e calculado pelo método Falconi-Perez (2008) com os coeficientes adaptados e diferenciação da areia compacta superficial. 101

Figura 92: atrito lateral nos trechos do ensaio Trin medido e calculado pelo método Falconi-Perez (2008) com os coeficientes adaptados e diferenciação da areia

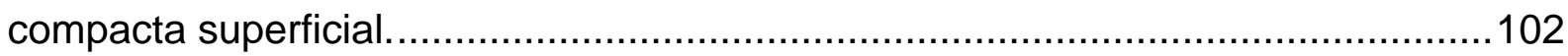

Figura 93: aplicação do modelo para o ensaio CN............................................105

Figura 94: aplicação do modelo para o ensaio CJM. ..........................................106

Figura 95: aplicação do modelo para o ensaio PçaFP........................................106

Figura 96: aplicação do modelo para o ensaio Terr_50. ......................................107

Figura 97: aplicação do modelo para o ensaio Terr_54 .....................................107

Figura 98: aplicação do modelo para o ensaio VdF_1 .......................................108

Figura 99: aplicação do modelo para o ensaio VdF_2 ......................................108

Figura 100: aplicação do modelo para o ensaio Corp_1.....................................109

Figura 101: aplicação do modelo para o ensaio Trin..............................................109

Figura 102: aplicação do modelo para o ensaio Leg_1 .......................................110

Figura 103: aplicação do modelo para o ensaio Leg_2.........................................110

Figura 104: aplicação do modelo para o ensaio TB_1 ......................................111

Figura 105: aplicação do modelo para o ensaio TB_2. ........................................111

Figura 106: aplicação do modelo para o ensaio PE. ........................................112

Figura 107: aplicação do modelo para o ensaio Kinb.......................................112

Figura 108: comparação entre os recalques na carga de trabalho estimados pelo modelo e medidos pelos ensaios. 
Figura 109: aplicação do modelo com os coeficientes adaptados para o ensaio CN.

Figura 110: aplicação do modelo com os coeficientes adaptados para o ensaio CJM.

Figura 111: aplicação do modelo com os coeficientes adaptados para o ensaio PçaFP.

Figura 112: aplicação do modelo com os coeficientes adaptados para o ensaio Terr_50.

Figura 113: aplicação do modelo com os coeficientes adaptados para o ensaio Terr_54.

Figura 114: aplicação do modelo com os coeficientes adaptados para o ensaio VdF_1.

Figura 115: aplicação do modelo com os coeficientes adaptados para o ensaio VdF_2.

Figura 116: aplicação do modelo com os coeficientes adaptados para o ensaio Corp_1.

Figura 117: aplicação do modelo com os coeficientes adaptados para o ensaio Trin.

Figura 118: aplicação do modelo com os coeficientes adaptados para o ensaio Leg_1.

Figura 119: aplicação do modelo com os coeficientes adaptados para o ensaio Leg_2.

Figura 120: aplicação do modelo com os coeficientes adaptados para o ensaio TB_1.

Figura 121: aplicação do modelo com os coeficientes adaptados para o ensaio TB_2. 120

Figura 122: aplicação do modelo com os coeficientes adaptados para o ensaio PE.

Figura 123: aplicação do modelo com os coeficientes adaptados para o ensaio Kinb.

Figura 124: comparação entre os recalques na carga de trabalho estimados pelo modelo (com os parâmetros adaptados) e medidos pelos ensaios. 


\section{LISTA DE TABELAS}

Tabela 1: características dos sedimentos da Baixada Santista (extraída de Massad, 2009-a) 10

Tabela 2: valores de $f_{\text {máx }}$ e y1 para o ensaio da Ponte sobre o Mar Pequeno (Massad, 2009-a)

Tabela 3: valores de fmáx para diversas provas de carga na Baixada Santista (Massad, 2009-a) 16

Tabela 4: Características da lama bentonítica (NBR 6122, 2010). .22

Tabela 5: Características do fluido estabilizante (NBR 6122, 2010). .22

Tabela 6: coeficiente $\mathrm{C}$ em função do tipo de solo (adaptada de Décourt e Quaresma, 1978). .26

Tabela 7: Valores do coeficiente $\alpha \mathrm{DQ}$ em função do tipo de estaca e de solo. .27

Tabela 8: Valores do coeficiente $\beta \mathrm{DQ}$ em função do tipo de estaca e de solo. .27

Tabela 9: Fatores de correção $F_{1}$ e $F_{2}$ (Aoki e Velloso, 1975, atualizado por Cintra e Aoki, 2010). .29

Tabela 10: coeficiente KAV e razão de atrito a AV (Aoki e Velloso, 1975). 29

Tabela 11: Valores de f utilizados para as argilas (adaptado de Falconi e Perez, 2008).

Tabela 12: Valores de KFP (adaptado de Falconi e Perez, 2008). 31

Tabela 13: Quantidade de provas de carga (NBR 6122/2010). 39

Tabela 14: Resumo das provas de carga estática analisadas. 53

Tabela 15: Resumo das provas de carga estática analisadas. .54

Tabela 16: cálculos de capacidade de carga das estacas por métodos semiempíricos.

Tabela 17: comparação entre a capacidade de carga calculada pelos métodos semiempíricos e a carga máxima atingida no ensaio, em kN .59

Tabela 18: leituras de deformação obtidas através dos strain gages (CN). 63

Tabela 19: dados da instrumentação e valores de ES obtidos pelo Método do Módulo Tangente de Fellenius (1989) modificado por Massad (2009-b) para o ensaio CN. .64

Tabela 20: forças calculadas em cada nível (CN). .65

Tabela 21: parâmetros de Cambefort para o ensaio CN. .66 
Tabela 22: leituras de deformação obtidas através dos strain gages (VdF_1)..... 69

Tabela 23: dados da instrumentação e valores de ES obtidos pelo Método do Módulo Tangente de Fellenius (1989) modificado por Massad (2009-b) para o ensaio VdF_1.

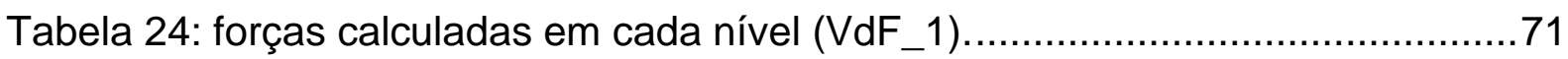

Tabela 25: parâmetros de Cambefort para o ensaio VdF_1. 73

Tabela 26: leituras de deformação médias obtidas através dos strain gages (VdF_2). .74

Tabela 27: dados da instrumentação e valores de ES obtidos pelo Método do Módulo Tangente de Fellenius (1989) modificado por Massad (2009-b) para o ensaio VdF_2. .74

Tabela 28: forças calculadas em cada nível (VdF_2) .....................................76

Tabela 29: parâmetros de Cambefort para o ensaio VdF_2. ...............................78

Tabela 30: leituras de deformação obtidas através dos strain gages (Corp_1).......80 Tabela 31: dados da instrumentação e valores de ES obtidos pelo Método do Módulo Tangente de Fellenius (1989) modificado por Massad (2009-b) para o ensaio Corp_1.

Tabela 32: forças calculadas em cada nível (Corp_1) 81

Tabela 33: parâmetros de Cambefort para o ensaio Corp_1. .84

Tabela 34: leituras de deformação obtidas através dos strain gages (Corp_2). .......86

Tabela 35: leituras de deformação obtidas através dos strain gages (Trin).

Tabela 36: dados da instrumentação e valores de ES obtidos pelo Método do Módulo Tangente de Fellenius (1989) modificado por Massad (2009-b) para o ensaio Trin. 88 Tabela 37: parâmetros de Cambefort para o ensaio Trin. .90 Tabela 38: trechos dos ensaios instrumentados que apresentam apenas uma camada de solo. .92

Tabela 39: parâmetros $f_{\text {máx }}$ da $1^{a}$ Lei de Cambefort determinados pelas provas de carga instrumentadas.

Tabela 40: parâmetros y da $_{1}$ a Lei de Cambefort determinados pelas provas de carga instrumentadas.

Tabela 41: resumo dos parâmetros determinados pelas provas de carga instrumentadas. 
Tabela 42: coeficientes do método Falconi-Perez (2008) adaptados ao ensaio CN. 96 Tabela 43: coeficientes do método Falconi-Perez (2008) adaptados ao ensaio VdF_1.

Tabela 44: coeficientes do método Falconi-Perez (2008) adaptados ao ensaio VdF_2.

Tabela 45: coeficientes do método Falconi-Perez (2008) adaptados ao ensaio Corp_1.

Tabela 46: coeficientes do método Falconi-Perez (2008) adaptados ao ensaio Trin.

Tabela 47: coeficientes do método Falconi-Perez (2008) adaptados ao ensaio CN com diferenciação da areia compacta superficial.

Tabela 48: coeficientes do método Falconi-Perez (2008) adaptados ao ensaio VdF_1 com diferenciação da areia compacta superficial.

Tabela 49: coeficientes do método Falconi-Perez (2008) adaptados ao ensaio VdF_2 com diferenciação da areia compacta superficial.

Tabela 50: coeficientes do método Falconi-Perez (2008) adaptados ao ensaio Corp_1 com diferenciação da areia compacta superficial.

Tabela 51: coeficientes do método Falconi-Perez (2008) adaptados ao ensaio Trin com diferenciação da areia compacta superficial.

Tabela 52: valores médios dos coeficientes do método Falconi-Perez (2008) adaptados com diferenciação da areia compacta superficial. 102 Tabela 53: parâmetros de Cambefort adotados inicialmente para o modelo de análise.

Tabela 54: parâmetros de Cambefort adaptados para a calibração do modelo de análise. 


\section{LISTA DE SÍMBOLOS}

\begin{tabular}{|c|c|}
\hline Qr & resistência total do conjunto solo-estaca \\
\hline QL & resistência por atrito lateral \\
\hline Qp & resistência de ponta \\
\hline$A_{L}$ & área lateral da estaca \\
\hline qL & tensão de ruptura por atrito lateral \\
\hline$A_{p}$ & tensão de ruptura da ponta \\
\hline D & diâmetro da estaca \\
\hline h & comprimento da estaca \\
\hline$q_{c}$ & $\begin{array}{l}\text { parâmetro do ensaio de penetração do cone (CPT) correspondente à } \\
\text { resistência de ponta do cone }\end{array}$ \\
\hline C & coeficiente de resistência de ponta do método de Décourt-Quaresma \\
\hline NP_DQ & $\begin{array}{l}\text { média dos valores de SPT da ponta da estaca, o imediatamente anterior } \\
\text { e o imediatamente superior, utilizado no método Décourt-Quaresma }\end{array}$ \\
\hline $\mathrm{N}_{\mathrm{L}}$ & média dos valores de SPT ao longo do fuste da estaca \\
\hline$\alpha \mathrm{DQ}$ & $\begin{array}{l}\text { coeficiente do método de Décourt-Quaresma correspondente à } \\
\text { resistência de ponta da estaca }\end{array}$ \\
\hline$\beta_{D Q}$ & $\begin{array}{l}\text { coeficiente do método de Décourt-Quaresma correspondente à } \\
\text { resistência por atrito lateral da estaca }\end{array}$ \\
\hline $\mathrm{rL}$ & $\begin{array}{l}\text { variável de resistência de ponta do método Aoki-Velloso, relacionado } \\
\text { com os resultados do ensaio CPT }\end{array}$ \\
\hline rp & $\begin{array}{l}\text { variável de resistência por atrito lateral do método Aoki-Velloso, } \\
\text { relacionado com os resultados do ensaio CPT }\end{array}$ \\
\hline$f_{s}$ & $\begin{array}{l}\text { parâmetro do ensaio de penetração do cone }(\mathrm{CPT}) \text { correspondente ao } \\
\text { atrito lateral unitário na luva }\end{array}$ \\
\hline NSPT & índice de resistência à penetração \\
\hline$\alpha_{A V}$ & razão de atrito do método Aoki-Velloso \\
\hline Kav & coeficiente do método Aoki-Velloso que relaciona Nspt e qc \\
\hline NP_AV & valor de SPT da ponta da estaca, utilizado no método Aoki-Velloso \\
\hline $\mathrm{U}$ & perímetro da estaca \\
\hline$F_{1}$ & $\begin{array}{l}\text { fator de correção da resistência de ponta da estaca do método Aoki- } \\
\text { Velloso }\end{array}$ \\
\hline $\mathrm{F}_{2}$ & $\begin{array}{l}\text { fator de correção da resistência por atrito lateral da estaca do método } \\
\text { Aoki-Velloso }\end{array}$ \\
\hline aFP & $\begin{array}{l}\text { coeficiente do método Falconi-Perez que, multiplicado pelo SPT, resulta } \\
\text { na adesão das camadas de areias e siltes }\end{array}$ \\
\hline Scirc & área circunscrita da estaca \\
\hline KFP & coeficiente de resistência de ponta do método Falconi-Perez \\
\hline NP_FP & $\begin{array}{l}\text { média dos valores de SPT da ponta da estaca e } 1,0 \mathrm{~m} \text { abaixo, utilizada } \\
\text { no método Falconi-Perez }\end{array}$ \\
\hline
\end{tabular}


deslocamento observado no centro de um elemento de estaca ou na ponta

atrito lateral unitário, parâmetro da $1^{\text {a }}$ Lei de Cambefort "quake" do atrito lateral, parâmetro da $1^{\text {a }}$ Lei de Cambefort inclinação do trecho pseudoelástico da 1aㅡ Lei de Cambefort atrito lateral unitário máximo, parâmetro da $1^{a}$ Lei de Cambefort resistência de ponta, parâmetro da $2^{\underline{a}}$ Lei de Cambefort "quake" da ponta, parâmetro da $2^{\mathrm{a}}$ Lei de Cambefort

$\mathrm{R}$ inclinação do trecho pseudoelástico da $2^{\mathrm{a}}$ Lei de Cambefort resistência de ponta máxima, parâmetro da $2^{2}$ Lei de Cambefort força atuando no topo de um elemento de estaca deformação de um elemento de estaca módulo de elasticidade do concreto da estaca

$\mathrm{S} \quad$ área da seção transversal da estaca

$\mathrm{K}_{\mathrm{r}} \quad$ rigidez da estaca como peça estrutural

$k \quad$ rigidez relativa do conjunto solo-estaca

Alr atrito lateral na ruptura

$\mathrm{yP}_{\mathrm{P}}$ deslocamento da ponta da estaca

Po carga aplicada no topo da estaca

yo deslocamento do topo da estaca

E $E_{0} \quad$ tensão elétrica de saída da ponte de Wheatstone

Eponte tensão de alimentação da ponte de Wheatstone

$\mathrm{K}_{\mathrm{s}} \quad$ fator do extensômetro

$\varepsilon_{0}$ deformação medida pelo extensômetro 


\section{INTRODUÇÃO}

\subsection{Preâmbulo}

A Região Metropolitana da Baixada Santista, criada em 1996, é formada por nove municípios: Bertioga, Cubatão, Guarujá, Itanhaém, Mongaguá, Peruíbe, Praia Grande, Santos e São Vicente. Com aproximadamente 1,85 milhão de habitantes, a região tem importante presença nas atividades de suporte ao comércio de exportação devido à proximidade do complexo portuário - o Porto de Santos é o maior e mais importante porto da América do Sul.

A cidade de Santos e a Baixada Santista possuem um perfil do subsolo bastante peculiar, objeto de estudo por muitos autores, que consiste em uma camada superficial de areia compacta, apoiada em camadas alternadas de argilas moles com diferentes datas de formação e, à profundidade de cerca de 60 metros, solo residual. O crescimento da região, na metade do século passado, fez com que fossem construídos grandes edifícios apoiados em fundação direta na camada de areia compacta supracitada. A proximidade desses edifícios e o número cada vez maior de pavimentos, entre outros fatores - como a presença, tempos atrás, de dunas na orla de Santos -, sobrecarregou a espessa camada de argila mole levemente préadensada abaixo da camada superficial de areia, acarretando elevados recalques por adensamento e recalques diferenciais nos pilares dos edifícios. Esses fenômenos deram origem aos famosos prédios "tortos" na orla da cidade.

Com o aumento da população e da gravidade dos recalques diferenciais, tornou-se indispensável a adoção de fundação profunda para apoio dos novos edifícios. Segundo Aoki e Angelino (1994), desde a década de 1960 relata-se o uso de estacas flutuantes, ou seja, com ponta nas camadas de argila de baixa resistência em profundidade. Entre as principais soluções de fundações profundas na região, destacam-se as estacas de aço (perfis I, H ou estacas tubadas), as estacas prémoldadas de concreto e as estacas escavadas de grande diâmetro com fluido. Já foram ou são utilizadas, em menor escala, estacas tipo Franki, tubulões a ar comprimido e estacas injetadas (raiz ou microestacas). Atualmente, para prédios com altos níveis de carregamentos, as estacas escavadas de grande diâmetro com fluido 
estabilizante (estacões e estacas barrete) e as estacas metálicas são mais utilizadas. Recentemente foi introduzido o uso de estacas metálicas de seção decrescente com a profundidade com composições soldadas de perfis de aço de alta resistência.

As soluções em estacas escavadas de grande diâmetro (estacões), quando dimensionadas por métodos semiempíricos baseados em valores de SPT, resultam em comprimentos acima de 50 metros. Hoje, existe a suspeita de que tais soluções sejam conservadoras e que os critérios de dimensionamento consagrados levem a projetos superdimensionados. Assim, há a necessidade de estabelecerem-se métodos que caracterizem de forma mais realista o comportamento dessas fundações.

\subsection{Objetivos e justificativa}

O objetivo principal deste trabalho foi a elaboração de um modelo matemático que simule o comportamento de uma estaca escavada de grande diâmetro com fluido estabilizante executada em solo típico de Santos e da Praia Grande, quando submetida a um carregamento axial estático. Através dos dados das provas de carga, o modelo matemático foi calibrado de forma a aproximar-se o máximo possível do comportamento real das estacas analisadas. A partir do modelo calibrado, foi possível a previsão da curva carga-recalque de estacas escavadas de grande diâmetro a partir dos dados de sondagens à percussão. A curva pode ser construída para uma estaca de certo comprimento, inicialmente previsto por métodos semiempíricos de capacidade de carga. A partir daí, pode-se simular a curva carga-recalque para estacas de menor comprimento e avaliar o comportamento dessas estacas mais curtas, do ponto de vista de recalques admissíveis, em comparação com o comportamento da estaca original, mais longa. $O$ intuito dessa análise é possibilitar o desenvolvimento de projetos mais eficientes e econômicos para esse tipo específico de fundação.

De maneira geral, as provas de carga estática executadas em estacão analisadas nesse trabalho não atingiram a ruptura. De fato, nas provas de carga em estacas desse tipo na Baixada Santista dimensionadas por métodos semiempíricos consagrados baseados em SPT, com comprimentos acima de 50 metros, raramente atinge-se a ruptura física e os recalques observados são relativamente baixos. Ainda 
assim, é interessante refinar e aprimorar os métodos de cálculo de capacidade de carga existentes para o solo específico da região. Particularmente, para o método de Falconi-Perez (2008), desenvolvido para estacas metálicas a partir de dados de provas de carga instrumentadas executadas na região, pode-se adaptar o coeficiente que calcula o atrito lateral na ruptura em função do SPT, para camadas de areia e silte, para que a aplicação do método seja ampliada para estacões na região em estudo da Baixada Santista.

A análise dos ensaios, principalmente das provas de carga instrumentadas, levanta outro questionamento acerca do comportamento das fundações profundas no solo em estudo da Baixada Santista. Em uma das provas de carga instrumentadas, Maset e Massad (2018) observaram valores de atrito lateral unitário na parte superior da camada de argila SFL menores do que os usuais. Isso pode ocorrer pelo que Massad (2009-b) descreveu como "efeito Estaca T", em estaca metálica com seção decrescente, em que, sob a ação do carregamento na estaca, a camada superficial de areia exerce uma pressão sobre o topo da camada de argila SFL subjacente, reduzindo drasticamente 0 atrito lateral máximo mobilizado. $A$ análise de todas as provas de carga instrumentadas em profundidade realizada neste trabalho permite verificar se o efeito "estaca T" foi observado com frequência nos estacões executados na Baixada Santista, e se ele deve ser levado em consideração na estimativa da curva carga-recalque no topo da estaca.

Os objetivos básicos da pesquisa são, portanto:

- desenvolver um modelo para previsão da curva carga-recalque de estacas escavadas de grande diâmetro na Baixada Santista para, assim, analisar o comportamento dessas estacas do ponto de vista de recalques admissíveis nas respectivas cargas de trabalho;

- análise do efeito "estaca T" nas provas de carga instrumentadas; e

- adaptação do método Falconi-Perez (2008) para a utilização em estacões na Baixada Santista. 


\subsection{Metodologia}

Na primeira parte, foram aplicados três métodos semiempíricos de cálculo de capacidade de carga para as estacas, e os valores obtidos foram comparados entre si e com as cargas máximas atingidas nas provas de carga estática.

$\mathrm{Na}$ segunda parte da análise, o foco foram os dados das provas de carga com instrumentação em profundidade. Através dos resultados da instrumentação, foram determinadas as funções de transferência de carga e os diagramas de transferência de carga em profundidade. Os parâmetros de Cambefort inferidos dessa análise foram comparados com valores da literatura. Para cada um dos ensaios instrumentados, os parâmetros de Cambefort obtidos foram utilizados na aplicação do método de CoyleReese (1966) para a determinação da curva carga-recalque no topo da estaca, e essa curva "calculada" foi comparada com a curva real do ensaio. Ainda com os resultados da instrumentação em profundidade, o atrito lateral mobilizado nos trechos entre níveis de instrumentação foi comparado com os valores de atrito lateral calculados pelo método de Falconi-Perez (2008), levando em consideração as camadas de solo atravessadas pela estaca em cada trecho. Os parâmetros que governam o cálculo do atrito lateral mobilizado pelo método de Falconi-Perez (2008) foram calibrados para que ficassem o mais próximos possível dos valores medidos pela instrumentação.

Finalmente, na terceira parte da análise, considerando os parâmetros de Cambefort inferidos da segunda parte, com algumas adaptações, o método de CoyleReese (1966) foi aplicado para todas as provas de carga, instrumentadas ou não, e as curvas obtidas foram comparadas com as curvas reais dos ensaios. Os parâmetros de Cambefort foram calibrados uma última vez, visando a melhor aderência possível entre as curvas calculadas e medidas.

\subsection{Estrutura do texto}

Além da Introdução, a dissertação foi dividida em quatro capítulos:

a) Revisão bibliográfica: inicialmente, foi traçado um panorama geral da cidade de Santos e do seu histórico ocupacional e de engenharia de fundações, além do contexto geológico da gênese dos sedimentos quaternários da Baixada Santista, que influencia diretamente nas 
fundações da região. O conceito de estacas escavadas de grande diâmetro, caso das estacas analisadas neste trabalho, foi apresentado e detalhado, com o método executivo e os principais parâmetros que podem influenciar seu comportamento. Um breve estudo dos métodos semiempíricos de cálculo de capacidade de carga de estacas baseados em SPT foi necessário para comparação dos comprimentos das estacas calculados por esses métodos e os resultados das provas de carga, além do refinamento e sugestão de adaptação dos métodos utilizando esses resultados. O modelo matemático de determinação da curva cargarecalque da estaca, que toma como base a distribuição de carga em profundidade, foi detalhado em seguida. Por fim, a conceituação de prova de carga estática instrumentada em profundidade foi necessária para a correta interpretação dos ensaios analisados no trabalho.

b) Casos de obras: foram apresentadas as 16 provas de carga analisadas neste trabalho, sendo 6 delas instrumentadas em profundidade, com informações suficientes para seu entendimento.

c) Análise dos resultados: todos os ensaios apresentados foram analisados, com ênfase nas informações fornecidas pelas provas de carga estática com instrumentação em profundidade. O modelo foi aplicado para todos os ensaios e a aderência entre as curvas cargarecalque obtidas pelo modelo e medidas nos ensaios foi avaliada.

d) Conclusões e sugestões para pesquisas futuras: foram apresentadas as conclusões gerais do trabalho, que concernem toda a análise dos dados apresentada nos capítulos anteriores, e as sugestões para pesquisas futuras. 


\section{REVISÃO BIBLIOGRÁFICA}

\subsection{Histórico geológico, geotécnico e ocupacional da Baixada Santista}

As investigações geológico-geotécnicas no litoral paulista de que se têm notícia iniciaram-se na década de 1940 para a construção da ponte sobre o rio Juqueriqueré, em Caraguatatuba. À época, pouco se sabia sobre a geologia da região, e a escassa informação existente sobre o assunto estava no livro Geology and Physical Geography of Brazil, publicado em 1870 em Boston pelo americano Charles Frederick Hart. Segundo Maffei et al (2006), em 1943, Avelino de Oliveira e Othon Leonardos publicaram o tratado "Geologia do Brasil", que descrevia as baixadas como "planícies holocênicas em plena fase de crescimento, por entre ilhas granítico-gneissicas" e as planícies de Santos e São Vicente como "dunas e vasas". A existência de dunas era de conhecimento do cartógrafo português João Teixeira Albernaz em 1631, conforme retratado no "Mapa das Ilhas de São Vicente e Santo Amaro" (Massad, 2009-a).

A partir da década de 1940, foram realizadas investigações geotécnicas para estudos diversos, como as fundações para a Cia. Docas de Santos, para construção de trecho da Via Anchieta, fundações da ponte sobre o Canal do Casqueiro e dos primeiros edifícios de apartamentos na Praia do Gonzaga, e as condições do subsolo da região começaram a ser delineadas. Na região de Cubatão, havia camada de cerca de 15 metros de argila orgânica muito mole, apoiada em uma camada de pedregulho e atingindo o topo de alteração de rocha gnáissica a cerca de 20 metros de profundidade. Na região do rio Casqueiro, o topo rochoso era atingido a 40 metros de profundidade, sobre o qual encontrava-se a argila mole entremeada por camadas de areia. A partir dali, em direção à praia, havia a presença de camada superficial de areia com espessura máxima de $15 \mathrm{~m}$, apoiada sobre a argila mole com lentes de areia. Na região de Santos, sabia-se que o topo rochoso era atingido em profundidades de até 80 metros.

À época acreditava-se que a camada de argila muito mole normalmente adensada encontrada em Cubatão, entremeada com lentes de areia, havia se formado em um único ciclo de sedimentação contínuo e ininterrupto, e mantinha suas propriedades ao longo de toda a profundidade em toda a região da Baixada Santista. 
Um esboço do perfil geológico da Baixada Santista, resultado dessas investigações, está ilustrado na Figura 1.
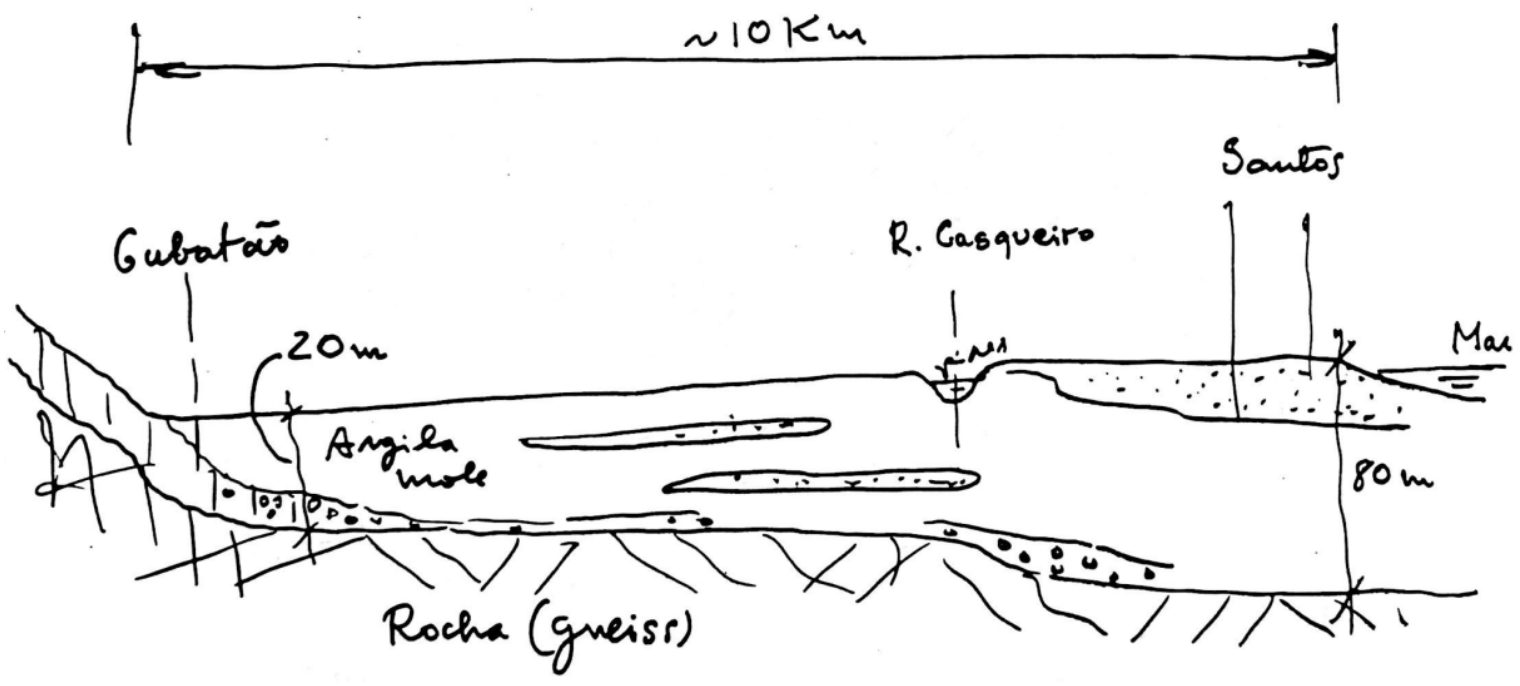

Figura 1: esboço de corte geológico da Baixada Santista de acordo com conhecimento da década de 1950 (Vargas, 1999).

Teixeira (1959), em um dos trabalhos publicados por ele no $1^{\circ}$ Congresso Panamericano de Mecânica dos Solos, no México, relatou caso em que, no subsolo de um edifício a ser construído em São Vicente, foi encontrada uma camada de argila de índices físicos similares às argilas muito moles da região, porém, inesperadamente, altamente pré-adensada. À época, não havia justificativa para tal fenômeno. Ao final da década de 1970, Suguio e Martin (1978) publicaram trabalho relatando a variação do nível do mar em vários locais da costa brasileira nos últimos 120.000 anos com datação de radiocarbono e classificando os sedimentos quaternários em relação a duas elevações do nível do mar, ocorridas em épocas distintas. Com base no trabalho de Suguio e Martin (1978) e no exame de inúmeras sondagens de simples reconhecimento e ensaios executados na região, Massad (1985), em sua tese de livre docência, classificou os sedimentos das argilas moles da Baixada Santista em três unidades de acordo com a sua gênese: as argilas transicionais, os sedimentos fluviolagunares e de baías, e os mangues. Essas três unidades genéticas possuem propriedades índice, como granulometria e limites de Atterberg, semelhantes, e diferenciam-se por suas propriedades de estado, como a pressão de préadensamento, o índice de vazios, o SPT e resistência não-drenada. Assim, a camada 
de argila altamente sobreadensada encontrada por Teixeira e por outros autores foi elucidada por Massad (1985) com base em dois episódios de ingressão do mar rumo ao continente relatadas por Suguio e Martin (1978).

A primeira elevação do nível do mar, ocorrida há cerca de 120 mil anos na época do Pleistoceno - que abrange entre 2,588 milhões e 11,7 mil anos atrás -, é conhecida pelos geólogos como "Transgressão Cananéia". Nela, o nível do mar atingiu $8 \pm 2$ metros acima do atual, e a deposição sedimentar deu origem ao que hoje chamamos de areias ou argilas transicionais (AT). Após esse episódio, com o abaixamento do nível do mar em $110 \mathrm{~m}$ abaixo do atual, os sedimentos passaram por um intenso processo de intemperização e, hoje, apresentam razões de sobreadensamento da ordem de 2,5 a 4 . Ainda nesse trabalho, relata-se outro episódio de elevação do nível do mar, este muito mais recente - cerca de 5 mil anos atrás - durante a época do Holoceno, que abrange de 11,7 mil anos atrás até os dias atuais. Nele, ocorreu a chamada "Transgressão Santos", em que o nível do mar se elevou a no máximo cerca de 5 metros acima do nível atual e formaram-se as argilas dos mangues e as argilas de sedimentos fluviolagunares e de baías (SFL).

O modelo geológico que explica os mecanismos de gênese das planícies quaternárias do Estado de São Paulo, proposto por Suguio e Martin (1994), é dividido em cinco estágios, resumidos na Figura 2.

1. Máximo da Transgressão Cananéia, em que o mar atingiu o pé da Serra do Mar e as areias e argilas transicionais e areias marinhas transgressivas da Formação Cananéia foram formadas;

2. Início da regressão do nível do mar e formação de cordões de areia, depositados sobre os sedimentos transgressivos e trabalhados superficialmente pela ação do vento;

3. Recuo do nível do mar até a cota $-110 \mathrm{~m}$ e consequente erosão dos depósitos da Formação Cananéia pela ação dos rios que drenavam a planície costeira, formando vales profundos;

4. Elevação do nível do mar durante a Transgressão Santos, invadindo as áreas rebaixadas pela erosão e formando lagunas com depósito de sedimentos areno argilosos ricos em matéria orgânica, e erodindo as partes altas da 
Formação Cananéia, ressedimentando as areias para formar depósitos marinhos e transicionais holocênicos;

5. Regressão do nível do mar à cota atual e formação de cordões litorâneos de regressão. Ao longo das flutuações do nível do mar durante a parte final da Transgressão Santos, várias gerações de cordões litorâneos foram formadas.

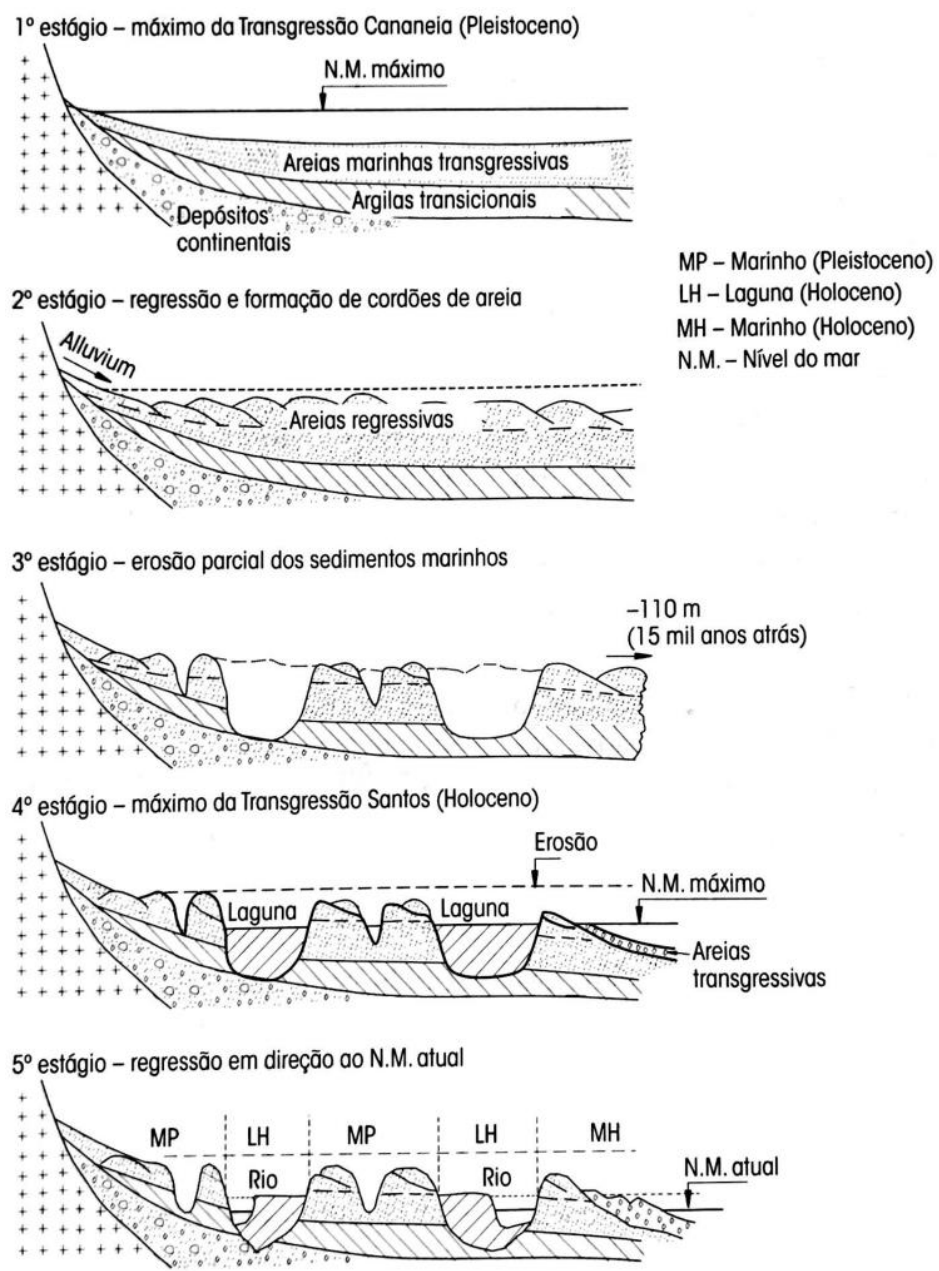

Figura 2: possíveis estádios da gênese das planícies sedimentares paulistas (Massad, 2009-a, apud Suguio e Martin, 1978).

Massad (1999) estudou os mecanismos de sobreadensamento dos sedimentos quaternários da Baixada Santista com base em resultados de ensaios adensamento e de piezocone. Para as argilas AT, as pressões de pré-adensamento, de maneira geral, são consistentes com as pressões totais de terra, o que corrobora a história geológica de sua formação. Para as argilas SFL, levemente sobreadensadas, Massad 
(1999) identificou os seguintes mecanismos de pré-adensamento: a oscilação negativa do nível do mar, já mencionada; a ação de dunas; e o efeito do envelhecimento das argilas ("aging"). O primeiro e o terceiro mecanismo resultam em razões de sobreadensamento entre 1,0 e 2,0. Segundo Massad (2009), em alguns locais da Baixada Santista, como a llha de Santo Amaro e parte da orla praiana, existem evidências geológicas e histórico-geográficas da existência de dunas eólicas, com alturas predominantemente entre 4 e 6 metros, resultando em argilas SFL muito sobreadensadas, com razões de sobreadensamento superiores a 2,0. Em função da variação de altura das dunas e, consequentemente, da sobrecarga aplicada, o sobreadensamento da argila SFL pode ocorrer de forma errática, acarretando recalques diferenciais e inclinações em edifícios construídos posteriormente. A ação de dunas no comportamento de edifícios na cidade de Santos, confirmada através de ensaios CPTU por Massad (2004), passou insuspeita durante o século passado.

Resumidamente, os sedimentos da Baixada Santista podem ser classificados de acordo com a Tabela 1:

Tabela 1: características dos sedimentos da Baixada Santista (extraída de Massad, 2009-a).

\begin{tabular}{|c|c|c|}
\hline & Sedimentos & Características gerais \\
\hline \multirow{2}{*}{ 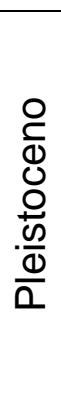 } & Areias & $\begin{array}{l}\text { Terraços alçados de } 6 \text { a } 7 \mathrm{~m} \text { acima do nível do } \\
\text { mar; amareladas na superfície e marrom-escura a } \\
\text { pretas em profundidade. }\end{array}$ \\
\hline & Argilas transicionais (AT) & $\begin{array}{l}\text { Ocorrem a } 20-35 \mathrm{~m} \text { de profundidade, às vezes } 15 \\
\mathrm{~m} \text { ou menos. Argilas médias a rijas, com folhas } \\
\text { vegetais carbonizadas e com nódulos de areia } \\
\text { quase pura, quando argilosas, ou bolotas de argila, } \\
\text { quando arenosas. }\end{array}$ \\
\hline \multirow[b]{2}{*}{$\begin{array}{l}\text { 응 } \\
\text { 응 } \\
\text { 응 } \\
\text { 소 }\end{array}$} & Areias & $\begin{array}{l}\text { Terraços de } 4 \text { a } 5 \mathrm{~m} \text { acima do nível do mar. Não } \\
\text { apresentam matéria orgânica. Revelam a ação de } \\
\text { dunas. }\end{array}$ \\
\hline & Argilas SFL & $\begin{array}{l}\text { Deposição em águas calmas de lagunas e de } \\
\text { baías. Camadas mais ou menos homogêneas e } \\
\text { uniformes de argilas muito moles a moles (regiões } \\
\text { de "calmaria"). } \\
\text { Deposição pelo retrabalhamento dos sedimentos } \\
\text { pleistocênicos ou sob a influência dos rios. } \\
\text { Acentuada heterogeneidade, disposição mais ou } \\
\text { menos caótica de argilas muito moles a moles } \\
\text { (regiões "conturbadas"). }\end{array}$ \\
\hline
\end{tabular}




\begin{tabular}{|l|l|l|}
\hline Argilas de mangues & $\begin{array}{l}\text { Sedimentadas sobre os SFL. Alternâncias, de } \\
\text { forma caótica, de argilas arenosas e areias } \\
\text { argilosas. }\end{array}$ \\
\hline
\end{tabular}

A Figura 3 mostra o perfil geotécnico sintético da orla praiana, conforme relatado por Teixeira (1994), ilustrando a ocorrência das camadas de areia e argila marinha.

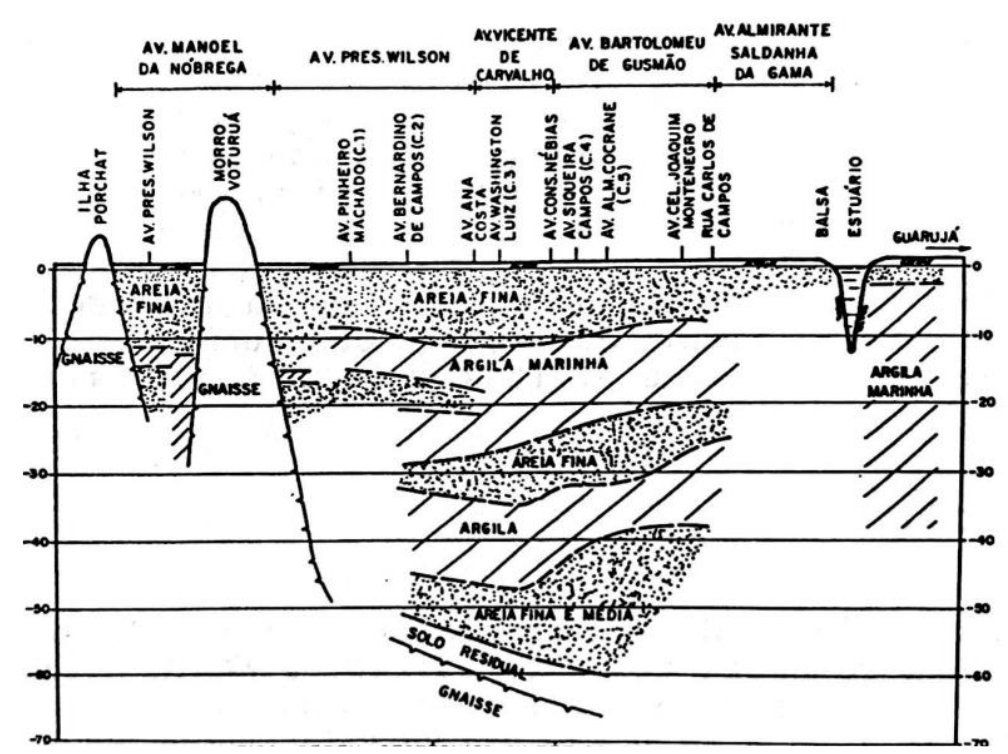

Figura 3: perfil geológico sintético da orla praiana (Teixeira, 1994).

Massad (2003) adaptou o perfil de Teixeira (1994) para incorporar a presença e continuidade das camadas de argilas transicionais (AT) nas imediações da orla praiana de Santos e questionar a espessura da camada de areia na região da Ponta da Praia, conforme Figura 4.

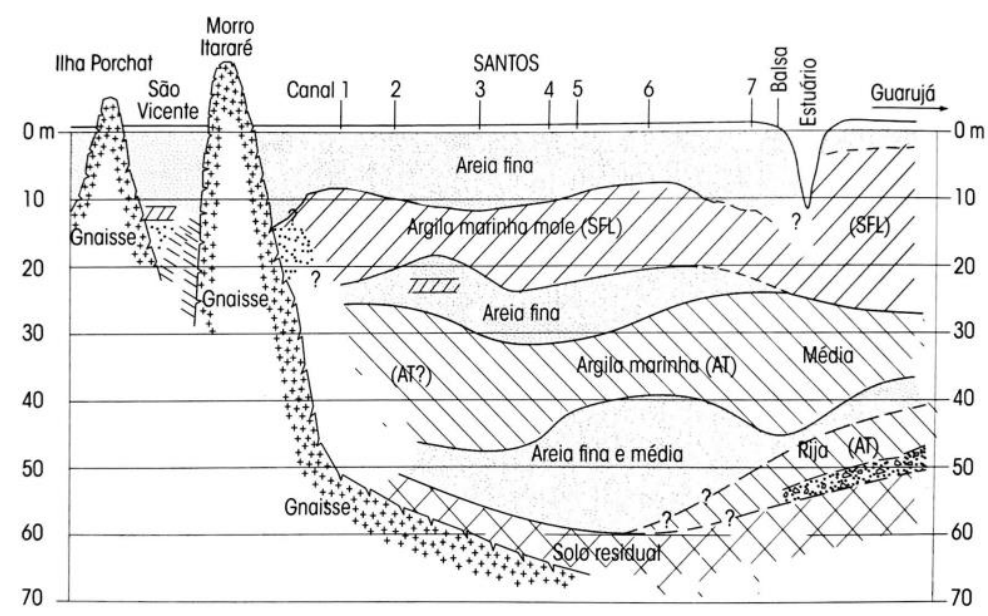

Figura 4: perfil geológico sintético da orla praiana (Massad, 2003, adaptado de Teixeira 1994). 
Dias (2010) readaptou o perfil de Teixeira (1994), esclarecendo as dúvidas quanto à espessura da camada de areia na Ponta da Praia e inseriu novo questionamento quanto às camadas de argila SFL e AT nessa mesma região. Segundo a autora, à medida em que se aproxima do Guarujá, essas camadas se confundem e não é possível afirmar a profundidade correta de sua ocorrência. O perfil adaptado por Dias (2010) está ilustrado na Figura 5.

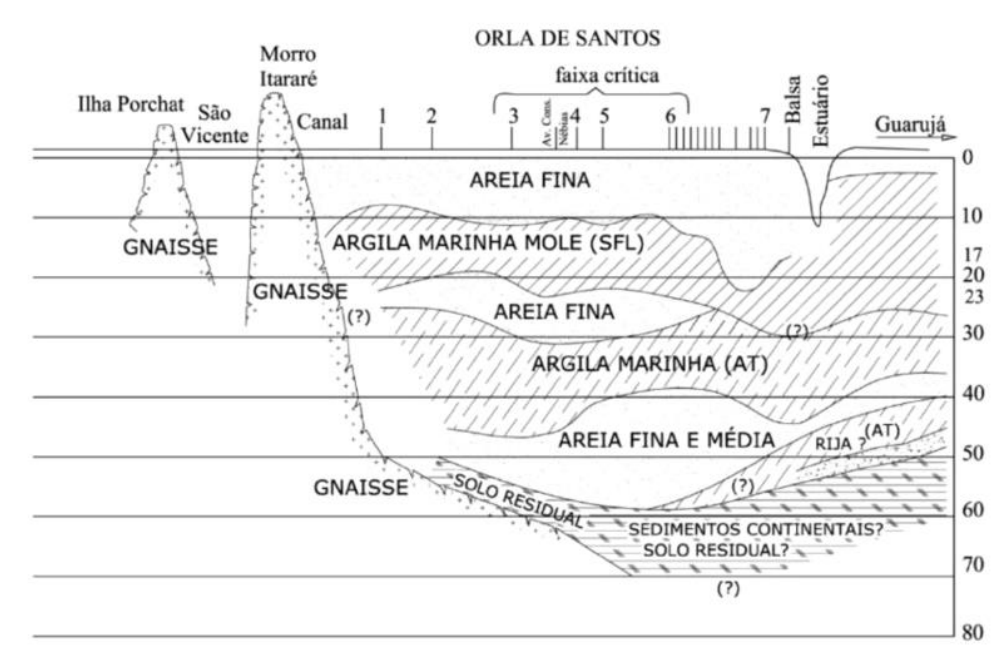

Figura 5: perfil geológico sintético da orla praiana (Dias, 2010).

A partir do final da década de 1940, intensificou-se a ocupação da orla da cidade de Santos com a construção de edifícios residenciais. A existência da camada superficial de areia compacta, com espessuras entre 10 e 15 metros e capacidade de suportar edifícios apoiados em fundação direta com tensão admissível de até $250 \mathrm{kPa}$, fez com que essa solução fosse amplamente adotada nos edifícios ao longo da praia.

Com a densificação da construção de edifícios contíguos e próximos, principalmente ao longo da orla praiana, os efeitos dos recalques diferenciais e desaprumo dos edifícios tornaram-se um problema cada vez mais evidente. Quatro casos de diferentes condições de inclinação de edifícios, em função do período de construção de cada um, estão ilustrados na Figura 6 (Teixeira, 1994) e explicados com mais detalhe a seguir. 


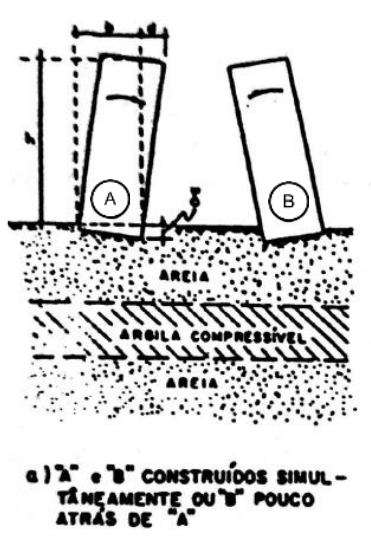

(a)

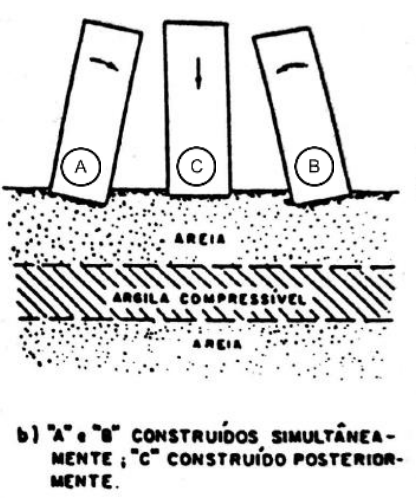

(b)

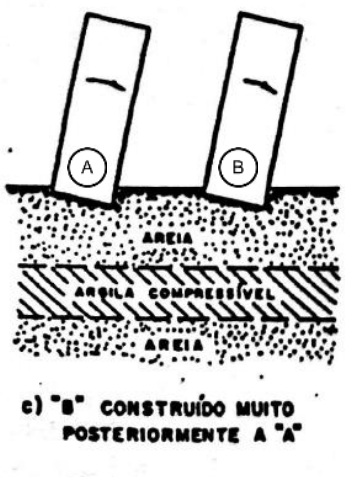

(c)

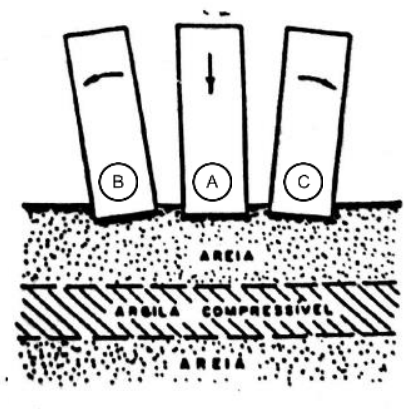

d) " $"$ "c" constnuidoos smul TÂmeamente, " $"$ " ExIstente

(d)

Figura 6: várias formas de desaprumos de edifícios em função da relatividade do tempo de construção (Teixeira, 1994).

Figura 6 (a): "A" e "B" construídos simultaneamente, ou "B" pouco antes de "A": os edifícios inclinam-se um em direção ao outro devido à sobreposição dos bulbos de tensões, gerando maior adensamento na camada de argila compressível entre os prédios;

Figura 6 (b): "A" e "B" construídos simultaneamente; "C" construído posteriormente: "A" e "B" inclinam-se um em direção ao outro e "C" recalca, sem desaprumo. A argila compressível sobre os prédios "A" e "B" já se encontra préadensada e a introdução do bulbo de tensões do prédio "C" provoca maiores recalques por adensamento na região central, que ainda não havia sofrido carregamento;

Figura 6 (c): "B" construído muito posteriormente a "A": "A" recalca em direção a "B" devido à sobreposição dos bulbos de tensão dos dois prédios; "B" recalca no sentido oposto a "A" devido ao pré-adensamento da camada compressível sob "A".

Figura 6 (d): "B" e "C" construído simultaneamente; "A" existente: a argila compressível sobre " $A$ " já se encontra pré-adensada devido ao carregamento do prédio central, e a construção de "B" e "C" provoca recalques maiores no lado em que a argila compressível ainda não sofreu nenhum carregamento.

Em casos de edifícios isolados, sem a influência de vizinhos, os recalques diferenciais e consequentes desaprumos podem ser explicados pelas pressões erráticas (não uniformes) exercidas pelas dunas (Massad, 2009).

A utilização de fundações profundas na Baixada Santista, com o intuito de atingir as camadas de argila mais profundas ou mesmo o solo residual e diminuir os 
recalques por adensamento, iniciou-se praticamente após a década de 1940. O primeiro relato de uso de estacas de aço longas como solução do problema de fundações de estruturas na Baixada Santista foi o caso das fundações da Ponte sobre o Rio Casqueiro, na Via Anchieta (Vargas, 1994). Segundo Teixeira (1994), quando da construção dos primeiros edifícios de grande porte na orla praiana no ano de 1946, as fundações profundas disponíveis eram limitadas a estacas pré-moldadas de concreto de no máximo 14 metros de comprimento, estacas Franki ou tubulões pneumáticos. Na década de 1960, Golombek (1965) relatou o uso de estacas flutuantes na cidade de Santos na década de 1960 para fundações de tanques e armazéns graneleiros em época em que a maioria dos edifícios residenciais era apoiado em fundação direta. Segundo Teixeira (1994), até 1970 todos os edifícios residenciais de até 18 pavimentos construídos na orla da cidade de Santos e de São Vicente foram apoiados em fundação direta sobre a camada de areia compacta superficial por questões econômicas - os construtores consideravam inviável o uso de fundações profundas nesse tipo de empreendimento. Aoki e Angelino (1994) destacaram as estacas de aço (perfis I ou $\mathrm{H}$ ou estacas tubadas), as estacas prémoldadas de concreto cravadas até camada de areia entre camadas de argilas moles, e as estacas escavadas com lama bentonítica com comprimentos de até 60 metros como as principais soluções de fundações profundas na região da Baixada Santista. Falconi e Perez (2007 e 2008), com base no trabalho pioneiro de Gusmão (2006), introduziram na cidade de Santos o uso de estacas metálicas de seção decrescente com a profundidade com composições soldadas de perfis de aço de alta resistência. O decréscimo da seção com a profundidade pode acarretar redução de até $15 \%$ em peso de aço.

Nos dias atuais, devido às magnitudes das cargas dos edifícios, geralmente acima de 20 pavimentos, são mais utilizados os perfis metálicos com aço de alta resistência e as estacas escavadas de grande diâmetro com fluido estabilizante (estacões e barretes) com comprimentos de até 60 metros. Estudos técnicoeconômicos de fundações para prédios indicam que, em edifícios de até 25 pavimentos, ambas as soluções são técnica e economicamente viáveis e igualmente competitivas. A partir dessa grandeza, os blocos de fundação em perfis metálicos, devido às baixas cargas de trabalho das bitolas comerciais, começam a ficar muito 
grandes e com uma grande quantidade de estacas, e começam a surgir interferências entre os blocos de fundações, tornando a solução em estacão mais atrativa.

Teixeira (1988), em trabalho que analisou estacas flutuantes curtas, concluiu que os métodos semiempíricos baseados em valores de SPT não conseguem prever adequadamente a capacidade de carga de estacas em solos de elevadas plasticidade e sensibilidade, caso das argilas da Baixada Santista. Almeida e Maset (2015), após análise de provas de carga estática em estacões de 80 e $100 \mathrm{~cm}$ de diâmetro que, para cargas de até 2,6 vezes a carga de trabalho, não atingiram a ruptura geotécnica e apresentaram deslocamentos não superiores a $25 \mathrm{~mm}$, chegaram à conclusão de que essas estacas, quando dimensionadas por métodos semiempíricos baseados em valores de SPT, estão superdimensionadas.

Massad (1990) analisou os resultados de diversas provas de carga estática em estacas na Baixada Santista com o objetivo de avaliar a influência da gênese dos sedimentos quaternários na capacidade de carga das estacas. O valor do atrito lateral unitário máximo foi calculado a partir dos dados das provas de carga instrumentadas em profundidade.

Os resultados de duas provas de carga instrumentadas referentes à Ponte sobre o Mar Pequeno estão resumidos na Tabela 2.

Tabela 2: valores de $f_{\text {máx }}$ e $y_{1}$ para o ensaio da Ponte sobre o Mar Pequeno (Massad, 2009-a).

\begin{tabular}{|c|c|c|}
\hline Camada & $\mathbf{f}$ máx $\mathbf{( k P a})$ & $\mathbf{y} \mathbf{~} \mathbf{( m m})$ \\
\hline Argila SFL & 20 & 2,5 \\
\hline Areia holocênica & 40 & 2,2 \\
\hline AT superior & 80 & $>5,5$ \\
\hline Areia pleistocênica & $>130$ & $>4,0$ \\
\hline AT inferior & $>60$ & $>3,3$ \\
\hline
\end{tabular}

As camadas inferiores (areia pleistocênica, AT inferior) não atingiram o esgotamento do atrito lateral.

Outras provas de carga foram analisadas impondo-se um valor para o atrito lateral unitário na camada de SFL e calculando-se o valor correspondente à AT. Os resultados estão ilustrados na Tabela 3.

Falconi e Perez (2008) analisaram os resultados de provas de carga estática instrumentadas em profundidade em estacas metálicas de seção decrescente. Os 
valores de $f_{\text {máx }}$ situaram-se entre 20 e 30 kPa para as argilas SFL e próximos a $60 \mathrm{kPa}$ para as argilas AT.

Tabela 3: valores de $f_{\text {máx }}$ para diversas provas de carga na Baixada Santista (Massad, 2009-a).

\begin{tabular}{|c|c|c|c|}
\hline \multirow{2}{*}{ Local } & \multicolumn{3}{|c|}{$\mathbf{f}$ máx (kPa) } \\
\cline { 2 - 4 } & SFL & AT & Areias holocênicas \\
\hline Ponte Mar Pequeno & 20 & 80 & 40 \\
\hline Ponte do Casqueiro & 20 & 70 & 40 \\
\hline Ponte do Rio Branco & - & - & 50 \\
\hline Dados de Teixeira & $20-30$ & 55 & - \\
\hline Dados de Vargas & $21-33$ & - & - \\
\hline Alemoa/PQU & 20 & 60 & - \\
\hline
\end{tabular}

Os estudos de Massad (1990, 2009-a) concluíram que a história geológica tem significativa influência na capacidade de carga das estacas instaladas nos sedimentos quaternários da Baixada Santista. $O$ valor de $f_{\text {máx, }}$ em particular, para estacas flutuantes, praticamente independe do comprimento da estaca, mas depende da proporção relativa entre a espessura de SFL e a espessura de AT atravessadas por ela.

\subsection{Estacas escavadas de grande diâmetro com fluido estabilizante}

As estacas escavadas com fluido estabilizante podem ser de dois tipos, a depender da geometria do furo e do equipamento utilizado: estacões, com seção circular e diâmetros entre 60 e 200 cm, e estacas barrete, com seções retangulares com dimensões de 40 a $120 \mathrm{~cm}$ por 250 ou $320 \mathrm{~cm}$. As provas de carga apresentadas nesse trabalho foram realizadas em estacas com seção circular, ou seja, estacões, portanto as estacas barrete não foram escopo desse trabalho. Vale ressaltar que, em Santos, é comum o uso de estacas barrete ou de uma combinação de estacas barrete e estacões para fundação de edifícios com altos carregamentos.

Este tipo de fundação é utilizado em obras com elevada concentração de cargas nos pilares e porte que justifique e possibilite o uso dos equipamentos envolvidos. Tem sido largamente utilizada na cidade de Santos pela adaptabilidade a diversos tipos de terreno, ausência de vibração (maior conforto às edificações e vizinhanças), além de atingir profundidades de até $70 \mathrm{~m}$. Usualmente as cargas 
adotadas variam entre 1.930 e $8.836 \mathrm{kN}$, respectivamente para os diâmetros de $70 \mathrm{e}$ $150 \mathrm{~cm}$ (com tensão de trabalho de $5 \mathrm{MPa}$ ) - porém, comercialmente, este tipo de estaca é executada com até 2,00 m de diâmetro.

Os estacões são escavados com o auxílio de guindaste com uma caçamba acoplada, acionada por haste telescópica. A perfuração é feita com a caçamba que, em intervalos de 0,5 a 1,0 m, remove o material do furo em movimentos circulares e, em seguida, deposita esse material ao lado de fora do furo. A caçamba é então reintroduzida no furo e o processo se repete de maneira contínua até atingir a cota de ponta prevista. Para a sustentação das paredes da escavação, é utilizado um fluido estabilizante, que pode ser lama bentonítica ou polímero sintético, que deve ser lançado simultaneamente à execução do furo. Após a escavação, antes da concretagem da estaca, procede-se à verificação dos parâmetros como $\mathrm{pH}$, densidade, viscosidade e, caso o fluido utilizado seja a lama bentonítica, da porcentagem de areia em suspensão no fluido. Caso essa porcentagem seja maior do que o limite de $3 \%$ definido por norma, deve-se proceder à desarenação da lama bentonítica, com a utilização de desarenador cônico e/ou vibratório, succionando o material do fundo do furo e retornando-o, após desarenação, pela parte superior da escavação. Para esse efeito, é necessária a utilização de bomba com potência suficiente para aspirar a lama e a areia do fundo da escavação, mesmo em estacas com profundidades superiores a 40 metros.

Terminada a perfuração, a armadura é posicionada com o auxílio de guindaste ou da própria perfuratriz, e fixada na camisa metálica junto à boca do furo. A concretagem é feita de baixo para cima e de modo contínuo e uniforme, com o auxílio de tubo tremonha centralizado no furo, expulsando a lama bentonítica ou o polímero, que são bombeados novamente para os silos para reutilização. Deve-se tomar cuidado especial em relação à distância entre o tubo tremonha e o topo do concreto (usualmente chamada de "ficha" do tubo tremonha), que não pode ser inferior a 3 metros em nenhum momento durante a concretagem, para evitar contaminação do concreto e seccionamento do fuste da estaca.

A sequência executiva está resumida na Figura 7 e ilustrada, etapa a etapa, nas Figuras 8 a 12 . 


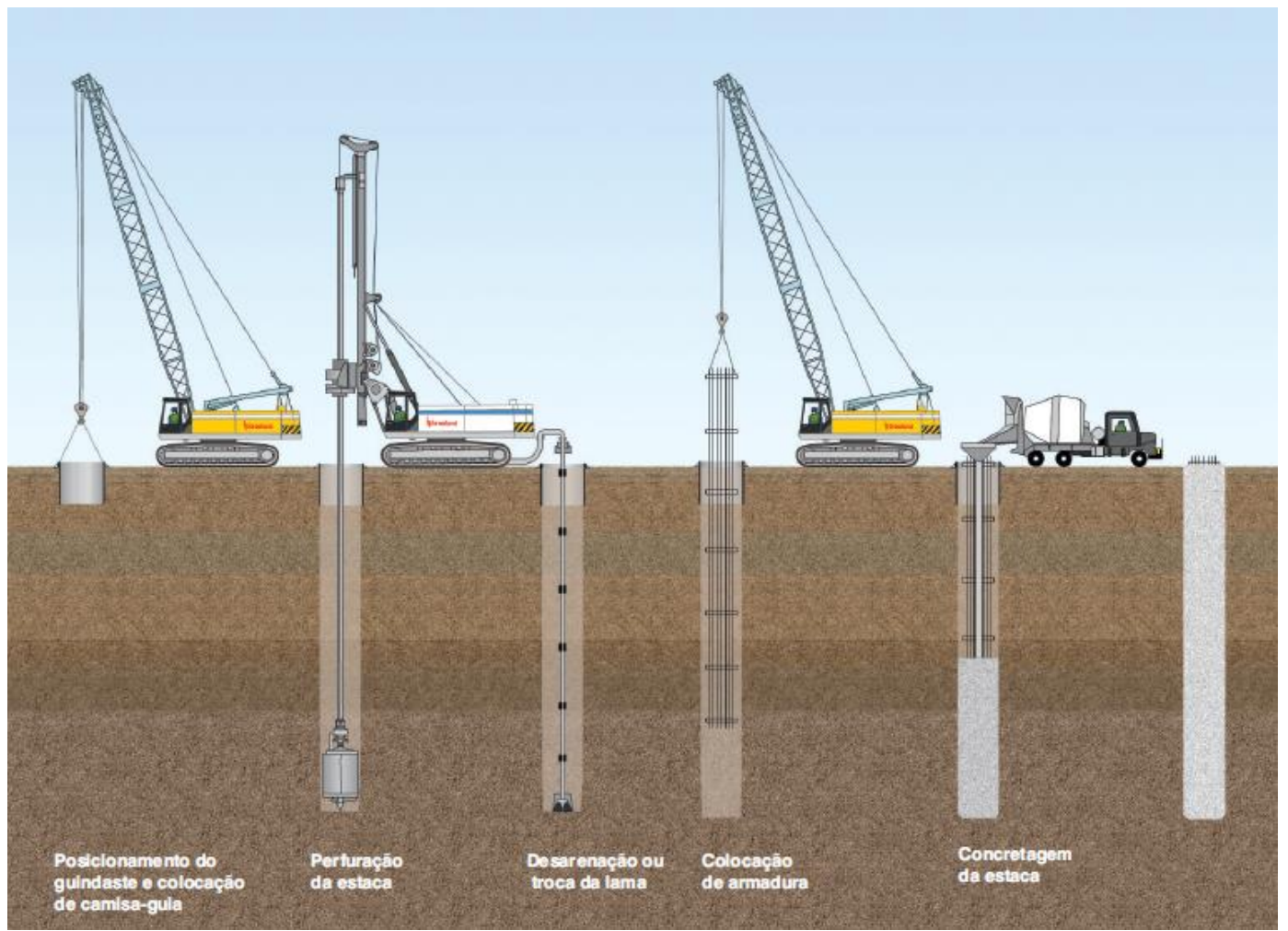

Figura 7: método executivo para estaca escavada de grande diâmetro com fluido estabilizante (Brasfond, 2018).

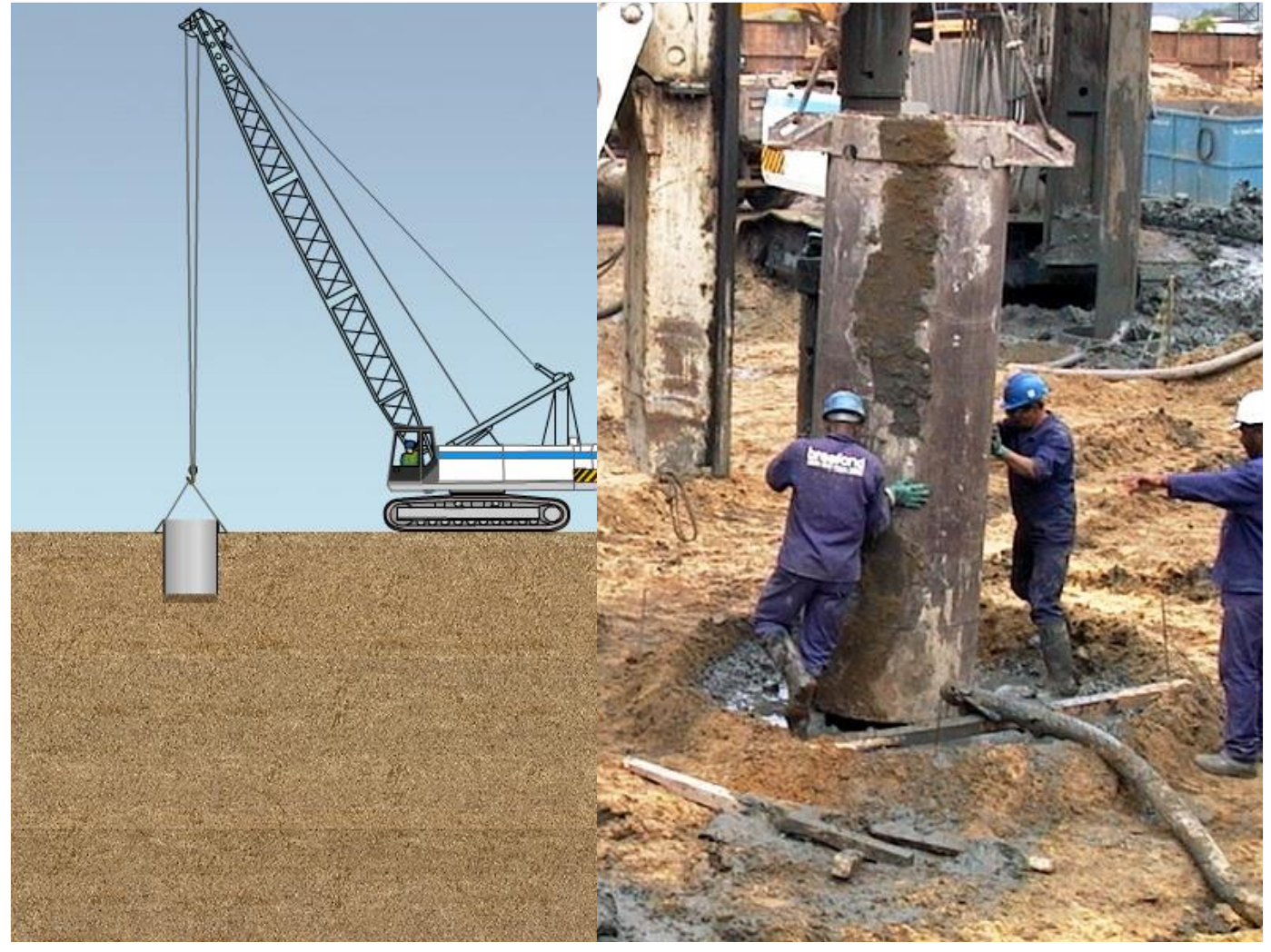

Figura 8: colocação da camisa guia (acervo ZF, 2019). 


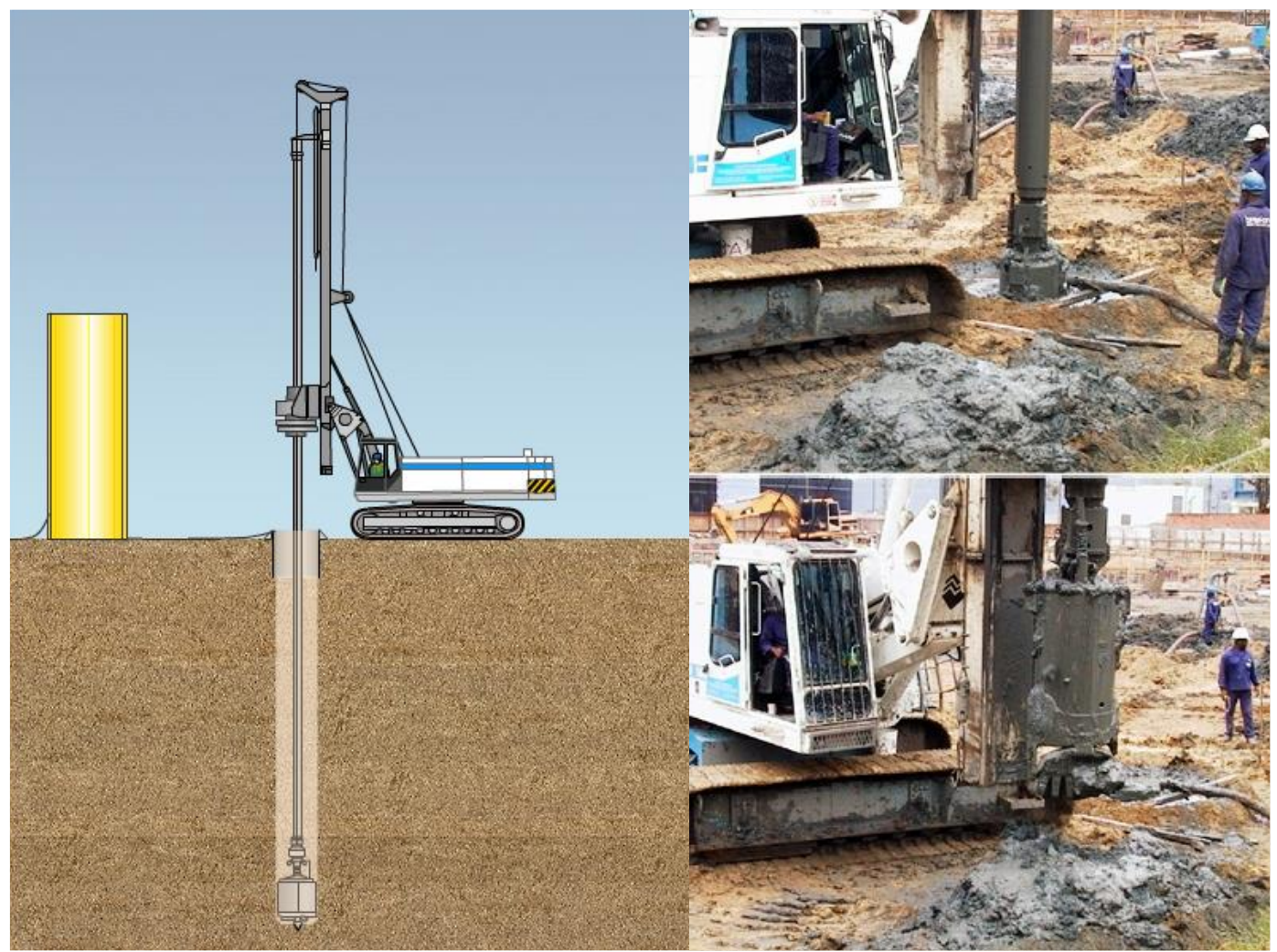

Figura 9: perfuração da estaca (acervo ZF, 2019).

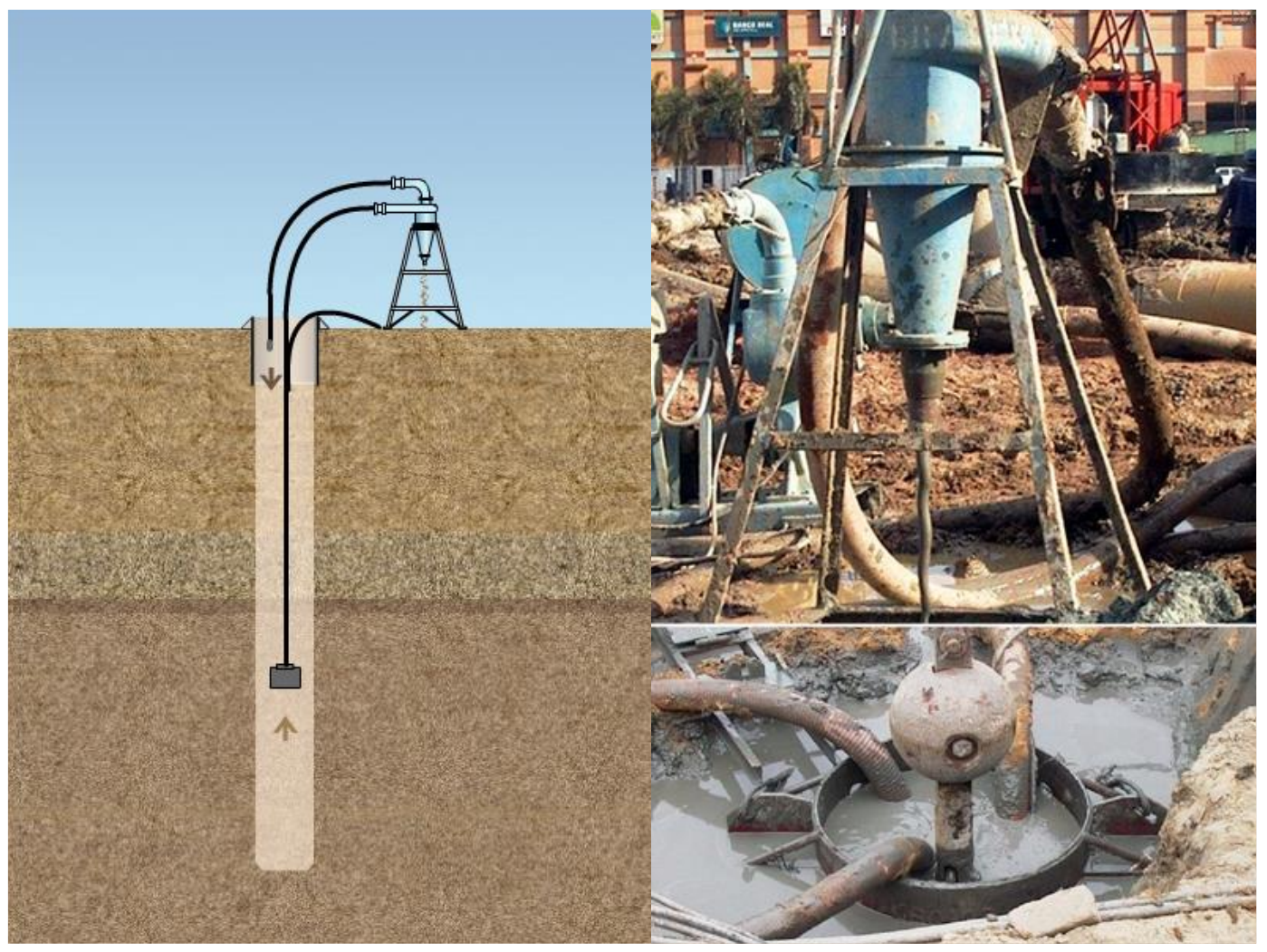

Figura 10: desarenação da lama bentonítica (acervo ZF, 2019). 


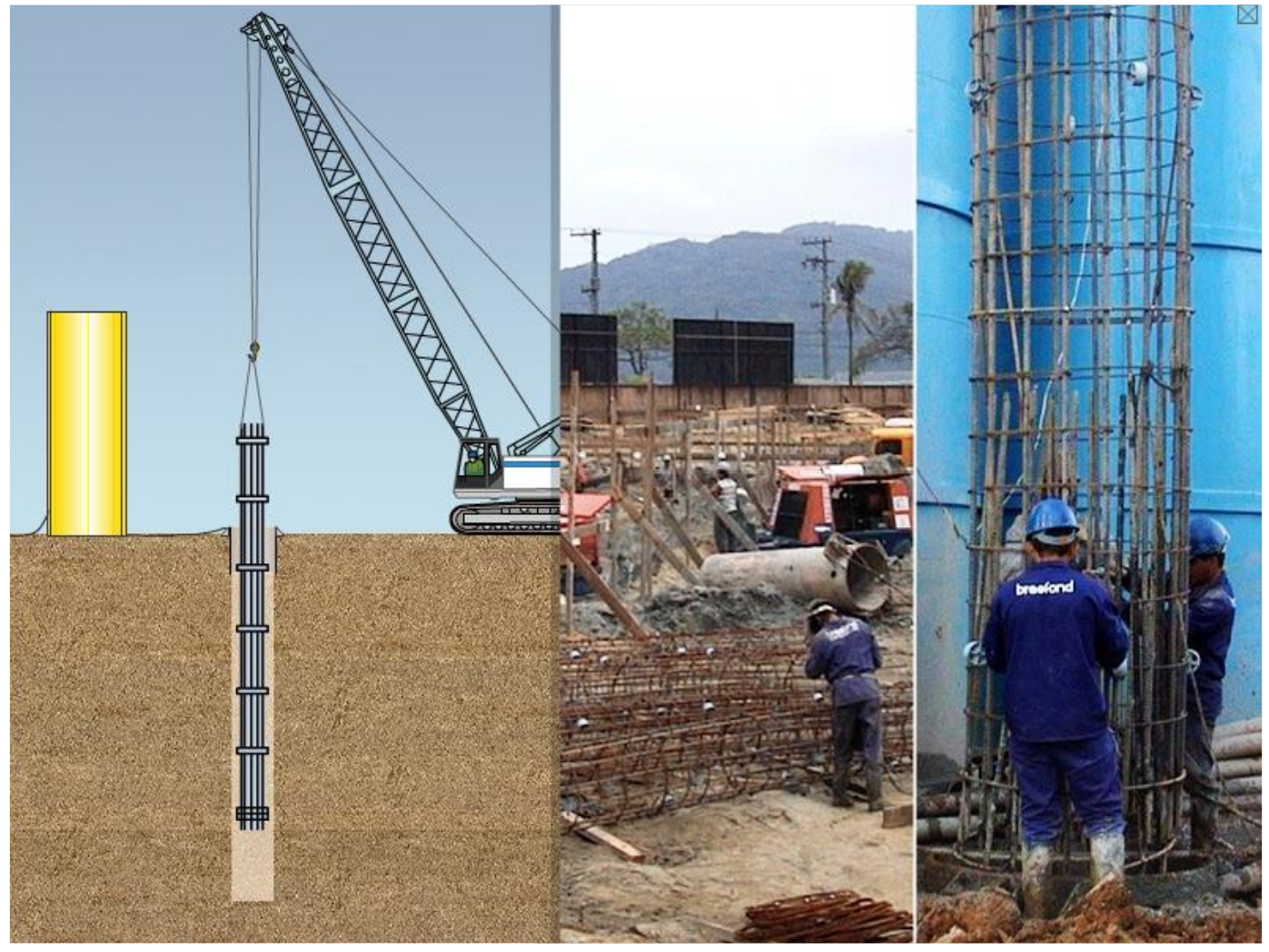

Figura 11: descida da armadura (acervo ZF, 2019).

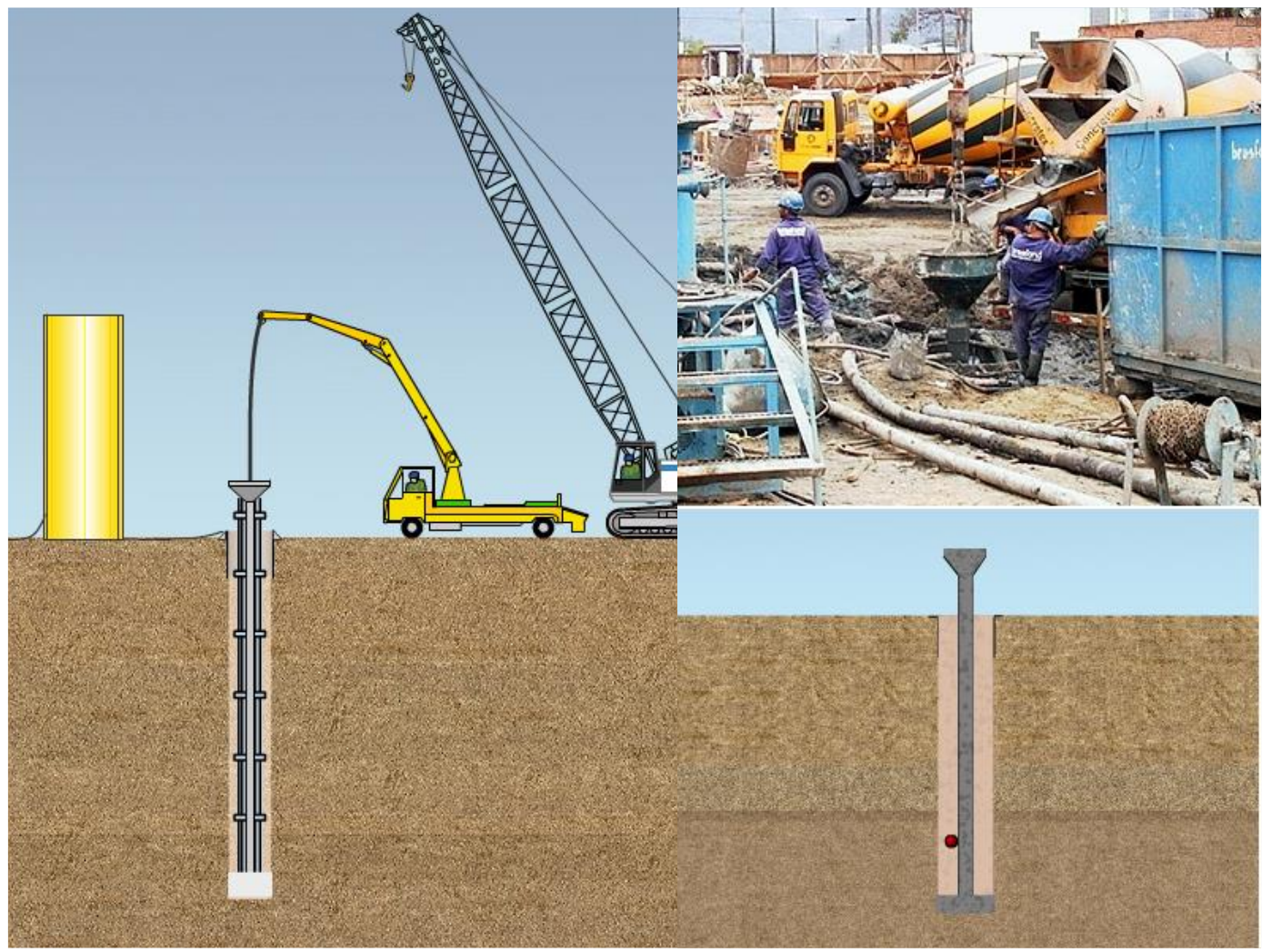

Figura 12: concretagem com tubo tremonha (acervo ZF, 2019). 
Os equipamentos necessários para a execução dos estacões, como silos para hidratação e armazenamento da lama bentonítica, funil e tubos tremonha, plataforma de concretagem, misturador, desarenador, armaduras, guindaste e perfuratriz, demandam considerável espaço no canteiro de obras, conforme Figura 13.

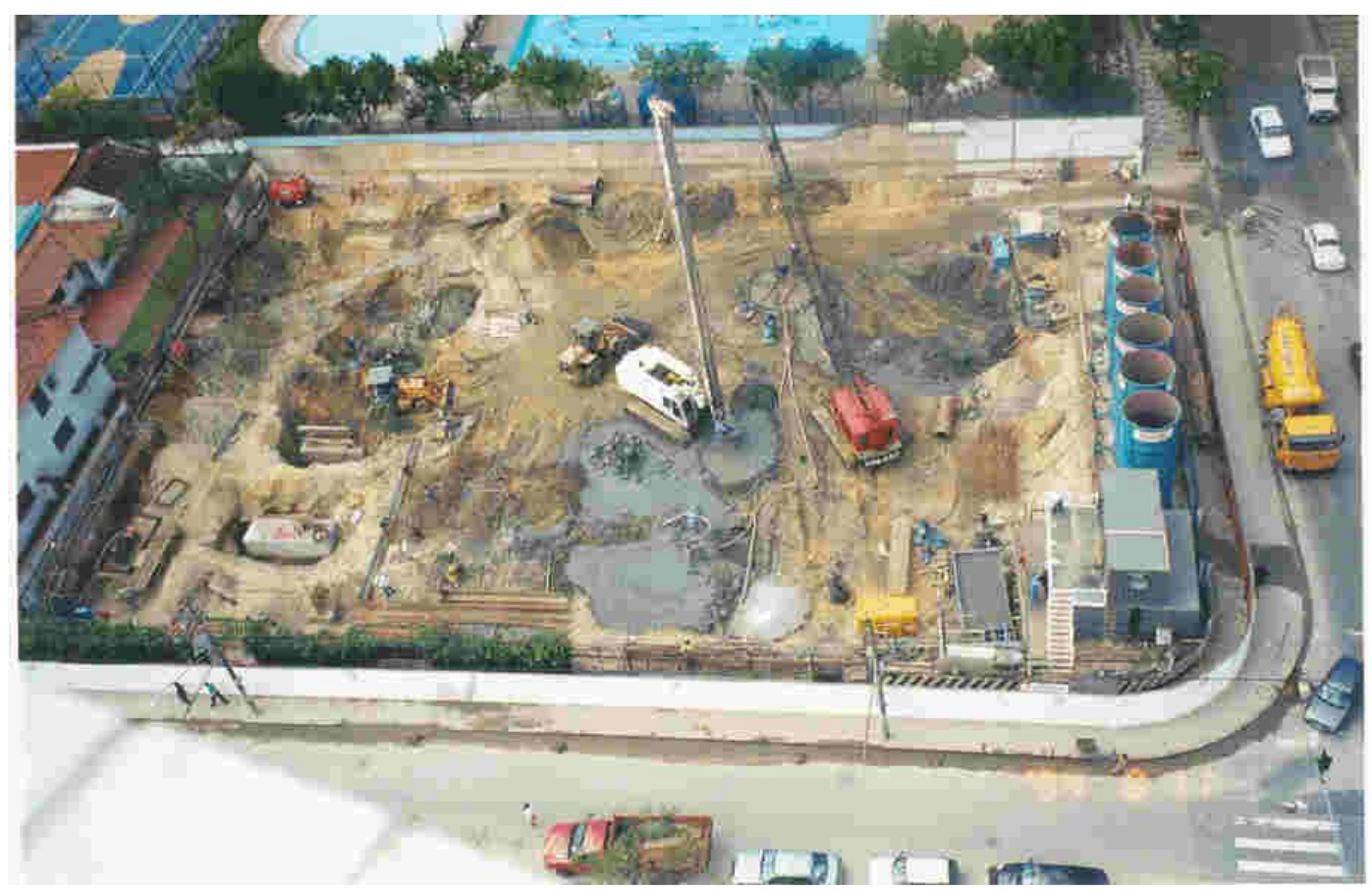

Figura 13: canteiro de obras (acervo ZF, 2019).

A lama bentonítica é um fluido formado pela mistura de bentonita (mistura cujo argilomineral predominante é a montmorilonita, composta por silicato de alumínio, magnésio e cálcio hidratado) com água limpa, e possui viscosidade superior à da água. Esse fluido tem três características muito importantes (Saes, 2017):

- Estabilidade, obtida pela não decantação das partículas de bentonita em suspensão por um longo período de tempo;

- Capacidade de formar rapidamente uma película impermeável ("cake") sobre uma superfície porosa;

- Tixotropia, ou seja, capacidade reversível de tornar-se líquida quando agitada e de formar uma estrutura "gelificada" quando cessado o movimento. 
A lama bentonítica, para estabilização da perfuração das estacas, deve possuir as características indicadas na Tabela 4. Essas características deverão ser comprovadas em obra antes do início da concretagem de cada estacão através de ensaios com a utilização dos equipamentos indicados na terceira coluna.

Tabela 4: Características da lama bentonítica (NBR 6122, 2010).

\begin{tabular}{|c|c|c|}
\hline Propriedades & Valores & $\begin{array}{c}\text { Equipamentos para } \\
\text { ensaio }\end{array}$ \\
\hline Densidade & $1,025 \mathrm{a} 1,100 \mathrm{~g} / \mathrm{cm}^{3}$ & Densímetro \\
\hline Viscosidade & $30 \mathrm{a} 90 \mathrm{~s}$ & Funil Marsh \\
\hline $\mathrm{pH}$ & $7 \mathrm{a} 11$ & Indicador de $\mathrm{pH}$ \\
\hline Teor de areia & $\leq 3 \%$ & $\begin{array}{c}\text { Baroid sand content ou } \\
\text { similar }\end{array}$ \\
\hline
\end{tabular}

O principal polímero utilizado comercialmente, por ser biodegradável, é a poliacrilamida em emulsão de alto peso molecular e cadeias longas (Brasfond, 2018). Em contato com a água, ocorre inchamento do polímero e aumento da viscosidade da água. Pode-se utilizar como aditivo outro polímero com a função de acelerar a floculação das partículas sólidas em suspensão ao final da escavação. Da mesma forma que a lama bentonítica, o polímero deve apresentar as propriedades indicadas na Tabela 5.

Tabela 5: Características do fluido estabilizante (NBR 6122, 2010).

\begin{tabular}{|c|c|c|}
\hline Propriedades & Valores & $\begin{array}{c}\text { Equipamentos para } \\
\text { ensaio }\end{array}$ \\
\hline Densidade & $1,005 \mathrm{a} 1,05 \mathrm{~g} / \mathrm{cm}^{3}$ & Densímetro \\
\hline Viscosidade & $35 \mathrm{a} 90 \mathrm{~s}$ & Funil Marsh \\
\hline $\mathrm{pH}$ & $7 \mathrm{a} 11$ & Indicador de $\mathrm{pH}$ \\
\hline Teor de areia & $\leq 3 \%$ & $\begin{array}{c}\text { Baroid sand content ou } \\
\text { similar }\end{array}$ \\
\hline
\end{tabular}

O uso da lama bentonítica como fluido estabilizante em obras de fundações é amplamente consagrado, e sua eficiência na estabilização de escavações é consenso no meio técnico. Porém, devido a questões ambientais, principalmente no que diz respeito ao descarte do material, o polímero sintético vem sendo cada vez mais utilizado. A lama bentonítica, quando descartada, pode infiltrar-se no solo e formar uma película impermeável, impedindo a passagem de água e causando impacto 
ambiental significativo - o polímero, por ser biodegradável, não causa esse problema. Os aspectos da escavação com ambos os tipos de fluido estabilizante (eficiência na estabilização do furo, tempo de execução, consumo de concreto e seção da estaca, capacidade de carga) vem sendo estudados por vários autores. Lam e Jefferis (2016) analisaram provas de carga em estacas executadas com diferentes tipos de fluido em 6 casos de obra na Europa (Reino Unido, Portugal, Itália e Alemanha), e constataram que as estacas executadas com polímero como fluido estabilizante apresentaram ótimo desempenho, comparável às estacas com lama bentonítica.

A capacidade de suporte da ponta das estacas escavadas com auxílio de fluido estabilizante é alvo de discussões constantes no meio geotécnico. Isso porque, devido ao processo executivo da escavação, em que as paredes da escavação são estabilizadas com o auxílio do fluido estabilizante, a areia fica em suspensão no fluido. O teor de areia em suspensão deve ser controlado para que não ultrapasse o limite estabelecido nas Tabelas 4 e 5. Porém, mesmo respeitando esse valor, pode ocorrer deposição da areia fofa no fundo da escavação da estaca no período entre o final da desarenação e o início da concretagem. A ABNT NBR 6122, desde 2010, limita a consideração da capacidade de carga da ponta da estaca escavada. A revisão mais recente da norma, em 2019, introduziu uma limitação ainda maior e preconizou procedimentos de limpeza da ponta da estaca.

Até a revisão anterior da norma, publicada em 2010, a carga admissível da estaca escavada calculada por método semiempírico deveria ser de no máximo 1,25 vez o atrito lateral calculado na ruptura - ou seja, no mínimo 80\% da carga admissível da estaca deveria ser resistida pelo atrito lateral, sendo a ponta responsável por suportar no máximo $20 \%$ desse valor. Para consideração de uma maior parcela de ponta, o processo executivo de limpeza da ponta deveria ser especificado pelo projetista e ratificado pelo executor - porém, a norma não especificava esse procedimento de limpeza.

A revisão de 2019 introduziu a necessidade de, sempre que seja considerada a contribuição da resistência de ponta, em qualquer magnitude, fazer menção explícita a esse critério no projeto. A norma introduziu também procedimentos executivos de limpeza para assegurar o contato efetivo entre a ponta da estaca e o solo competente ou rocha. Caso o contato efetivo entre o concreto e o solo firme ou rocha não possa 
ser assegurado pelo executor, deve-se considerar resistência nula na ponta da estaca. Essa consideração provém de um consenso no meio geotécnico e entre os revisores da norma, corroborado por provas de carga, de que, quando executadas sem um procedimento de limpeza de ponta, estacas escavadas com fluido estabilizante podem apresentar resíduos na ponta, e esta não oferece resistência ao deslocamento da estaca.

\subsection{Métodos semiempíricos de cálculo de capacidade de carga baseados em SPT}

As rotinas de dimensionamento de fundações profundas baseadas em critérios de Estado Limite Último levam em consideração a carga de ruptura do conjunto estaca-solo, sobre a qual é aplicado um fator de segurança global. Para estacas, ao aplicar-se uma carga axial no topo da estaca, mobilizam-se ao longo do fuste e na seção da ponta tensões resistentes, cuja magnitude depende do tipo de solo e de sua resistência. Considera-se que a ruptura do conjunto é determinada por duas parcelas: a resistência da estaca por atrito lateral do fuste e a parcela da resistência de ponta. Segundo Cintra e Aoki (2010), no valor de carga que representa a ruptura física da estaca, esta estaria na iminência de deslocar-se infinitamente para baixo, esgotada a capacidade do sistema de mobilizar resistência. Vale ressaltar que o conceito de ruptura física não se relaciona com a ruptura estrutural do elemento estaca e, no dimensionamento a ELU, ambos os critérios devem ser satisfeitos com os devidos fatores de segurança.

A resistência do conjunto estaca-solo por atrito lateral tem como variáveis a área lateral da estaca circular e os parâmetros das camadas de solo em que a estaca está imersa. A resistência de ponta depende da resistência do solo adjacente à ponta, cuja influência varia de acordo com o método semiempírico considerado, e da área da seção transversal na ponta da estaca. Assim, expressão genérica para a capacidade de carga de uma estaca circular pode ser escrita por

$$
Q_{r}=Q_{L}+Q_{P}
$$

em que: 
Qr: resistência total do conjunto solo-estaca;

QL: resistência por atrito lateral;

Qp: resistência de ponta.

Considerando a resistência do conjunto solo-estaca em termos de tensões, pode-se reescrever a fórmula acima como

$$
Q_{r}=A_{L} \cdot q_{L}+A_{P} \cdot q_{P}=\pi \cdot D \cdot h \cdot q_{L}+\frac{\pi \cdot D^{2}}{4} \cdot q_{P}
$$

em que:

$A_{L}$ : área lateral da estaca;

qL: tensão de ruptura por atrito lateral;

Ap: área de ponta da estaca;

qP: tensão de ruptura da ponta;

D: diâmetro da estaca;

h: comprimento da estaca.

A resistência do conjunto solo-estaca por atrito lateral e por ponta dependem de parâmetros do solo em que a estaca está imersa e o seu cálculo varia de acordo com o método adotado.

Para o cálculo de capacidade de carga de estacas escavadas de grande diâmetro, são mais utilizados os métodos de Décourt-Quaresma (1978) e Aoki-Velloso (1975). O método de Décourt-Quaresma foi inicialmente concebido baseado em provas de carga estáticas realizadas em estacas pré-moldadas de concreto e utiliza os valores de SPT do solo para o cálculo das parcelas de resistência. Já o método de Aoki-Velloso (1975) foi baseado em ensaios em diferentes tipos de estaca - Franki, pré-moldadas de concreto e de aço - e utiliza o parâmetro $q_{c}$ do ensaio de penetração do cone (CPT). Como no Brasil a grande maioria das obras dispõe de resultados de ensaios SPT, e não CPT, o método de Aoki-Velloso utiliza correlações entre esses os parâmetros de SPT e qc. 
Em 2008, Falconi e Perez desenvolveram método semiempírico de cálculo de capacidade de carga de estacas metálicas na Baixada Santista. Baseado em 5 provas de carga estática, sendo uma com instrumentação em profundidade, o método relaciona os valores de SPT das camadas de areia e silte, multiplicados por um coeficiente $\alpha$, e a classificação típica das argilas da Baixada Santista como SFL e AT para cálculo da adesão estaca-solo. Para a resistência de ponta dos perfis, são utilizados coeficientes $\mathrm{K}$ que variam com o SPT do solo onde a ponta está apoiada. Neste trabalho, foi feita a adaptação dos coeficientes para utilização do método em estacas escavadas de grande diâmetro.

\subsubsection{Método de Décourt-Quaresma (1978)}

Décourt e Quaresma (1978) apresentaram no VI COBRAMSEF método de cálculo de capacidade de carga de estacas baseado em valores de SPT. Inicialmente desenvolvido com base em ensaios em estacas pré-moldadas de concreto, o método foi revisto e aprimorado pelos autores em publicações posteriores para abranger maior número de estacas e processos executivos.

De acordo com o método, a tensão de ruptura de ponta é dada por

$$
q_{P}=C . N_{P_{-} D Q}
$$

Em que

C: coeficiente que varia em função do tipo de solo (ver Tabela 6);

NP_DQ: média dos valores de SPT da ponta da estaca, o imediatamente anterior e o imediatamente superior.

Tabela 6: coeficiente C em função do tipo de solo (adaptada de Décourt e Quaresma, 1978).

\begin{tabular}{|c|c|}
\hline Tipo de solo & C (kPa) \\
\hline Argila & 120 \\
\hline Silte argiloso (solo residual) & 200 \\
\hline Silte arenoso (solo residual) & 250 \\
\hline Areia & 400 \\
\hline
\end{tabular}

Para o atrito lateral na ruptura, vale a relação (adaptada de Décourt, 1982) 


$$
q_{L}=10\left(\frac{N_{L}}{3}+1\right)
$$

em que

$\mathrm{NL}$ : média dos SPTs ao longo do fuste da estaca, $3 \leq \mathrm{N}_{\mathrm{L}} \leq 50$;

q em kPa.

Para a utilização do método em outros tipos de estacas que não a pré-moldada de concreto, deve-se considerar os coeficientes $\alpha$ e $\beta$, que são coeficientes de majoração ou de minoração para as tensões de ruptura de ponta e de atrito lateral.

Assim, a Equação 1 pode ser reescrita para o método de Décourt-Quaresma da seguinte maneira

$$
Q_{r}=\beta_{D Q} \cdot \pi \cdot D \cdot h \cdot 10\left(\frac{N_{L}}{3}+1\right)+\alpha_{D Q} \cdot \frac{\pi \cdot D^{2}}{4} \cdot C \cdot N_{P}
$$

Os valores de $\alpha_{D Q}$ e $\beta_{D Q}$ recomendados de acordo com o tipo de estaca são apresentados nas Tabelas a seguir (Décourt et al, 2016).

Tabela 7: Valores do coeficiente $\alpha_{D Q}$ em função do tipo de estaca e de solo.

\begin{tabular}{|c|c|c|c|c|c|}
\hline Tipo de estaca & $\begin{array}{c}\text { Escavada } \\
\text { em geral }\end{array}$ & $\begin{array}{c}\text { Escavada } \\
\text { (bentonita) }\end{array}$ & $\begin{array}{c}\text { Hélice } \\
\text { contínua }\end{array}$ & Raiz & $\begin{array}{c}\text { Injetada } \\
\text { sob altas } \\
\text { pressões }\end{array}$ \\
\hline Argilas & 0,85 & 0,85 & 0,30 & 0,85 & 1,00 \\
\hline $\begin{array}{c}\text { Solos } \\
\text { intermediários }\end{array}$ & 0,60 & 0,60 & 0,30 & 0,60 & 1,00 \\
\hline Areias & 0,50 & 0,50 & 0,30 & 0,50 & 1,00 \\
\hline
\end{tabular}

Tabela 8: Valores do coeficiente $\beta_{D Q}$ em função do tipo de estaca e de solo.

\begin{tabular}{|c|c|c|c|c|c|c|}
\hline Tipo de estaca & $\begin{array}{c}\text { Escavada } \\
\text { em geral }\end{array}$ & $\begin{array}{c}\text { Escavada } \\
\text { (bentonita) }\end{array}$ & $\begin{array}{c}\text { Hélice } \\
\text { contínua }\end{array}$ & Ômega & Raiz & $\begin{array}{c}\text { Injetada } \\
\text { sob altas } \\
\text { pressões }\end{array}$ \\
\hline Argilas & 0,80 & 0,90 & 1,00 & 1,00 & 1,50 & 3,00 \\
\hline $\begin{array}{c}\text { Solos } \\
\text { intermediários }\end{array}$ & 0,65 & 0,75 & 1,00 & 1,00 & 1,50 & 3,00 \\
\hline Areias & 0,50 & 0,60 & 1,00 & 1,00 & 1,50 & 3,00 \\
\hline
\end{tabular}




\subsubsection{Método de Aoki-Velloso (1975)}

O método de Aoki-Velloso (1975) relaciona as incógnitas geotécnicas de resistência lateral e de ponta de uma estaca com resultados de ensaios CPT, por meio dos valores da resistência de ponta do cone $\left(q_{c}\right)$ e do atrito lateral unitário na luva $\left(f_{s}\right)$.

Sendo rL e rp as incógnitas geotécnicas, que podem ser correlacionadas com os resultados do ensaio CPT:

$$
\begin{aligned}
& r_{P}=\frac{q_{C}}{F_{1}} \\
& r_{L}=\frac{f_{s}}{F_{2}}
\end{aligned}
$$

Sendo $F_{1}$ e $F_{2}$ fatores de correção que levam em conta a diferença de comportamento entre a estaca e o conte do CPT, além da influência do método executivo de cada tipo de estaca.

No Brasil, a sondagem à percussão SPT é amplamente utilizada, enquanto o ensaio de cone não é tão empregado. Quando se dispõe apenas de resultados de ensaios de sondagem à percussão, pode-se utilizar a seguinte correlação entre a resistência de ponta do cone $q_{c}$ e o índice de resistência à penetração NsPT. O atrito lateral unitário na luva fs também pode ser exprimido em função do NSPT através da razão de atrito $\alpha_{A v}$. Sendo assim, pode-se escrever:

$$
\begin{gathered}
\alpha_{A V}=\frac{f_{s}}{q_{c}} \\
q_{C}=K_{A V} \cdot N_{S P T} \\
f_{S}=\alpha_{A V} \cdot q_{C}=\alpha_{A V} \cdot K_{A V} \cdot N_{S P T}
\end{gathered}
$$

Sendo que o coeficiente $\mathrm{K}_{\mathrm{AV}}$ depende do tipo de solo (ver Tabela 5).

Sendo NP_Av e N $\mathrm{L}$ os valores de SPT da ponta da estaca e da média dos valores em uma camada de solo, as incógnitas geotécnicas podem ser reescritas: 


$$
\begin{gathered}
r_{P}=\frac{K_{A V} \cdot N_{P \_A V}}{F_{1}} \\
r_{L}=\frac{\alpha_{A V} \cdot K_{A V} \cdot N_{L}}{F_{2}}
\end{gathered}
$$

Reescrevendo a equação 1, a fórmula da capacidade de carga resulta:

$$
Q_{r}=\frac{K_{A V} \cdot N_{P A V}}{F_{1}} A_{P}+\frac{U}{F_{2}} \sum \alpha_{A V} \cdot K_{A V} \cdot N_{L} \cdot h
$$

Tabela 9: Fatores de correção $F_{1}$ e $F_{2}$ (Aoki e Velloso, 1975, atualizado por Cintra e Aoki, 2010).

\begin{tabular}{|c|c|c|}
\hline Tipo de estaca & $\mathbf{F}_{\mathbf{1}}$ & $\mathbf{F}_{\mathbf{2}}$ \\
\hline Franki & 2,50 & $2 \mathrm{~F}_{1}$ \\
\hline Metálica & 1,75 & $2 \mathrm{~F}_{1}$ \\
\hline Pré-moldada & $1+\mathrm{D} / 0,80$ & $2 \mathrm{~F}_{1}$ \\
\hline Escavada & 3,0 & $2 \mathrm{~F}_{1}$ \\
\hline $\begin{array}{c}\text { Raiz, hélice contínua e } \\
\text { ômega }\end{array}$ & 2,0 & $2 \mathrm{~F}_{1}$ \\
\hline
\end{tabular}

Tabela 10: coeficiente $K_{A V}$ e razão de atrito $\alpha_{A V}$ (Aoki e Velloso, 1975).

\begin{tabular}{|c|c|c|}
\hline Solo & KAV $_{\mathbf{A p a}} \mathbf{M}$ & $\boldsymbol{\alpha}_{\mathbf{A V}}(\%)$ \\
\hline Areia & 1,00 & 1,4 \\
\hline Areia siltosa & 0,80 & 2,0 \\
\hline Areia silto argilosa & 0,70 & 2,4 \\
\hline Areia argilosa & 0,60 & 3,0 \\
\hline Areia argilo siltosa & 0,50 & 2,8 \\
\hline Silte & 0,40 & 3,0 \\
\hline Silte arenoso & 0,55 & 2,2 \\
\hline Silte areno argiloso & 0,45 & 2,8 \\
\hline Silte argiloso & 0,23 & 3,4 \\
\hline Silte argilo arenoso & 0,25 & 3,0 \\
\hline Argila & 0,20 & 6,0 \\
\hline Argila arenosa & 0,35 & 2,4 \\
\hline Argila areno siltosa & 0,30 & 2,8 \\
\hline Argila siltosa & 0,22 & 4,0 \\
\hline Argila silto arenosa & 0,33 & 3,0 \\
\hline
\end{tabular}




\subsubsection{Método de Falconi e Perez (2008)}

Baseando-se em resultados de provas de carga estática instrumentadas em profundidade em perfis metálicos na Baixada Santista, Falconi e Perez (2008) desenvolveram método semiempírico de capacidade de carga específico para essa região e esse tipo de estaca. O método leva em consideração a classificação geológica das argilas marinhas, atribuindo para cada uma diferentes valores de adesão estaca-solo de acordo com sua gênese para determinação do atrito lateral mobilizado. No caso de areias e siltes, o atrito lateral mobilizado é calculado em função do SPT. A carga de ponta do perfil é calculada de acordo com o valor médio de SPT na ponta e 1,00 m abaixo dela, independentemente do tipo de solo.

O método pode ser resumido da seguinte maneira (Falconi e Perez, 2008):

1. Cálculo da capacidade de carga por atrito lateral $(Q\llcorner)$ :

$$
\boldsymbol{Q}_{\boldsymbol{L}}=\boldsymbol{U} \cdot \sum(\boldsymbol{h} \cdot \boldsymbol{f})
$$

Sendo que:

f: adesão $[\mathrm{kPa}]$

$\mathrm{U}$ : perímetro colado da estaca [m]

h: espessura da camada de solo [m]

Tabela 11: Valores de $\mathrm{f}$ utilizados para as argilas (adaptado de Falconi e Perez, 2008).

\begin{tabular}{|c|c|c|}
\hline Camada & SPT médio NL & $\mathbf{f ~ [ k P a ] ~}$ \\
\hline Argila marinha & $\bar{N}<2$ & 20 \\
\hline Argila marinha (tipo SFL) & $2 \leq \bar{N}<4$ & 30 \\
\hline Argila marinha (tipo $A T$ ) & $4 \leq \bar{N} \leq 6$ & 60 \\
\hline
\end{tabular}

Para as areias, recomenda-se

$$
f=2,1 . N_{L}
$$

Sendo que:

f: adesão média $[\mathrm{kPa}]$ 
NL: média dos valores de SPT das camadas de areia e/ou silte.

2. Cálculo da capacidade de carga na ponta da estaca (Qp):

$$
Q_{P}=S_{c i r c} \cdot K_{F P}
$$

Sendo que:

Acirc: área circunscrita à ponta da estaca [m²];

KFP: coeficiente da ponta que varia com o SPT médio do solo [kPa];

NP_FP: média dos valores de SPT na ponta e 1,0 m abaixo.

Tabela 12: Valores de $K_{F P}$ (adaptado de Falconi e Perez, 2008).

\begin{tabular}{|c|c|}
\hline $\mathbf{N P}_{\mathrm{FP}}$ & $\mathbf{K}_{\mathrm{FP}}[\mathrm{kPa}]$ \\
\hline $10 \leq \bar{N} \leq 30$ & $2.000 \leq \mathrm{N} \leq 4.000$ \\
\hline $\bar{N} \geq 40$ & $10.000 \leq \mathrm{N} \leq 40.000$ \\
\hline
\end{tabular}

Vale ressaltar que o método de Falconi e Perez foi desenvolvido para estacas metálicas e que, até o momento, não foram determinados coeficientes para utilização do método em outros tipos de estacas. Neste trabalho, utilizando os resultados das provas de carga estática instrumentadas em profundidade, procurar-se-á a calibração do método para sua utilização no cálculo de capacidade de carga de estacas escavadas de grande diâmetro com fluido estabilizante na Baixada Santista.

\subsection{Modelo matemático para análise de provas de carga}

\subsubsection{Modelo baseado nas Leis de Cambefort modificadas}

Para o desenvolvimento do modelo, considera-se uma estaca vertical isolada, compressível, submetida a um carregamento axial. Além disso, considera-se a hipótese de rupturas progressivas, ou seja, de que a resistência última não ocorre necessariamente simultaneamente em todos os pontos da estaca e as tensões (de ponta ou atrito lateral) mobilizadas são diferentes em cada um deles, em função do recalque. 
Para tais hipóteses, podem-se utilizar as relações propostas por Cambefort (1964), que dizem respeito aos deslocamentos verticais de ponta e de fuste necessários em um ponto para mobilizar a resistência última de uma estaca. A representação das leis de Cambefort (1964) em sua forma simplificada por Cassan (1978) para atrito lateral (f) e resistência de ponta (q) é mostrada na Figura 14 a seguir.

a) PRIMEIRA LEI

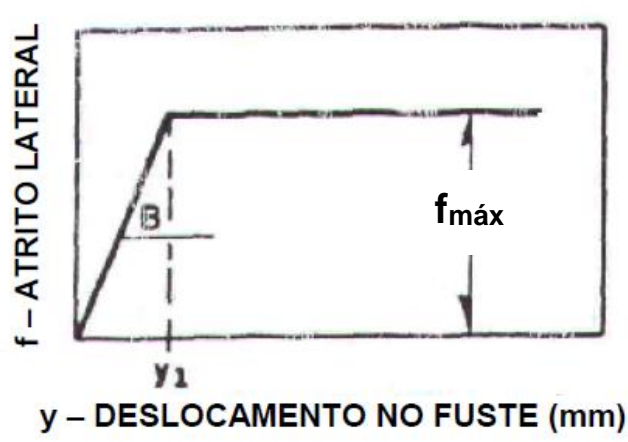

b) SEGUNDA LEI

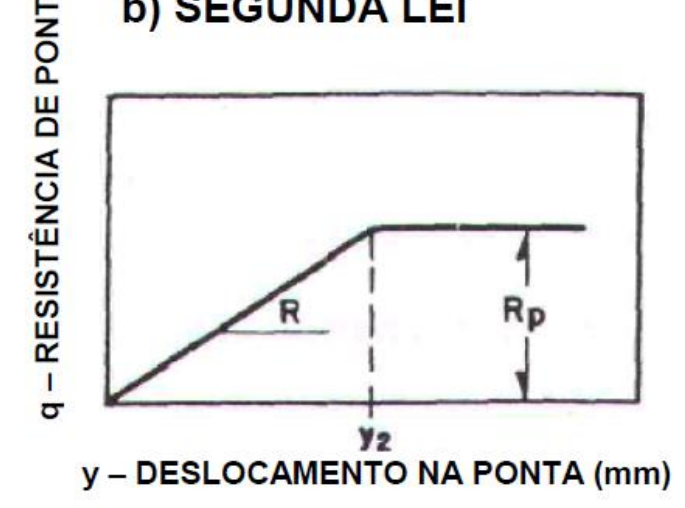

Figura 14: Leis de Cambefort (1964) modificadas por Cassan (1978) (extraída de Massad, 1995).

Da Figura 14, pode-se inferir que

$\begin{array}{lllll}f=B \cdot y & \text { para } \mathrm{y} \leq \mathrm{y}_{1} & \text { e } & f=f_{\text {máx }}=B \cdot y_{1} & \text { para } \mathrm{y} \geq \mathrm{y}_{1} \\ q=R \cdot y & \text { para } \mathrm{y} \leq \mathrm{y}_{2} & \text { e } & q=R_{P}=R \cdot y_{2} & \text { para } \mathrm{y} \geq \mathrm{y}_{2}\end{array}$

Sendo

f: atrito lateral unitário;

q: resistência de ponta;

$\mathrm{y}_{1}$ : "quake" do atrito lateral, da ordem de alguns milímetros;

y2: "quake" da ponta, que pode alcançar dezenas de milímetros e depende das dimensões da ponta da estaca (Massad, 1992). 


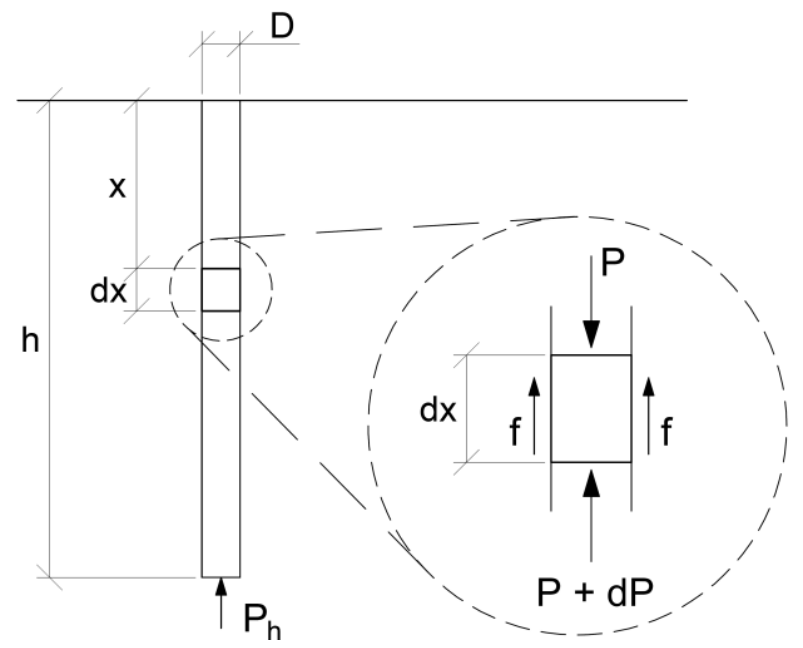

Figura 15: forças atuando em um elemento de estaca (adaptado de Massad, 1992).

Considere-se uma estaca. Ignorando-se o seu peso próprio, a equação de equilíbrio para um elemento de comprimento $\mathrm{dx}$ pode ser escrita:

$$
P=P+d P+\pi D f d x
$$

ou

$$
\frac{d P}{d x}=-\pi D f
$$

Pela lei de Hooke, tem-se:

$$
\varepsilon=\frac{d y}{d x}=-\frac{P}{E . S}
$$

sendo

$\varepsilon$ : deformação do elemento;

E: módulo de elasticidade da estaca;

S: área da seção transversal da estaca.

A partir das equações (18) e (19), pode-se escrever

$$
\frac{d^{2} y}{d x^{2}}=\frac{\pi D f}{E S}
$$

A equação (20) determina a transferência de carga da estaca para o solo. 


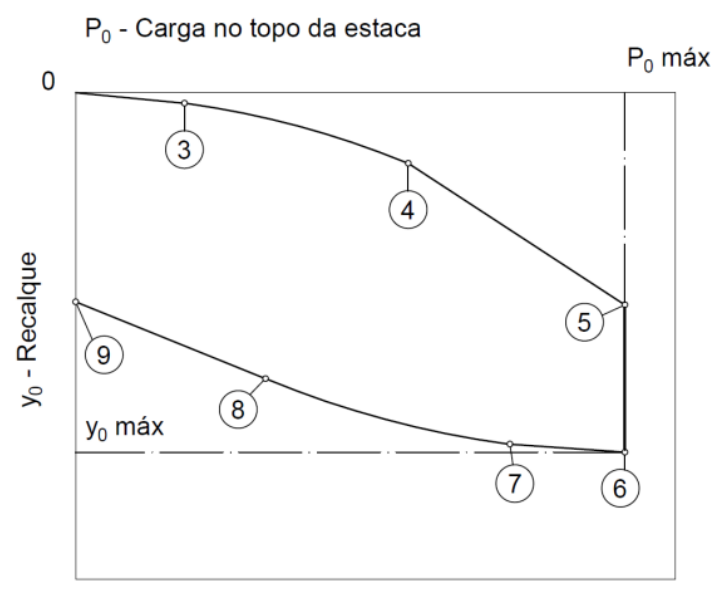

Figura 16: curva carga-recalque teórica do topo da estaca (adaptado de Massad, 1992).

Em uma prova de carga, pode-se identificar quatro trechos distintos para 0 fenômeno de transferência de carga, associados a cinco pontos da curva cargarecalque no topo da estaca (Massad, 1995). Antes de apresentar as equações que descrevem cada trecho da curva carga-recalque, convém introduzir dois coeficientes, a rigidez da estaca como peça estrutural $\mathrm{K}_{\mathrm{r}}$ :

$$
K_{r}=\frac{E . S}{h}
$$

E o coeficiente de rigidez relativa solo-estaca k definido por Massad (1992),

$$
k=\frac{A_{l r}}{K_{r} \cdot y_{1}}=\left(\frac{h}{D}\right)^{2} \cdot\left(\frac{B . D}{E}\right)
$$

Sendo:

Alr: atrito lateral na ruptura;

O primeiro trecho da Figura 16, (0-3), corresponde ao desenvolvimento do atrito lateral ao longo do trecho pseudoelástico da Primeira Lei de Cambefort - no ponto 3, tem-se $y=y_{1}$ e $f=f_{\text {máx }}$, e valem as expressões

$$
\begin{array}{r}
P_{0}=\mu \cdot A_{l r} \cdot \frac{\beta_{3}^{\prime}}{z} \cdot \frac{y_{0}}{\mu \cdot y_{1}} \\
\beta^{\prime}=\frac{\tanh z+\lambda}{1+\lambda \cdot \tanh z}
\end{array}
$$




$$
\begin{gathered}
z=\sqrt{\boldsymbol{k}} \\
\lambda=\frac{\frac{R \cdot S}{K_{r}}}{z}
\end{gathered}
$$

O segundo trecho (3-4) está relacionado com a mobilização progressiva do atrito lateral máximo ( $f_{\text {máx }}$ ) do topo (ponto 3) até a ponta da estaca (ponto 4), e a expressão da curva teórica nesse trecho é

$$
\frac{y_{0}}{\mu \cdot y_{1}}=\left(1-\frac{\beta^{\prime 2}}{2}\right)+\frac{k}{2}\left(\frac{P_{0}}{\mu \cdot A_{l r}}\right)^{2}
$$

No terceiro trecho (4-5), conforme a carga no topo da estaca aumenta, o solo da ponta reage ao longo do trecho pseudoelástico da Segunda Lei de Cambefort, e vale a expressão

$$
\frac{P_{0}-\mu \cdot A_{l r}}{y_{0}-\frac{\mu \cdot A_{l r}}{2 K_{r}}}=\frac{1}{\frac{1}{R S}+\frac{1}{K_{r}}}
$$

Finalmente, no ponto 5, é atingida a ruptura, caracterizada pelo quarto trecho (5-6), em que há acréscimo de deformação sem acréscimo de carga.

Massad (1992) alterou as Relações de Cambefort, incorporando as cargas residuais na ponta para estacas cravadas ou com pré-carregamento com a introdução do fator $\mu$. Tal modificação não se aplica para as provas de carga estudadas nesse trabalho pois, por se tratarem de estacas moldadas in loco e submetidas a um primeiro carregamento, não há cargas residuais na ponta. Portanto, para os casos de estudo desse trabalho, $\mu=1$. As relações de Cambefort modificadas para estacas escavadas submetidas a um primeiro carregamento estão ilustradas na Figura 17 (extraída de Massad, 1992). 


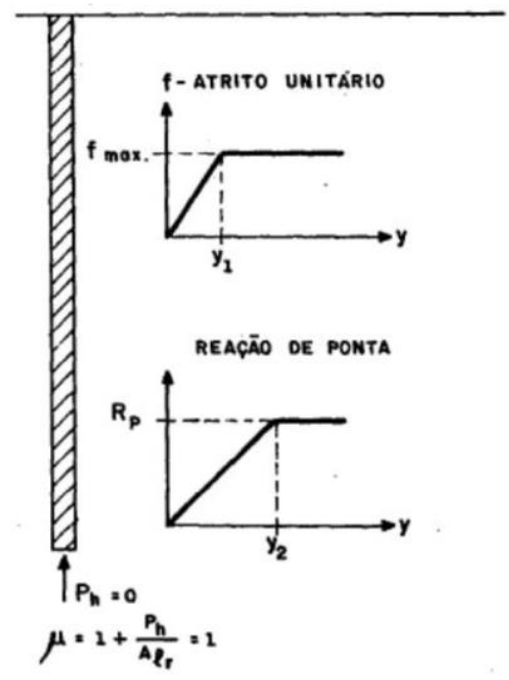

Figura 17: Relações de Cambefort modificadas para estacas escavadas submetidas ao primeiro carregamento (Massad, 1992).

O modelo aqui descrito, embora seja importante para o entendimento dos conceitos relativos às Relações de Cambefort, não foi aplicado para as provas de carga estática analisadas no trabalho, em virtude dos elevados comprimentos (até 60 metros) dos estacões e de o perfil geotécnico típico da Baixada Santista ser bastante heterogêneo.

\subsubsection{Método de Coyle Reese (1966)}

Coyle e Reese (1966) propuseram método analítico para estimativa da curva carga-recalque do topo de uma estaca, admitidas conhecidas as funções de transferência de carga (relações de Cambefort) por atrito lateral e pela ponta. Para aplicação do método, a estaca deve ser subdividida em $\mathrm{n}$ elementos, conforme a Figura 18 a seguir.

O procedimento detalhado por Coyle e Reese (1966) inicia-se pelo limite inferior da estaca, assumindo um valor de recalque para a ponta e computando as cargas e deslocamentos de cada um dos elementos, de baixo para cima. Para diferentes valores de recalques assumidos para a ponta resultarão diferentes valores de carga e recalque no topo da estaca, e uma curva carga-recalque pode ser construída. O processo pode ser detalhado pelos seguintes passos (Coyle e Reese, 1966, adaptado por Massad, 2017): 


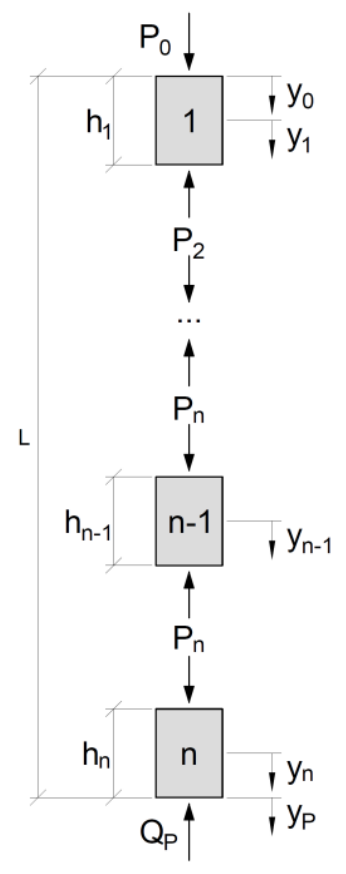

Figura 18: llustração da aplicação do método de Coyle Reese (1966).

1. Subdividir a estaca em $\mathrm{n}$ elementos;

2. Adotar um valor para o recalque da ponta yp;

3. Calcular a carga na ponta Qp correspondente a esse deslocamento. Para tal, pode-se utilizar formulações conhecidas, como a fórmula de Skempton (1951), recomendada pelos autores, ou a fórmula de Boussinesq para uma placa rígida circular. Pode-se ainda assumir carga zero na ponta da estaca;

4. Estimar o deslocamento $y_{n}$ no centro do n-ésimo elemento admitindo $\mathrm{y}_{\mathrm{n}}=\mathrm{yP}$

5. No gráfico de adesão por atrito lateral em função do deslocamento do fuste (1a Lei de Cambefort), encontrar o valor da adesão $f_{n}$ correspondente a $y_{n}$ estimado no item anterior;

6. Utilizando $f_{n}$ determinada no item 5 , calcular a força normal $P_{n}$ no topo do $n$-ésimo elemento, de altura $h_{n}$, pela expressão

$$
\boldsymbol{P}_{\boldsymbol{n}}=\boldsymbol{Q}_{\boldsymbol{P}}+\boldsymbol{f}_{\boldsymbol{n}} \cdot \boldsymbol{h}_{\boldsymbol{n}} \cdot \boldsymbol{\pi} \cdot \mathrm{D}
$$

7. Calcular o encurtamento elástico da metade inferior do n-ésimo elemento utilizando a expressão 


$$
\Delta e_{n}=\frac{\left(\frac{Q_{P}+P_{n}}{2}+Q_{P}\right)}{2} \cdot \frac{\left(\frac{h_{n}}{2}\right)}{E_{p} \cdot S}
$$

8. Calcular o novo valor do deslocamento no centro do n-ésimo elemento y'n pela expressão

$$
y_{n}^{\prime}=y_{P}+\Delta e_{n}
$$

9. Se $y_{n}^{\prime} \neq y_{n}$, repetir os itens 4 a 8 até convergência.

10. Repetir o processo para o (n-1)-ésimo elemento, a partir do qual $Q_{P}=$ $\mathrm{P}$, até convergência, e assim sucessivamente até o elemento do topo da estaca, para o qual se obtém um par de valores $\mathrm{P}_{0}$-yo da curva cargarecalque do topo da estaca.

11. Repetir o processo para outros valores de yp tantos quantos pontos se queira da curva carga-recalque.

Em seu trabalho, os autores aplicaram o método para 6 provas de carga em estacas metálicas instaladas em argila em diferentes cidades dos Estados Unidos. Ao comparar as curvas carga-recalque teóricas obtidas pelo método, constatou-se que os erros obtidos para os recalques correspondentes à metade da carga máxima do ensaio foram significativamente baixos, especialmente considerando a grande variabilidade das propriedades das estacas e das condições dos ensaios (Coyle e Reese, 1966).

\subsection{Provas de carga estática comuns e instrumentadas em profundidade}

\subsubsection{Generalidades}

A revisão da NBR 6122, em 2010, tornou obrigatória a realização de ensaios em obras cujo número de estacas exceda o valor que depende do tipo de estaca, especificado na Tabela 13. Caso o número de estacas exceda 2 vezes o valor da coluna $\mathrm{B}$, é obrigatório que pelo menos um dos ensaios seja uma prova de carga estática.

De acordo com a NBR 12131/2006, a prova de carga consiste, basicamente, em aplicar esforços estáticos à estaca e registrar os deslocamentos correspondentes. Os esforços aplicados podem ser axiais (tração ou compressão) ou transversais. 
Tabela 13: Quantidade de provas de carga (NBR 6122/2010).

\begin{tabular}{|c|c|c|}
\hline Tipo de estaca & $\begin{array}{c}\text { A } \\
\text { Tensão admissível máxima } \\
\text { abaixo da qual não serão } \\
\text { obrigatórias provas de carga, } \\
\text { desde que o número de } \\
\text { estacas da obra seja inferior } \\
\text { à coluna (B), em MPa }\end{array}$ & $\begin{array}{c}\text { Búmero total de estacas } \\
\text { da obra a partir do qual } \\
\text { serão obrigatórias } \\
\text { provas de carga }\end{array}$ \\
\hline Pré-moldada & 7,0 & 100 \\
\hline Madeira & - & 100 \\
\hline Aço & 0,5 fyk & 100 \\
\hline $\begin{array}{c}\text { Hélice e hélice de } \\
\text { deslocamento } \\
\text { (monitoradas) }\end{array}$ & 5,0 & 100 \\
\hline $\begin{array}{c}\text { Estacas escavadas com } \\
\text { ou sem fluido } \varphi \geq 70 \mathrm{~cm}\end{array}$ & 5,0 & 75 \\
\hline Raiz & 15,5 & 75 \\
\hline Microestaca & 15,5 & 75 \\
\hline Trado segmentado & 5,0 & 50 \\
\hline Franki & 7,0 & 100 \\
\hline $\begin{array}{c}\text { Escavadas sem fluido } \\
\varphi<70 \mathrm{~cm}\end{array}$ & 4,0 & 100 \\
\hline Strauss & 4,0 & 100 \\
\hline \multicolumn{2}{|c|}{}
\end{tabular}

Os carregamentos aplicados podem ser, a critério do projetista, de quatro tipos: lento, rápido, misto (lento seguido de rápido) e cíclico. Esses tipos de carregamento podem gerar diferentes deslocamentos e a interpretação dever considerar o tipo de carregamento a ser empregado na vida útil do estaqueamento. $O$ ensaio de carregamento cíclico não será detalhado por não ser escopo deste trabalho.

O ensaio de carregamento lento possui critério de estabilização e tempo mínimo de 30 minutos. Cada estágio não deve ser superior a $20 \%$ da carga de trabalho prevista para a estaca ensaiada. $O$ ensaio de carregamento rápido possui estágios de 10 minutos, independente de estabilização, e cada estágio não deve ser superior a $10 \%$ da carga de trabalho prevista para a estaca ensaiada. O ensaio de carregamento misto é executado até 1,2 vezes a cada de trabalho como o ensaio de carregamento lento e, até o estágio final, como o rápido.

O dispositivo de aplicação de carga é constituído por um ou mais macacos hidráulicos, alimentado por bombas elétricas ou manuais, atuando contra um sistema de reação. O sistema de reação pode ser de plataforma (cargueira) ou vigas 
interligadas a tirantes ou estacas. Todas as provas de carga analisadas neste trabalho foram realizadas com estacas de reação.

As provas de carga permitem verificar aspectos importantes como a capacidade de carga, os deslocamentos do elemento de fundação e, ainda, no caso de estacas instrumentadas, a transferência de carga em profundidade (Albuquerque, 2001). Atualmente, a instrumentação em profundidade, apesar de ferramenta poderosa para auxiliar na interpretação do comportamento da estaca, não é obrigatória por norma, e comumente é realizada a critério do cliente e/ou para fins acadêmicos. A NBR 12131/2006 menciona apenas que, "em provas de carga com instrumentação ao longo do comprimento da estaca, devem ser apresentadas as descrições detalhadas dos instrumentos utilizados, sua locação e os resultados obtidos, em forma de tabela, com leituras, a formulação usada para a interpretação dos dados e a interpretação gráfica da análise". A instrumentação em profundidade permite uma melhor compreensão do fenômeno de transferência de carga da estaca para o terreno através da medida do encurtamento ou alongamento da estaca (Massad, 2017). De posse dos resultados da instrumentação, é possível separar as parcelas de atrito e ponta da carga total, aplicada no topo da estaca, e obter valores de atrito lateral unitário para as várias camadas atravessadas pela estaca, além da reação de ponta. Esses valores podem ser utilizados nas Relações de Cambefort para estimativa da curva carga-recalque do topo da estaca.

As Figuras 19 a 25 ilustram os sistemas de montagem do ensaio, de aplicação de carga e de reação em duas provas de carga estática realizadas em Santos, analisadas neste trabalho. 


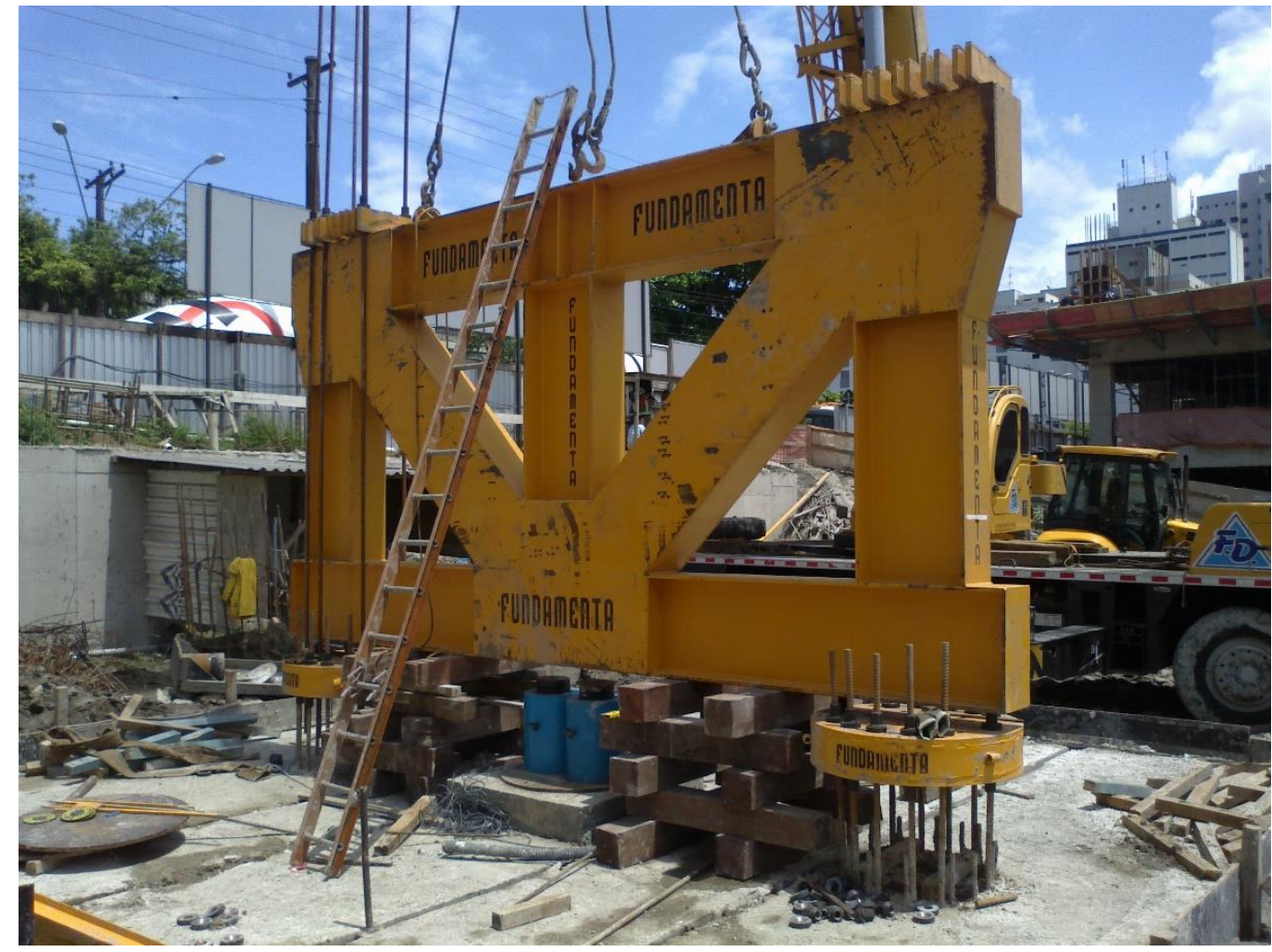

Figura 19: montagem de prova de carga estática com dois macacos hidráulicos em Santos (acervo ZF, 2019).

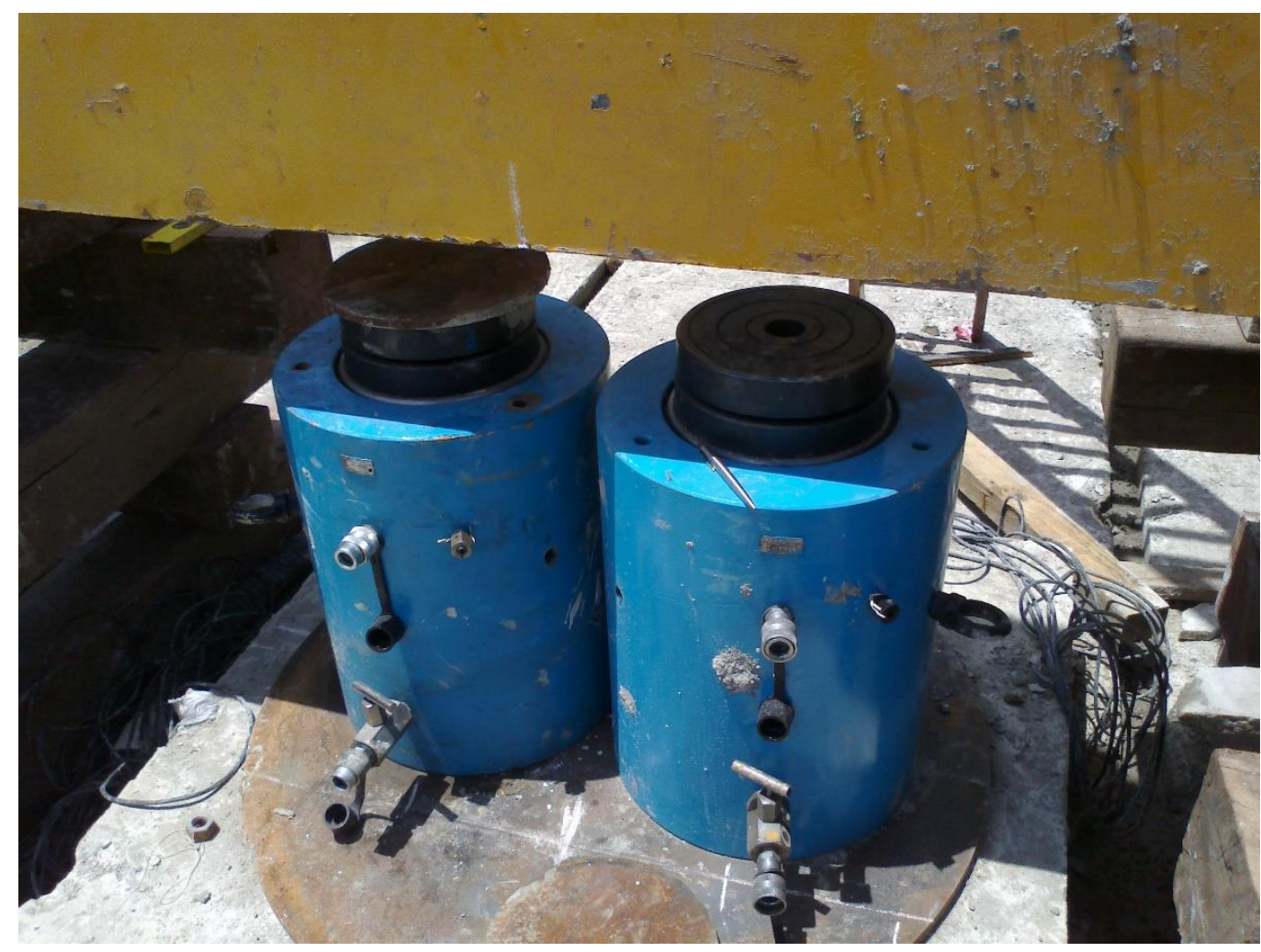

Figura 20: detalhe dos dois macacos hidráulicos utilizados para aplicação de carga (acervo ZF, 2019). 


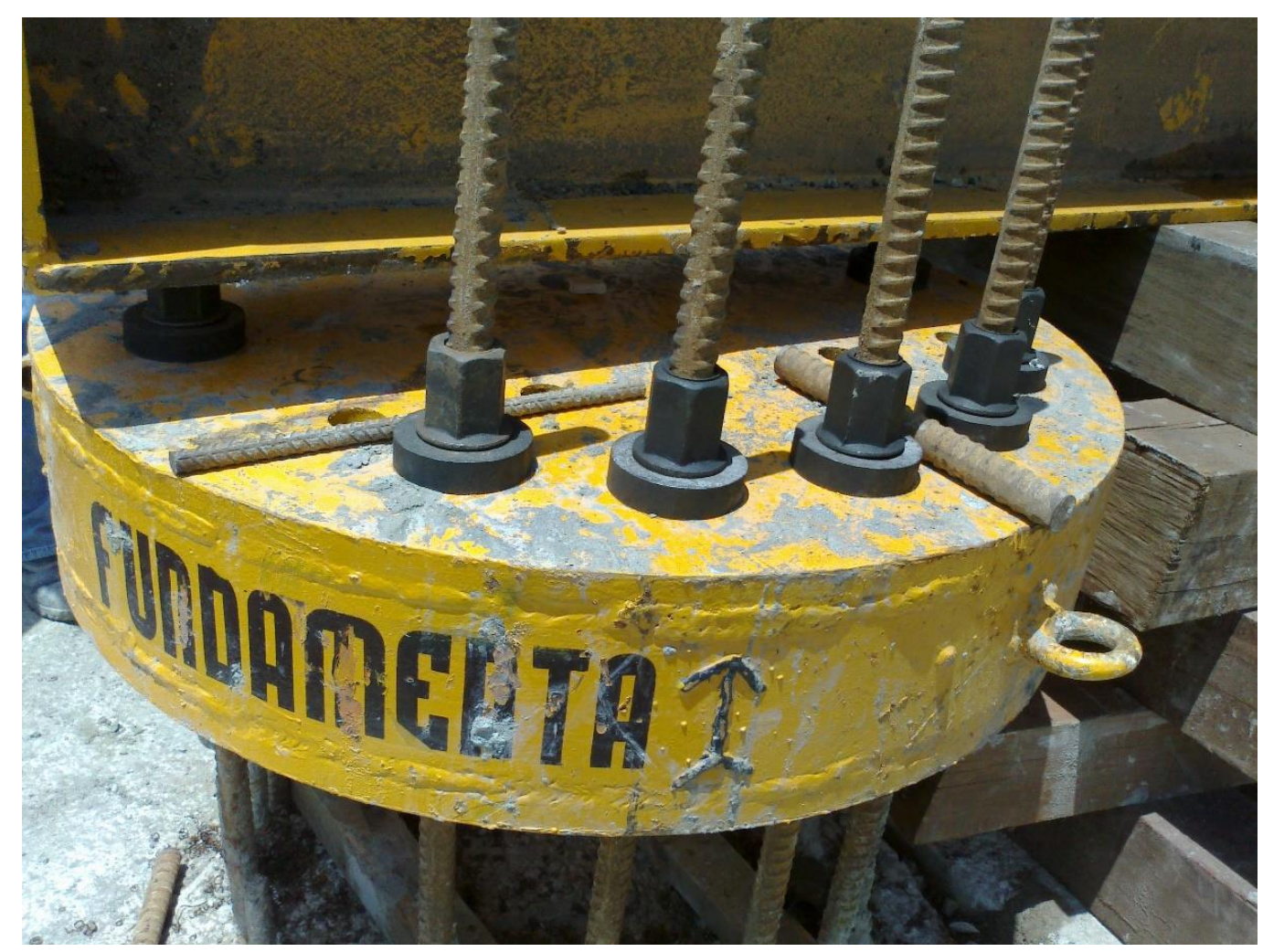

Figura 21: detalhe do bloco de transferência de carga da estaca de reação para a viga (acervo ZF, 2019).

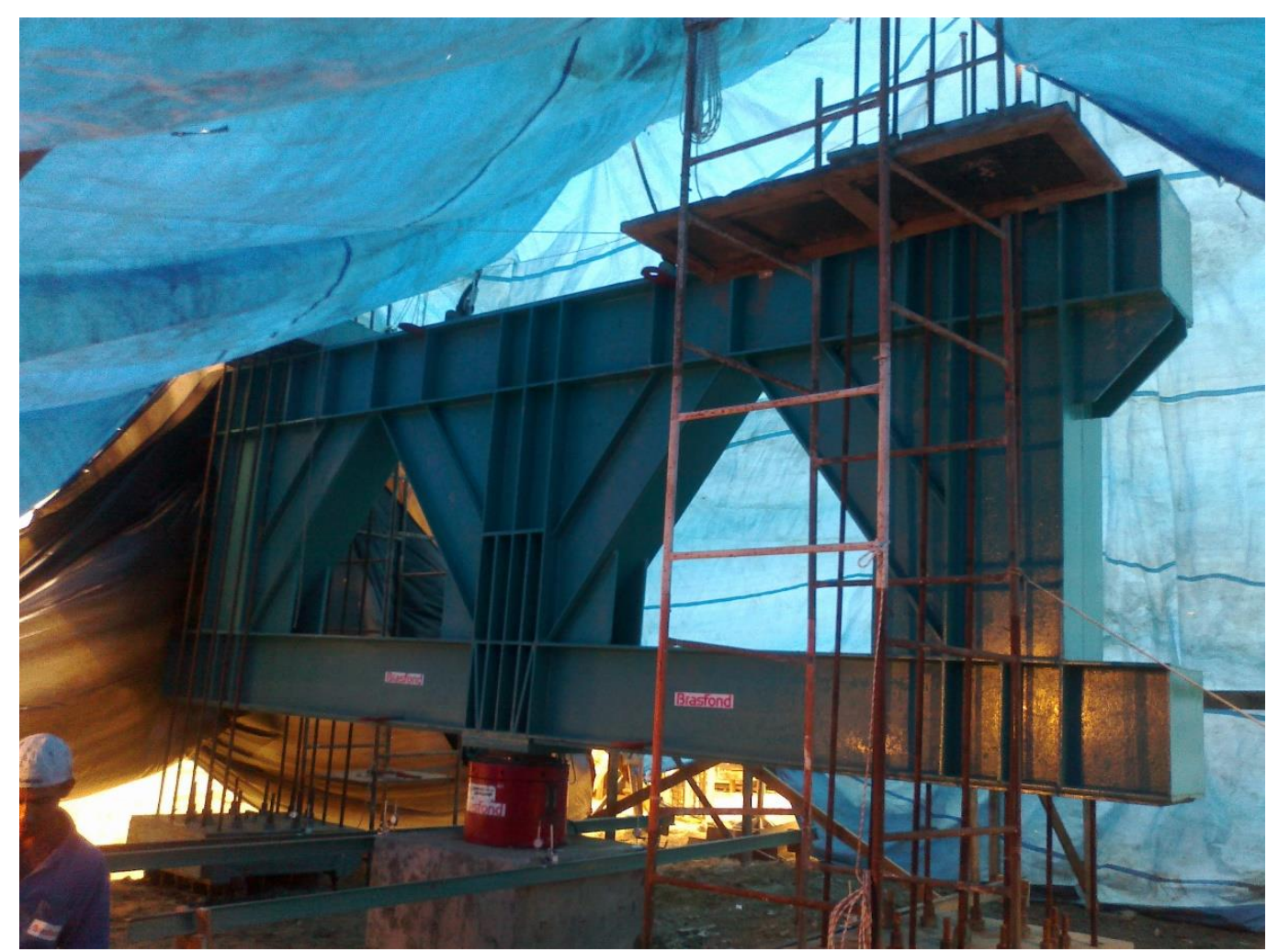

Figura 22: montagem de prova de carga estática com um macaco hidráulico em Santos (acervo ZF, 2019). 


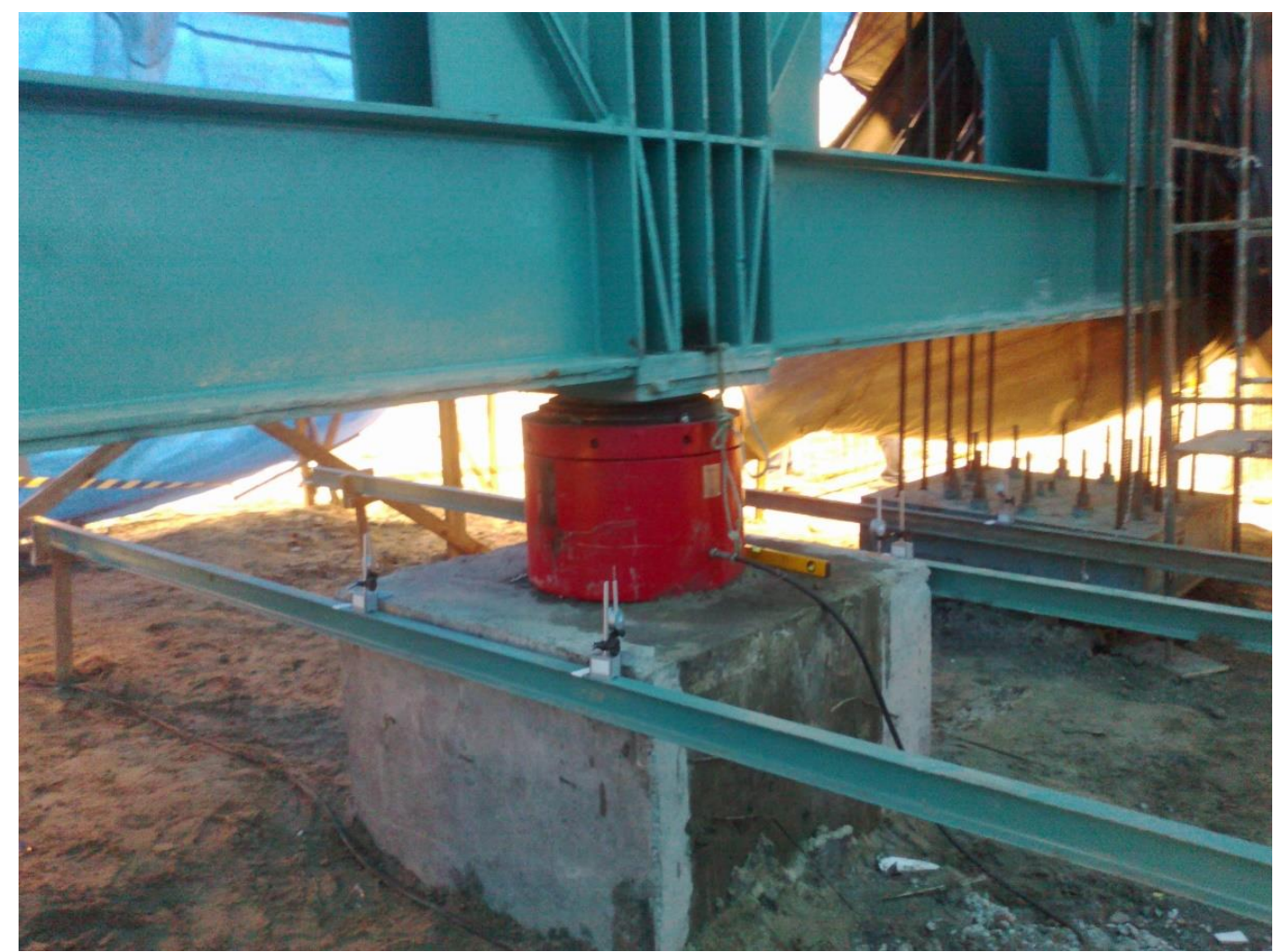

Figura 23: detalhe do macaco hidráulico e das vigas de referência com os deflectômetros (acervo ZF, 2019).

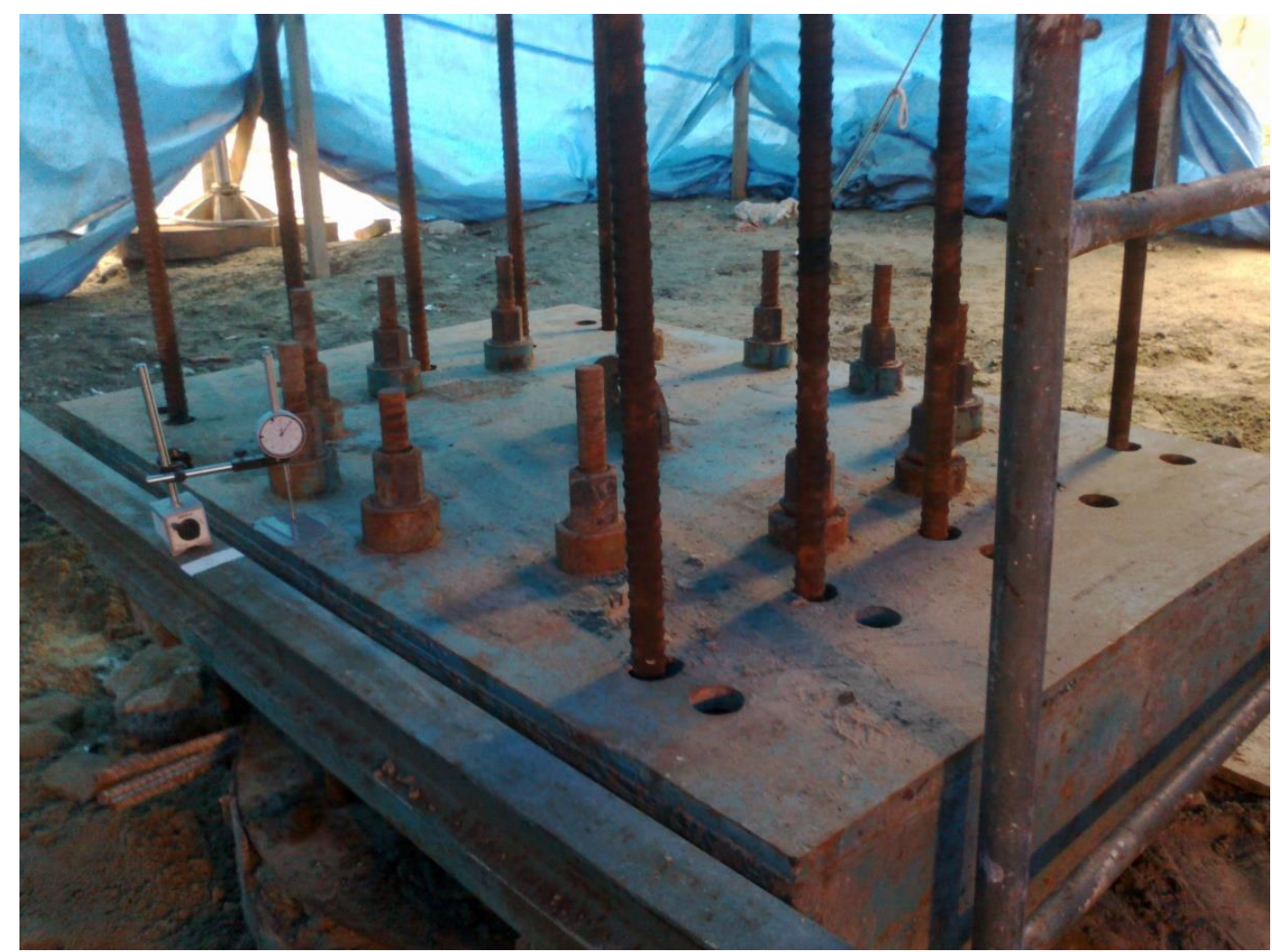

Figura 24: detalhe do bloco de transferência da estaca de reação para a viga e do deflectômetro (acervo ZF, 2019). 


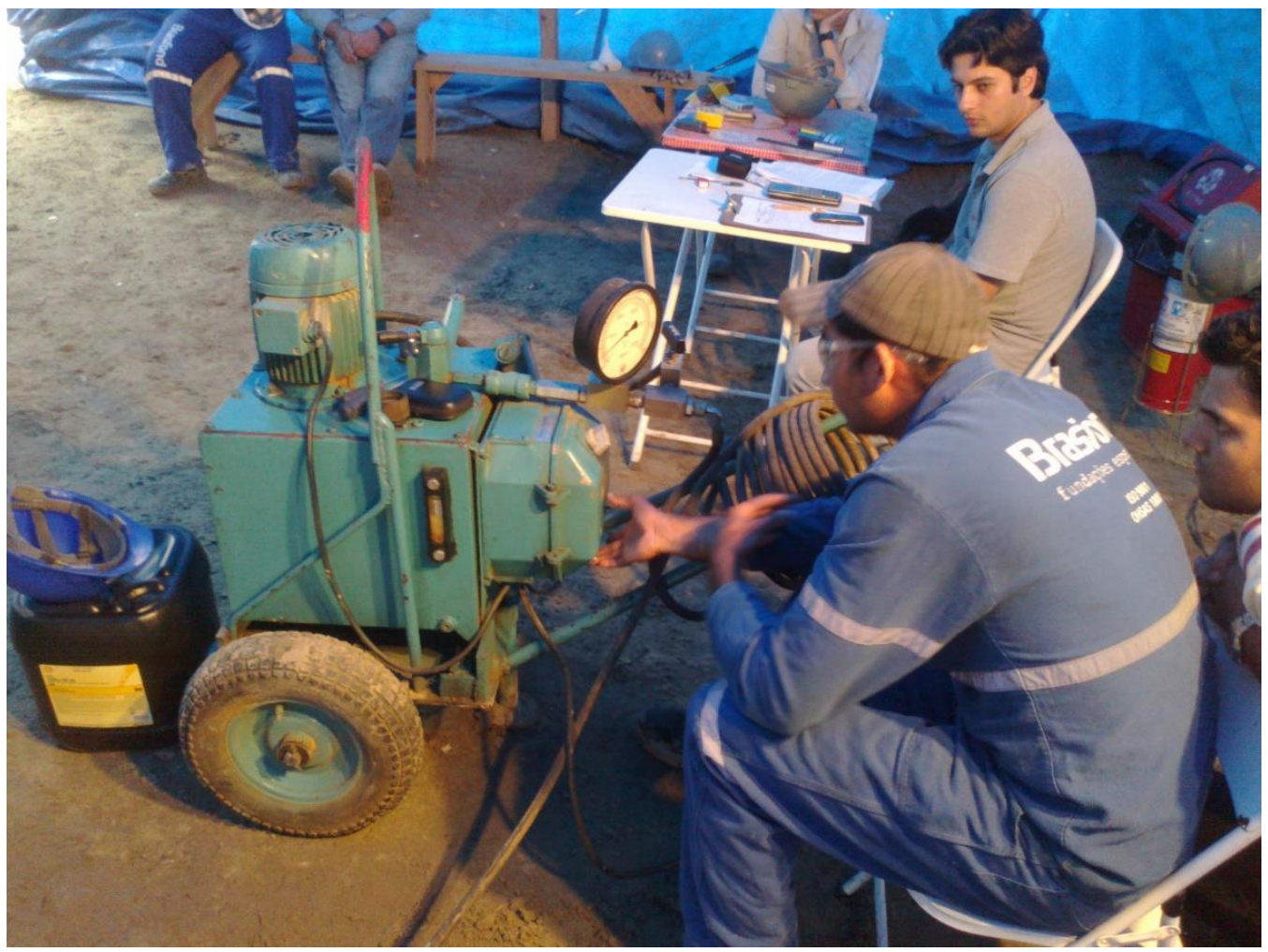

Figura 25: centralina hidráulica com motor elétrico e equipe de controle do ensaio (acervo ZF, 2019).

\subsubsection{Técnicas de instrumentação em profundidade}

Os instrumentos mais utilizados no Brasil para a medição de deslocamentos em profundidade são os tell tales e os strain gages, detalhados a seguir.

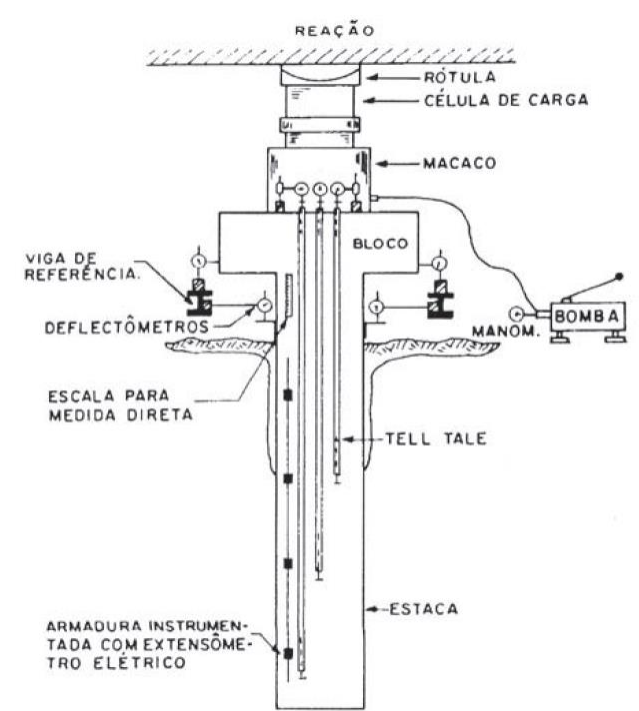

Figura 26: instrumentação em profundidade para prova de carga estática (Niyama et al, 2017). 


\subsubsection{Tell tales}

Um tell tale consiste, basicamente, de um tubo guia de 1" $(25 \mathrm{~mm})$ de diâmetro e, dentro dele, hastes de alumínio trefiladas vazadas com diâmetro externo de 5/8" (15 mm) e interno de 3/8" (9 mm), dotadas de roscas internas nas duas pontas, unidas por parafusos. O tubo é instalado dentro da estaca, solidarizado a ela em apenas um ponto pré-estabelecido através de pinos de espera, com as pontas das hastes em diversos níveis de profundidade. Nesse tipo de instrumentação, obtém-se os valores de deformação de maneira direta (Albuquerque, 2001). As leituras de deslocamento das hastes nos diversos níveis em profundidade são realizadas com deflectômetros instalados junto ao topo da estaca. Através dessas leituras, determina-se o encurtamento elástico da estaca em cada trecho entre níveis consecutivos e, pela lei de Hooke, a carga mobilizada por atrito lateral ao longo do trecho.

Atualmente, os tell tales são mais empregados em ensaios bidirecionais, para leituras do deslocamento em profundidade das parcelas do fuste e da ponta da estaca.

\subsubsection{Strain gages}

Strain gages ou extensômetros elétricos de resistência têm uma estrutura formada por um elemento sensor em forma de grade, feito de uma folha metálica resistiva fina ( 3 a $6 \mu \mathrm{m}$ de espessura), colocado em uma base de filme plástico fino (15 a $16 \mu \mathrm{m}$ de espessura) e laminado com uma fina camada de filme. O strain gage é solidarizado com um objeto medidor, como uma barra de aço, para que o elemento sensor seja comprimido ou tracionado de acordo com a tensão suportada pelo objeto medidor. Em cada barra de aço, os extensômetros estão ligados em uma configuração de ponte de Wheatstone completa. Nessa configuração, a tensão elétrica de saída é dada pela equação:

$$
E_{0}=\frac{1}{2}(1+v) E_{p o n t e} \cdot K_{S} \cdot \varepsilon_{0}
$$

em que:

E0: tensão elétrica de saída da ponte;

Eponte: tensão de alimentação da ponte;

Ks: fator do extensômetro (gage fator); 
$\varepsilon_{0}$ : deformação medida;

v: coeficiente de Poisson do aço $=0,3$.

As leituras de resistividade são realizadas através de painel e caixa seletora e posteriormente convertidas em medidas de deformação.

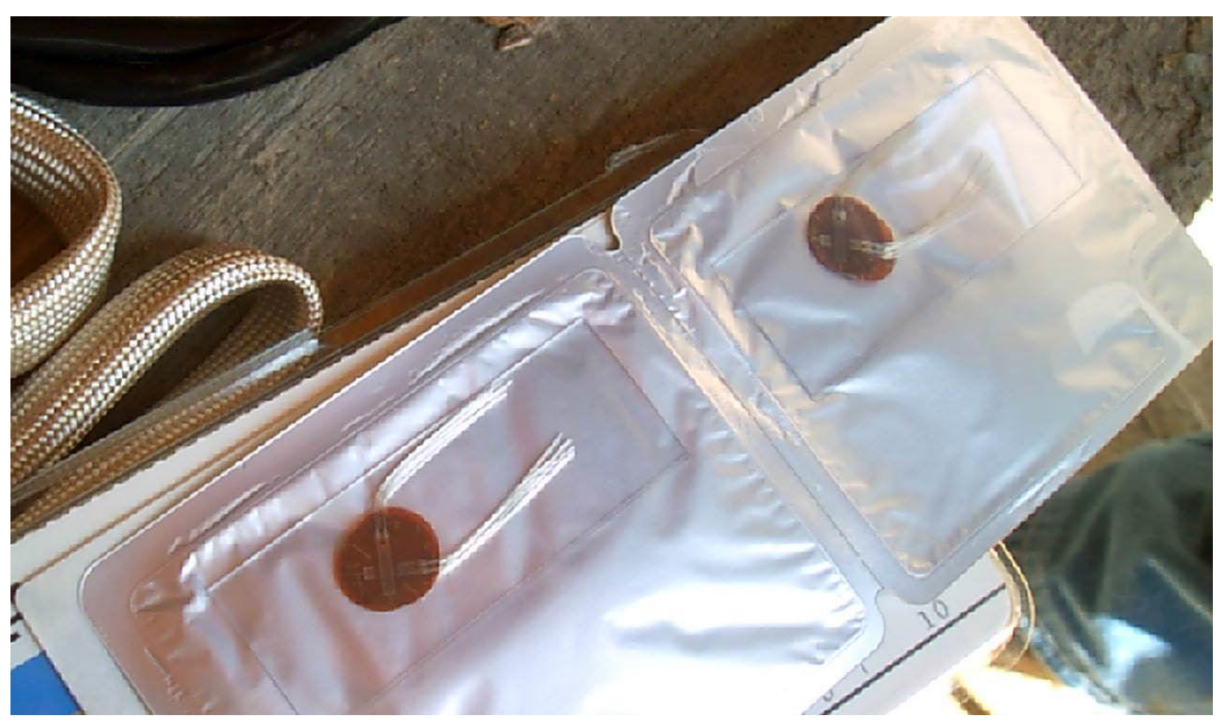

Figura 27: Strain gages (acervo ZF, 2019).

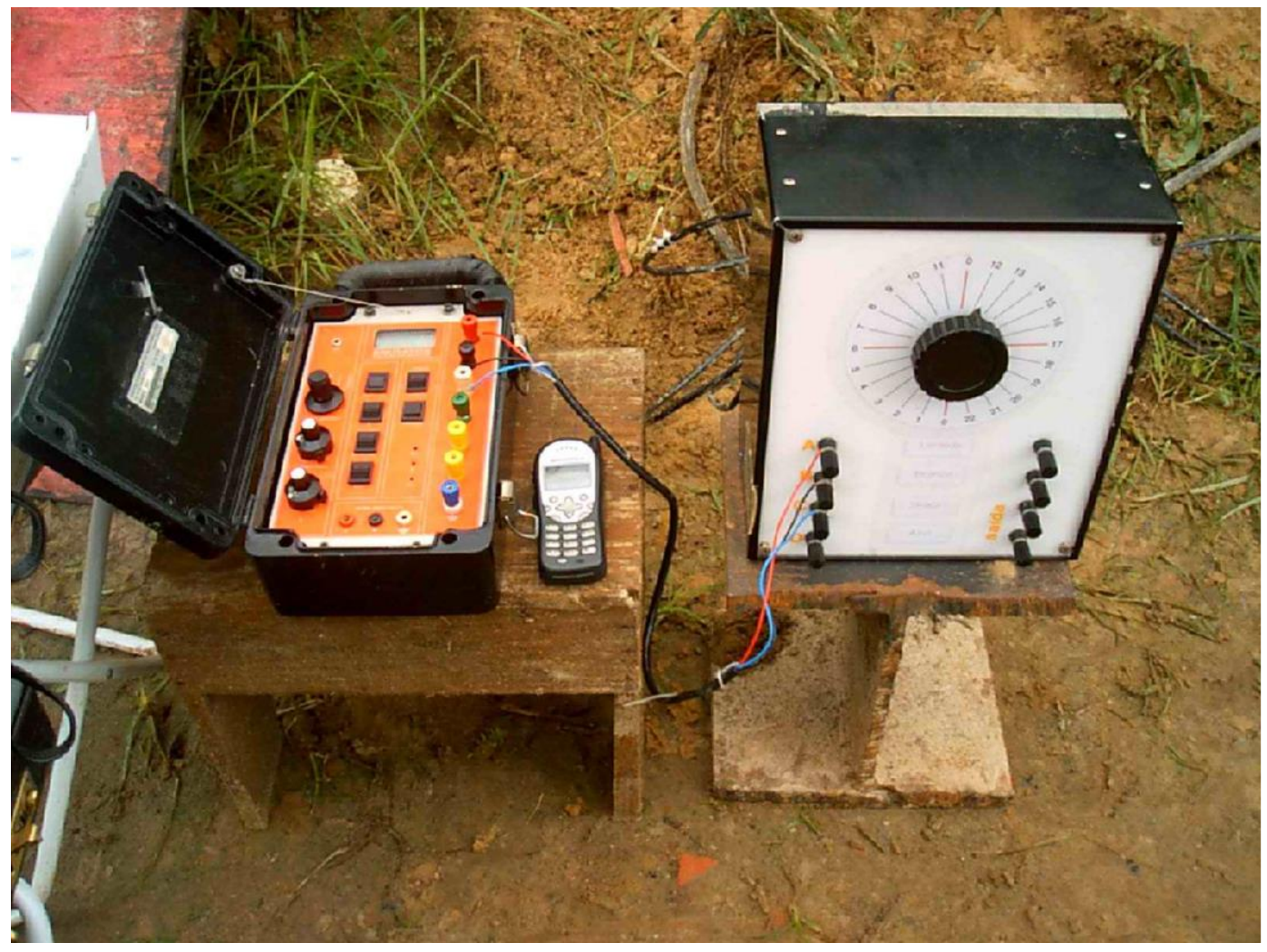

Figura 28: painel e caixa seletora (acervo ZF, 2019). 


\subsubsection{Método do Módulo Tangente de Fellenius (1989)}

Em uma prova de carga estática instrumentada em profundidade, a deformação axial devida à carga aplicada é medida ou calculada com a utilização de instrumentos como strain gages ou tell tales. Essas medidas de deformação são utilizadas para avaliar a distribuição de carga na estaca em profundidade. Segundo Fellenius (1989), essa avaliação depende do módulo de elasticidade da estaca, da sua seção transversal e da precisão das medições.

Em estacas de aço, o módulo de elasticidade é bem definido, e o método do Módulo Tangente pode ser utilizado para determinar a grandeza ES com precisão. Em estacas de concreto, porém, o módulo de elasticidade não é constante, pois é função da carga aplicada no ensaio e a consequente magnitude da deformação no concreto. Além disso, a área da seção transversal da estaca de concreto moldada in loco também varia com a profundidade. A precisa determinação do fator ES é fundamental para se obter a distribuição de carga em profundidade a partir dos valores de deformação medidos em uma prova de carga instrumentada. O Método do Módulo Tangente, apresentado por Fellenius (1989), permite a determinação do módulo de elasticidade da estaca a partir do gráfico de incremento de carga (ou tensão) com o incremento da deformação versus a deformação, para estacas metálicas ou de concreto.

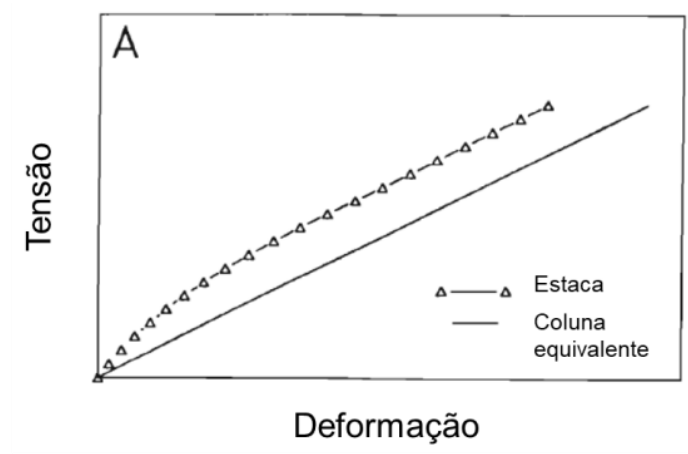

(a)

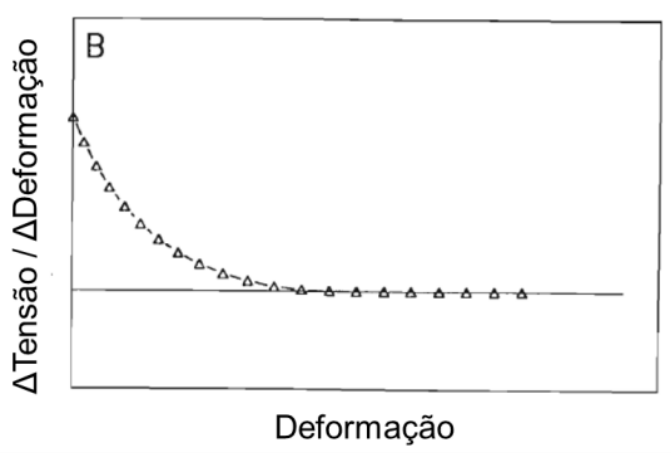

(b)

Figura 29: curvas típicas de uma prova de carga instrumentada em estaca com módulo de elasticidade constante (metálica) (Fellenius, 1989).

a. Gráfico tensão-deformação no topo da estaca (curva superior) e da coluna não confinada correspondente;

b. Gráfico do módulo tangente em função da deformação. 


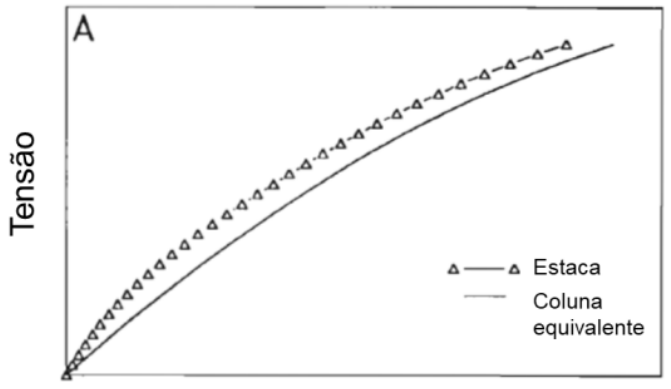

Deformação

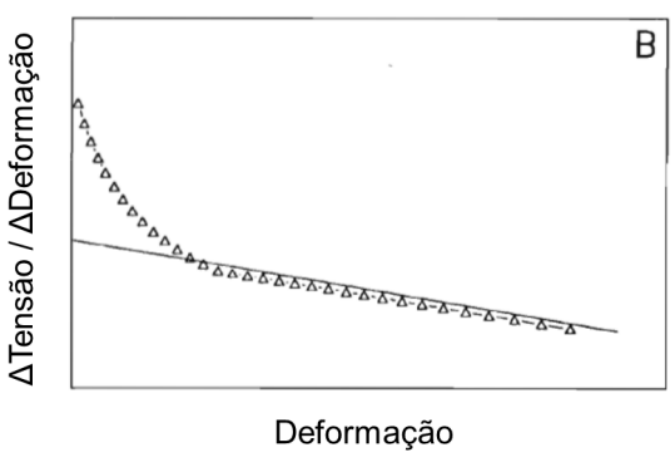

(b)

Figura 30: curvas típicas de prova de carga instrumentada em estaca com módulo de elasticidade que diminui com o aumento da tensão aplicada (concreto) (Fellenius, 1989).

a. Gráfico tensão-deformação no topo da estaca (curva superior) e da coluna não confinada correspondente;

b. Gráfico do módulo tangente em função da deformação.

O método de Fellenius (1989) pode ser adaptado da seguinte maneira (Massad, 2009-b):

(a) para cada estágio de carregamento, determinam-se as deformações médias $\varepsilon$ em cada nível de instrumentação;

(b) plota-se o gráfico carga aplicada no topo da estaca $\mathrm{P}_{0}$ versus deformação média $\varepsilon$ para cada trecho instrumentado. Supondo-se que a carga $\mathrm{P}_{0}$

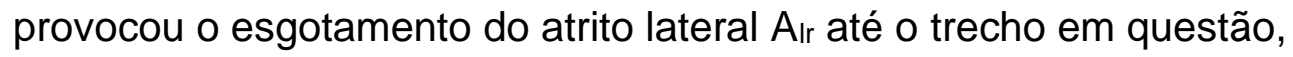

$$
P_{0}=A_{l r}+E . S . \varepsilon
$$

e a função $P_{0}=f(\varepsilon)$ passa a ser uma reta com inclinação $E S$;

(c) a inclinação dos trechos retilíneos fornecerá o valor de ES para cada nível de instrumentação. 


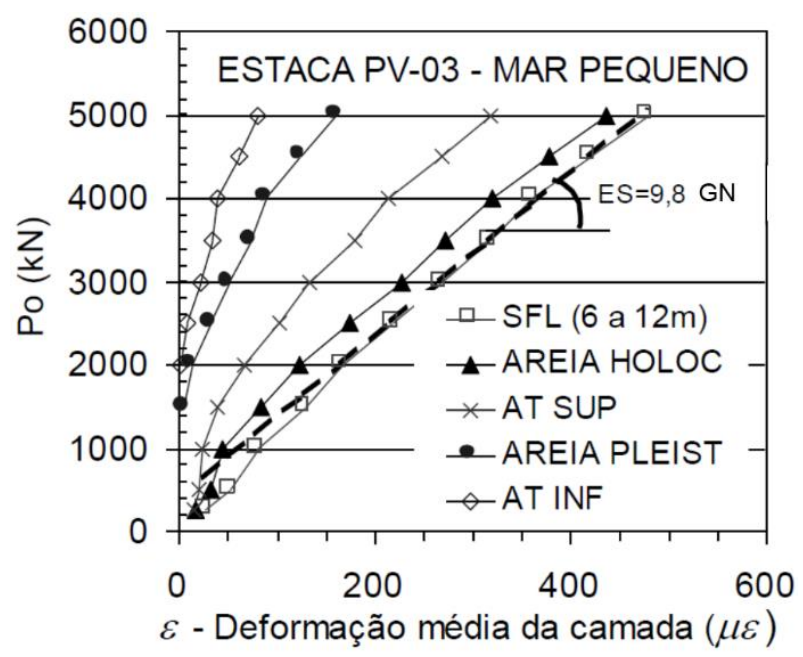

Figura 31: exemplo de gráfico para obtenção do ES em ensaio com 5 níveis de instrumentação pelo método do Módulo Tangente de Fellenius (1989) adaptado por Massad (2009-b) (adaptado de Massad, 2009-b).

\subsection{Efeito "estaca T" da interface areia compacta-argila SFL}

Massad (2009-b) interpretou os resultados de 4 provas de carga estática instrumentadas em profundidade em estacas metálicas na Baixada Santista. Em uma delas, em perfil metálico de seção decrescente em Santos, analisando os diagramas e as funções de transferência de carga, o autor observou que $o$ atrito lateral esgotouse rapidamente em quase todos os trechos entre níveis de instrumentação, exceto o superior, que consistia apenas de areia compacta. Enquanto o valor de y 1 para as camadas de argila e areia SFL, argila AT e sedimentos transicionais encontrados foram menores que $5 \mathrm{~mm}$, na camada superficial de areia, observou-se o valor de 36 $\mathrm{mm}$. Tal fenômeno, segundo o autor, ocorre devido à interação entre a camada superficial de areia compacta e a argila SFL subjacente: "sob a ação da estaca, esta camada superficial exerceu uma pressão sobre o topo da camada de argila de SFL subjacente, reduzindo drasticamente seu atrito lateral unitário máximo" (Massad, 2009-b). O autor, então, comparou esse fenômeno ao comportamento de uma "estaca T" ou "sapataca" ou, ainda, ao comportamento da "ponta" de uma estaca. Segundo Décourt et al (2016), uma "estaca T" ou "sapataca" é um tipo de fundação mista, ou seja, transfere cargas ao solo por três mecanismos: ao longo do fuste e da ponta do 
elemento vertical, como nas estacas convencionais, e pelo seu topo, como nas fundações rasas.

Para analisar a influência do efeito estaca T, Massad (2009-b) adaptou o modelo matemático conhecido como Método das Duas Retas de Massad e Lazo (1998). O autor considerou a camada superficial de areia compacta como a "sapata fictícia" do conjunto "estaca T" e a porção da estaca abaixo da camada de areia até a ponta como a "estaca fictícia" do conjunto. Utilizando o Método das Duas Retas Adaptado a Estacas T (Massad, 2009-b), foi possível separar as parcelas de atrito lateral e "ponta", equivalentes à resistência da "estaca fictícia" e da "sapata fictícia", respectivamente, para cada uma das provas de carga estática analisadas. $\mathrm{O}$ autor chegou às seguintes conclusões:

a) nas obras em Santos, de maneira geral, os valores de $y_{1}$ foram de alguns $\mathrm{mm}$, com exceção da camada de areia compacta superficial, que requereu dezenas de $\mathrm{mm}$ e, em alguns casos, não chegou a ser atingido (o atrito lateral não se esgotou) - nesses casos, houve comportamento análogo ao da "ponta" de uma estaca;

b) o efeito de "ponta" ou "estaca $T$ " da camada superficial de areia compacta no topo da camada de argila SFL foi confirmado pelo diagrama de transferência de carga de uma das provas de carga instrumentadas;

c) em pelo menos uma das estacas instrumentadas, esse efeito provocou uma redução drástica no atrito lateral da argila SFL logo abaixo da camada de areia superficial, sendo essa redução tanto maior quanto mais resistente for essa camada, podendo até levar a uma situação de atrito negativo;

d) o Método das Duas Retas e Massad e Lazo (1998) foi adaptado para as estacas longas de Santos como o Método das Duas Retas Adaptado a Estacas $T$, possibilitando o cálculo das parcelas de carga por atrito lateral (estaca "fictícia" da estaca T) e por "ponta" (resistência da "sapata fictícia"), com base na curva carga-recalque do topo.

e) deve-se considerar o "efeito estaca T" no dimensionamento de estacas flutuantes muito longas na cidade de Santos. 


\section{CASOS DE OBRAS}

\subsection{Características das obras e das estacas ensaiadas}

As provas de carga estática analisadas nesse trabalho foram executadas em estacas escavadas de grande diâmetro com fluido estabilizante (estacões) em obras localizadas na Baixada Santista. No total, foram analisadas 16 provas de carga estática de 11 obras distintas, sendo 6 delas instrumentadas em profundidade com strain gages. As Figuras 32 e 33 mostram a localização das obras no mapa das cidades de Santos e Praia Grande, com as provas de carga instrumentadas em marcador verde e as não instrumentadas em marcador amarelo. A fim de simplificação, foram utilizadas abreviaturas para identificar cada prova de carga estática, seguindo a mesma linha do trabalho de Almeida e Maset (2015). As Tabelas 14 e 15 contêm um resumo das provas de carga analisadas neste trabalho. No Anexo I encontram-se os resultados das provas de carga, juntamente com as sondagens mais próximas de cada estaca ensaiada. 


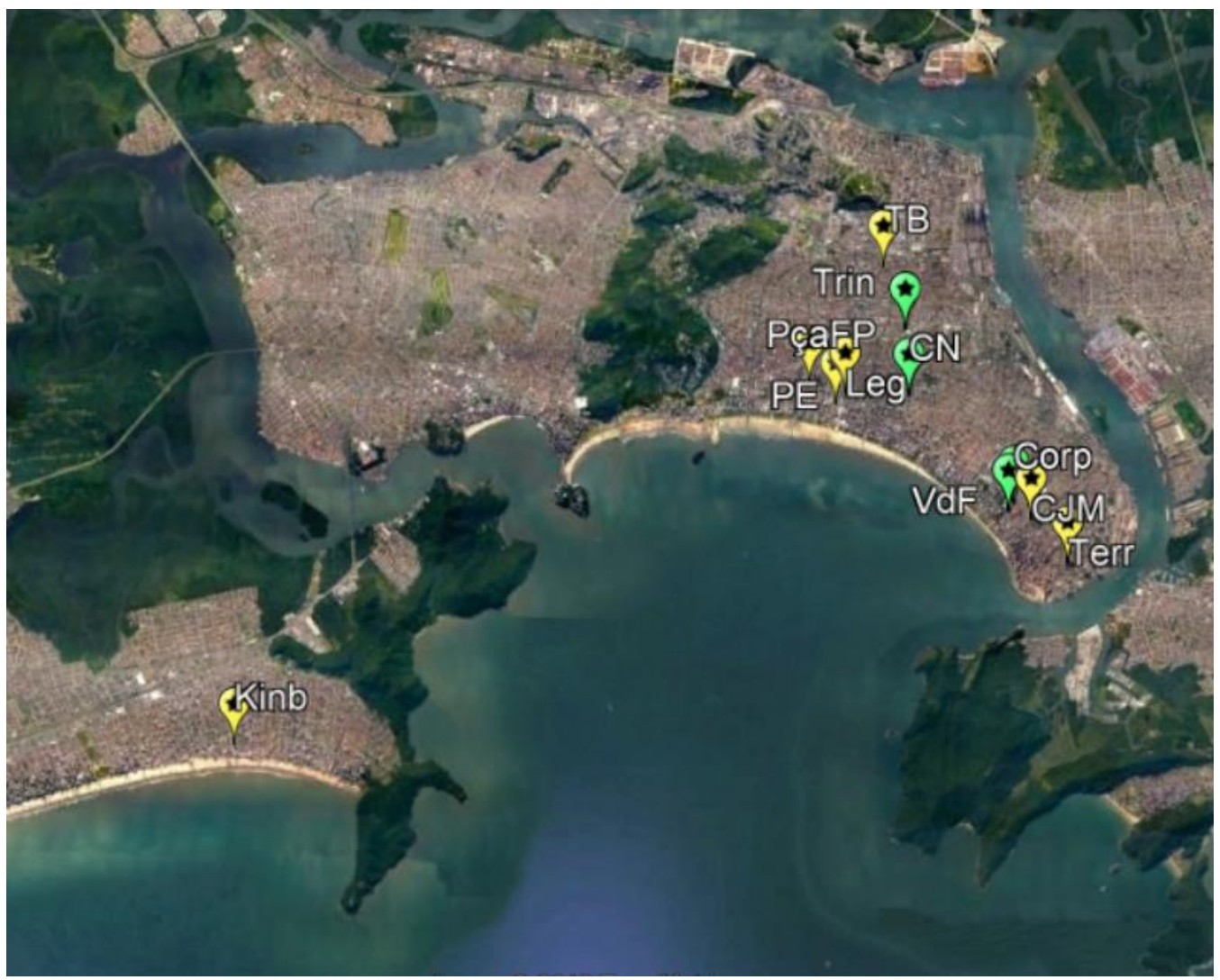

Figura 32: localização das obras nas cidades de Santos e Praia Grande/SP.

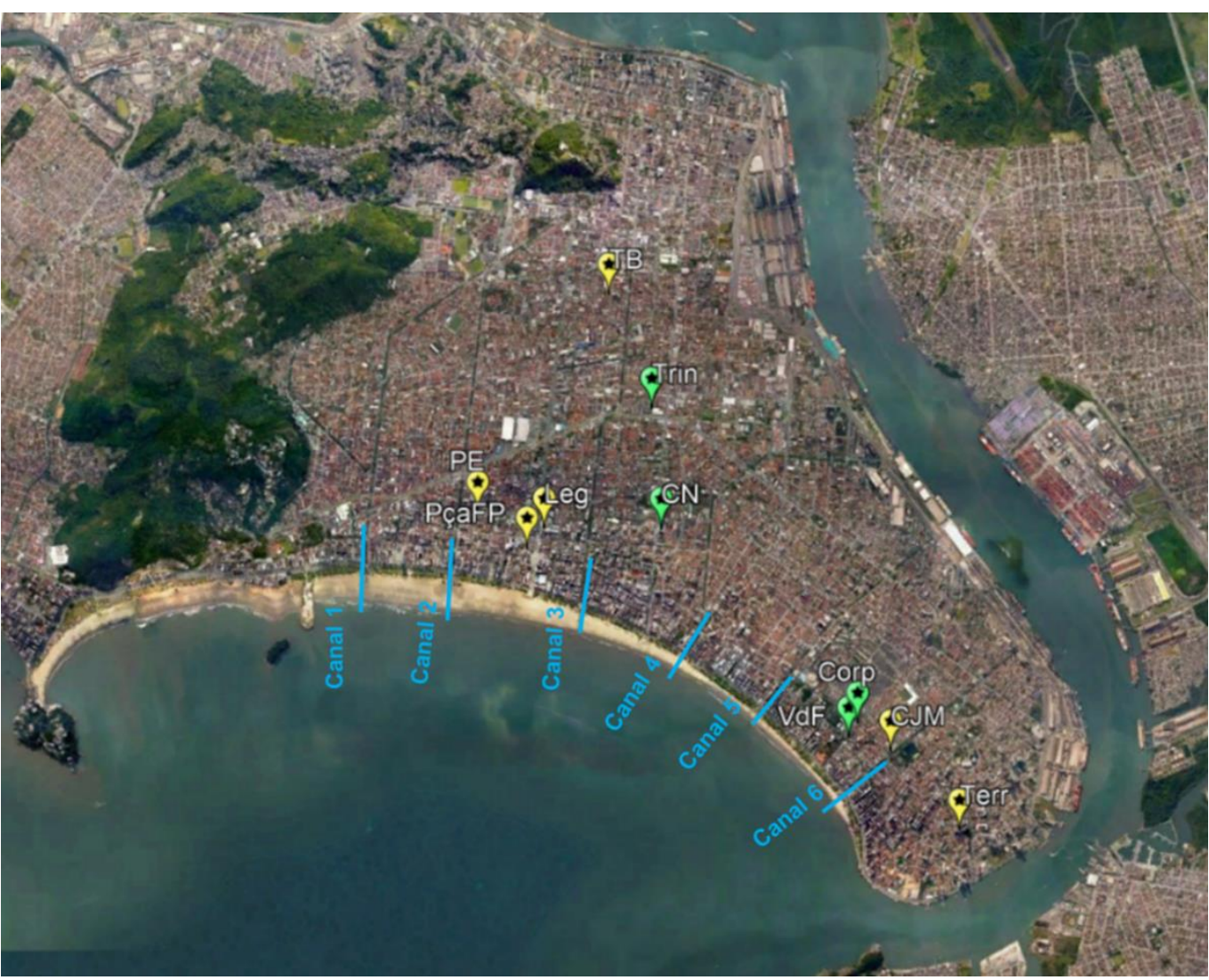

Figura 33: localização das obras na cidade de Santos/SP. 
Tabela 14: Resumo das provas de carga estática analisadas.

\begin{tabular}{|c|c|c|c|c|c|c|c|c|c|}
\hline Cidade & Obra & Localização & PCE & Abreviação & Instrumentada & $\begin{array}{c}\text { Data de } \\
\text { execução } \\
\text { da estaca }\end{array}$ & $\begin{array}{c}\text { Data de } \\
\text { execução } \\
\text { da PCE }\end{array}$ & $\begin{array}{c}\text { Fluido } \\
\text { estabilizante }\end{array}$ & $\begin{array}{c}\text { Tipo de } \\
\text { carregamento }\end{array}$ \\
\hline \multirow{14}{*}{ Santos/SP } & 1 & $\begin{array}{l}\text { Av. Conselheiro } \\
\text { Nébias }\end{array}$ & 1 & $\mathrm{CN}$ & SIM & $05 / 03 / 2010$ & $22 / 03 / 2010$ & Polímero & Misto \\
\hline & 2 & $\begin{array}{c}\text { Av. Cel. Joaquim } \\
\text { Montenegro }\end{array}$ & 2 & CJM & NÃO & 22/09/2012 & 19/10/2012 & Polímero & Misto \\
\hline & 3 & Av. Mal. Deodoro & 3 & PçaFP & NÃO & $14 / 07 / 2010$ & $10 / 08 / 2010$ & Polímero & Misto \\
\hline & \multirow{2}{*}{4} & \multirow{2}{*}{$\begin{array}{l}\text { Rua Senador Cesar } \\
\text { Lacerda de Vergueiro }\end{array}$} & 4 & Terr_50 & NÃO & 09/03/2012 & $26 / 04 / 2012$ & Lama bentonítica & Misto \\
\hline & & & 5 & Terr_54 & NÃO & $06 / 05 / 2012$ & $23 / 06 / 2012$ & Lama bentonítica & Misto \\
\hline & \multirow{2}{*}{5} & \multirow{2}{*}{ Av. Epitácio Pessoa } & 6 & VdF_1 & SIM & $05 / 05 / 2011$ & $18 / 06 / 2011$ & Lama bentonítica & Misto \\
\hline & & & 7 & VdF_2 & SIM & $31 / 08 / 2011$ & $21 / 10 / 2011$ & Lama bentonítica & Misto \\
\hline & \multirow{2}{*}{6} & \multirow{2}{*}{$\begin{array}{l}\text { Rua Guaiaó x Rua } \\
\text { Prof. Pirajá da Silva }\end{array}$} & 8 & Corp_1 & SIM & $31 / 07 / 2012$ & $29 / 08 / 2012$ & Lama bentonítica & Misto \\
\hline & & & 9 & Corp_2 & SIM & $31 / 07 / 2012$ & $31 / 08 / 2012$ & Lama bentonítica & Misto \\
\hline & 9 & $\begin{array}{c}\text { Rua Barão de } \\
\text { Paranapiacaba }\end{array}$ & 10 & Trin & SIM & $19 / 06 / 2015$ & $14 / 08 / 2015$ & - & - \\
\hline & 7 & Av. Ana Costa & 12 & Leg_2 & NÃO & $21 / 12 / 2012$ & $06 / 05 / 2013$ & Polímero & Rápido \\
\hline & \multirow{2}{*}{8} & \multirow{2}{*}{ Av. Senador Feijó } & 13 & TB_1 & NÃO & $06 / 12 / 2011$ & $02 / 01 / 2012$ & Lama bentonítica & Lento \\
\hline & & & 14 & TB_2 & NÃO & $26 / 10 / 2011$ & $05 / 01 / 2012$ & Lama bentonítica & Lento \\
\hline & 10 & Rua Pernambuco & 15 & PE & NÃO & - & $01 / 09 / 2017$ & Lama bentonítica & Lento \\
\hline \begin{tabular}{c|} 
Praia \\
Grande/SP
\end{tabular} & 11 & $\begin{array}{l}\text { Rua Luiz Antonio de } \\
\text { Andrade Vieira }\end{array}$ & 16 & Kinb & NÃO & $15 / 12 / 2015$ & $13 / 01 / 2016$ & Lama bentonítica & Misto \\
\hline
\end{tabular}


Tabela 15: Resumo das provas de carga estática analisadas.

\begin{tabular}{|c|c|c|c|c|c|c|c|c|}
\hline Cidade & Abreviação & $\begin{array}{l}\text { Diâmetro da } \\
\text { estaca }(\mathrm{cm})\end{array}$ & $\begin{array}{l}\text { Comprimento } \\
\text { da estaca }(m)\end{array}$ & $\begin{array}{c}\text { Carga } \\
\text { máxima do } \\
\text { ensaio (kN) }\end{array}$ & $\begin{array}{l}\text { Carga } \\
\text { máx / } \\
\text { Carga } \\
\text { de } \\
\text { trabalho } \\
\end{array}$ & \begin{tabular}{|c}
$\begin{array}{c}\text { Recalque } \\
\text { na carga } \\
\text { de } \\
\text { trabalho } \\
(\mathrm{mm})\end{array}$ \\
\end{tabular} & $\begin{array}{c}\text { Recalque } \\
\text { na carga } \\
\text { máxima } \\
(\mathrm{mm})\end{array}$ & Observações \\
\hline \multirow{15}{*}{ Santos/SP } & $\mathrm{CN}$ & 100 & 54,0 & 10.140 & 2,6 & 2,69 & 17,11 & - \\
\hline & CJM & 100 & 53,4 & 9.000 & 2,3 & 4,79 & 16,61 & - \\
\hline & PçaFP & 100 & 51,0 & 9.840 & 2,5 & 3,06 & 17,55 & - \\
\hline & Terr_50 & 100 & 55,0 & 8.190 & 2,1 & 5,26 & 19,21 & - \\
\hline & Terr_54 & 100 & 55,0 & 7.800 & 2,0 & 4,69 & 15,62 & - \\
\hline & VdF_1 & 100 & 57,5 & 6.370 & 1,6 & 2,56 & 9,26 & $\begin{array}{l}\text { Ensaio interrompido por ruptura das } \\
\text { barras de reação. }\end{array}$ \\
\hline & VdF_2 & 100 & 57,0 & 7.600 & 1,9 & 4,00 & 21,26 & $\begin{array}{l}\text { Ensaio interrompido por constatação de } \\
\text { ruptura geotécnica. }\end{array}$ \\
\hline & Corp_1 & 100 & 60,0 & 6.800 & 1,7 & 4,47 & 11,00 & $\begin{array}{l}\text { Ensaio interrompido por ocorrência de } \\
\text { torção na viga de reação. }\end{array}$ \\
\hline & Corp_2 & 100 & 60,0 & 8.000 & 2,1 & 3,32 & 10,29 & $\begin{array}{c}\text { Ensaio realizado na mesma estaca que } \\
\text { Corp_1. }\end{array}$ \\
\hline & Trin & 100 & 58,3 & 9.370 & 2,4 & 4,55 & 15,81 & $\begin{array}{c}\text { Estaca foi ensaiada até } 8.120 \mathrm{kN}, \\
\text { descarregada, e depois recarregada até } \\
9.370 \mathrm{kN} \text {. Apenas o primeiro } \\
\text { carregamento forneceu resultados de } \\
\text { instrumentação em profundidade. }\end{array}$ \\
\hline & Leg_1 & 80 & 51,3 & 4.490 & 1,8 & 3,02 & 6,91 & \\
\hline & Leg_2 & 80 & 51,1 & 4.990 & 2,0 & 1,92 & 5,74 & - \\
\hline & TB_1 & 80 & 52,4 & 5.020 & 2,0 & 6,51 & 18,06 & - \\
\hline & TB_2 & 80 & 52,4 & 3.650 & 1,5 & 3,13 & 5,72 & - \\
\hline & PE & 80 & 54,8 & 5.010 & 2,0 & 3,04 & 11,15 & - \\
\hline $\begin{array}{c}\text { Praia } \\
\text { Grande/SP }\end{array}$ & Kinb & 90 & 52,1 & 9.535 & 3,0 & 3,42 & 19,31 & - \\
\hline
\end{tabular}




\section{ANÁLISE DOS RESULTADOS}

É importante ressaltar que a grande maioria dos ensaios, com exceção de VdF_2, não atingiram a ruptura física, mesmo acima de 2 vezes a carga de trabalho da estaca. Isso ocorre pela suspeita, citada anteriormente, de que o critério de Estado Limite Último, ou seja, carga de ruptura, não seja o mais adequado para a análise de estacões na Baixada Santista devido às altas cargas suportadas por essas estacas e aos pequenos recalques observados nos ensaios. Acredita-se que a abordagem atual de dimensionamento, que utiliza métodos semiempíricos de capacidade de carga baseados em valores de SPT, leva a projetos conservadores e antieconômicos.

A tentativa de se estabelecer uma rotina de projeto baseada em Estado Limite de Serviço passa, naturalmente, pela determinação do recalque correspondente à carga de trabalho aplicada no topo do estacão através da construção da curva cargarecalque da estaca. Empiricamente, busca-se a reprodução de curvas carga-recalque semelhantes àquelas geradas pelas provas de carga executadas.

\subsection{Detalhamento da metodologia de análise}

Apresenta-se a seguir um detalhamento da metodologia usada nas análises.

Inicialmente, foram analisados os métodos semiempíricos de cálculo de capacidade de carga dos estacões ensaiados através de três métodos consagrados: os métodos de Aoki-Velloso (1975), Décourt-Quaresma (1978) e Falconi-Perez (2008). Os valores de capacidade de carga por atrito lateral e ponta obtidos por cada método foram comparados entre si, e os valores da carga total de ruptura geotécnica foram comparados com as cargas máximas atingidas nas provas de carga estática.

Em um segundo momento, foram utilizados os dados das 6 provas de carga estática instrumentadas em profundidade - CN, VdF_1, VdF_2, Corp_1, Corp_2 e Trin - para construir as funções de transferência de carga para os trechos entre níveis de instrumentação. Os valores de $f_{\text {máx, }} y_{1}, R_{p}$ e $y_{2}$, quando obtidos, foram comparados com valores da literatura. O método de Coyle Reese (1966) foi aplicado para todos os ensaios instrumentados, utilizando as funções de transferência de carga para cada trecho obtidas a partir dos próprios ensaios, e as curvas carga-recalque teóricas foram comparadas com as curvas reais. $O$ parâmetro $f_{\text {máx }}$ da $1^{\text {ạ }}$ Lei de Cambefort foi obtido 
também através da comparação do cálculo de capacidade de carga pelo método Falconi-Perez (2008) com o atrito lateral mobilizado entre níveis de instrumentação. O método de Coyle-Reese (1966), utilizando os parâmetros de Cambefort obtidos, com algumas modificações, foi aplicado a todos os ensaios.

Resumidamente, a análise contemplou as seguintes etapas:

1) Apresentação dos cálculos de capacidade de carga pelos métodos semiempíricos baseados em SPT mais consagrados, para todos os estacões, com seus respectivos comprimentos executados em obra;

2) Análise das 6 provas de carga instrumentadas em profundidade

a) Determinação do termo ES para cada trecho entre níveis de instrumentação através do Método do Módulo Tangente de Fellenius (1989) adaptado por Massad (2009-b);

b) Construção das funções de transferência de carga a partir dos resultados da instrumentação em profundidade, para cada trecho entre níveis de instrumentação, utilizando os valores de ES obtidos no item anterior;

c) Comparação dos parâmetros de Cambefort obtidos pela instrumentação com os valores da bibliografia;

d) Aplicação do método de Coyle-Reese (1966) para determinação da curva carga-recalque no topo da estaca.

3) Para as 6 provas de carga instrumentadas em profundidade, comparação do atrito lateral mobilizado medido pela instrumentação e calculado pelo método FalconiPerez (2008)

a) Cálculo do atrito lateral na ruptura pelo método Falconi-Perez (2008) para cada trecho entre níveis de instrumentação;

b) Comparação com os valores de atrito lateral mobilizados em cada trecho, medidos pela instrumentação, e adaptação do atrito lateral na ruptura para as argilas SFL e AT e do coeficiente a para areias e siltes do método FalconiPerez (2008).

4) Aplicação do método de Coyle-Reese (1966) para a simulação da curva cargarecalque no topo da estaca para todos os ensaios, instrumentados em profundidade ou não, utilizando os dados das sondagens à percussão e os parâmetros de Cambefort obtidos pelas análises dos ensaios instrumentados. 


\subsection{Capacidade de carga das estacas ensaiadas}

Através dos métodos semiempíricos de cálculo de capacidade de carga apresentados no item 2.3, foram calculadas as capacidades de carga de todos os estacões ensaiados, instrumentados em profundidade ou não. Os resultados para a capacidade de carga por atrito lateral, resistência de ponta e total estão apresentados na Tabela 16 e nas Figuras 34 a 36.

Tabela 16: cálculos de capacidade de carga das estacas por métodos semiempíricos.

\begin{tabular}{|c|c|c|c|c|c|c|c|c|c|}
\hline \multirow{2}{*}{ Obra } & \multicolumn{3}{|c|}{$\begin{array}{c}\text { Décourt-Quaresma } \\
\text { (1978) }\end{array}$} & \multicolumn{3}{|c|}{ Aoki-Velloso (1975) } & \multicolumn{3}{|c|}{ Falconi-Perez (2008) } \\
\hline & $\begin{array}{c}\mathrm{QL}_{\mathrm{L}} \\
(\mathrm{kN})\end{array}$ & $\begin{array}{c}Q \mathrm{Qp} \\
(\mathrm{kN})\end{array}$ & $\begin{array}{c}Q_{R} \\
(\mathbf{k N})\end{array}$ & $\begin{array}{c}Q_{\mathrm{L}} \\
(\mathbf{k N})\end{array}$ & $\begin{array}{c}\text { Qp } \\
(\mathbf{k N})\end{array}$ & $\begin{array}{c}Q_{R} \\
(k N)\end{array}$ & $\begin{array}{c}Q_{\mathrm{L}} \\
(\mathbf{k N})\end{array}$ & $\begin{array}{c}Q p \\
(k N)\end{array}$ & $\begin{array}{c}Q_{R} \\
(k N)\end{array}$ \\
\hline CN & 5.128 & 7.592 & 12.720 & 3.742 & 12.566 & 16.308 & 6.045 & 15.708 & 21.753 \\
\hline CJM & 5.558 & 3.299 & 8.856 & 4.936 & 6.545 & 11.481 & 6.394 & 2.003 & 8.397 \\
\hline PçaFP & 6.011 & 3.770 & 9.780 & 5.517 & 4.581 & 10.098 & \begin{tabular}{|l|}
5.937 \\
\end{tabular} & 2.867 & 8.803 \\
\hline Terr_50 & 5.336 & 5.288 & 10.624 & 4.464 & 10.053 & 14.518 & \begin{tabular}{|l|}
6.688 \\
\end{tabular} & 4.320 & 11.008 \\
\hline Terr_54 & 5.719 & 9.425 & 15.144 & 5.027 & 12.566 & 17.594 & 6.772 & 15.708 & 22.480 \\
\hline VdF 1 & 5.304 & 1.228 & 6.532 & 3.449 & 778 & 4.227 & \begin{tabular}{|l|}
7.239 \\
\end{tabular} & 2.238 & 9.478 \\
\hline VdF_2 & 5.471 & 2.317 & 7.788 & 4.886 & 4 & 299 & 7.0 & 827 & 13 \\
\hline Corp & 5.714 & 2.723 & 8.43 & 5.459 & 3.8 & 308 & 5.959 & 2.513 & 3.473 \\
\hline Trin & 6.526 & 2.867 & 9.30 & 5.753 & 3.024 & .777 & 7.863 & 2.631 & 10.494 \\
\hline Leg_1 & 4.335 & 1.307 & 5.642 & 3.937 & 2.145 & 6.082 & 6.176 & 1.206 & 7.382 \\
\hline Leg_2 & 4.161 & 2.011 & 6.171 & 3.703 & 2.815 & 6.518 & 5.209 & 1.734 & 6.943 \\
\hline TB_1 & 3.197 & 4.122 & 7.319 & 2.366 & 3.083 & 5.449 & 3.197 & 4.122 & 7.319 \\
\hline TB_2 & 3.073 & 2.212 & 5.285 & 2.427 & 2.580 & 5.008 & 3.943 & 1.734 & 5.677 \\
\hline$\overline{\mathrm{PE}}$ & 3.616 & 2.287 & 5.903 & 2.856 & 2.488 & 5.345 & 5.225 & 3.217 & 8.442 \\
\hline Kinb & 5.923 & 1.696 & 7.620 & 4.993 & 2.523 & 7.516 & \begin{tabular}{|l|l|}
7.148 \\
\end{tabular} & 1.622 & 8.770 \\
\hline
\end{tabular}

Observa-se que, de maneira geral, o método de Falconi-Perez (2008) apresentou os valores mais altos de capacidade de carga por atrito lateral. Por ser específico para a região da Baixada Santista, o método leva em consideração a gênese dos sedimentos quaternários da região, com a diferenciação entre as argilas SFL e AT, e apresenta valores de atrito lateral unitário mais elevados do que se levasse em consideração apenas o SPT das camadas de argila.

Em relação à resistência de ponta, os valores calculados pelos três métodos apresentaram bastante variação. 


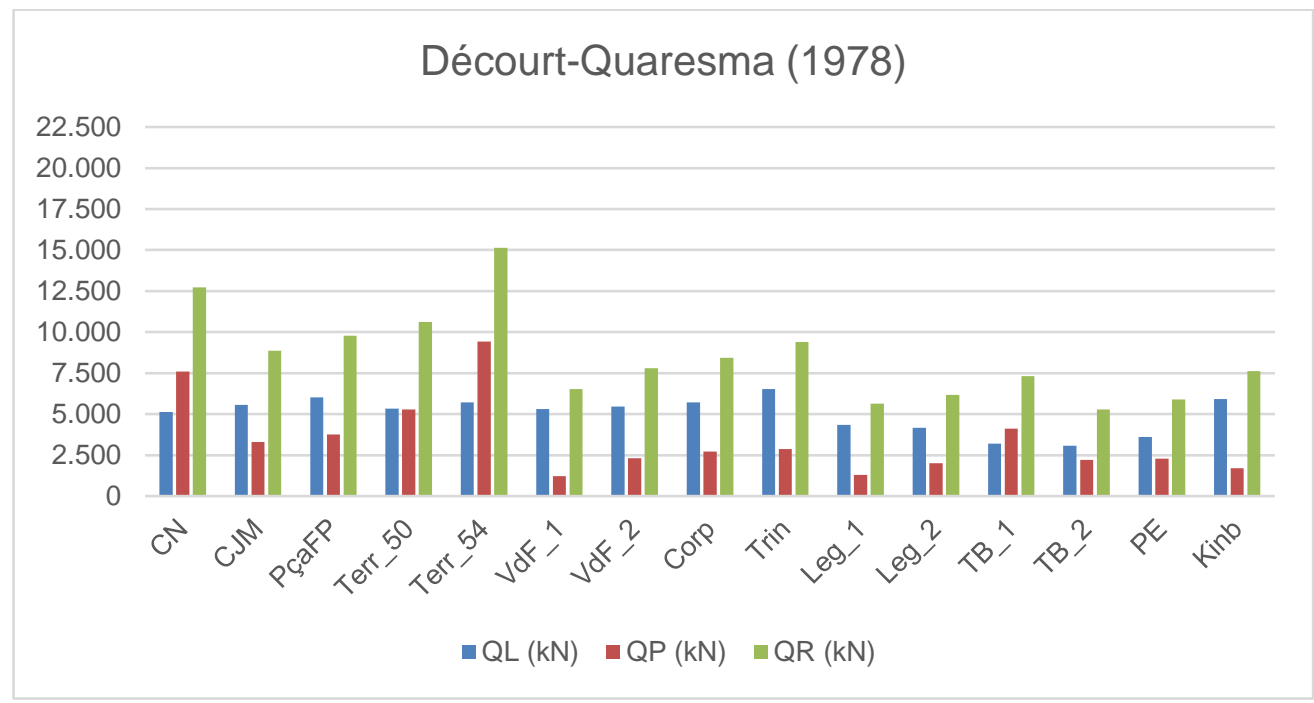

Figura 34: capacidades de carga calculadas pelo método de Décourt-Quaresma (1978).

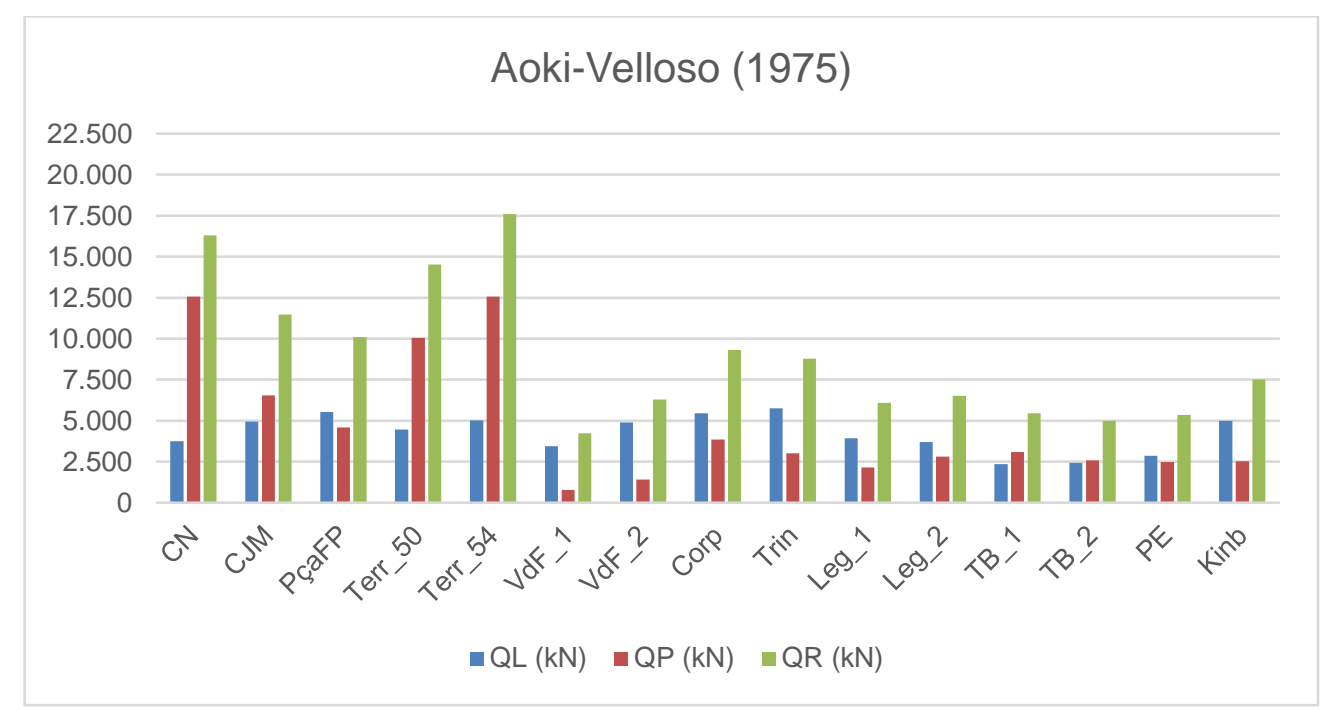

Figura 35: capacidades de carga calculadas pelo método de Aoki-Velloso (1975).

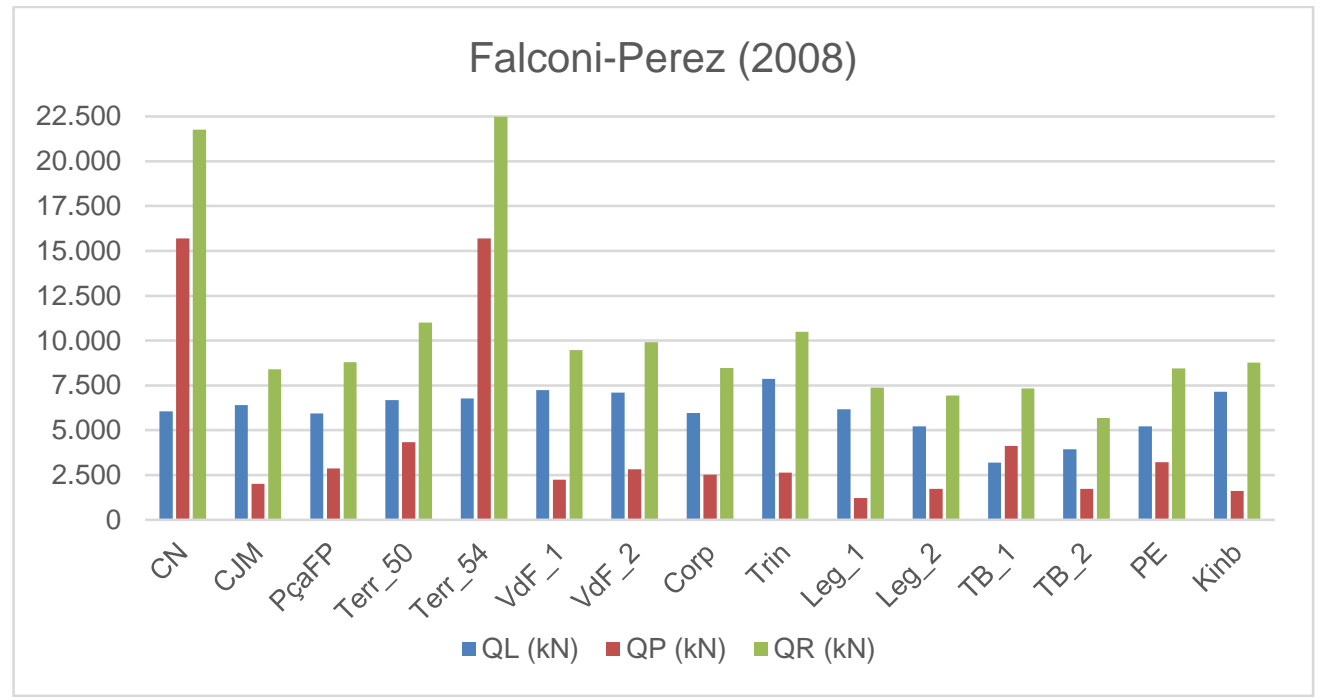

Figura 36: capacidades de carga calculadas pelo método de Falconi-Perez (2008). 
O método de Falconi-Perez (2008) apresentou alguns valores particularmente altos para a resistência de ponta, observados nos ensaios CN e Terr_54. No cálculo da resistência de ponta, o método não possui nenhuma diferenciação em função do tipo de solo de apoio, e a tensão resistente de ponta é calculada baseando-se somente no SPT. Além disso, o método foi concebido baseado em provas de carga estática em perfis metálicos, que, por ser uma estaca cravada, apresenta um bom desempenho da ponta. Quanto ao estacão, como mencionado no item 2.2, devido ao método executivo de escavação, a areia fica em suspensão no fluido estabilizante e, se não executada a limpeza da ponta da estaca, sua capacidade de carga pode ser bastante comprometida. Assim, não se pode comprovar que o método Falconi-Perez (2008) calcula com precisão a capacidade de carga de ponta de estacões na Baixada Santista.

A Tabela 17 e as Figuras 37 e 38 comparam a carga de ruptura total (atrito lateral mais ponta) calculada pelos métodos com a carga máxima atingida em cada ensaio.

Tabela 17: comparação entre a capacidade de carga calculada pelos métodos semiempíricos e a carga máxima atingida no ensaio, em $\mathbf{k N}$.

\begin{tabular}{|c|c|c|c|c|}
\hline Obra & $\begin{array}{c}\text { Décourt- } \\
\text { Quaresma } \\
(\mathbf{1 9 7 8 )}\end{array}$ & $\begin{array}{c}\text { Aoki-Velloso } \\
\mathbf{( 1 9 7 5 )}\end{array}$ & $\begin{array}{c}\text { Falconi-Perez } \\
\mathbf{( 2 0 0 8 )}\end{array}$ & $\begin{array}{c}\text { Carga máxima } \\
\text { do ensaio }\end{array}$ \\
\hline CN & 12.720 & 16.300 & 21.750 & 10.140 \\
\hline CJM & 8.850 & 11.480 & 8.390 & 9.000 \\
\hline PçaFP & 9.780 & 10.090 & 8.800 & 9.840 \\
\hline Terr_50 & 10.620 & 14.510 & 11.000 & 8.190 \\
\hline Terr_54 & 15.140 & 17.590 & 22.470 & 7.800 \\
\hline VdF_1 & 6.530 & 4.220 & 9.470 & 6.370 \\
\hline VdF_2 & 7.780 & 6.290 & 9.910 & 7.600 \\
\hline Corp & 8.430 & 9.300 & 8.470 & 6.800 \\
\hline Trin & 9.390 & 8.770 & 10.490 & 9.370 \\
\hline Leg_1 & 5.640 & 6.080 & 7.380 & 4.490 \\
\hline Leg_2 & 6.170 & 6.510 & 6.940 & 4.990 \\
\hline TB_1 & 7.310 & 5.440 & 7.310 & 5.020 \\
\hline TB_2 & 5.280 & 5.000 & 5.670 & 3.650 \\
\hline PE & 5.900 & 5.340 & 8.440 & 5.010 \\
\hline Kinb & 7.610 & 7.510 & 8.770 & 9.535 \\
\hline
\end{tabular}




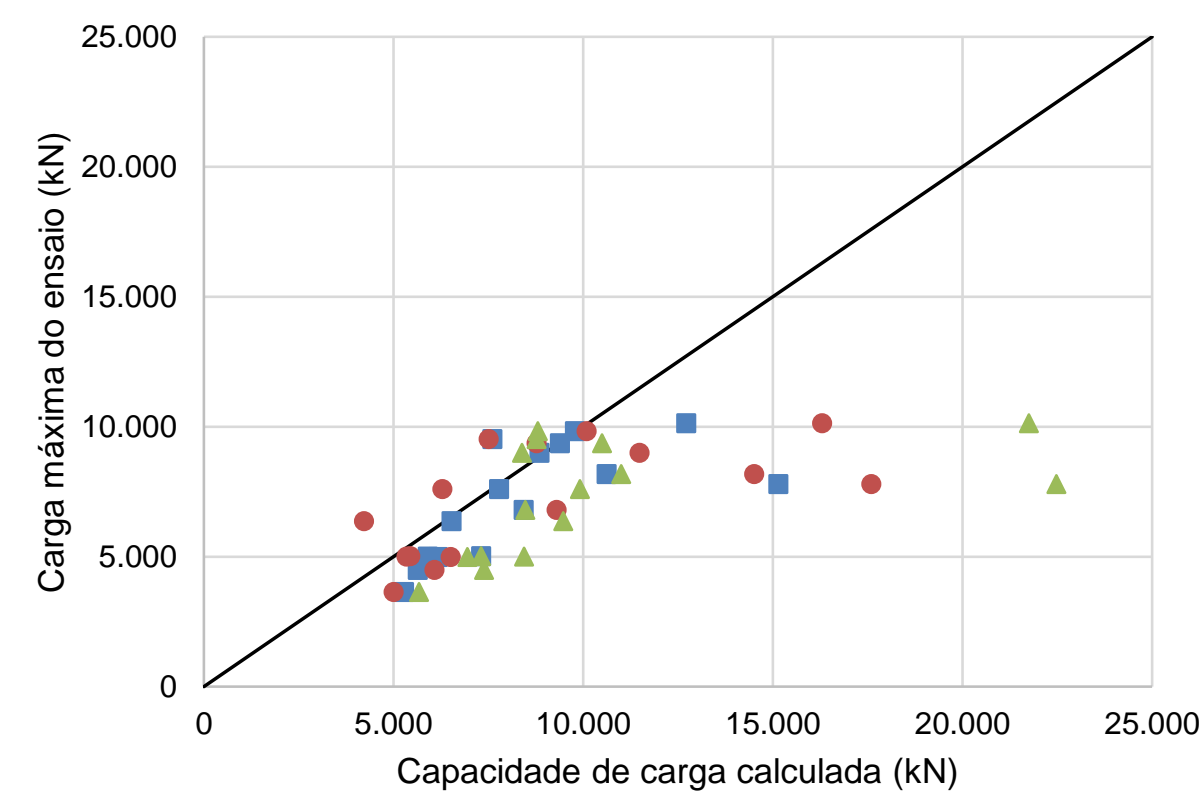

Décourt-Quaresma (1978) • Aoki-Velloso (1975) _ Falconi-Perez (2008)

Figura 37: comparação entre a capacidade de carga calculada pelos métodos semiempíricos e a carga máxima atingida no ensaio, em $\mathbf{k N}$.

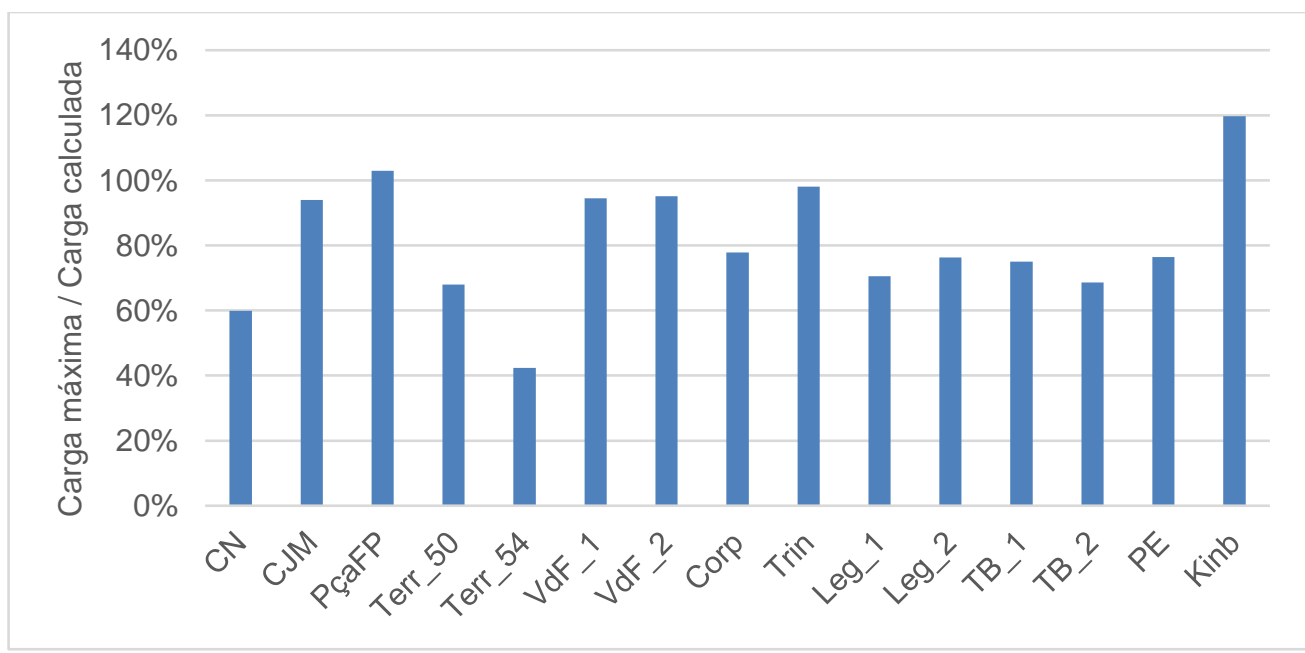

Figura 38: relação entre a capacidade de carga média calculada pelos três métodos semiempíricos e a carga máxima atingida no ensaio.

Pode-se concluir que, quando dimensionados por métodos semiempíricos consagrados baseados em SPT, os estacões ficam, em geral, superdimensionados. 


\subsection{Provas de carga instrumentadas: parâmetros de Cambefort}

Apresenta-se a seguir, em detalhe, a metodologia adotada para a análise das provas de carga com instrumentação em profundidade, resumida em 4.1.

1. A partir dos valores das leituras de deformação obtidas pelos strain gages, constrói-se o gráfico carga aplicada no topo da estaca em função da deformação média em cada nível, em cada estágio de carregamento;

2. Aplica-se o Método do Módulo Tangente de Fellenius (1989) adaptado por Massad (2009-b) para determinação do valor de ES em cada trecho de instrumentação em que houve esgotamento do atrito lateral acima do nível considerado;

3. Determina-se o valor de ES - pode-se utilizar o valor de apenas um nível de instrumentação, ou a média de todos os valores encontrados, ou ainda, pode-se utilizar um valor de ES para cada nível de instrumentação;

4. Os valores das leituras de deformação obtidas por cada strain gage são interpolados por polinômios de até $5^{\circ}$ grau;

5. Através das deformações em cada estágio e o valor de ES adotado, utilizando a Lei de Hooke pode-se calcular as forças atuantes em cada nível de instrumentação e construir as curvas de distribuição de carga em profundidade;

6. Calculam-se as forças médias e os encurtamentos elásticos em cada trecho entre níveis de instrumentação, em cada estágio. Em alguns casos, os valores de encurtamento elástico da estaca calculados foram ajustados para que a sua somatória fosse igual ao deslocamento medido no topo da estaca (ou o deslocamento do topo menos o da ponta, caso seja admitido deslocamento da ponta da estaca). Esse problema decorreu da relativamente pequena quantidade de níveis de instrumentação (4 a 6), em estacas com até 60,0 m de comprimento;

7. São construídas as funções de transferência de carga por atrito lateral unitário (1 $1^{\underline{a}}$ Lei de Cambefort). 
8. Caso o último nível de instrumentação esteja muito longe da ponta real da estaca, pode-se admitir carga e deslocamento nulos na ponta da estaca e construir a função de transferência de carga entre o último nível e a ponta real da estaca utilizando a $2^{\mathrm{a}}$ Lei de Cambefort, transformando esse trecho em uma "ponta fictícia";

9. A partir das funções de transferência de carga, determinam-se os parâmetros da $1^{\underline{a}}$ Lei de Cambefort $f_{\text {máx }}$ e $y_{1}$; ou o parâmetro da $2^{\underline{a}}$ Lei de Cambefort R.S do trecho pseudoelástico da ponta fictícia;

10. Finalmente, com base em

a. D e ES da estaca

b. comprimento de cada trecho entre níveis de instrumentação

c. parâmetros de Cambefort

d. consideração da "ponta fictícia" ou de carga nula na ponta da estaca

pode-se aplicar o Método de Coyle-Reese (1966) para determinar a curva carga-recalque $\mathrm{P}_{0}$-yo no topo da estaca;

11. A curva $P_{0}-y_{0}$ obtida pelo método é comparada com a curva medida na prova de carga estática.

A metodologia detalhada acima foi aplicada para cada uma das 6 provas de carga com instrumentação em profundidade nos próximos itens. 


\subsubsection{CN}

A estaca de 1,0 m de diâmetro e 54,0 m de comprimento foi instrumentada em profundidade em seis níveis, com dois sensores por seção. Porém, do total de doze, apenas quatro sensores "sobreviveram" à concretagem da estaca, um em cada nível, conforme indicado na Tabela 18.

Tabela 18: leituras de deformação obtidas através dos strain gages (CN).

\begin{tabular}{|c|c|c|c|c|}
\hline \multirow{2}{*}{ Carga no topo (kN) } & \multicolumn{5}{|c|}{ Deformação medida $(\boldsymbol{\mu} \boldsymbol{\varepsilon})$} \\
\cline { 2 - 5 } & SG 01 & SG 02 & SG 05 & SG 06 \\
\hline 0 & 0 & 0 & 0 & 0 \\
\hline 780 & 5 & 10 & 8 & 9 \\
\hline 1.560 & 23 & 13 & 12 & 8 \\
\hline 2.340 & 35 & 21 & 12 & 13 \\
\hline 3.120 & 55 & 28 & 14 & 15 \\
\hline 3.900 & 87 & 40 & 15 & 20 \\
\hline 4.680 & 122 & 54 & 18 & 26 \\
\hline 5.070 & 132 & 58 & 23 & 26 \\
\hline 5.460 & 150 & 67 & 26 & 25 \\
\hline 5.850 & 160 & 72 & 32 & 23 \\
\hline 6.240 & 175 & 82 & 35 & 26 \\
\hline 6.630 & 185 & 88 & 42 & 25 \\
\hline 7.020 & 202 & 99 & 47 & 27 \\
\hline 7.410 & 215 & 118 & 54 & 32 \\
\hline 7.800 & 233 & 134 & 64 & 34 \\
\hline 8.190 & 251 & 153 & 72 & 42 \\
\hline 8.580 & 270 & 170 & 81 & 45 \\
\hline 8.970 & 284 & 184 & 88 & 51 \\
\hline 9.360 & 308 & 208 & 100 & 59 \\
\hline 9.750 & 322 & 222 & 106 & 65 \\
\hline 10.140 & 349 & 244 & 118 & 75 \\
\hline
\end{tabular}

Com base nos dados apresentados, foi construída a Figura 39 e preparada a Tabela 19, que resume algumas informações e os valores de ES encontrados. 


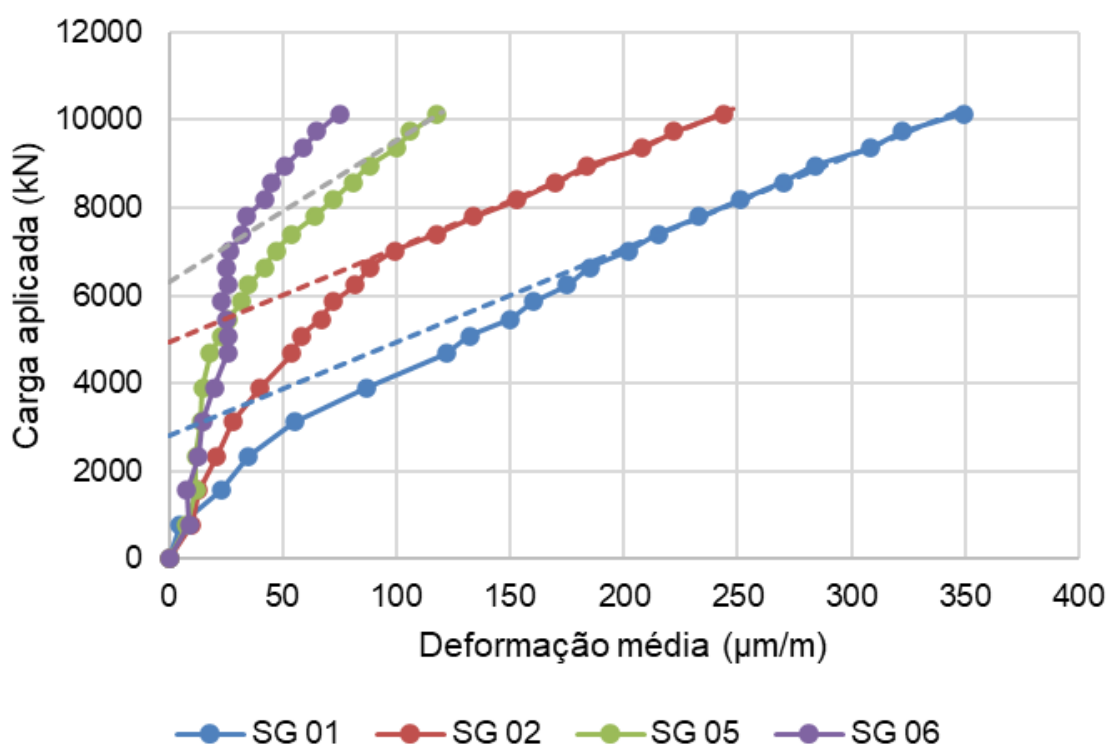

Figura 39: carga aplicada no topo da estaca em função da deformação média em cada nível de instrumentação para a prova de carga $\mathrm{CN}$.

Tabela 19: dados da instrumentação e valores de ES obtidos pelo Método do Módulo Tangente de Fellenius (1989) modificado por Massad (2009-b) para o ensaio CN.

\begin{tabular}{|c|c|c|c|}
\hline Nível & Profundidade $(\mathbf{m})$ & $\begin{array}{c}\text { Quantidade de } \\
\text { sensores úteis }\end{array}$ & ES (GN) \\
\hline SG 01 & 14,8 & 1 & 23,4 \\
\hline SG 02 & 30,1 & 1 & 21,5 \\
\hline SG 05 & 43,3 & 1 & - \\
\hline SG 06 & 46,3 & 1 & - \\
\hline
\end{tabular}

O valor considerado foi igual à média dos dois primeiros níveis: 22,45 GN.

Para a obtenção das funções de transferência de carga e da curva cargarecalque do topo da estaca, algumas hipóteses e simplificações foram adotadas:

- foi considerada carga zero na ponta da estaca, possibilitando a determinação do trecho SG 06-P;

- apesar de ter sido considerada carga zero na ponta da estaca, considerou-se deslocamento da ponta entre 1 e $2 \mathrm{~mm}$, como se o solo da ponta da estaca estivesse "desestruturado", apresentando reação nula, mas permitindo pequenos deslocamentos. Como visto em 2.2, 
sobre a consideração da carga de ponta em estacões, essa hipótese é plausível desde que não haja limpeza de ponta da estaca.

A Tabela 20 apresenta as forças calculadas através da interpolação polinomial das deformações e utilizando a Lei de Hooke. Esses mesmos valores estão apresentados graficamente na Figura 40 , com a consideração mencionada anteriormente de carga zero na ponta da estaca.

Observa-se que, no mínimo, nos dois primeiros trechos (SG 01-02 e 02-05) ocorreu esgotamento do atrito lateral unitário, fato que será corroborado pelas funções de transferência de carga mais adiante. No último trecho (SG 05-06), que contempla 3,0 m de espessura de argila AT, observa-se um alto valor de atrito lateral unitário, pela inclinação das retas do diagrama de transferência de carga nesse trecho. No último nível de instrumentação, 9,1 m acima da ponta real da estaca, na carga máxima do ensaio foi calculado um valor de força correspondente a 15,8\% da carga aplicada no topo da estaca.

Tabela 20: forças calculadas em cada nível (CN).

\begin{tabular}{|c|c|c|c|c|}
\hline \multirow{2}{*}{ Carga no topo (kN) } & \multicolumn{4}{|c|}{ Força calculada (kN) } \\
\cline { 2 - 5 } & SG 01 & SG 02 & SG 05 & SG 06 \\
\hline 780 & 107 & 214 & 171 & 193 \\
\hline 1.560 & 492 & 278 & 257 & 171 \\
\hline 2.340 & 749 & 449 & 257 & 278 \\
\hline 3.120 & 1.177 & 599 & 300 & 321 \\
\hline 3.900 & 1.862 & 856 & 321 & 428 \\
\hline 4.680 & 2.611 & 1.156 & 385 & 556 \\
\hline 5.070 & 2.825 & 1.241 & 492 & 556 \\
\hline 5.460 & 3.210 & 1.434 & 556 & 535 \\
\hline 5.850 & 3.424 & 1.541 & 685 & 492 \\
\hline 6.240 & 3.745 & 1.755 & 749 & 556 \\
\hline 6.630 & 3.959 & 1.883 & 899 & 535 \\
\hline 7.020 & 4.323 & 2.119 & 1.006 & 578 \\
\hline 7.410 & 4.601 & 2.525 & 1.156 & 685 \\
\hline 7.800 & 4.986 & 2.868 & 1.370 & 728 \\
\hline 8.190 & 5.371 & 3.274 & 1.541 & 899 \\
\hline 8.580 & 5.778 & 3.638 & 1.733 & 963 \\
\hline 8.970 & 6.078 & 3.938 & 1.883 & 1.091 \\
\hline 9.360 & 6.591 & 4.451 & 2.140 & 1.263 \\
\hline 9.750 & 6.891 & 4.751 & 2.268 & 1.391 \\
\hline 10.140 & 7.469 & 5.222 & 2.525 & 1.605 \\
\hline
\end{tabular}




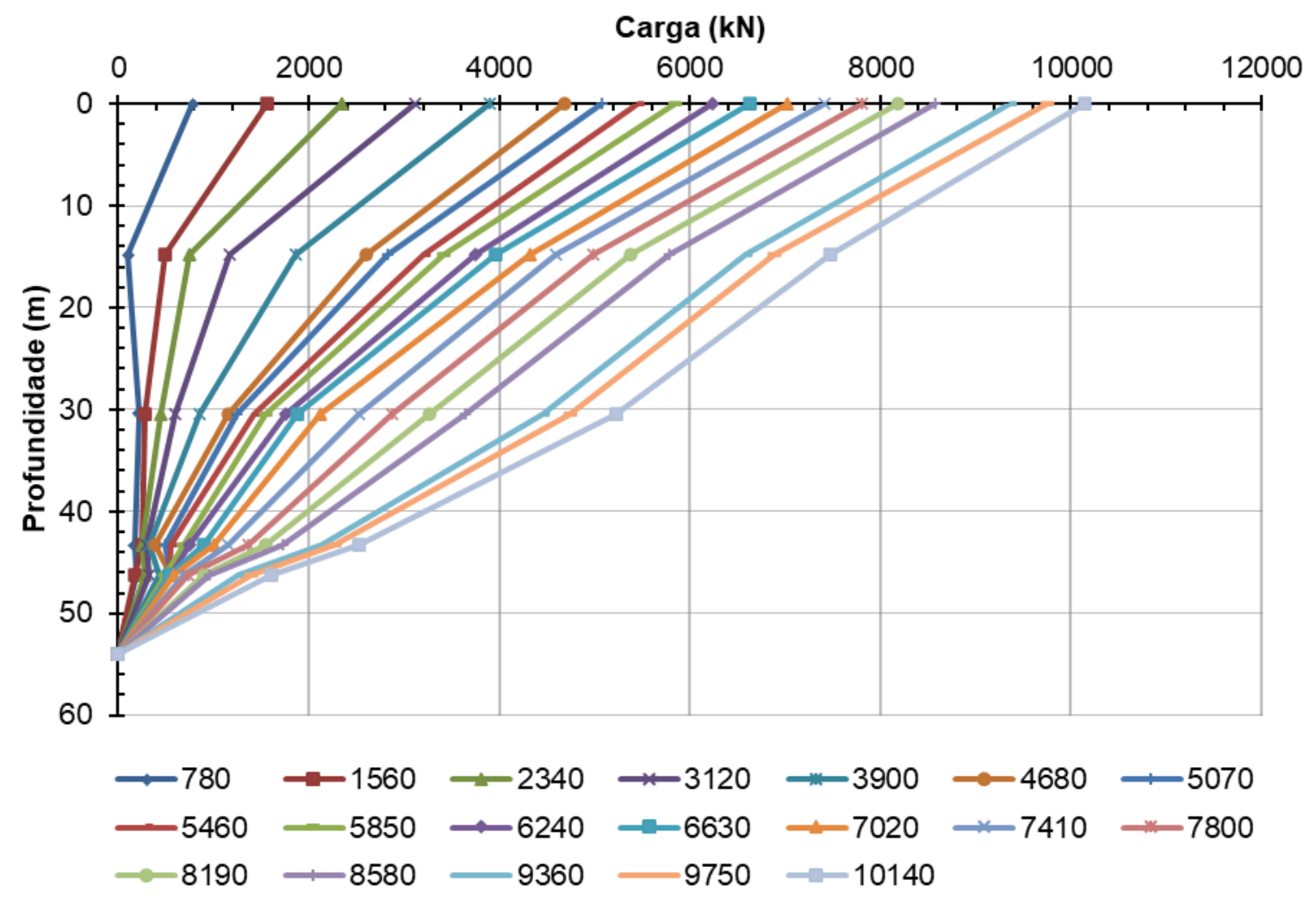

Figura 40: diagramas de transferência de carga em profundidade para o ensaio $\mathrm{CN}$.

As funções de transferência de carga para cada trecho estão apresentadas nas Figuras 41 a 45. Nas mesmas figuras, estão indicadas as relações de Cambefort (1964) simplificadas. A Tabela 21 resume os parâmetros de Cambefort inferidos para cada trecho.

Tabela 21: parâmetros de Cambefort para o ensaio $\mathrm{CN}$.

\begin{tabular}{|c|c|c|c|c|}
\hline Trecho & Comprimento $\mathbf{( m )}$ & $\mathbf{f}_{\text {máx }} \mathbf{( k P a )}$ & $\mathbf{y} \mathbf{1}(\mathbf{m m})$ & $\mathbf{B}(\mathbf{k P a} / \mathbf{m m})$ \\
\hline Topo- SG 01 & 14,8 & 60 & 2,5 & 20,0 \\
\hline SG 01-02 & 15,3 & 45 & 2,0 & 25,0 \\
\hline SG 02-05 & 13,2 & 65 & 3,5 & 18,6 \\
\hline SG 05-06 & 3,0 & 100 & 2,0 & 50,0 \\
\hline SG 06-P & 7,7 & - & - & 23,33 \\
\hline
\end{tabular}




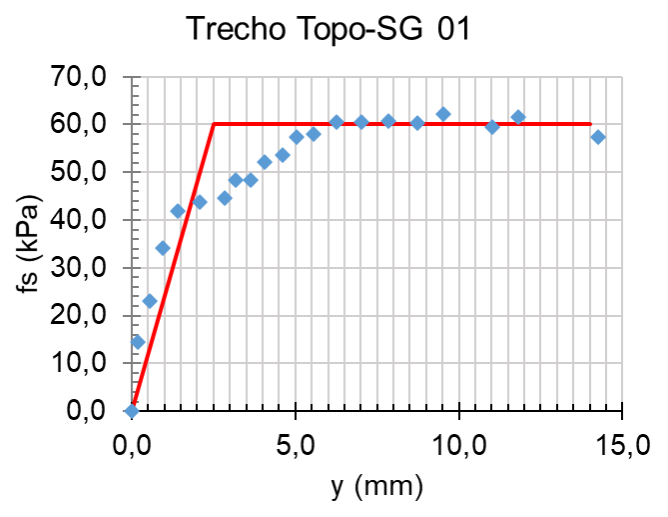

Figura 41: função de transferência de carga para o trecho topo - SG 01 do ensaio $C N$.

Trecho SG 02-05

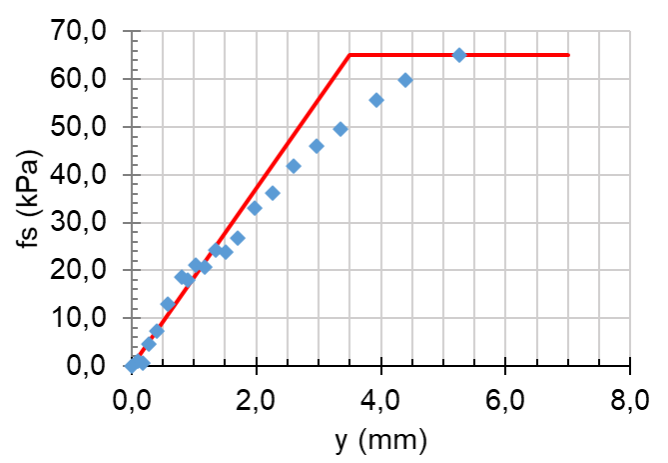

Figura 43: função de transferência de carga para o trecho SG 02-05 do ensaio CN.

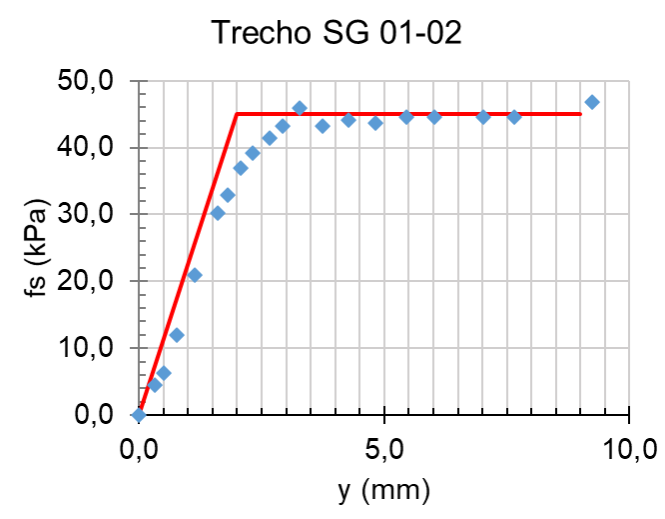

Figura 42: função de transferência de carga para o trecho SG 01-02 do ensaio $\mathrm{CN}$.

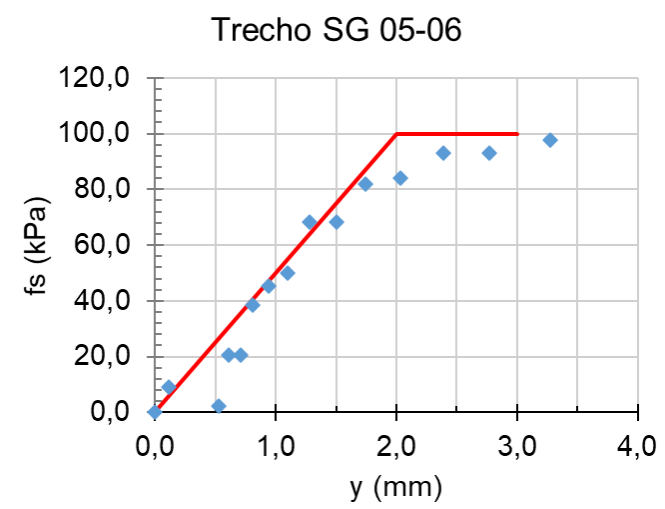

Figura 44: função de transferência de carga para o trecho SG 05-06 do ensaio CN.

Trecho SG 06-P

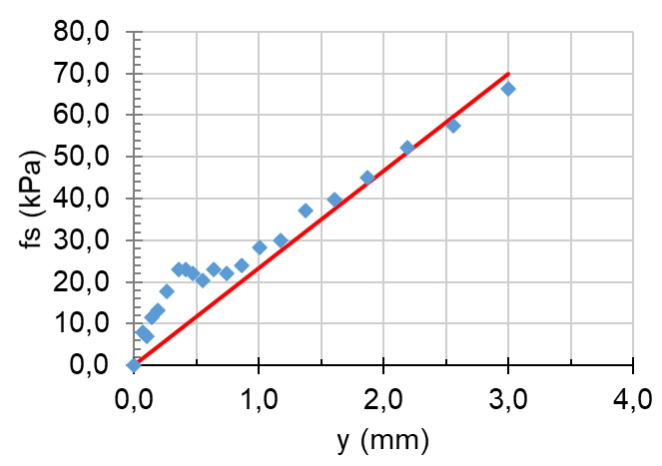

Figura 45: função de transferência de carga para o trecho SG 06-P do ensaio CN.

O trecho Topo-SG 01 consiste em camada de 10,9 m de espessura de areia compacta e 3,9 m de espessura de argila SFL. O valor de $f_{\text {máx }}=60 \mathrm{kPa}$ está um pouco acima dos valores das Tabelas 2 e 3 para esses tipos de solo, principalmente a argila 
SFL. O valor de $\mathrm{y}_{1}=2,5 \mathrm{~mm}$ está dentro do esperado. O trecho SG 01-02 contempla 13,4 $\mathrm{m}$ de argila SFL e 1,9 m de areia argilosa. $O$ valor de $f_{\text {máx }}$ de $45 \mathrm{kPa}$ está um pouco acima dos valores apresentados nas Tabelas 2 e 3 para argilas SFL, e pode ter sofrido influência da camada de areia ao final do trecho. Já o valor de y de 2,0 mm é coerente com os valores. No trecho SG 02-05 observa-se alternância de camadas de areia pouco a medianamente compacta e argila AT. O valor de fmáx de $65 \mathrm{kPa}$ está entre os valores observados nas Tabelas 2 e 3 para areias holocênicas e argilas AT. Já o trecho 05-06 apresenta 3,0 m de argila AT e fmáx de $100 \mathrm{kPa}$, um pouco acima do observado para esse tipo de solo nas Tabelas 2 e 3. Do nível SG 06 até a ponta da estaca, encontra-se solo residual (silte areno argiloso e areia siltosa), com SPTs maiores que 15 golpes, e o valor máximo observado de fs de $55 \mathrm{kPa}$ não necessariamente representa o atrito lateral unitário máximo do trecho, pois não foi observado esgotamento das leituras.

O método de Coyle-Reese (1966) foi aplicado considerando carga zero na ponta da estaca e os parâmetros de Cambefort da Tabela 21. A curva $\mathrm{P}_{0}$-yo resultante está ilustrada na Figura 46.

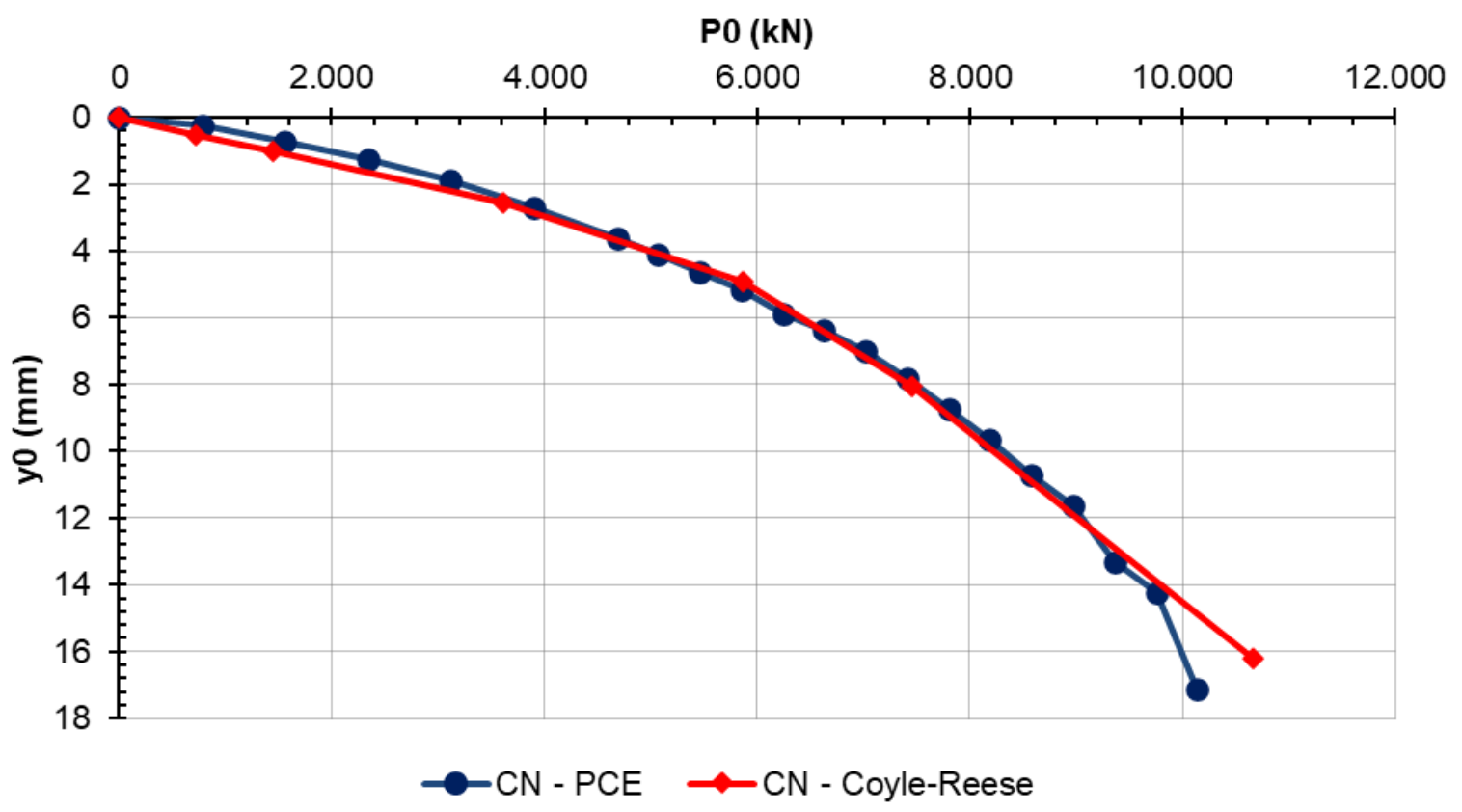

Figura 46: curva carga-recalque no topo da estaca obtida pelo método de Coyle-Reese (1966) para o ensaio $\mathrm{CN}$. 
Observa-se excelente aderência entre a curva do ensaio e a curva obtida pela aplicação do método de Coyle-Reese (1966) com consideração de deslocamento na ponta real da estaca sem mobilização de resistência.

\subsubsection{VdF_1}

A estaca de $1 \mathrm{~m}$ de diâmetro e $60 \mathrm{~m}$ de comprimento foi instrumentada em profundidade em seis níveis com dois sensores por seção. Do total de doze, três sensores foram danificados e tiveram suas leituras desconsideradas. No último estágio, houve a ruptura de uma barra de uma das estacas de reação, e o ensaio foi interrompido. Portanto, as leituras do estágio de 6.370 kN não foram consideradas.

É importante ressaltar que, apesar de os sensores SG 02-B e SG 04-A não terem sido danificados durante a concretagem da estaca, suas leituras apresentaramse muito inconsistentes. A rigor, nos cinco primeiros níveis de instrumentação, a leitura apresentada na Tabela 22 é de apenas um sensor por seção.

Tabela 22: leituras de deformação obtidas através dos strain gages (VdF_1).

\begin{tabular}{|c|c|c|c|c|c|c|}
\hline \multirow{2}{*}{ Carga no topo (kN) } & \multicolumn{7}{|c|}{ Deformação calculada ( $\boldsymbol{\mu \varepsilon})$} \\
\cline { 2 - 7 } & SG 01 & SG 02 & SG 03 & SG 04 & SG 05 & SG 06 \\
\hline 850 & 6,2 & 1,5 & 0,8 & 0,8 & 0,3 & 0 \\
\hline 1.700 & 28,8 & 8,5 & 5,4 & 3,8 & 1,8 & 0,2 \\
\hline 2.550 & 57,3 & 18,1 & 11,2 & 8,5 & 3,8 & 0,2 \\
\hline 3.400 & 86,9 & 27,7 & 18,8 & 14,6 & 4,5 & 0,2 \\
\hline 4.250 & 116,2 & 38,8 & 28,8 & 22,3 & 7,9 & 0 \\
\hline 5.100 & 145 & 54,2 & 43,8 & 34,2 & 11,6 & 0 \\
\hline 5.525 & 175,8 & 64,6 & 49,2 & 39,2 & 13,6 & 0,2 \\
\hline 5.950 & 192,7 & 67,3 & 51,2 & 39,6 & 14 & 0,8 \\
\hline 6.370 & 181,2 & 62,7 & 57,7 & 46,5 & 16,6 & 1,5 \\
\hline
\end{tabular}

A Figura 47 ilustra o gráfico da carga aplicada no topo da estaca em função da deformação em cada estágio de carregamento. Pode-se observar que os três últimos pontos, principalmente o último, referente ao estágio de $6.370 \mathrm{kN}$, apresentaram leituras um pouco inconsistentes. Aplicando-se o Método do Módulo Tangente de Fellenius (1989) adaptado por Massad (2009-b), e desprezando o último ponto, foi possível determinar o valor de ES apenas no nível SG 01, em que houve estabilização das leituras. O valor encontrado está indicado na Tabela 23. 


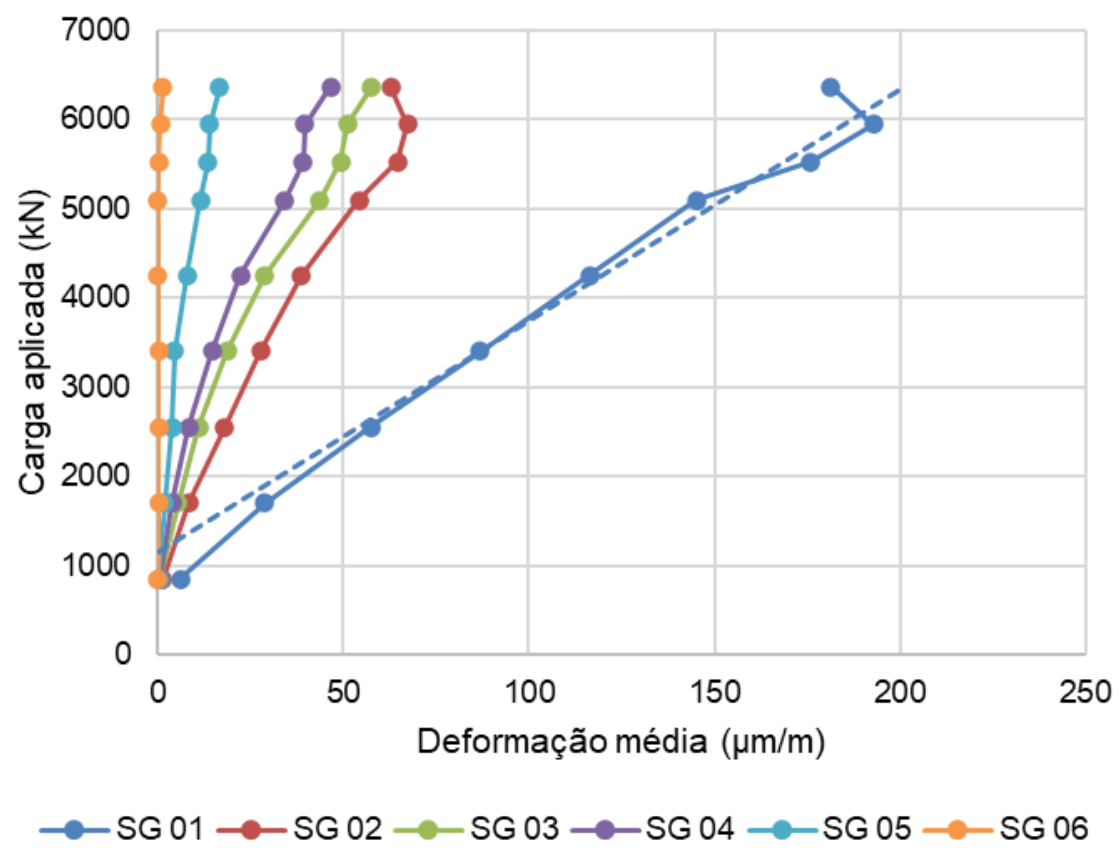

Figura 47: carga aplicada no topo da estaca em função da deformação média em cada nível de instrumentação para a prova de carga VdF_1.

Tabela 23: dados da instrumentação e valores de ES obtidos pelo Método do Módulo Tangente de Fellenius (1989) modificado por Massad (2009-b) para o ensaio VdF_1.

\begin{tabular}{|c|c|c|c|}
\hline Nível & Profundidade $(\mathbf{m})$ & $\begin{array}{c}\text { Quantidade de } \\
\text { sensores úteis }\end{array}$ & ES (GN) \\
\hline SG 01 & 8,5 & 1 & 25,9 \\
\hline SG 02 & 30,0 & 2 & - \\
\hline SG 03 & 40,5 & 1 & - \\
\hline SG 04 & 44,5 & 2 & - \\
\hline SG 05 & 53,5 & 1 & - \\
\hline SG 06 & 58,5 & 2 & - \\
\hline
\end{tabular}

Para o ensaio VdF_1, foi considerada a hipótese de que a carga registrada no último nível de instrumentação, a 59 m de profundidade, é igual à carga de ponta da estaca.

A Tabela 24 apresenta as forças calculadas em cada nível de instrumentação em profundidade através da aplicação da Lei de Hooke às interpolações polinomiais dos valores da Tabela 22, considerando o valor de ES de 25,9 GN. Os diagramas de transferência de carga em profundidade estão apresentados na Figura 48. 
Tabela 24: forças calculadas em cada nível (VdF_1).

\begin{tabular}{|c|c|c|c|c|c|c|}
\hline \multirow{2}{*}{ Carga no topo (kN) } & \multicolumn{7}{|c|}{ Deformação medida $(\boldsymbol{\mu \varepsilon})$} \\
\cline { 2 - 7 } & SG 01 & SG 02 & SG 03 & SG 04 & SG 05 & SG 06 \\
\hline 850 & 178 & 45 & 37 & 34 & 6 & 1 \\
\hline 1.700 & 766 & 219 & 109 & 79 & 59 & 5 \\
\hline 2.550 & 1438 & 448 & 276 & 210 & 83 & 8 \\
\hline 3.400 & 2193 & 728 & 511 & 401 & 128 & 6 \\
\hline 4.250 & 3033 & 1050 & 789 & 627 & 210 & 0 \\
\hline 5.100 & 3956 & 1408 & 1082 & 860 & 310 & 1 \\
\hline 5.525 & 4449 & 1599 & 1226 & 972 & 352 & 7 \\
\hline 5.950 & 4963 & 1796 & 1364 & 1076 & 377 & 21 \\
\hline
\end{tabular}

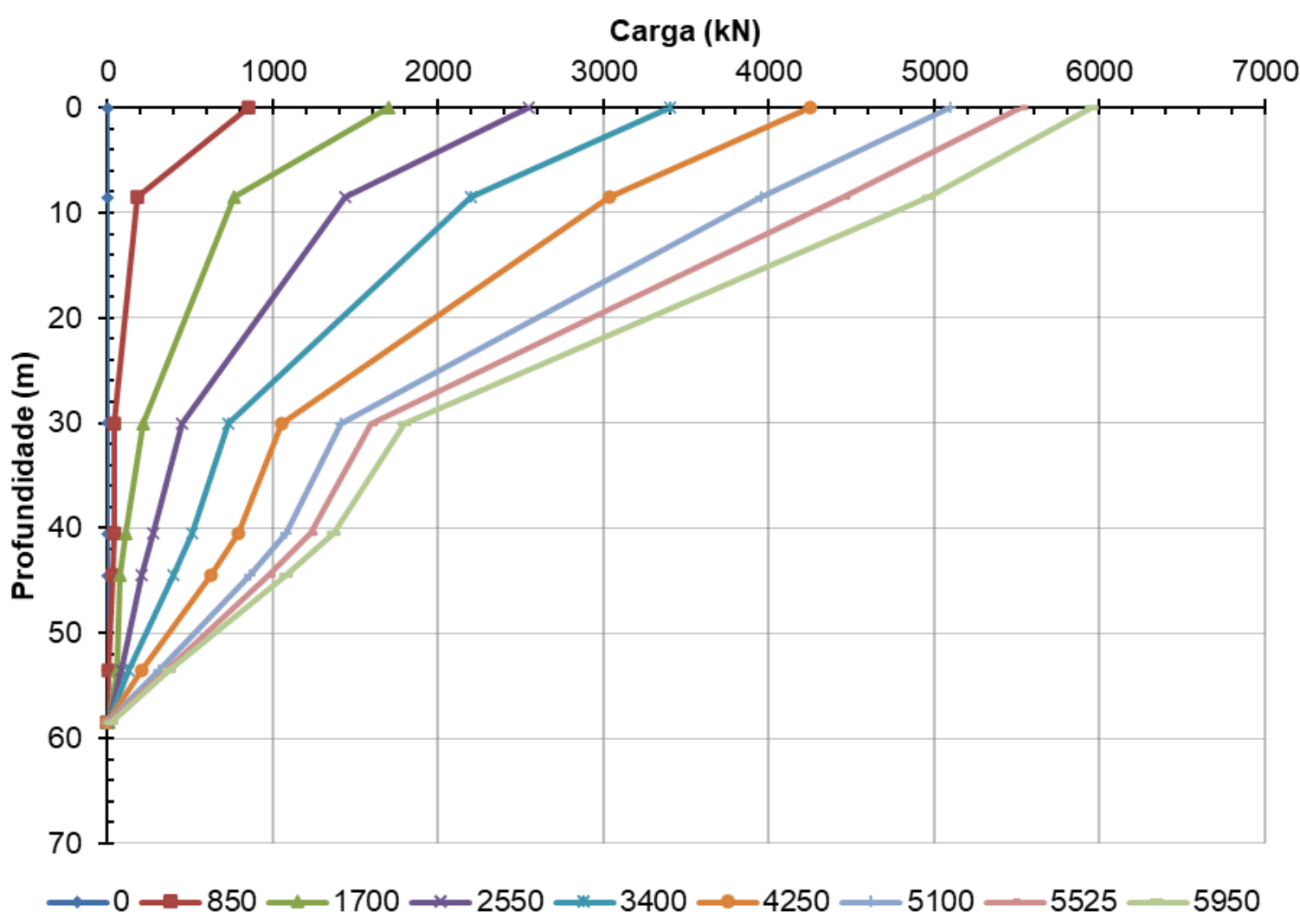

Figura 48: diagramas de transferência de carga para o ensaio VdF_1.

As funções de transferência de carga e as relações de Cambefort (1964) simplificadas estão apresentadas nas Figuras 49 a 54. A Tabela 25 apresenta os parâmetros de Cambefort obtidos da análise. 


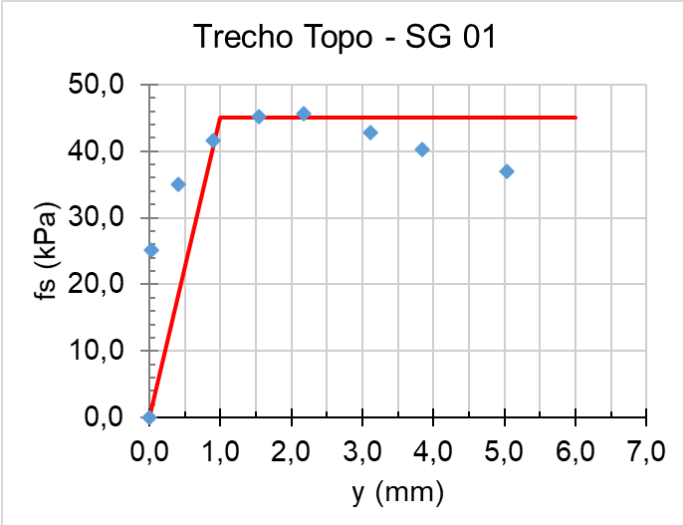

Figura 49: função de transferência de carga para o trecho topo - SG01 do ensaio VdF_1.

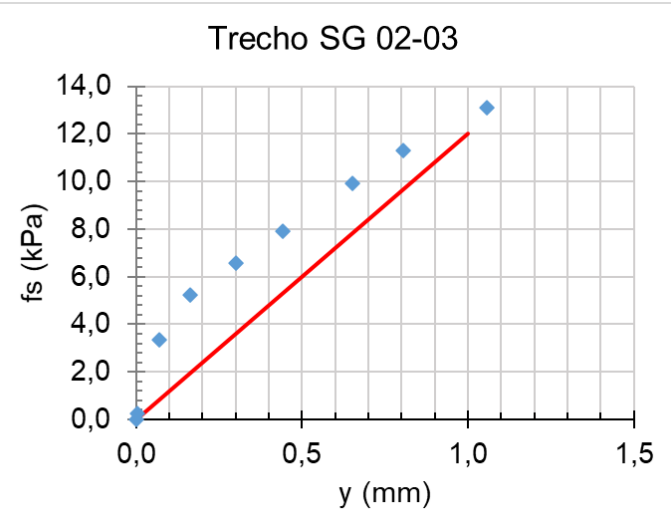

Figura 51: função de transferência de carga para o trecho SG02 - SG03 do ensaio VdF_1.

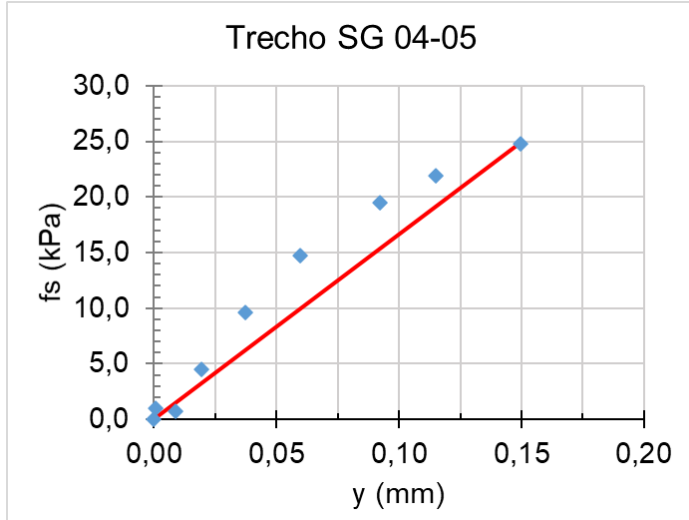

Figura 53: função de transferência de carga para o trecho SG04 - 05 do ensaio VdF_1.

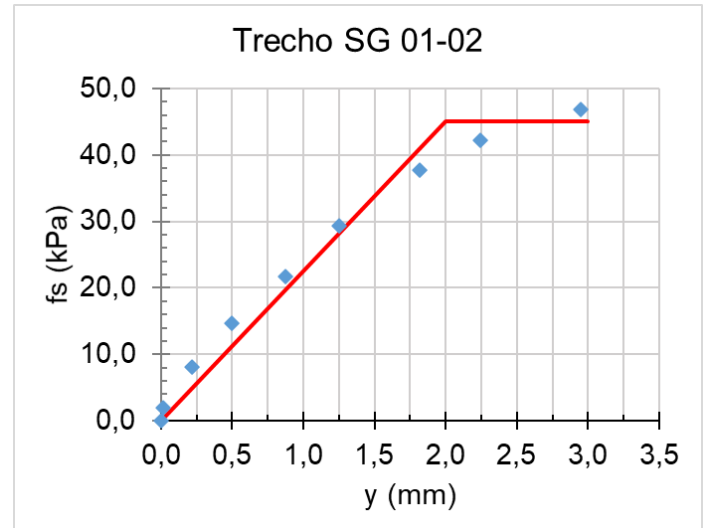

Figura 50: função de transferência de carga para o trecho SG01 - SG02 do ensaio VdF_1.

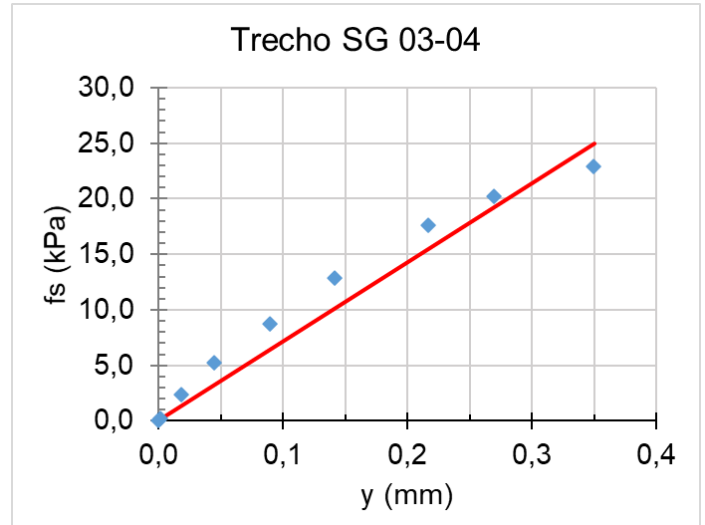

Figura 52: função de transferência de carga para o trecho SG03 - SG04 do ensaio VdF_1.

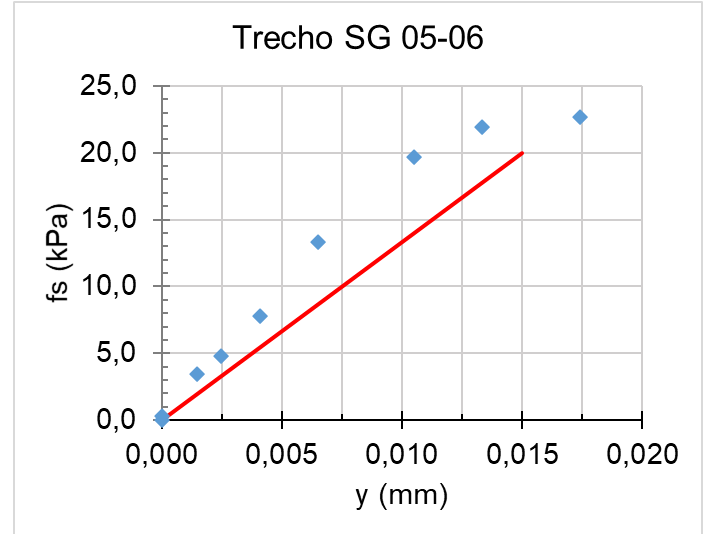

Figura 54: função de transferência de carga para o trecho SG05 - 06 do ensaio VdF_1. 
Tabela 25: parâmetros de Cambefort para o ensaio VdF_1.

\begin{tabular}{|c|c|c|c|c|}
\hline Trecho & Comprimento $(\mathbf{m})$ & $\left.\mathbf{f}_{\text {máx }} \mathbf{( k P a}\right)$ & $\mathbf{y}_{\mathbf{1}}(\mathbf{m m})$ & $\mathbf{B}(\mathbf{k P a} / \mathbf{m m})$ \\
\hline Topo- SG 01 & 8,5 & 45 & 1,0 & 45,0 \\
\hline SG 01-02 & 21,5 & 45 & 2,0 & 22,5 \\
\hline SG 02-03 & 10,5 & - & - & 12,0 \\
\hline SG 03-04 & 4,0 & - & - & 71,43 \\
\hline SG 04-05 & 9,0 & - & - & 166,67 \\
\hline SG 05-06 & 5,0 & - & - & 1333,33 \\
\hline
\end{tabular}

Analisando as Figuras 49 a 54 e a Tabela 25, observa-se esgotamento do atrito lateral apenas nos dois primeiros trechos, portanto apenas neles foram determinados os parâmetros $f_{\text {máx }}$ e $\mathrm{y}_{1}$. A partir do trecho SG $02-03$, as leituras obtidas pelos strain gages apresentaram valores muito baixos de deformação, resultando em valores muito baixos de y nas funções de transferência de carga. Consequentemente, os valores de B obtidos resultaram bastante elevados, em comparação com os demais ensaios analisados, o que pode gerar inconsistências na aplicação do método de Coyle-Reese (1966) - sem o limite de $f_{\text {máx }}$ estabelecido, os altos valores de B podem resultar em valores irreais de $\mathrm{f}_{\mathrm{s}}$ nos trechos mais profundos.

Diante das inconsistências mencionadas, decidiu-se desprezar o ensaio VdF_1.

\subsubsection{VdF_2}

Similarmente ao ensaio $\mathrm{VdF}_{-} 1$, a estaca de $1,0 \mathrm{~m}$ de diâmetro e $60,0 \mathrm{~m}$ de comprimento foi instrumentada em profundidade em seis níveis com dois sensores por seção. Do total de doze, três sensores foram danificados e tiveram suas leituras desconsideradas. As deformações medidas estão indicadas na Tabela 26.

No estágio correspondente a $7.600 \mathrm{kN}$, foi relatado que os deflectômetros e os strain gages não estabilizavam suas leituras e o conjunto macaco-bomba-manômetro não mantinha a carga do estágio. Constatou-se a ruptura geotécnica do conjunto soloestaca e, após a aplicação da carga máxima atingida no ensaio durante 120 minutos, procedeu-se ao descarregamento. 
Tabela 26: leituras de deformação médias obtidas através dos strain gages (VdF_2).

\begin{tabular}{|c|c|c|c|c|c|c|}
\hline \multirow{2}{*}{ Carga no topo (kN) } & \multicolumn{7}{|c|}{ Deformação medida $(\boldsymbol{\mu \varepsilon})$} \\
\cline { 2 - 7 } & SG 01 & SG 02 & SG 03 & SG 04 & SG 05 & SG 06 \\
\hline 800 & 12,3 & 3,8 & 2,3 & 1 & 0 & 0,4 \\
\hline 1.600 & 41,9 & 11,5 & 7,3 & 2,9 & 1,2 & 1,2 \\
\hline 2.400 & 77,3 & 21,5 & 13,8 & 6 & 2,3 & 1,2 \\
\hline 3.200 & 111,3 & 34,2 & 21,9 & 9,6 & 3,7 & 1,5 \\
\hline 4.000 & 146,9 & 48,8 & 32,7 & 15,6 & 6,2 & 2,3 \\
\hline 4.800 & 190 & 69,6 & 48,5 & 25,8 & 10,4 & 3,5 \\
\hline 5.200 & 204,4 & 76,2 & 53,8 & 29,4 & 12,1 & 4,2 \\
\hline 5.600 & 218,7 & 84,6 & 60,8 & 34,4 & 14,4 & 5,8 \\
\hline 6.000 & 233,8 & 95 & 70,8 & 43,5 & 18,8 & 6,9 \\
\hline 6.400 & 255,4 & 110 & 86,2 & 57,7 & 25,2 & 7,7 \\
\hline 6.800 & 280,4 & 131,9 & 110,4 & 81,2 & 37,3 & 8,5 \\
\hline 7.200 & 294,6 & 146,2 & 125 & 94,4 & 45,8 & 9,2 \\
\hline 7.600 & 298,1 & 157,7 & 144,6 & 114,8 & 64,4 & 10 \\
\hline
\end{tabular}

Com base nos dados da Tabela 26, foi construída a Figura 55 e preparada a Tabela 27, que resume algumas informações e os valores de ES encontrados.

Tabela 27: dados da instrumentação e valores de ES obtidos pelo Método do Módulo Tangente de Fellenius (1989) modificado por Massad (2009-b) para o ensaio VdF_2.

\begin{tabular}{|c|c|c|c|}
\hline Nível & Profundidade (m) & $\begin{array}{c}\text { Quantidade de } \\
\text { sensores úteis }\end{array}$ & ES (GN) \\
\hline SG 01 & 7,5 & 2 & 20,0 \\
\hline SG 02 & 30,5 & 1 & 24,8 \\
\hline SG 03 & 38,5 & 1 & 23,2 \\
\hline SG 04 & 44,5 & 2 & 23,5 \\
\hline SG 05 & 49,0 & 2 & 21,5 \\
\hline SG 06 & 59,0 & 1 & - \\
\hline
\end{tabular}

O valor de ES adotado para a análise do ensaio foi a média dos valores obtidos pelos cinco primeiros níveis de instrumentação: 22,6 GN. 


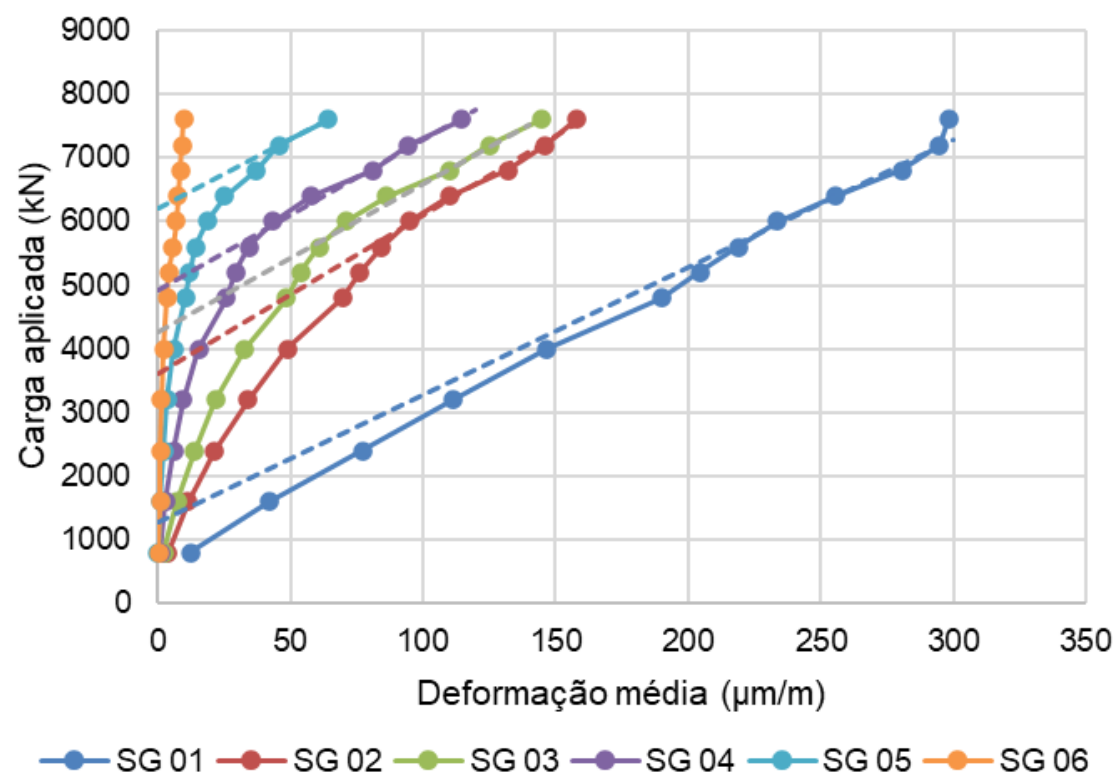

Figura 55: carga aplicada no topo da estaca em função da deformação média em cada nível de instrumentação para a prova de carga VdF_2.

Para esse ensaio, foi considerada carga de ponta da estaca igual à carga registrada no último nível de instrumentação, a $59 \mathrm{~m}$ de profundidade.

Através da interpolação polinomial dos valores das deformações, utilizando a Lei de Hooke, foram calculadas as forças atuantes em cada nível de instrumentação, em cada estágio. Esses valores estão apresentados na Tabela 28 e o diagrama de transferência de carga em profundidade está apresentado na Figura 56.

Pode-se observar que, nos trechos Topo-SG01 e SG01-02, ocorreu esgotamento do atrito lateral unitário, evidenciado pela inclinação constante dos trechos nos últimos estágios do ensaio. O trecho SG02-03, em comparação com os demais, apresentou um valor baixo de atrito lateral unitário. Já os trechos SG03-04 e 04-05 apresentaram valores mais altos de atrito lateral unitário, observado pelas linhas com inclinação mais abatida. No último nível de instrumentação, na carga máxima de ensaio, a força calculada foi equivalente a $3 \%$ da carga aplicada no topo da estaca, portanto, é coerente afirmar que a maior parte da carga aplicada no topo é mobilizada por atrito lateral, e a carga que chega na ponta real da estaca é muito baixa. 
Tabela 28: forças calculadas em cada nível (VdF_2).

\begin{tabular}{|c|c|c|c|c|c|c|}
\hline \multirow{2}{*}{ Carga no topo (kN) } & \multicolumn{7}{|c|}{ Força calculada (kN) } \\
\cline { 2 - 7 } & SG 01 & SG 02 & SG 03 & SG 04 & SG 05 & SG 06 \\
\hline 800 & 192 & 131 & 27 & 0 & 7 & 10 \\
\hline 1.600 & 992 & 254 & 198 & 104 & 10 & 26 \\
\hline 2.400 & 1.790 & 452 & 343 & 162 & 52 & 29 \\
\hline 3.200 & 2.586 & 725 & 501 & 215 & 99 & 34 \\
\hline 4.000 & 3.382 & 1.073 & 710 & 313 & 142 & 50 \\
\hline 4.800 & 4.177 & 1.496 & 1.008 & 505 & 200 & 82 \\
\hline 5.200 & 4.573 & 1.736 & 1.202 & 652 & 248 & 102 \\
\hline 5.600 & 4.970 & 1.994 & 1.432 & 839 & 318 & 126 \\
\hline 6.000 & 5.366 & 2.271 & 1.703 & 1.075 & 420 & 150 \\
\hline 6.400 & 5.762 & 2.566 & 2.021 & 1.365 & 566 & 174 \\
\hline 6.800 & 6.158 & 2.881 & 2.389 & 1.714 & 769 & 195 \\
\hline 7.200 & 6.553 & 3.214 & 2.812 & 2.130 & 1.043 & 212 \\
\hline 7.600 & 6.948 & 3.566 & 3.296 & 2.617 & 1.404 & 221 \\
\hline
\end{tabular}

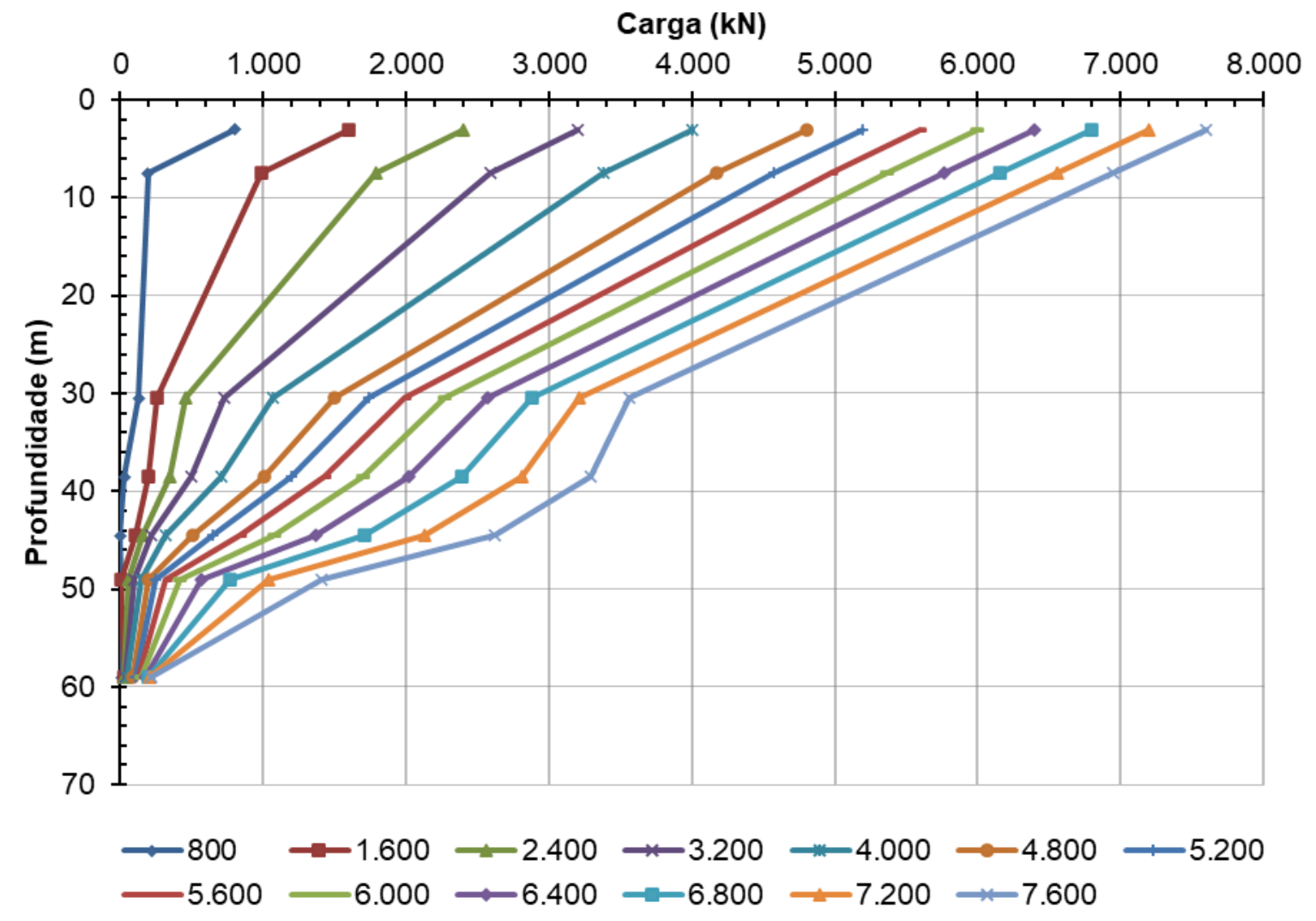

Figura 56: diagramas de transferência de carga para o ensaio VdF_2. 
Nas Figuras 57 a 62 encontram-se as funções de transferência de carga e as relações de Cambefort (1964) simplificadas para cada trecho. A Tabela 29 apresenta os parâmetros de Cambefort obtidos.

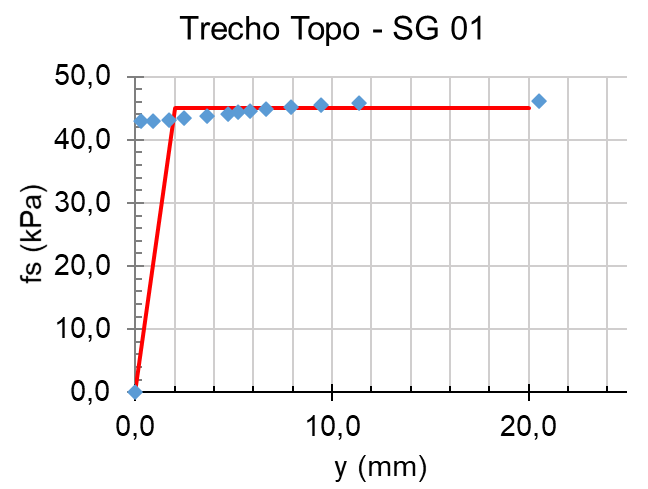

Figura 57: função de transferência de carga para o trecho topo - SG01 do ensaio VdF_2.

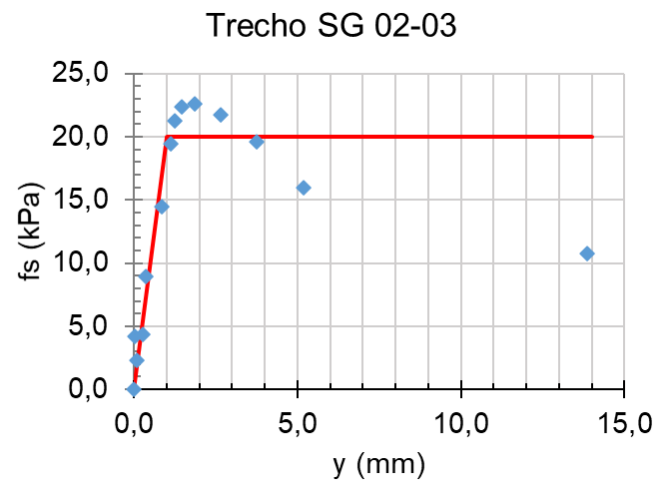

Figura 59: função de transferência de carga para o trecho SG02 - SG03 do ensaio VdF_2

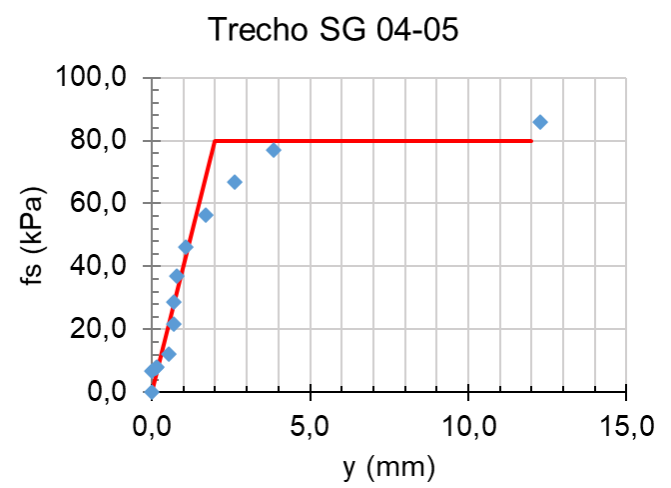

Figura 61: função de transferência de carga para o trecho SG04 - 05 do ensaio VdF_2.

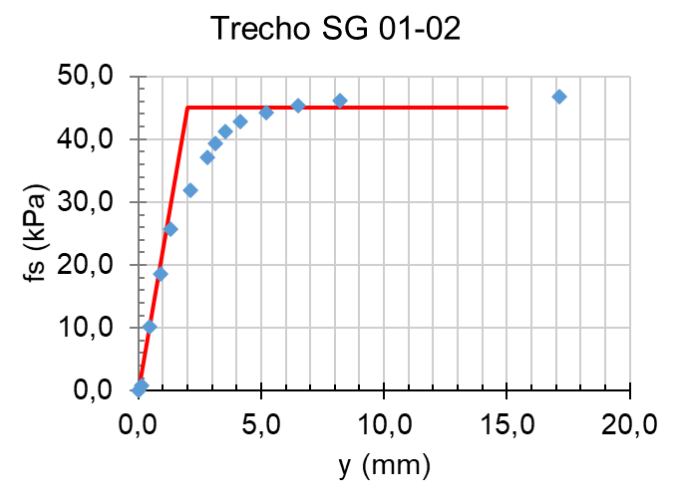

Figura 58: função de transferência de carga para o trecho SG01 - SG02 do ensaio VdF_2.

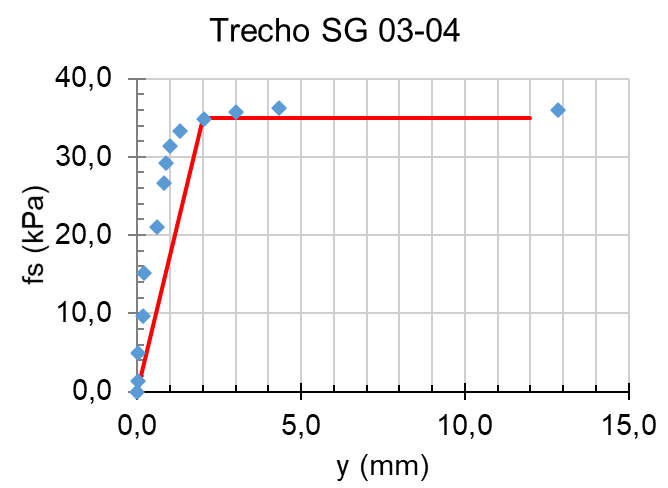

Figura 60: função de transferência de carga para o trecho SG03 - SG04 do ensaio VdF_2.

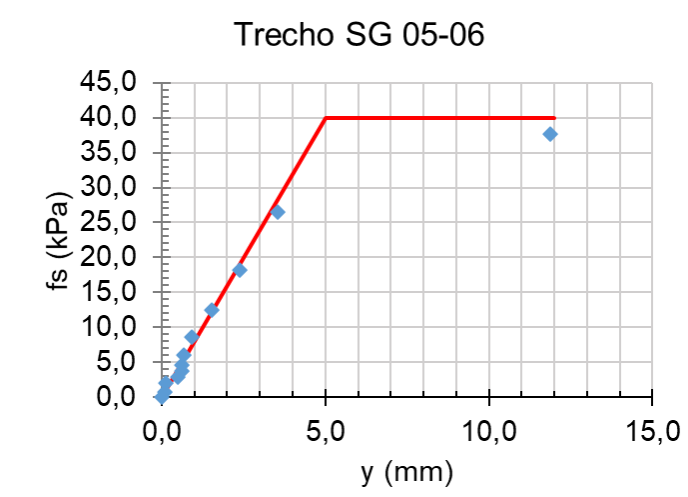

Figura 62: função de transferência de carga para o trecho SG05 - 06 do ensaio VdF_2. 
Tabela 29: parâmetros de Cambefort para o ensaio VdF_2.

\begin{tabular}{|c|c|c|c|c|}
\hline Trecho & Comprimento $\mathbf{( m )}$ & $\mathbf{f}_{\text {máx }} \mathbf{( k P a )}$ & $\mathbf{y} \mathbf{1}(\mathbf{m m})$ & $\mathbf{B} \mathbf{( k P a} / \mathbf{m m})$ \\
\hline Topo- SG 01 & 4,5 & 45 & 2,0 & 22,5 \\
\hline SG 01-02 & 23,0 & 45 & 2,0 & 22,5 \\
\hline SG 02-03 & 8,0 & 20 & 1,0 & 10,0 \\
\hline SG 03-04 & 6,0 & 35 & 2,0 & 17,5 \\
\hline SG 04-05 & 4,5 & 80 & 2,0 & 40,0 \\
\hline SG 05-06 & 10,0 & 40 & 5,0 & 8,0 \\
\hline
\end{tabular}

O trecho entre o topo da estaca e o primeiro nível consiste em 4,5 m de areia compacta. Os valores de $f_{\text {máx }}=45 \mathrm{kPa}$ e y $1=2,0 \mathrm{~mm}$ obtidos estão coerentes com os valores de areias holocênicas das Tabelas 2 e 3 . O trecho entre o primeiro e o segundo níveis contempla 16,4 m de argila SFL, 4,0 m de areia argilosa pouco compacta e mais 2,6 $\mathrm{m}$ de argila $S F L$ ao final. $O$ valor de $f_{\text {máx }}=45 \mathrm{kPa}$ observado é mais alto que o comumente observado para a argila SFL, provavelmente devido à influência da camada de areia holocênica. $O$ trecho entre os strain gages 02 e 03 é constituído metade por areia siltosa com SPT de 15 a 17 golpes e metade por argila AT. Nesse trecho, observa-se um comportamento estranho dos diagramas de transferência de carga - a inclinação das retas indica baixo valor de atrito lateral unitário em comparação com os demais, o que é corroborado pelo valor de fmáx de $20 \mathrm{kPa}$. Porém, esperava-se que a areia siltosa, com essa magnitude de SPT, em conjunto com a argila AT, apresentasse valores bem mais altos de atrito lateral unitário. Talvez tenha havido algum erro nas leituras, ou o perfil geotécnico no exato local da estaca seja um pouco diferente da sondagem. $O$ trecho entre os níveis 03 e 04 é constituído por areia siltosa com SPT de 24 a 33 golpes, e apresenta $f_{\text {máx }}$ de $35 \mathrm{kPa}$, um pouco abaixo do esperado. O trecho 04-05 apresenta apenas argila AT e o fmáx de $80 \mathrm{kPa}$ encontrado é coerente com os apresentados nas Tabelas 2 e 3 . É interessante observar que, no trecho entre os dois últimos níveis (05-06), o valor do atrito lateral unitário é relativamente baixo. Esse fato é coerente com a sondagem, que apresenta, nesse trecho, silte areno argiloso (solo residual) com valores baixos de SPT, de 6 e 7 golpes - o fmáx encontrado para esse trecho foi de $40 \mathrm{kPa}$, muito abaixo do esperado. Pela profundidade da camada, o valor de y1 mais alto observado $(5,0 \mathrm{~mm})$ é coerente com as Tabelas 2 e 3 para os sedimentos pleistocênicos. 
Aplicou-se o método de Coyle-Reese (1966) para obtenção da curva cargarecalque do topo da estaca considerando, para a carga na base do último elemento (trecho SG 05-06), a carga medida no último nível de instrumentação (SG 06) para o correspondente estágio da prova de carga, devido à proximidade da ponta da estaca. A curva resultante está ilustrada na Figura 63.

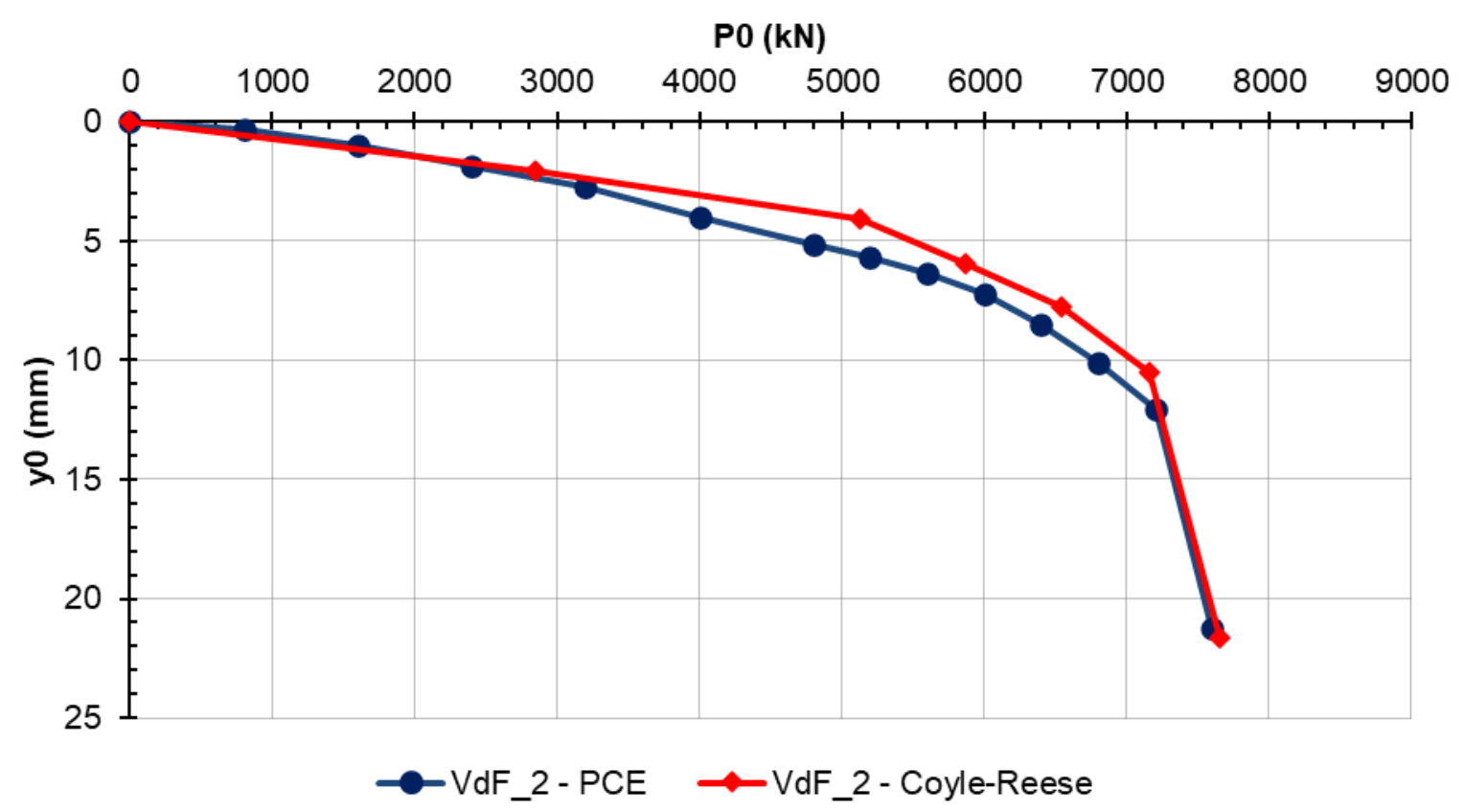

Figura 63: curva carga-recalque no topo da estaca obtida pelo método de Coyle-Reese (1966) para o ensaio VdF_2.

Constata-se boa aderência entre as curvas medida no ensaio e resultante da aplicação do método, principalmente no trecho acima de $7.000 \mathrm{kN}$, em que é observada a ruptura geotécnica. Na carga de trabalho da estaca $(3.900 \mathrm{kN})$, a curva teórica apresentou um deslocamento um pouco menor que o real.

\subsubsection{Corp_1}

A estaca de $1 \mathrm{~m}$ de diâmetro e $60 \mathrm{~m}$ de comprimento foi instrumentada em profundidade com strain gages em seis níveis. O último nível de strain gage encontrase aos 55,9 m de profundidade, ou seja, 4,1 $\mathrm{m}$ acima da ponta da estaca. $\mathrm{O}$ ensaio atingiu $6.800 \mathrm{kN}$ e, nesse estágio, observou-se torção das vigas do sistema de reação. 
Por segurança, optou-se por interromper o ensaio, proceder ao descarregamento da estaca, e reensaiá-la depois de alguns dias (ensaio Corp_2 apresentado mais adiante).

Os valores de deformação medidos no ensaio estão apresentados na Tabela 29, a aplicação do Método do Módulo Tangente de Fellenius (1989) modificado por Massad (2009-b) está ilustrada na Figura 64, e os dados da instrumentação e valores de ES obtidos estão apresentados na Tabela 31.

Tabela 30: leituras de deformação obtidas através dos strain gages (Corp_1).

\begin{tabular}{|c|c|c|c|c|c|c|}
\hline \multirow{2}{*}{ Carga no topo (kN) } & \multicolumn{7}{|c|}{ Deformação medida $(\boldsymbol{\mu \varepsilon})$} \\
\cline { 2 - 7 } & SG 01 & SG 02 & SG 03 & SG 04 & SG 05 & SG 06 \\
\hline 800 & 14,2 & 6,2 & 4,8 & 4,2 & 1,5 & 1 \\
\hline 1.600 & 46 & 22,9 & 14,2 & 9,2 & 6 & 2,1 \\
\hline 2.400 & 82,1 & 39,2 & 22,5 & 15,6 & 10,6 & 2,3 \\
\hline 3.200 & 107,7 & 53,5 & 31,3 & 19,8 & 15,2 & 4 \\
\hline 4.000 & 144,4 & 73,5 & 45 & 31,3 & 22,3 & 4 \\
\hline 4.800 & 192,9 & 100,8 & 68,8 & 46,3 & 34,6 & 7,1 \\
\hline 5.200 & 222,3 & 120,8 & 81,5 & 57,1 & 40,4 & 7,9 \\
\hline 5.600 & 237,3 & 137,1 & 91,9 & 63,1 & 45,6 & 8,7 \\
\hline 6.000 & 258,8 & 150,4 & 105,2 & 72,9 & 52,3 & 10,2 \\
\hline 6.400 & 278,5 & 170,2 & 122,5 & 83,5 & 61,5 & 10,8 \\
\hline 6.800 & 277,1 & 194 & 147,9 & 102,3 & 76,9 & 16,3 \\
\hline
\end{tabular}

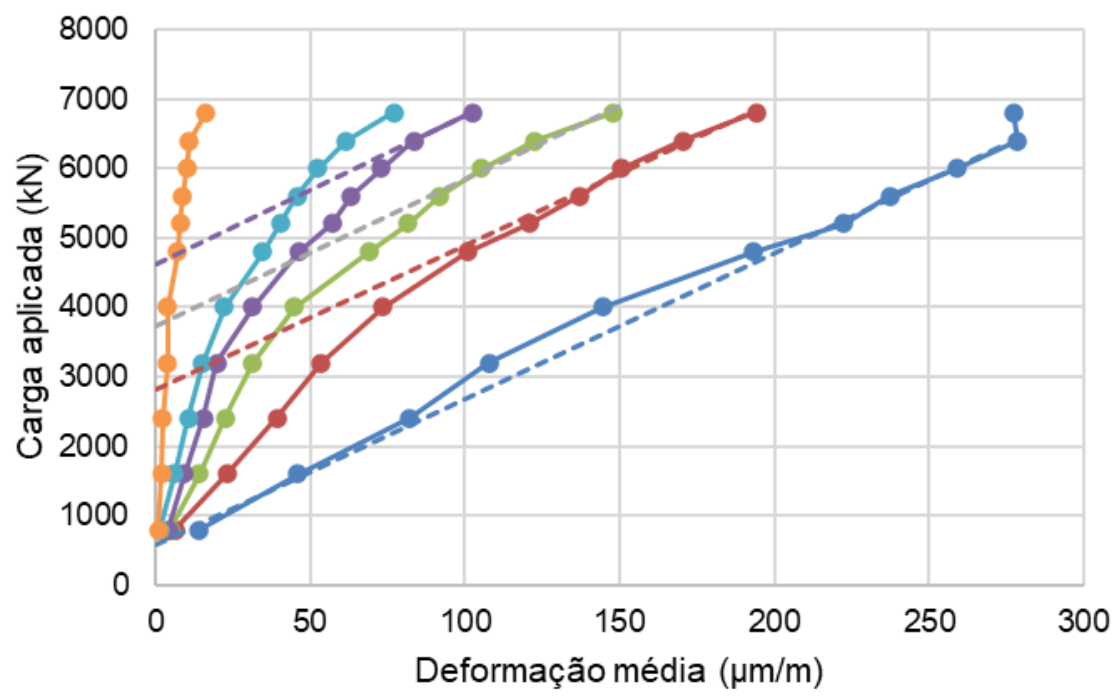

$\multimap$ SG $01 \multimap$ SG $02 \multimap$ SG $03 \multimap$ SG $04 \multimap$ SG $05 \multimap$ SG 06

Figura 64: carga aplicada no topo da estaca em função da deformação média em cada nível de instrumentação para a prova de carga Corp_1. 
Tabela 31: dados da instrumentação e valores de ES obtidos pelo Método do Módulo Tangente de Fellenius (1989) modificado por Massad (2009-b) para o ensaio Corp_1.

\begin{tabular}{|c|c|c|c|}
\hline Nível & Profundidade (m) & $\begin{array}{c}\text { Quantidade de } \\
\text { sensores úteis }\end{array}$ & ES (GN) \\
\hline SG 01 & 8,9 & 2 & 20,9 \\
\hline SG 02 & 24,0 & 2 & 20,7 \\
\hline SG 03 & 31,9 & 2 & 21,1 \\
\hline SG 04 & 36,9 & 2 & 21,3 \\
\hline SG 05 & 45,6 & 2 & - \\
\hline SG 06 & 55,9 & 2 & - \\
\hline
\end{tabular}

O valor de ES adotado na análise foi igual à média dos valores dos níveis 1 a 4: $21,0 \mathrm{GN}$.

Para a determinação das funções de transferência de carga, foi admitida carga zero na ponta da estaca, possibilitando a determinação do trecho SG 06-P.

As forças em cada nível de instrumentação foram calculadas através da aplicação da Lei de Hooke aos valores de deformação, interpolados por funções polinomiais. Os valores estão apresentados na Tabela 32 e o diagrama de transferência de carga em profundidade está ilustrado na Figura 65.

No último estágio de carregamento, correspondente a $6.800 \mathrm{kN}$ de carga aplicada no topo da estaca, a força calculada no último nível de instrumentação corresponde a 4,8\% desse valor. Os trechos SG 01-02 e 02-03 apresentam valores muito próximos de atrito lateral unitário, observado pela quase continuidade das linhas referentes a esses trechos.

Tabela 32: forças calculadas em cada nível (Corp_1).

\begin{tabular}{|c|c|c|c|c|c|c|}
\hline \multirow{2}{*}{ Carga no topo (kN) } & \multicolumn{7}{|c|}{ Força calculada (kN) } \\
\cline { 2 - 7 } & SG 01 & SG 02 & SG 03 & SG 04 & SG 05 & SG 06 \\
\hline 800 & 238 & 208 & 184 & 135 & 28 & 25 \\
\hline 1.600 & 953 & 423 & 239 & 164 & 127 & 33 \\
\hline 2.400 & 1691 & 727 & 391 & 264 & 223 & 55 \\
\hline 3.200 & 2452 & 1122 & 642 & 433 & 335 & 80 \\
\hline 4.000 & 3235 & 1607 & 990 & 673 & 483 & 104 \\
\hline 4.800 & 4040 & 2182 & 1437 & 982 & 688 & 133 \\
\hline 5.200 & 4451 & 2503 & 1696 & 1164 & 817 & 152 \\
\hline 5.600 & 4867 & 2847 & 1981 & 1362 & 968 & 178 \\
\hline 6.000 & 5290 & 3213 & 2289 & 1579 & 1142 & 213 \\
\hline 6.400 & 5717 & 3602 & 2623 & 1812 & 1343 & 260 \\
\hline 6.800 & 6151 & 4013 & 2980 & 2064 & 1573 & 323 \\
\hline
\end{tabular}




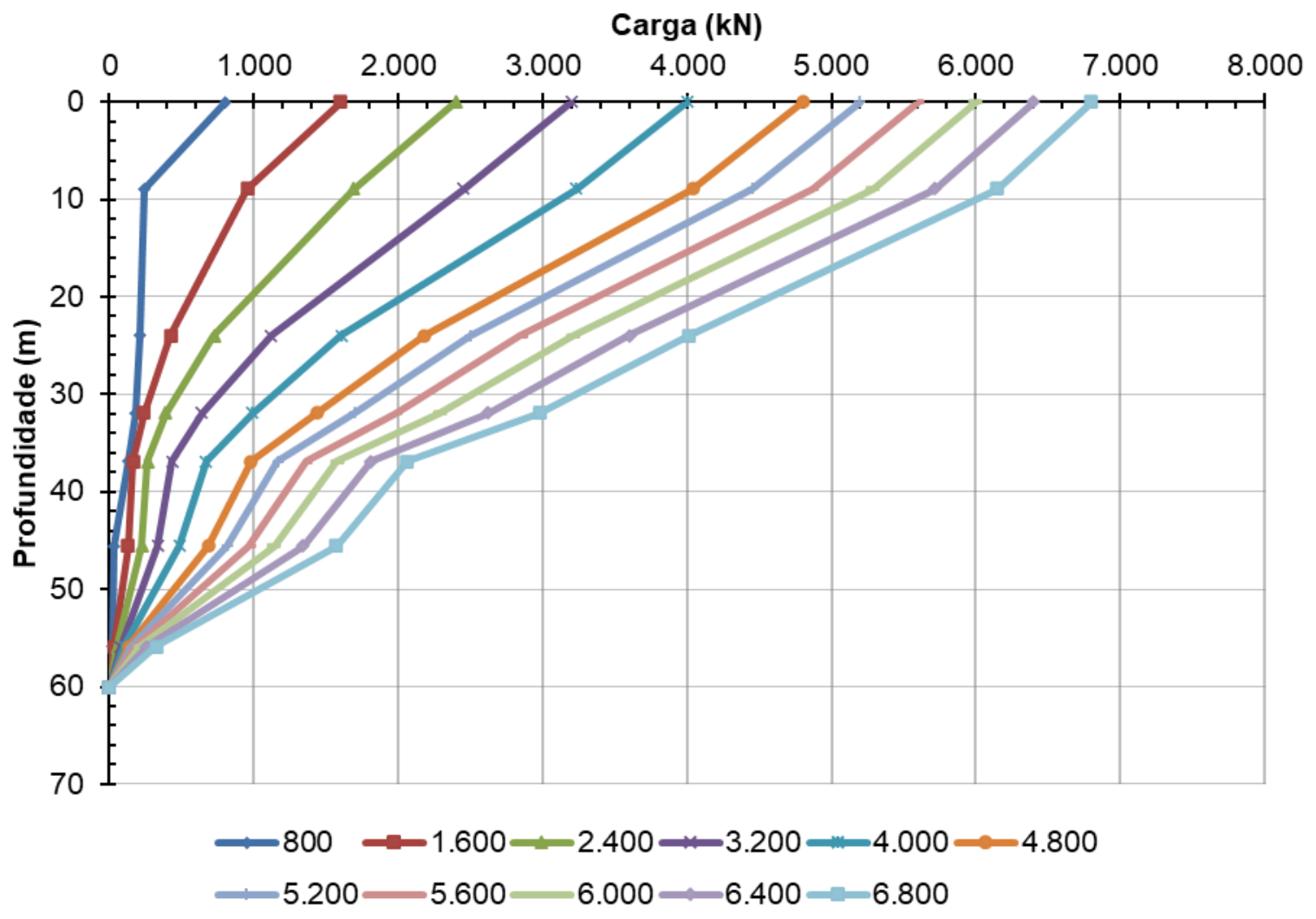

Figura 65: diagramas de transferência de carga para o ensaio Corp_1.

As Figuras 66 a 72 apresentam as funções de transferência de carga e as relações de Cambefort (1964) simplificadas para cada trecho entre níveis de instrumentação. Na Tabela 33 estão apresentados os parâmetros de Cambefort obtidos.

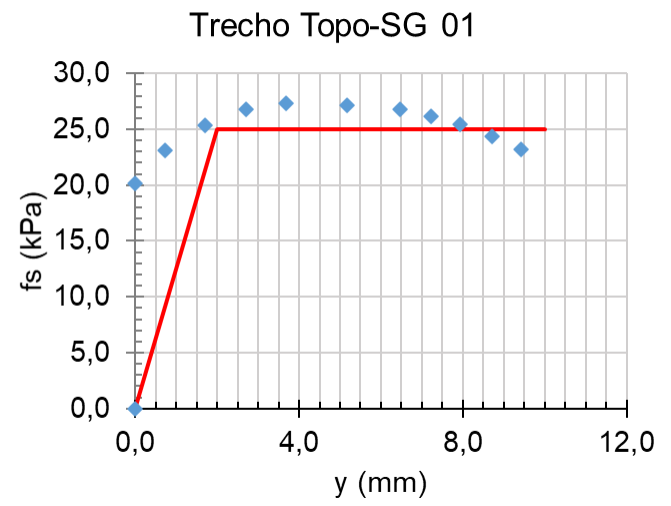

Figura 66: função de transferência de carga para o trecho topo-SG01 do ensaio Corp_1.

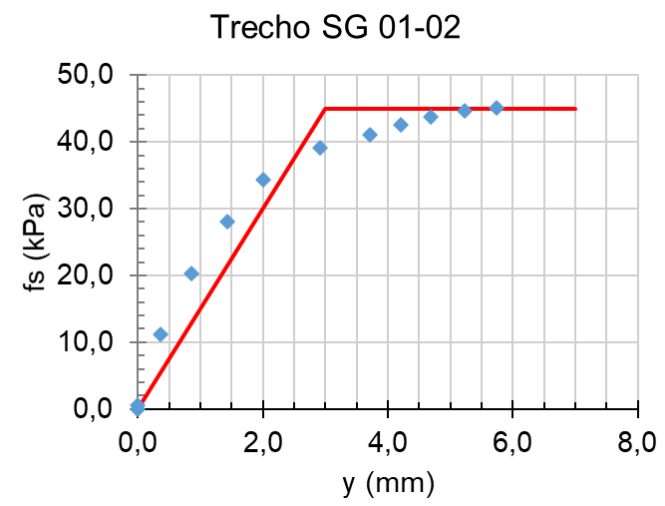

Figura 67: função de transferência de carga para o trecho SG01-SG02 do ensaio Corp_1. 
Trecho SG 02-03

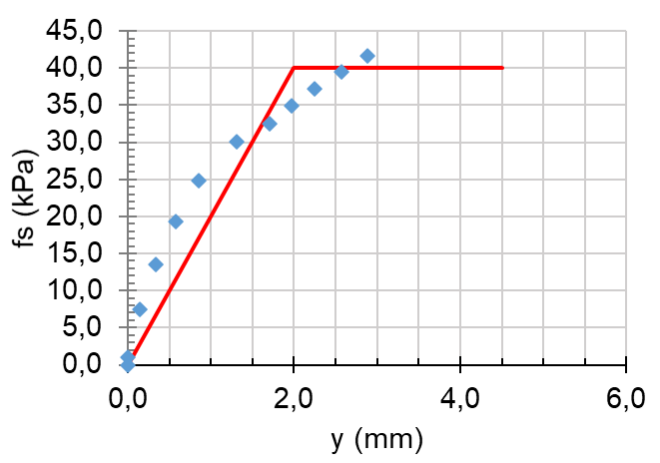

Figura 68: função de transferência de carga para o trecho SG02-SG03 do ensaio Corp_1. Trecho SG 04-05

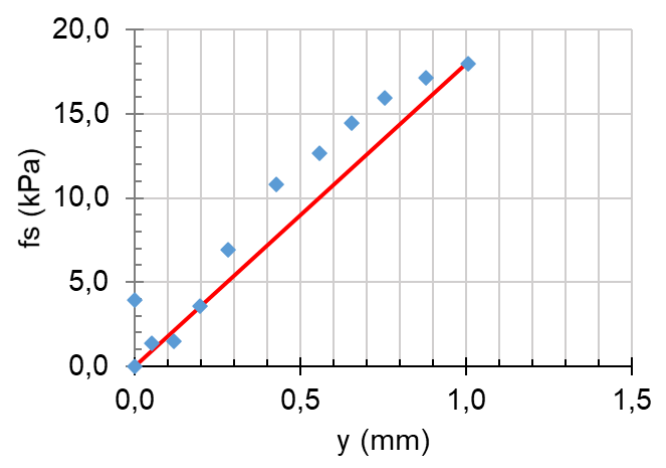

Figura 70: função de transferência de carga para o trecho SG04-05 do ensaio Corp_1.

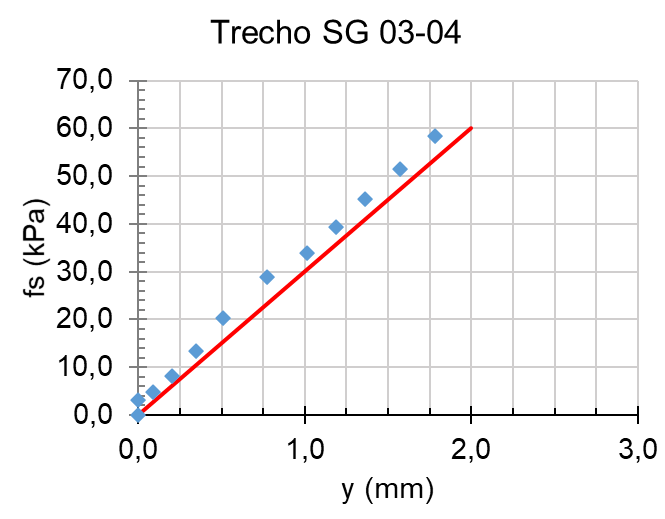

Figura 69: função de transferência de carga para o trecho SG03-SG04 do ensaio Corp_1.

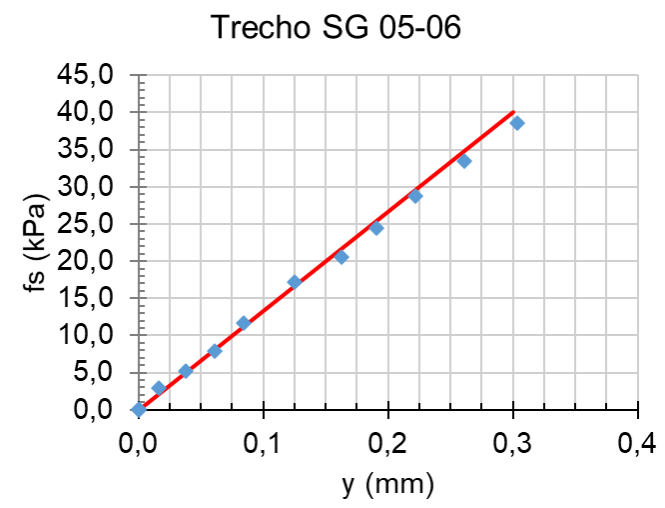

Figura 71: função de transferência de carga para o trecho SG05-06 do ensaio Corp_1.

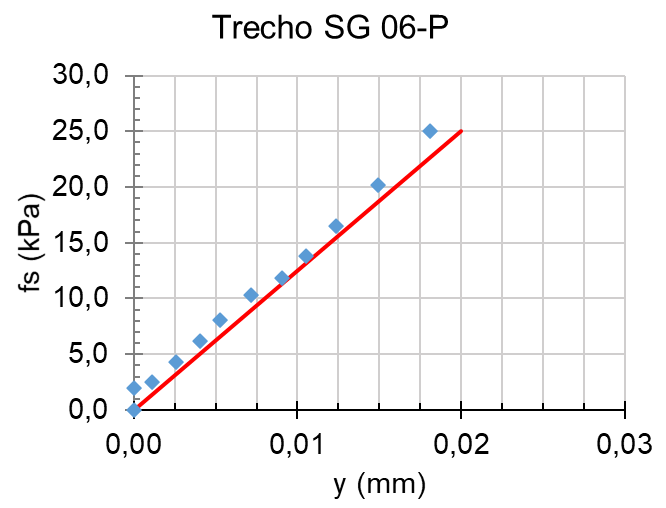

Figura 72: função de transferência de carga para o trecho SG06-P do ensaio Corp_1. 
Tabela 33: parâmetros de Cambefort para o ensaio Corp_1.

\begin{tabular}{|c|c|c|c|c|}
\hline Trecho & Comprimento (m) & $\mathbf{f}_{\text {máx }} \mathbf{( k P a )}$ & $\mathbf{y}$ ( $\mathbf{( m m})$ & $\mathbf{B}(\mathbf{k P a} / \mathbf{m m})$ \\
\hline Topo - SG 01 & 8,9 & 25 & 2,0 & 12,5 \\
\hline SG 01-02 & 15,1 & 45 & 3,0 & 15,0 \\
\hline SG 02-03 & 7,9 & 40 & 2,0 & 20,0 \\
\hline SG 03-04 & 5,0 & - & - & 30,0 \\
\hline SG 04-05 & 8,7 & - & - & 18,0 \\
\hline SG 05-06 & 10,3 & - & - & 133,33 \\
\hline SG 06-P & 4,1 & - & - & 1250,0 \\
\hline
\end{tabular}

A prova de carga estática apresentou valores baixos de deslocamento no topo da estaca, atingindo o máximo de 11,2 mm na carga máxima de ensaio de $6.800 \mathrm{kN}$. Esses baixos valores de carga e deslocamento no topo da estaca refletiram-se nas deformações em profundidade e, consequentemente, nas funções de transferência de carga. Observou-se esgotamento do atrito lateral unitário máximo apenas nos três primeiros trechos, ou seja, até os 31,9 m de profundidade da estaca. Abaixo disso, não foi possível determinar os parâmetros de Cambefort, e as funções de transferência de carga contemplam uma gama muito baixa de valores de y.

No trecho inicial da estaca, entre o topo e o primeiro nível de instrumentação, há a ocorrência de camada de areia siltosa. $O$ valor de fmáx $=25 \mathrm{kPa}$ obtido está abaixo do esperado para esse tipo de solo, de acordo com as Tabelas 2 e 3. Já o valor de $y_{1}$ = 2,0 mm está coerente com o esperado. Entre os níveis 2 e 3, observa-se camada de argila SFL, e tanto o valor de $f_{\text {máx }}=45 \mathrm{kPa}$ quanto $\mathrm{y}_{1}=3,0 \mathrm{~mm}$ obtidos para esse trecho estão acima do esperado. O trecho 02-03, último em que houve esgotamento do atrito lateral unitário, consiste em camada de areia argilosa, e os valores obtidos de $f_{\text {máx }}=40 \mathrm{kPa}$ e $\mathrm{y}_{1}=2,0 \mathrm{~mm}$ estão coerentes com os valores das areias holocênicas observados nas Tabelas 2 e 3.

Utilizando os parâmetros de Cambefort da Tabela 32, a curva carga-recalque no topo da estaca foi estimada com o método de Coyle-Reese, conforme apresentada na Figura 73. 


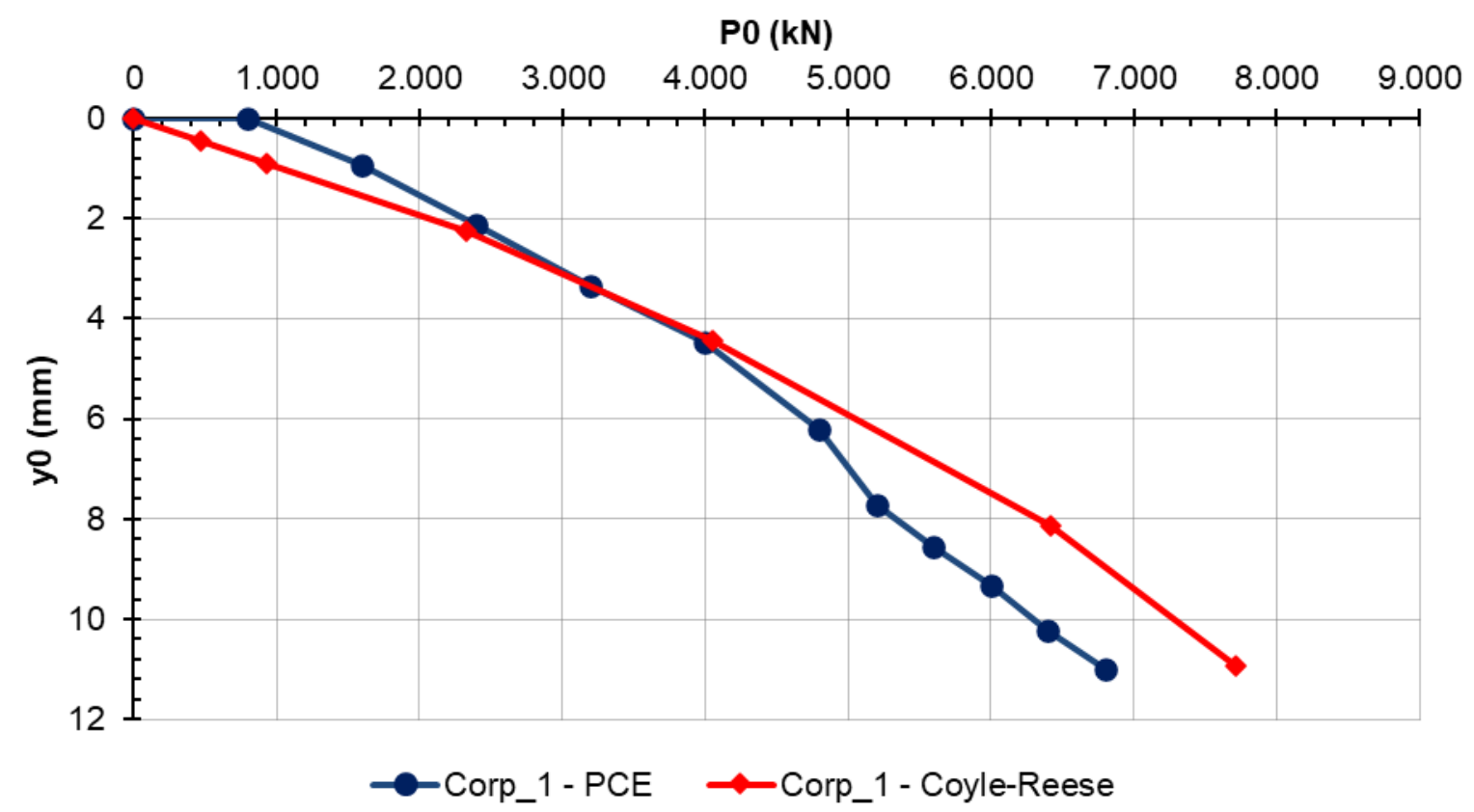

Figura 73: curva carga-recalque no topo da estaca obtida pelo método de Coyle-Reese (1966) para o ensaio Corp_1.

Observa-se que, até a carga de trabalho da estaca, a curva calculada apresenta valores de deslocamento um pouco maiores que a curva real do ensaio, mas elas apresentam certa aderência. A partir de cerca de 4.000 kN, a curva calculada apresenta valores menores de deslocamento. Provavelmente, isso se deve ao fato de, para as camadas a partir do SG 03, a curva ter sido estimada apenas com o parâmetro $B$ da 1ํㅡㄴ Lei de Cambefort, sem a consideração do patamar de esgotamento do atrito lateral unitário.

\subsubsection{Corp_2}

Como o ensaio Corp_1 foi interrompido no estágio de 6.800 kN, com valores baixos de deslocamento no topo, decidiu-se repetir o ensaio na mesma estaca alguns dias depois para avaliar as deformações medidas pelos strain gages e o comportamento da estaca com o recarregamento.

Os valores de deformação medidos nesse ensaio estão apresentados na Tabela 34 a seguir. 
Tabela 34: leituras de deformação obtidas através dos strain gages (Corp_2).

\begin{tabular}{|c|c|c|c|c|c|c|}
\hline \multirow{2}{*}{ Carga no topo (kN) $)$} & \multicolumn{7}{|c|}{ Deformação medida $(\boldsymbol{\mu} \boldsymbol{\varepsilon})$} \\
\cline { 2 - 7 } & SG 01 & SG 02 & SG 03 & SG 04 & SG 05 & SG 06 \\
\hline 800 & 14,4 & 5,6 & 3,3 & 1,3 & 1,2 & 0,8 \\
\hline 1.600 & 42,9 & 19,4 & 10,8 & 6 & 1,9 & 1,9 \\
\hline 2.400 & 72,1 & 33,3 & 18,36 & 12,5 & 4,4 & 2,1 \\
\hline 3.200 & 106,2 & 51,7 & 28,7 & 19,8 & 6,3 & 3,8 \\
\hline 4.000 & 127,7 & 64,4 & 36,2 & 24,2 & 9 & 3,8 \\
\hline 4.800 & 160,8 & 82,3 & 46,3 & 33,5 & 12,3 & 6,9 \\
\hline 5.200 & 186 & 97,5 & 54,6 & 40,6 & 16,2 & 7,7 \\
\hline 5.600 & 204,8 & 109,6 & 63,7 & 45,2 & 19,2 & 8,5 \\
\hline 6.000 & 227,3 & 122,7 & 74,4 & 52,3 & 22,7 & 10 \\
\hline 6.400 & 239,2 & 131,7 & 81,2 & 57,1 & 25,2 & 10,6 \\
\hline 6.800 & 252,1 & 141,7 & 89,4 & 63,5 & 27,7 & 11,5 \\
\hline 7.200 & 266 & 155,4 & 101,5 & 71,9 & 31,9 & 12,3 \\
\hline 7.600 & 283,8 & 176,2 & 120,8 & 86,3 & 40,2 & 15 \\
\hline 8.000 & 341,3 & 226,5 & 174,2 & 123,7 & 64,2 & 4,4 \\
\hline
\end{tabular}

A Figura 74 ilustra o gráfico de carga aplicada no topo $x$ deformação em cada nível, de acordo com os valores da Tabela 34, e a aplicação do Método do Módulo Tangente de Fellenius (1989) modificado por Massad (2009-b) para o ensaio.

Observa-se que só foi possível determinar os valores de ES para os três primeiros níveis de instrumentação, o que não é coerente com o ensaio anterior, no qual foi possível determinar ES até o nível SG 04. Além disso, o ensaio Corp_2 apresentou deslocamentos no topo da estaca muito baixos, inferiores aos observados para Corp_1 - na carga máxima de ensaio, de $8.000 \mathrm{kN}$, a estaca deslocou apenas $10,29 \mathrm{~mm}$. Isso ocorre porque, como a estaca foi submetida a um carregamento anterior (Corp_1), ela já apresenta um valor de deformação residual (plástica), e existem tensões residuais ao longo do fuste.

Ao proceder com a metodologia do trabalho, no cálculo dos diagramas e das funções de transferência de carga para o ensaio, devido às inconsistências apresentadas anteriormente, não se chegou a resultados satisfatórios. Por esse motivo, decidiu-se desprezar o ensaio Corp_2. 


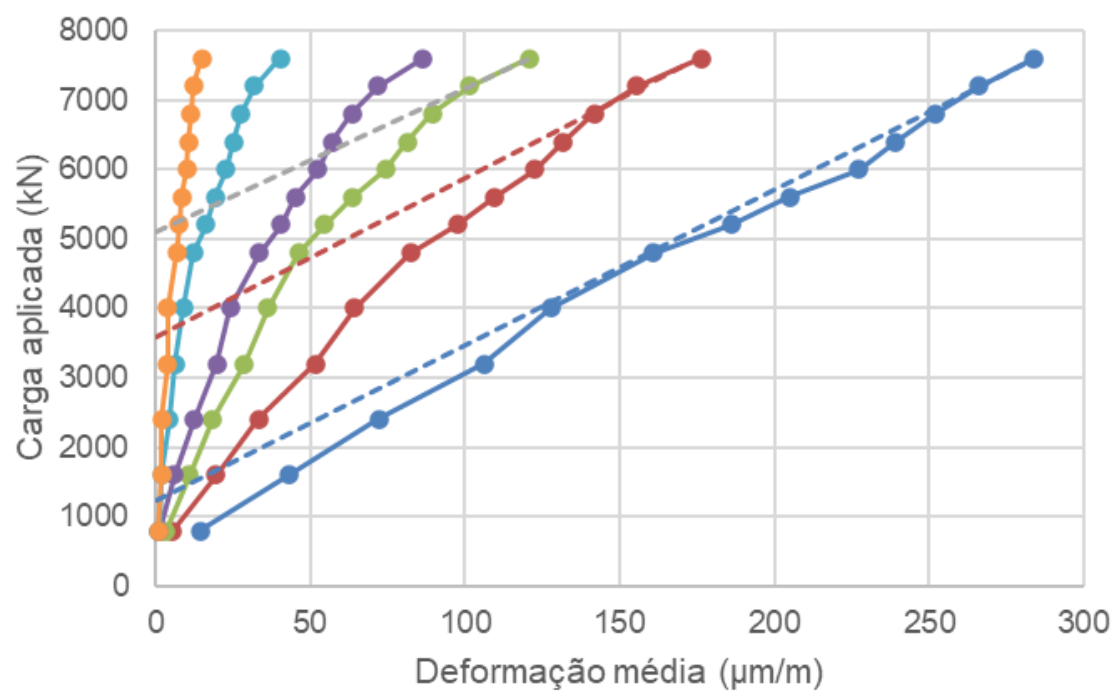

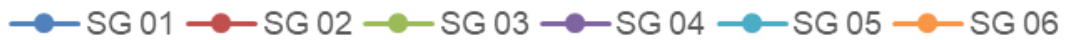

Figura 74: carga aplicada no topo da estaca em função da deformação média em cada nível de instrumentação para a prova de carga Corp_2.

\subsubsection{Trin}

A estaca ensaiada foi instrumentada com strain gages em quatro níveis. Como a estaca foi executada com $58,3 \mathrm{~m}$ de comprimento, o comprimento abaixo do último nível de instrumentação é de $26,8 \mathrm{~m}$. As leituras de deformação estão apresentadas na Tabela 35.

Tabela 35: leituras de deformação obtidas através dos strain gages (Trin).

\begin{tabular}{|c|c|c|c|c|}
\hline \multirow{2}{*}{ Carga no topo (kN) $)$} & \multicolumn{4}{|c|}{ Deformação medida $(\boldsymbol{\mu \varepsilon})$} \\
\cline { 2 - 5 } & SG 01 & SG 02 & SG 03 & SG 04 \\
\hline 0 & 0,0 & $-1,0$ & 0,0 & 0,1 \\
\hline 848 & 39,4 & 6,6 & 11,0 & $-18,5$ \\
\hline 1558 & 96,5 & 41,8 & 28,4 & $-35,9$ \\
\hline 2446 & 156,4 & 34,6 & 51,4 & $-5,3$ \\
\hline 3156 & 202,3 & 76,3 & 72,2 & $-3,0$ \\
\hline 4044 & 262,2 & 127,5 & 101,2 & $-3,0$ \\
\hline 4754 & 299,5 & 155,8 & 126,0 & 26,7 \\
\hline 5642 & 370,1 & 220,6 & 185,4 & 80,5 \\
\hline 6352 & 411,1 & 250,0 & 217,9 & 109,2 \\
\hline 7240 & 461,6 & 292,1 & 253,8 & 154,8 \\
\hline 8120 & 533,6 & 344,2 & 298,0 & 223,7 \\
\hline 8120 & 535,4 & 410,4 & 296,1 & 213,4 \\
\hline
\end{tabular}


Com base nesses dados foi construída a Figura 75 e preparada a Tabela 36, que resume algumas informações e os valores de ES encontrados.

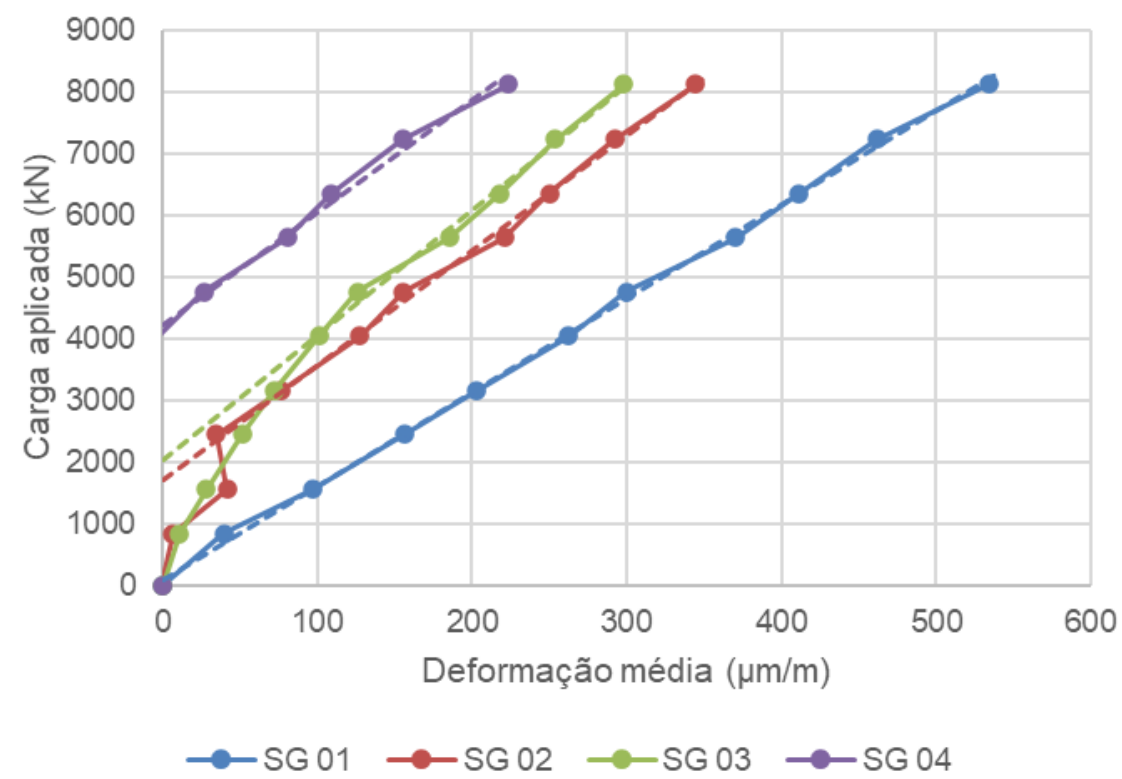

Figura 75: carga aplicada no topo da estaca em função da deformação média em cada nível de instrumentação para a prova de carga Trin.

Tabela 36: dados da instrumentação e valores de ES obtidos pelo Método do Módulo Tangente de Fellenius (1989) modificado por Massad (2009-b) para o ensaio Trin.

\begin{tabular}{|c|c|c|c|}
\hline Nível & Profundidade $(\mathbf{m})$ & $\begin{array}{c}\text { Quantidade de } \\
\text { sensores úteis }\end{array}$ & ES (GN) \\
\hline SG 01 & 1,50 & 2 & 15,2 \\
\hline SG 02 & 11,00 & 3 & 18,6 \\
\hline SG 03 & 19,50 & 1 & 20,3 \\
\hline SG 04 & 31,50 & 2 & 18,3 \\
\hline
\end{tabular}

Foi considerado na análise o respectivo valor de ES para cada trecho entre níveis de instrumentação.

Para a obtenção das funções de transferência de carga, as seguintes hipóteses e simplificações foram admitidas:

- foi considerada carga zero na ponta real da estaca, possibilitando a determinação do trecho SG 04-P; 
- o último trecho da estaca (SG 04-P), com 26,8 m de comprimento, foi considerado como a "ponta fictícia" da estaca.

A Figura 76 apresenta a distribuição das cargas em profundidade para todos os estágios de carregamento. Observa-se, pela inclinação das retas correspondentes ao primeiro trecho entre níveis de instrumentação, que o atrito lateral unitário máximo foi mais alto nesse trecho do que no segundo, o que é corroborado a seguir pelas funções de transferência de carga. No segundo nível de strain gages, observa-se que a deformação medida no terceiro estágio de aplicação de carga, correspondente a $2.446 \mathrm{kN}$, é menor que a medida no estágio anterior, de $1.558 \mathrm{kN}$, provavelmente devido a um erro de leitura da instrumentação. No quarto nível de instrumentação, antes do 6º estágio de aplicação de carga $(4.754 \mathrm{kN})$, as leituras acusavam valores negativos de deformação, que foram considerados iguais a zero.

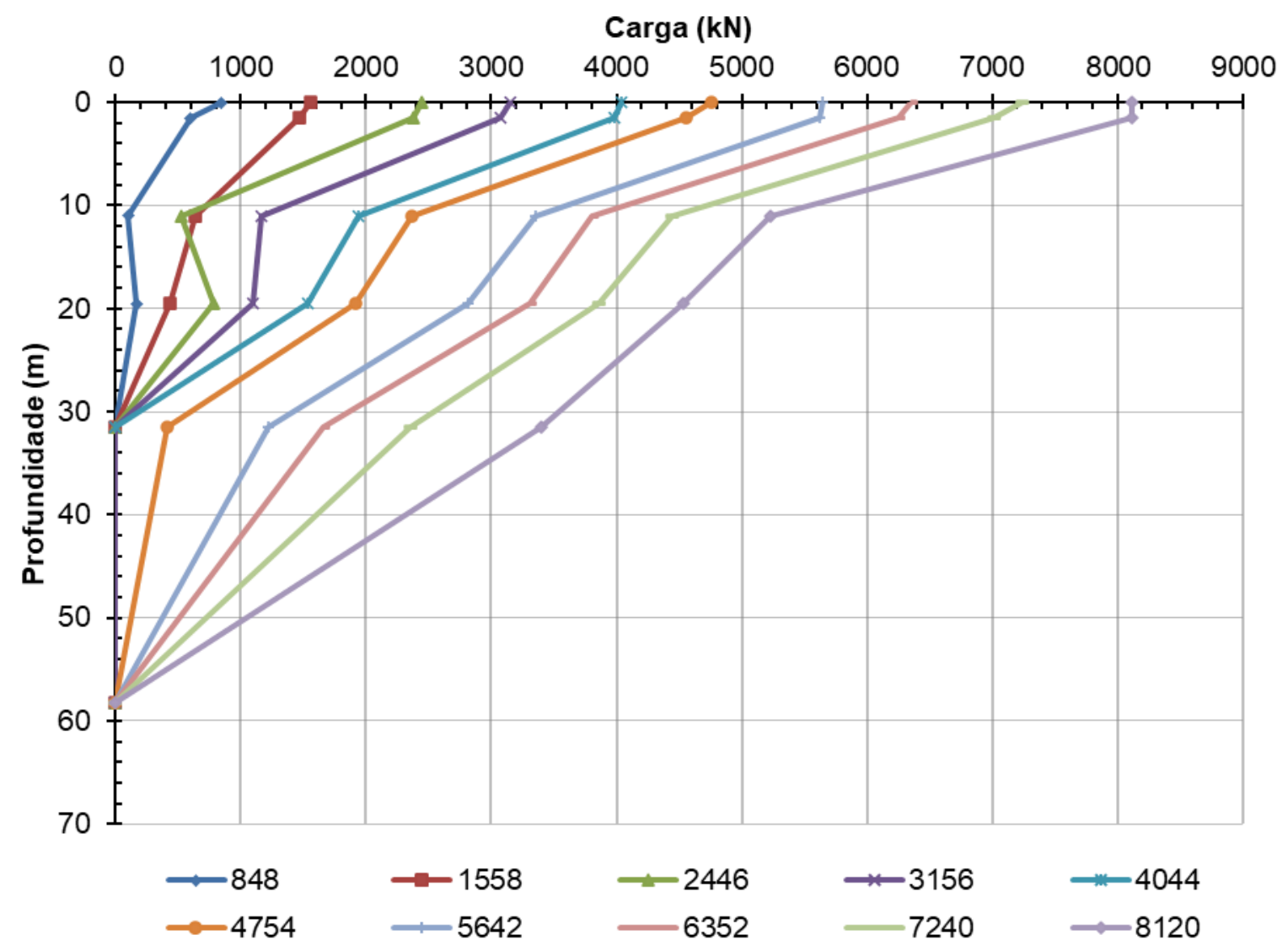

Figura 76: diagramas de transferência de carga em profundidade do ensaio Trin. 
Nas Figuras 77 a 80 encontram-se as funções de transferência de carga e as relações de Cambefort simplificadas para cada trecho. A Tabela 37 apresenta os parâmetros de Cambefort obtidos.

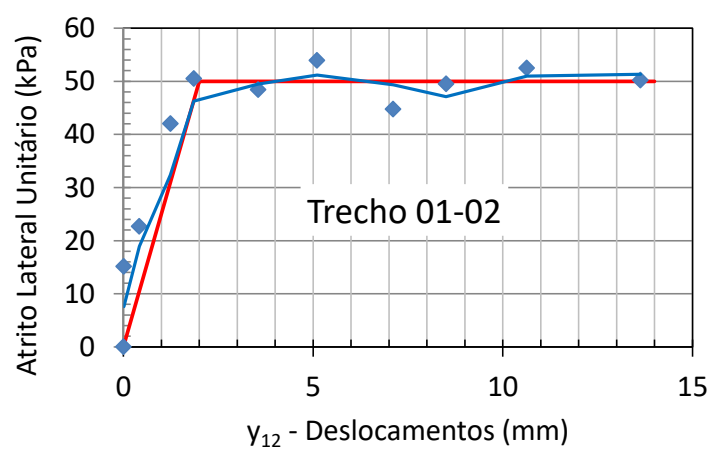

Figura 77: função de transferência de carga para o trecho SG 01-02 do ensaio Trin.

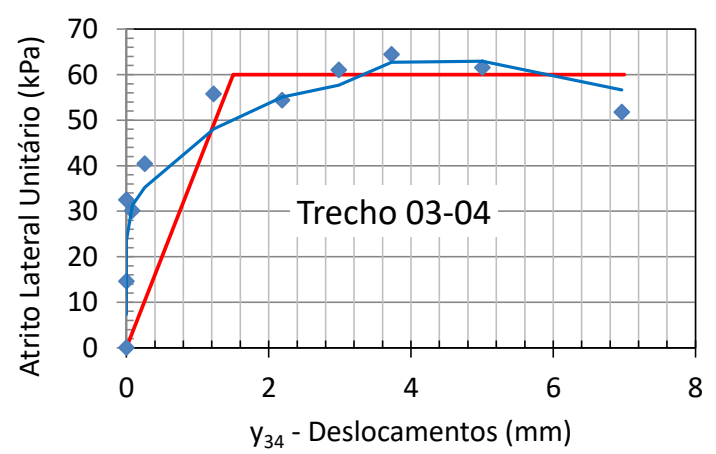

Figura 79: função de transferência de carga para o trecho SG 03-04 do ensaio Trin.

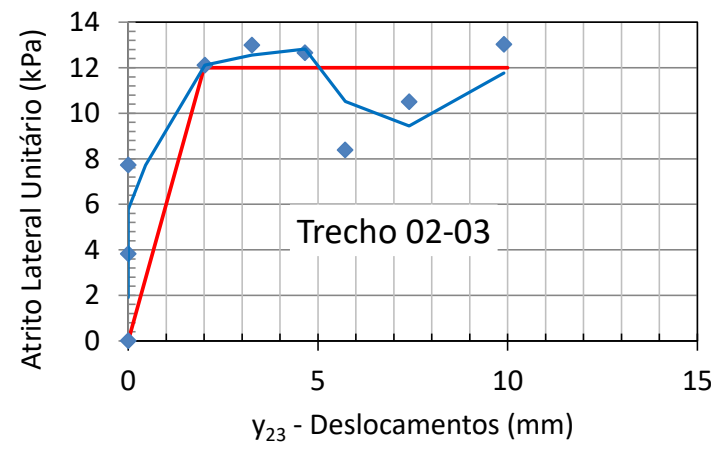

Figura 78: função de transferência de carga para o trecho SG 02-03 do ensaio Trin.

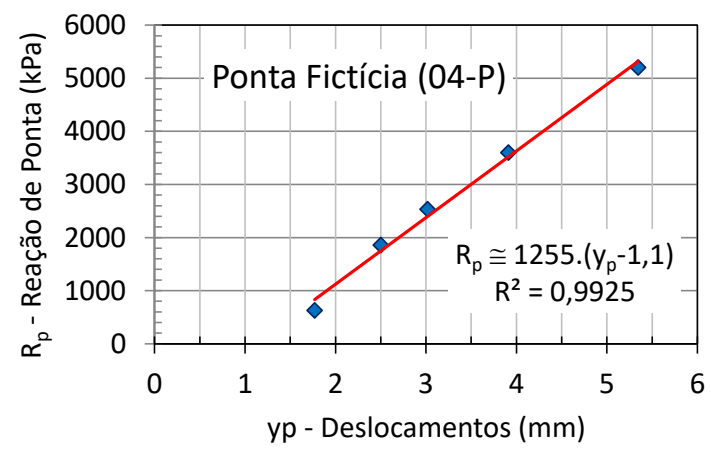

Figura 80: função de transferência de carga para o trecho SG 04-P (ponta fictícia) do ensaio Trin.

Tabela 37: parâmetros de Cambefort para o ensaio Trin.

\begin{tabular}{|c|c|c|c|c|}
\hline Trecho & Comprimento $(\mathbf{m})$ & $\mathbf{f}_{\text {máx }}(\mathbf{k P a})$ & $\mathbf{y} \mathbf{( \mathbf { m m } )}$ & $\mathbf{B}(\mathbf{k P a} / \mathbf{m m})$ \\
\hline SG 01-02 & 9,5 & 50 & 2,0 & 25,0 \\
\hline SG 02-03 & 8,5 & 12 & 2,0 & 6,0 \\
\hline SG 03-04 & 12,0 & 60 & 1,5 & 40,0 \\
\hline
\end{tabular}


No trecho entre os dois primeiros níveis de instrumentação, observa-se camada de areia fina pouco siltosa compacta. Os valores de $\mathrm{y}_{1}=2,0 \mathrm{~mm}$ e $\mathrm{f}_{\text {máx }}=50 \mathrm{kPa}$ são consistentes com valores da literatura obtidos de outros ensaios, como os da Ponte sobre o Mar Pequeno (Tabelas 2 e 3). No trecho entre os níveis 02 e 03, observa-se presença exclusiva de argila SFL. O valor de $\mathrm{y}_{1}=2,0 \mathrm{~mm}$ é consistente com valores da literatura, porém, o valor de $f_{\text {máx }}=12 \mathrm{kPa}$ está ligeiramente abaixo do esperado. Isso pode ser explicado pelo efeito de "estaca T" conceituado por Massad (2009-b), em que a camada superficial de areia compacta, sob efeito do carregamento da estaca, exerce pressão sobre a camada de argila mole subjacente, diminuindo o atrito lateral unitário no topo dessa camada. No trecho 03-04 observa-se alternância de camadas de argila SFL e areia silto argilosa, resultando em valores mais elevados de $f_{\text {máx. }}$

A Figura 81 mostra o resultado da aplicação do método de Coyle-Reese (1966) à prova de carga Trin, utilizando os parâmetros da Tabela 36. Constata-se excelente aderência entre as curvas teórica e real do ensaio.

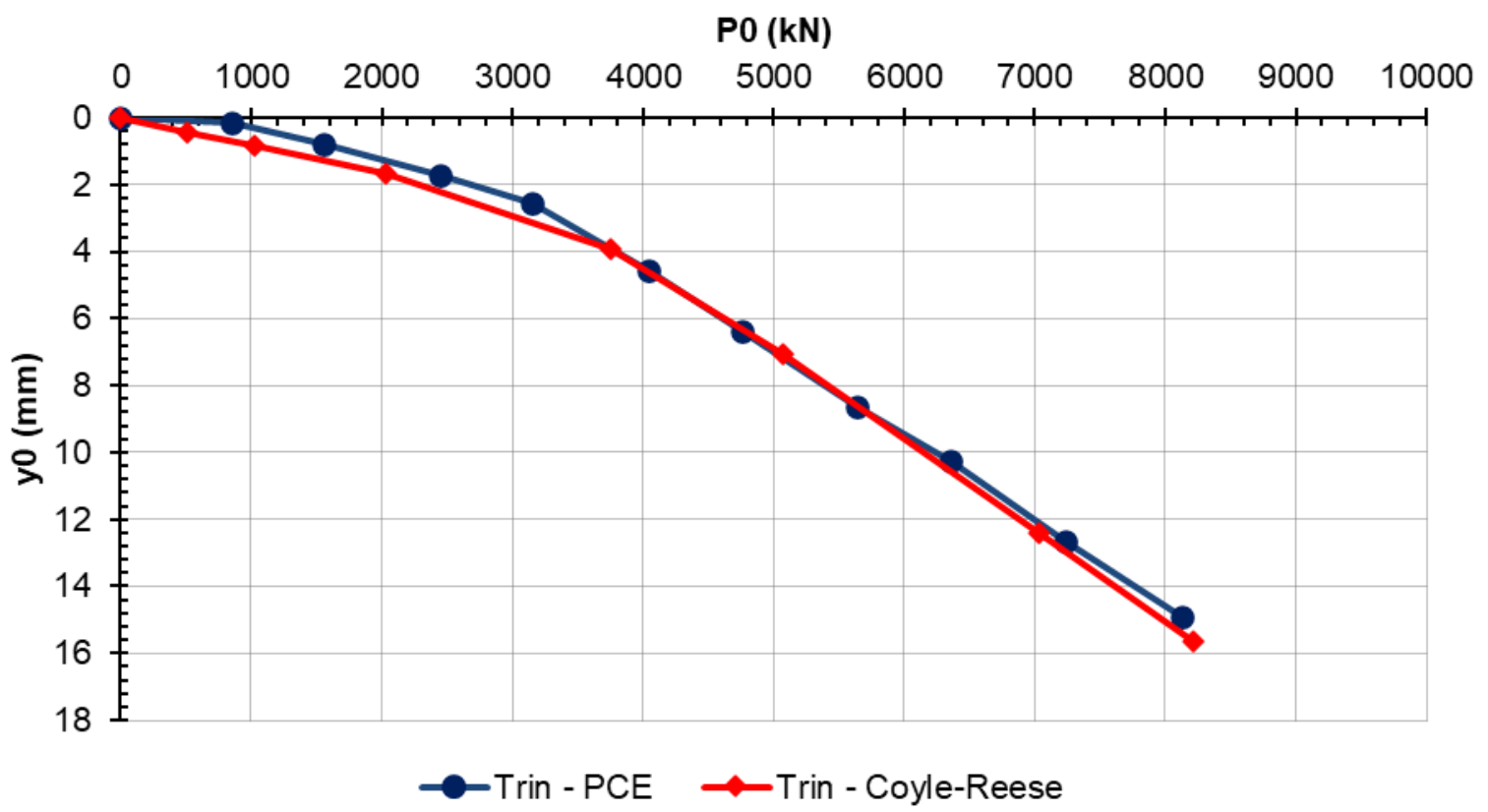

Figura 81: curva carga-recalque no topo da estaca obtida pelo método de Coyle-Reese (1966) para o ensaio Trin. 


\subsubsection{Resumo das análises das provas de carga instrumentadas}

Das seis provas de carga estática com instrumentação em profundidade apresentadas neste trabalho, duas - VdF_1 e Corp_2 (recarregamento da Corp_1) apresentaram resultados inconsistentes e não puderam ser analisadas. Para as outras quatro - CN, VdF_2, Corp_1 e Trin -, foram construídas as funções de transferência de carga e os diagramas de transferência de carga em profundidade, determinando os parâmetros de Cambefort para os trechos entre níveis de instrumentação. Esses parâmetros, por sua vez, nem sempre podem ser indicativos dos parâmetros de Cambefort de um tipo de solo específico típico da Baixada Santista, uma vez que, na maioria dos trechos entre níveis consecutivos de instrumentação, observou-se a presença de mais de uma camada distinta de solo. Assim, os parâmetros $f_{\text {máx }}$ e y1 determinados para esses trechos são, na verdade, uma composição dos parâmetros das diferentes camadas de solo atravessadas pela estaca.

Observando as sondagens mais próximas de cada um dos ensaios representadas nas Figuras I-1, I-13, I-18 e I-23 do Anexo I -, pode-se observar alguns trechos entre níveis consecutivos de instrumentação que apresentaram apenas uma camada de solo e, portanto, os parâmetros de Cambefort determinados para eles representam o comportamento desse tipo específico de solo. Essas observações estão ilustradas na Tabela 38.

Tabela 38: trechos dos ensaios instrumentados que apresentam apenas uma camada de solo.

\begin{tabular}{|c|c|c|}
\hline Ensaio & Trecho & Solo \\
\hline CN & SG 05-06 & Argila AT \\
\hline \multirow{2}{*}{ VdF_2 } & Topo - SG 01 & Areia compacta superficial \\
\cline { 2 - 3 } & SG 04-05 & Argila AT \\
\hline \multirow{2}{*}{ Corp_1 } & SG 01-02 & Argila SFL \\
\cline { 2 - 3 } & SG 03-04 & Argila SFL \\
\hline \multirow{2}{*}{ Trin } & SG 01-02 & Areia compacta superficial \\
\cline { 2 - 3 } & SG 02-03 & Argila SFL \\
\hline
\end{tabular}

As Tabelas 39 e 40 apresentam o resumo dos parâmetros de Cambefort encontrados para os trechos indicados na Tabela 38, com exceção do trecho SG 0304 do ensaio Corp_1, que não atingiu o esgotamento do atrito lateral. 


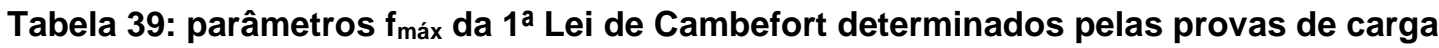
instrumentadas.

\begin{tabular}{|c|c|c|c|}
\hline \multirow{2}{*}{ Ensaio } & \multicolumn{3}{|c|}{$\mathbf{f}$ máx (kPa) } \\
\cline { 2 - 4 } & Areia compacta superficial & Argila SFL & Argila AT \\
\hline CN & - & - & 100 \\
\hline VdF_2 & 45 & - & 80 \\
\hline Corp_1 & - & 45 & - \\
\hline Trin & 50 & 12 & - \\
\hline
\end{tabular}

Tabela 40: parâmetros $y_{1}$ da $1^{\text {a }}$ Lei de Cambefort determinados pelas provas de carga instrumentadas.

\begin{tabular}{|c|c|c|c|}
\hline \multirow{2}{*}{ Ensaio } & \multicolumn{3}{|c|}{ y1 (mm) } \\
\cline { 2 - 4 } & Areia compacta superficial & Argila SFL & Argila AT \\
\hline CN & - & - & 2,0 \\
\hline VdF_2 & 2,0 & - & 2,0 \\
\hline Corp_1 & 2,0 & 3,0 & - \\
\hline Trin & 2,0 & 2,0 & - \\
\hline
\end{tabular}

A Tabela 41 apresenta um resumo dos resultados agrupados por tipo de solo atravessados pelos estacões. Observa-se que os valores de $\mathrm{f}_{\text {máx }}$ situam-se, em geral, acima dos usuais, indicados nas Tabelas 2 e 3 . Os valores de $y_{1}$ para as argilas SFL são similares aos usuais indicados na Tabela 2, o mesmo não ocorrendo com os valores das argilas AT.

Tabela 41: resumo dos parâmetros determinados pelas provas de carga instrumentadas.

\begin{tabular}{|c|c|c|}
\hline Solo & $\mathbf{f}_{\operatorname{máx}} \mathbf{( k P a )}$ & $\mathbf{y} \mathbf{( m m})$ \\
\hline Areia compacta superficial & 45 a 50 & 2 \\
\hline Argila SFL & 12 a 45 & 2 a 3 \\
\hline Argila AT & 80 a 100 & 2 \\
\hline
\end{tabular}




\subsection{Adaptação dos coeficientes do método Falconi-Perez (2008) para a sua utilização em estacas escavadas de grande diâmetro}

Conforme detalhado no item 2.3.3, o método Falconi-Perez (2008) foi desenvolvido para o cálculo de capacidade de carga de estacas metálicas na Baixada Santista, com base em resultados de provas de carga estática na região, algumas delas com instrumentação em profundidade. Para o cálculo da capacidade de carga por atrito lateral, os autores fixaram a adesão para quatro tipos de solo típicos da região, levando em consideração a sua gênese: argilas de mangue, argilas SFL, argilas AT, e areias ou siltes. As argilas possuem a adesão constante e independente do valor do SPT, enquanto, para as areias ou siltes, foi introduzido coeficiente que, multiplicado pelo SPT médio da camada de solo, resulta na adesão dessa camada. No método, os autores fixaram o valor de 2,1 (para f em kPa) para esse coeficiente, chamado neste trabalho de $\alpha$ FP.

O objetivo das análises feitas a seguir é adaptar os valores de adesão das argilas SFL e AT (as argilas de mangue não são escopo dessa análise, pois em nenhuma das obras analisadas havia a presença desse solo) e o coeficiente $\alpha$ FP do método Falconi-Perez (2008), apresentados na Tabela 11 e na Equação 15, para que ele possa ser utilizado também para o cálculo de capacidade de carga por atrito lateral para estacas escavadas de grande diâmetro na Baixada Santista.

Essa adaptação se justifica através da análise da Figura 82, obtida com os dados das Tabelas 16 e 17 (QL estimado pelo método de Falconi-Perez (2008) e carga máxima de ensaio, respectivamente). Vê-se que as diferenças entre cargas máximas medidas (puramente de atrito) e os correspondentes QL estimados pelo método podem atingir até $68 \%$ para mais. Os dois casos com 12 e $27 \%$ para menos referemse, respectivamente, aos ensaios VdF_1 e Leg_1, que foram interrompidos antes de atingir 2 vezes as correspondentes cargas de trabalho. 


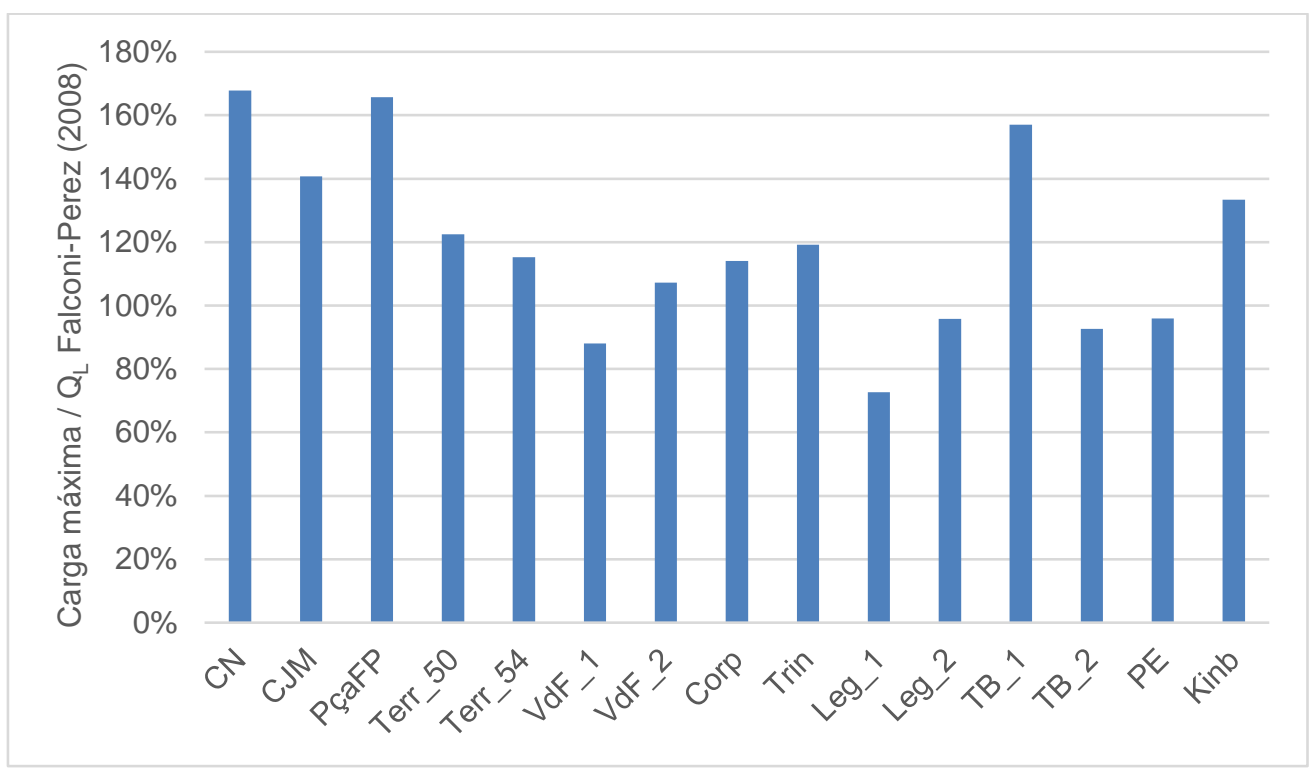

Figura 82: comparação entre a carga máxima do ensaio e o atrito lateral estimado pelo método Falconi-Perez (2008).

A adaptação dos coeficientes de cálculo do atrito lateral pelo método de Falconi-Perez (2008) foi feita com base nos resultados das provas de carga estática instrumentadas em profundidade. Utilizando os diagramas de transferência de carga obtidos em 4.3.1 a 4.3.6, para cada ensaio, o atrito lateral medido em cada trecho entre níveis de instrumentação foi comparado com o atrito lateral calculado pelo método, adaptando os coeficientes para que os valores medido e calculado apresentassem a melhor aderência possível. Os resultados das análises para 5 das 6 provas de carga instrumentadas - o ensaio Corp_2 foi desprezado pois foi executado na mesma estaca que Corp_1, e, por se tratar de um recarregamento e pelos motivos tratados em 4.3.5, os resultados da instrumentação foram inconsistentes - estão ilustrados nas Figuras 83 a 87 e os coeficientes adaptados estão mostrados nas Tabelas 42 a 46. 
Tabela 42: coeficientes do método Falconi-Perez (2008) adaptados ao ensaio CN.

\begin{tabular}{|c|c|c|}
\hline Solo & aFP (kPa) & $\mathbf{f ~ ( k P a )}$ \\
\hline Argila SFL & - & 45 \\
\hline Argila AT & - & 100 \\
\hline Areia/silte & 4 & - \\
\hline
\end{tabular}

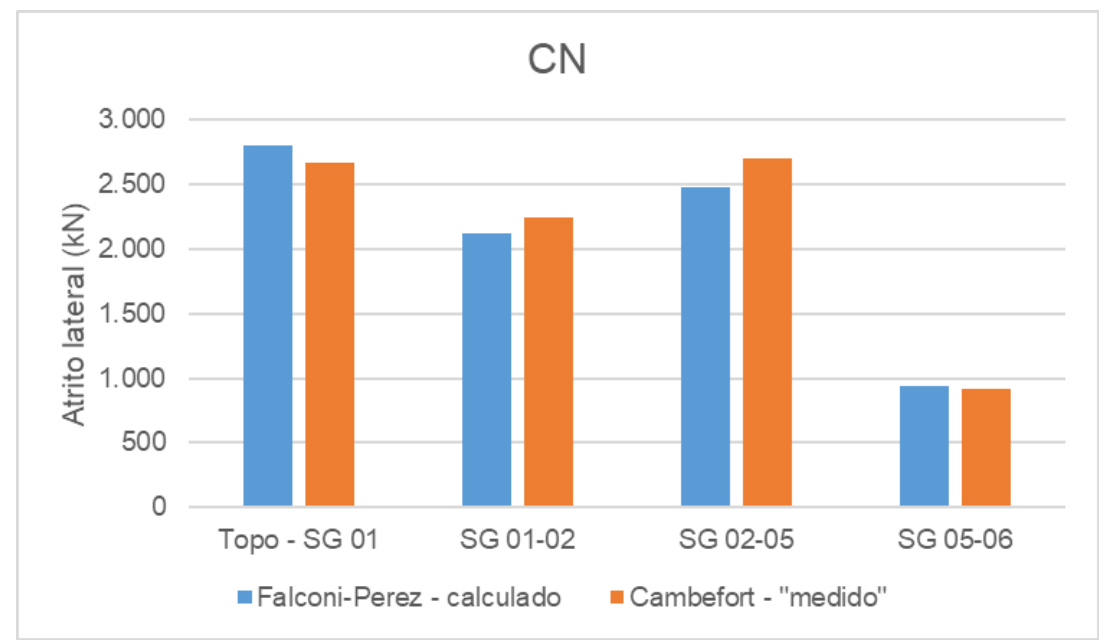

Figura 83: atrito lateral nos trechos do ensaio CN medido e calculado pelo método FalconiPerez (2008) com os coeficientes adaptados.

Tabela 43: coeficientes do método Falconi-Perez (2008) adaptados ao ensaio VdF_1.

\begin{tabular}{|c|c|c|}
\hline Solo & $\boldsymbol{\alpha}$ FP (kPa) & $\mathbf{f}(\mathbf{k P a})$ \\
\hline Argila SFL & - & 45 \\
\hline Argila AT & - & 60 \\
\hline Areia/silte & 6 & - \\
\hline
\end{tabular}

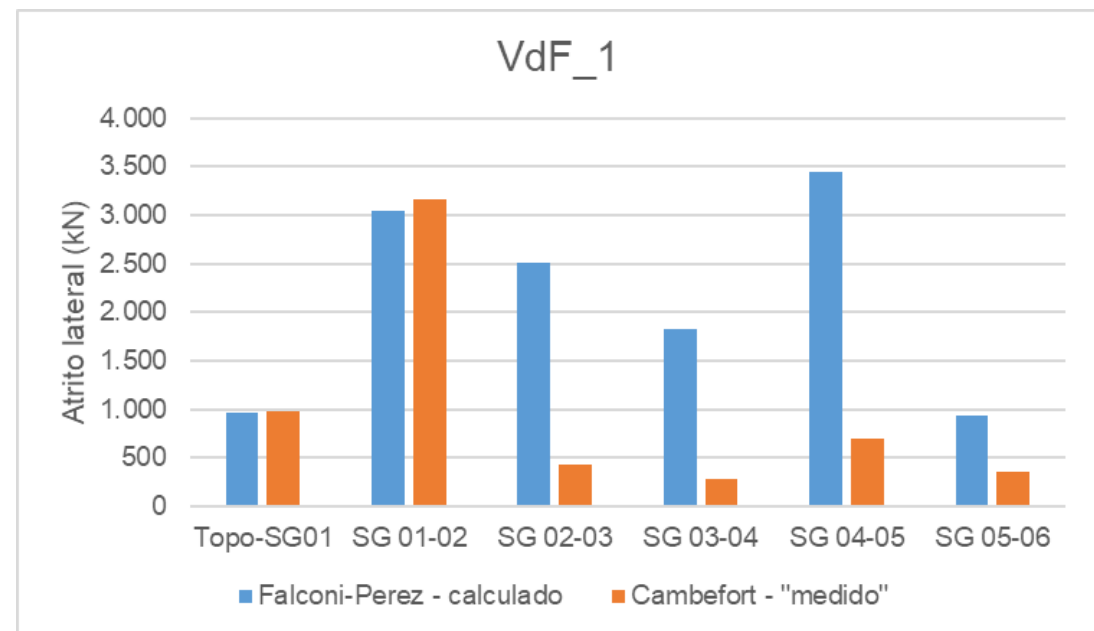

Figura 84: atrito lateral nos trechos do ensaio VdF_1 medido e calculado pelo método FalconiPerez (2008) com os coeficientes adaptados. 
Tabela 44: coeficientes do método Falconi-Perez (2008) adaptados ao ensaio VdF_2.

\begin{tabular}{|c|c|c|}
\hline Solo & aFP (kPa) & $\mathbf{f ~ ( k P a )}$ \\
\hline Argila SFL & - & 50 \\
\hline Argila AT & - & 60 \\
\hline Areia/silte & 4 & - \\
\hline
\end{tabular}

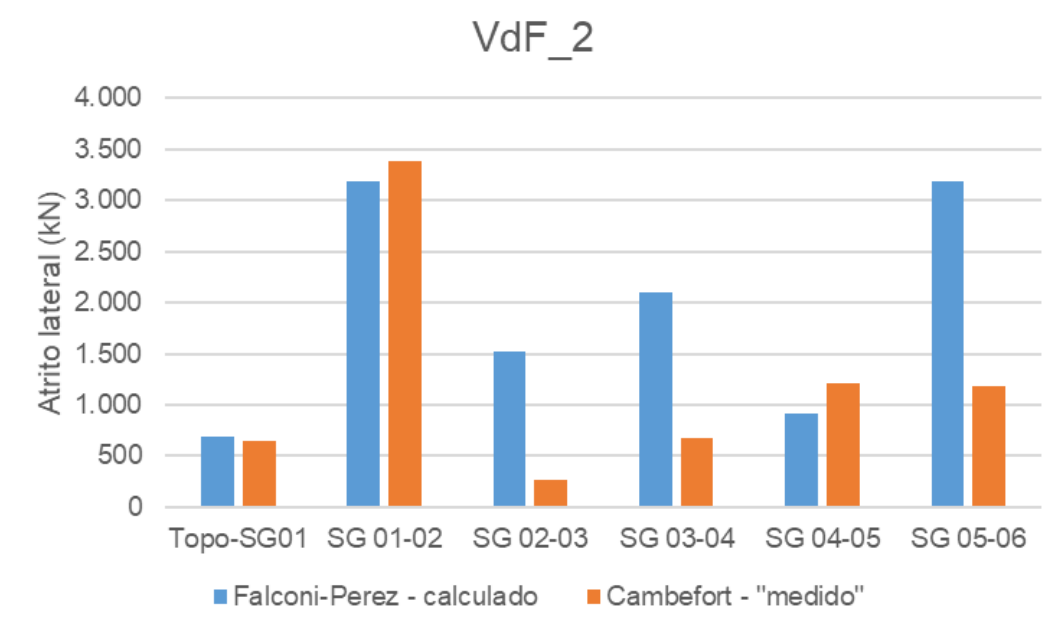

Figura 85: atrito lateral nos trechos do ensaio VdF_2 medido e calculado pelo método FalconiPerez (2008) com os coeficientes adaptados.

Tabela 45: coeficientes do método Falconi-Perez (2008) adaptados ao ensaio Corp_1.

\begin{tabular}{|c|c|c|}
\hline Solo & $\boldsymbol{\alpha}_{\mathrm{FP}}(\mathbf{k P a})$ & $\mathbf{f}(\mathbf{k P a})$ \\
\hline Argila SFL & - & 50 \\
\hline Argila AT & - & 60 \\
\hline Areia/silte & 3,5 & - \\
\hline
\end{tabular}

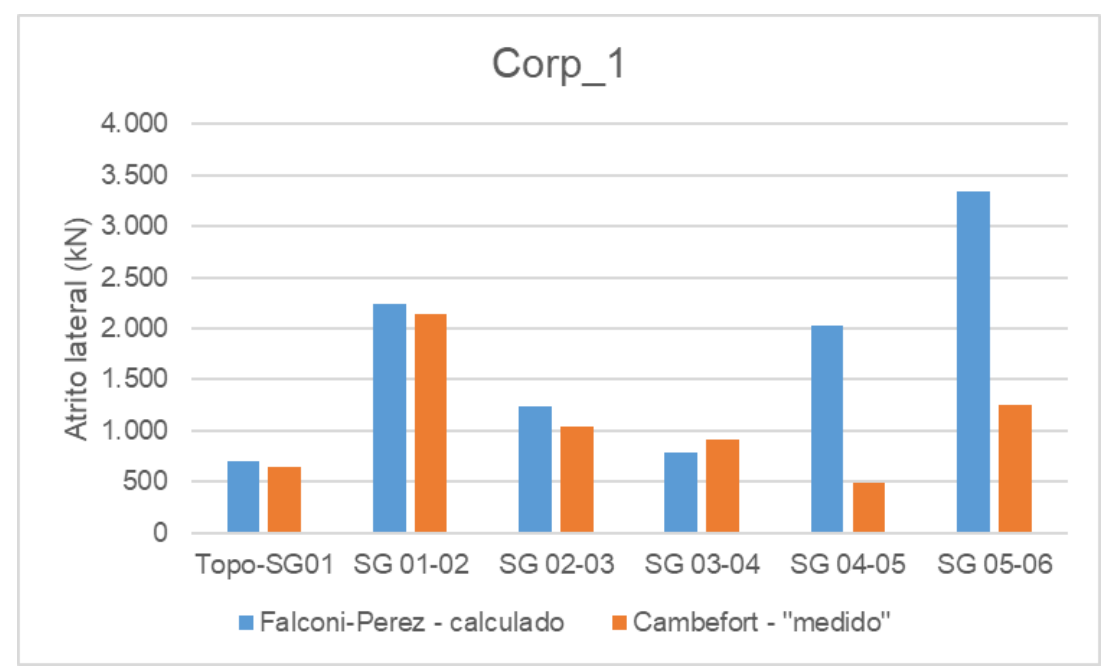

Figura 86: atrito lateral nos trechos do ensaio Corp_1 medido e calculado pelo método FalconiPerez (2008) com os coeficientes adaptados. 
Tabela 46: coeficientes do método Falconi-Perez (2008) adaptados ao ensaio Trin.

\begin{tabular}{|c|c|c|}
\hline Solo & aFP (kPa) & $\mathbf{f ~ ( k P a )}$ \\
\hline Argila SFL & - & 30 \\
\hline Argila AT & - & 60 \\
\hline Areia/silte & 7 & - \\
\hline
\end{tabular}

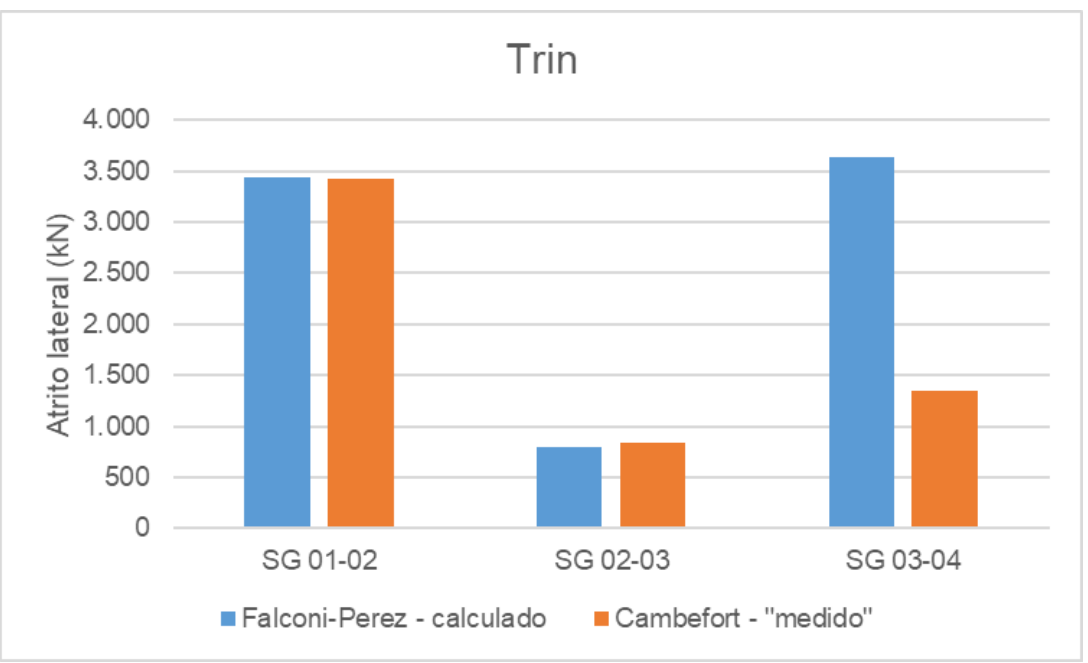

Figura 87: atrito lateral nos trechos do ensaio Trin medido e calculado pelo método FalconiPerez (2008) com os coeficientes adaptados.

Pelas Figuras 83 a 87, observa-se que o atrito lateral calculado e medido apresenta boa aderência apenas para os primeiros trechos. Nos trechos mais profundos, com exceção do ensaio $\mathrm{CN}$, observou-se que o atrito lateral calculado resultou muito maior do que o medido. Isso pode ocorrer pois, nos trechos mais profundos, conforme analisado nos itens 4.3.1 a 4.3.6, na maioria dos ensaios, não foi atingido o esgotamento do atrito lateral e o valor medido não representa o valor de

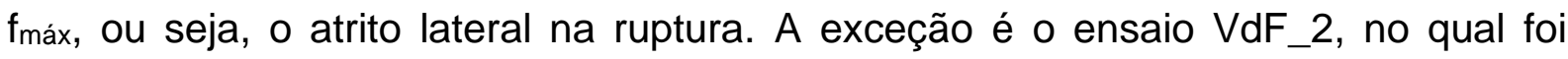
constatada a ruptura geotécnica da estaca, o que foi corroborado pelos resultados da instrumentação em profundidade em 4.3.3.

Para tentar melhorar a aderência entre os valores de atrito lateral medidos e calculados pelo método, decidiu-se diferenciar a camada de areia compacta superficial das areias e siltes pleistocênicos em profundidade, adotando coeficientes diferenciados para os dois tipos de solo. Os resultados desta segunda análise estão ilustrados nas Figuras 88 a 92 e os coeficientes adaptados estão demonstrados nas Tabelas 47 a 51. 
Tabela 47: coeficientes do método Falconi-Perez (2008) adaptados ao ensaio CN com diferenciação da areia compacta superficial.

\begin{tabular}{|c|c|c|}
\hline Solo & a FP & $\mathbf{f ~ ( k P a )}$ \\
\hline Argila SFL & - & 40 \\
\hline Argila AT & - & 10 \\
\hline Areia/silte & 5 & - \\
\hline Areia compacta superficial & 4 & \\
\hline
\end{tabular}

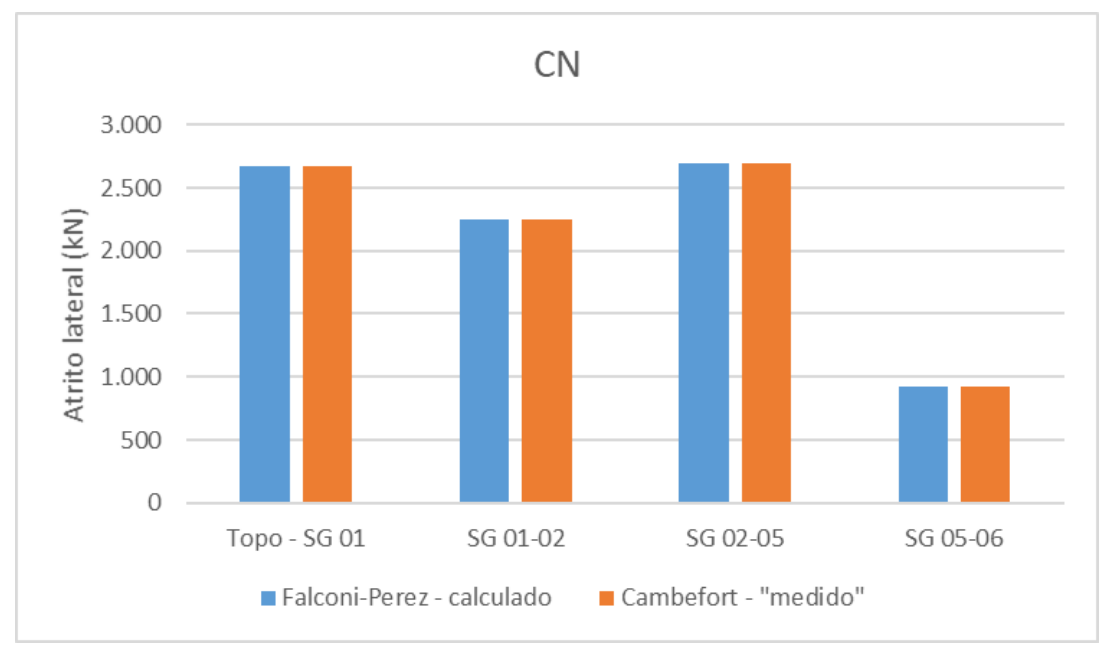

Figura 88: atrito lateral nos trechos do ensaio $\mathrm{CN}$ medido e calculado pelo método Falconi-Perez (2008) com os coeficientes adaptados e diferenciação da areia compacta superficial.

Tabela 48: coeficientes do método Falconi-Perez (2008) adaptados ao ensaio VdF_1 com diferenciação da areia compacta superficial.

\begin{tabular}{|c|c|c|}
\hline Solo & aFP & $\mathbf{f ~ ( k P a )}$ \\
\hline Argila SFL & - & 45 \\
\hline Argila AT & - & 45 \\
\hline Areia/silte & 0,8 & - \\
\hline Areia compacta superficial & 6 & \\
\hline
\end{tabular}




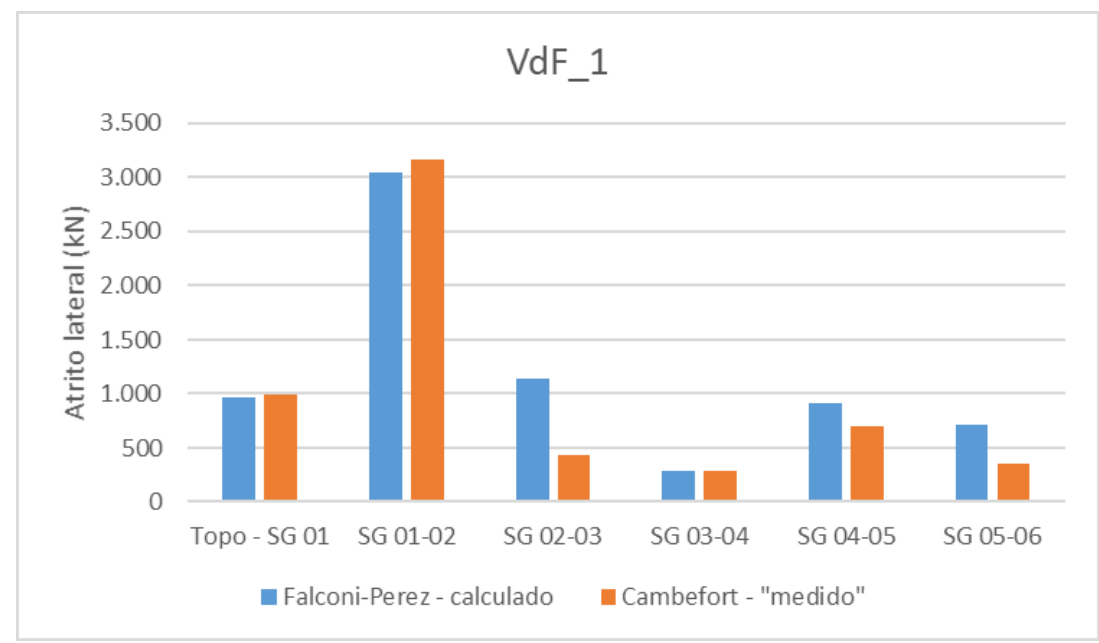

Figura 89: atrito lateral nos trechos do ensaio VdF_1 medido e calculado pelo método FalconiPerez (2008) com os coeficientes adaptados e diferenciação da areia compacta superficial.

Tabela 49: coeficientes do método Falconi-Perez (2008) adaptados ao ensaio VdF_2 com diferenciação da areia compacta superficial.

\begin{tabular}{|c|c|c|}
\hline Solo & aFP & $\mathbf{f ~ ( k P a )}$ \\
\hline Argila SFL & - & 55 \\
\hline Argila AT & - & 60 \\
\hline Areia/silte & 1,5 & - \\
\hline Areia compacta superficial & 3,5 & \\
\hline
\end{tabular}

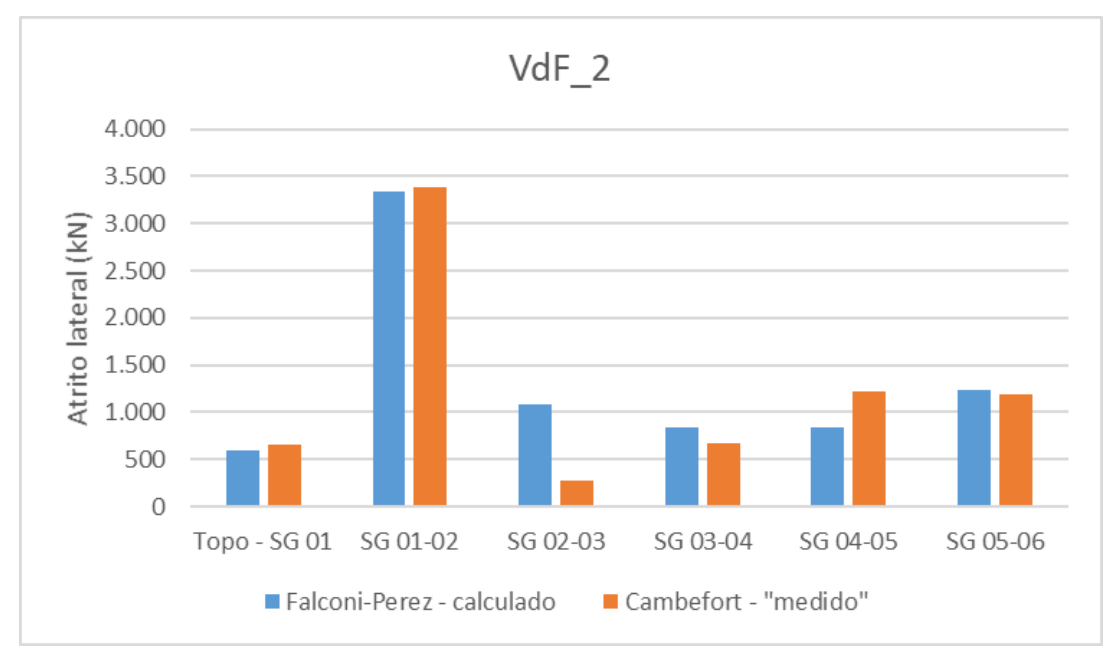

Figura 90: atrito lateral nos trechos do ensaio VdF_2 medido e calculado pelo método FalconiPerez (2008) com os coeficientes adaptados e diferenciação da areia compacta superficial. 
Tabela 50: coeficientes do método Falconi-Perez (2008) adaptados ao ensaio Corp_1 com diferenciação da areia compacta superficial.

\begin{tabular}{|c|c|c|}
\hline Solo & aFP & $\mathbf{f}(\mathbf{k P a})$ \\
\hline Argila SFL & - & 50 \\
\hline Argila AT & - & 50 \\
\hline Areia/silte & 1,3 & - \\
\hline Areia compacta superficial & 3,5 & \\
\hline
\end{tabular}

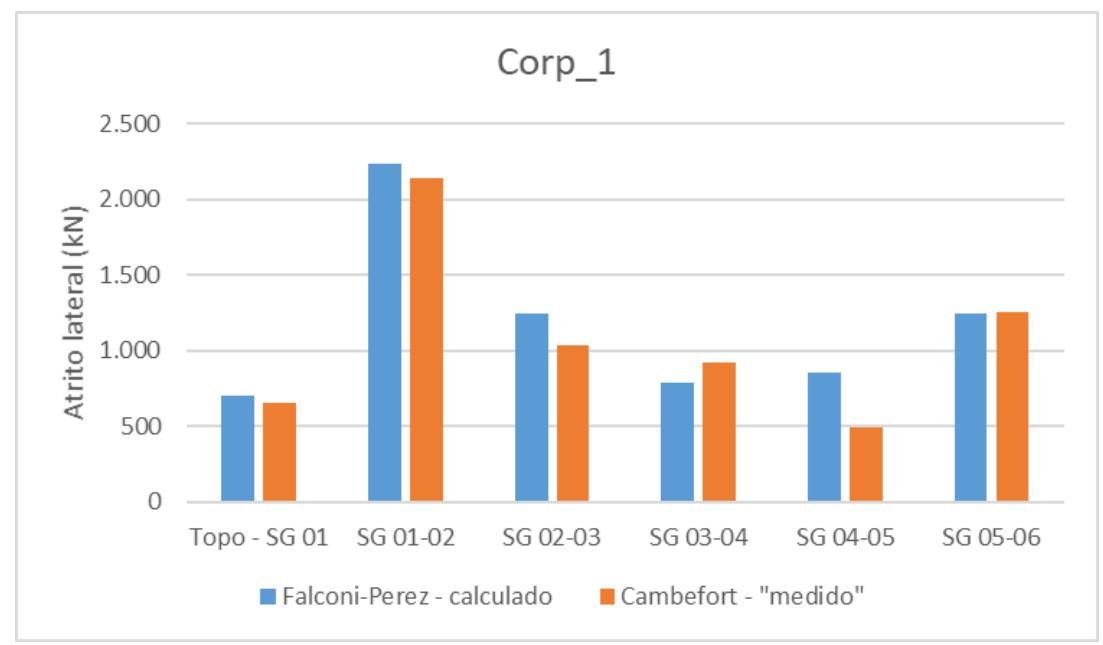

Figura 91: atrito lateral nos trechos do ensaio Corp_1 medido e calculado pelo método FalconiPerez (2008) com os coeficientes adaptados e diferenciação da areia compacta superficial.

Tabela 51: coeficientes do método Falconi-Perez (2008) adaptados ao ensaio Trin com diferenciação da areia compacta superficial.

\begin{tabular}{|c|c|c|}
\hline Solo & $\boldsymbol{\alpha}_{\mathrm{FP}}$ & $\mathbf{f}(\mathbf{k P a})$ \\
\hline Argila SFL & - & 30 \\
\hline Argila AT & - & 60 \\
\hline Areia/silte & 2 & - \\
\hline Areia compacta superficial & 5 & \\
\hline
\end{tabular}




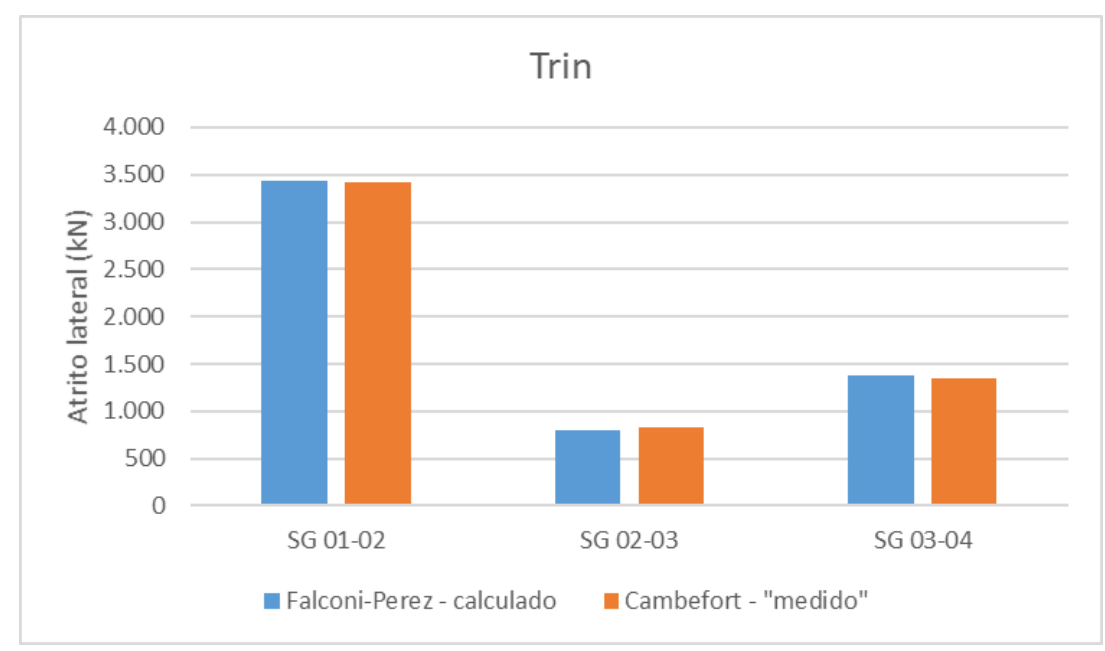

Figura 92: atrito lateral nos trechos do ensaio Trin medido e calculado pelo método FalconiPerez (2008) com os coeficientes adaptados e diferenciação da areia compacta superficial.

Diferenciando-se os valores de afP para a areia compacta superficial, os resultados apresentaram boa aderência. Os baixos valores observados para as camadas de areia e silte em profundidade, além da argila AT, provavelmente devemse ao fato já mencionado de que as camadas mais profundas de solo não atingiram o esgotamento do atrito lateral e, portanto os valores medidos não correspondem a fmáx. Por outro lado, esses valores estão mais coerentes com os resultados observados no ensaio VdF_2, que atingiu o esgotamento do atrito lateral ao longo de toda a estaca.

As médias dos valores dos coeficientes estão demonstrados na Tabela 52.

Tabela 52: valores médios dos coeficientes do método Falconi-Perez (2008) adaptados com diferenciação da areia compacta superficial.

\begin{tabular}{|c|c|c|}
\hline Solo & aFP & $\mathbf{f}(\mathbf{k P a})$ \\
\hline Argila SFL & - & 44 \\
\hline Argila AT & - & 45 \\
\hline Areia/silte & 2,1 & - \\
\hline Areia compacta superficial & 4,4 & \\
\hline
\end{tabular}

Observa-se que o valor médio de afp para as camadas de areia e silte coincide com o valor proposto por Falconi e Perez (2008) na Equação 15, apesar de essas camadas não terem atingido o esgotamento do atrito lateral na maioria dos ensaios analisados, conforme já mencionado. 
O método Falconi-Perez (2008), assim como os outros métodos semiempíricos apresentados no item 2.3, contém diretrizes para o cálculo da capacidade de carga da ponta das estacas. Porém, na maioria dos ensaios analisados neste trabalho, não se atingiu a ruptura geotécnica, e as estacas ensaiadas apresentaram deslocamentos no topo baixos, de até $20 \mathrm{~mm}$. Os resultados das instrumentações em profundidade também indicam que a carga mobilizada na ponta da estaca é muito baixa, praticamente nula em alguns casos. Assim, não foi avaliada a carga de ruptura da ponta das estacas.

\subsection{Modelo para determinação da curva $\mathrm{P}_{0}-\mathrm{y}_{0}$ de estacas escavadas de grande diâmetro com fluido estabilizante na Baixada Santista a partir dos dados das sondagens à percussão}

O objetivo deste trabalho, conforme já mencionado em capítulos anteriores, é estabelecer um modelo de análise de estacas escavadas de grande diâmetro com fluido estabilizante executadas na região da Baixada Santista. Para tanto, com base nas provas de carga instrumentadas em profundidade, foram determinados valores de $f_{\text {máx }}$ e y1 para as várias camadas de solo características da região. Os valores de $f_{\text {máx }}$ foram determinados de duas maneiras: obtendo-se os parâmetros de Cambefort para as provas de carga instrumentadas em profundidade através do método de Coyle-Reese (1966); e aplicando o método semiempírico de cálculo de capacidade de carga por atrito lateral de Falconi-Perez (2008), adaptando seus coeficientes para obter a maior aderência possível com os resultados da instrumentação em profundidade. Já os valores de $\mathrm{y}_{1}$, quando possível, foram obtidos através do método de Coyle-Reese (1966), conforme descrito no item 4.3.

Para a simulação da curva carga-recalque no topo da estaca escavada de grande diâmetro com fluido estabilizante executada na Baixada Santista, quando submetida a um carregamento axial, de acordo com o modelo proposto nesse trabalho, foram feitas as seguintes considerações:

- as camadas de solo da sondagem mais próxima foram classificadas em:

- areia compacta superficial

- argila SFL 
○ argila AT

- areias e siltes

- cada camada de solo foi considerada como um elemento para a aplicação do método de Coyle-Reese (1966)

- adotado um valor de $\mathrm{E}=28 \mathrm{GPa}$, igual à média dos valores encontrados pelo Método do Módulo Tangente de Fellenius (1989) nas análises das provas de carga instrumentadas no item 4.3

- adotada carga de ponta igual a zero

\subsubsection{Aplicação do modelo utilizando os parâmetros determinados nos itens 4.3} e 4.4

O modelo de análise será inicialmente aplicado para todas as provas de carga, instrumentadas ou não, utilizando os parâmetros de Cambefort indicados na Tabela 53.

Tabela 53: parâmetros de Cambefort adotados inicialmente para o modelo de análise.

\begin{tabular}{|c|c|c|c|}
\hline Solo & $\boldsymbol{\alpha}$ & $\mathbf{f}_{\text {máx }} \mathbf{( k P a )}$ & $\mathbf{y}_{\mathbf{1}}(\mathbf{m m})$ \\
\hline Areia compacta superficial & 4,4 & - & 2,0 \\
\hline Argila SFL & - & 40 & 2,0 \\
\hline Argila AT & - & 60 & 2,0 \\
\hline Areia/silte & 2,1 & - & 5,0 \\
\hline
\end{tabular}

Para a areia compacta superficial e as camadas de areia e silte em profundidade, adotou-se atrito lateral unitário em função do SPT através do parâmetro $\alpha$, similar ao método de Falconi-Perez (2008). Para $\alpha$, foram adotados os valores determinados no item 4.4, destacando o fato de que o a para as areias e siltes é igual ao utilizado pelo método de Falconi-Perez (2008). Para a argila SFL, adotou-se o valor de $40 \mathrm{kPa}$, um pouco maior do que o utilizado por Falconi e Perez (2008), mas mais coerente com os valores encontrados nos itens 4.3 e 4.4. Para a argila AT, foi adotado o valor de $60 \mathrm{kPa}$, igual ao método de Falconi-Perez (2008), pois o valor médio de $45 \mathrm{kPa}$ encontrado no item 4.4 não representa o atrito lateral na ruptura. Para $\mathrm{y}_{1}$, adotou-se 2,0 $\mathrm{mm}$ para a maioria dos tipos de solo, de acordo com os valores 
encontrados no item 4.3. Para as camadas de areia e silte em profundidade, abaixo da primeira camada de argila SFL, os valores de $\mathrm{y}_{1}$ não puderam ser determinados em 4.3, e foi adotado o valor de 5,0 mm.

As Figuras 93 a 107 representam a aplicação do modelo proposto para as 15 estacas ensaiadas, com a carga de trabalho da estaca indicada por uma linha tracejada. O ensaio Corp_2, como foi executado na mesma estaca do Corp_1, não está representado. Foram adotados diferentes valores de yp para cada ensaio para que a curva determinada pelo modelo ficasse o mais próxima possível do intervalo de pontos da curva real do ensaio.

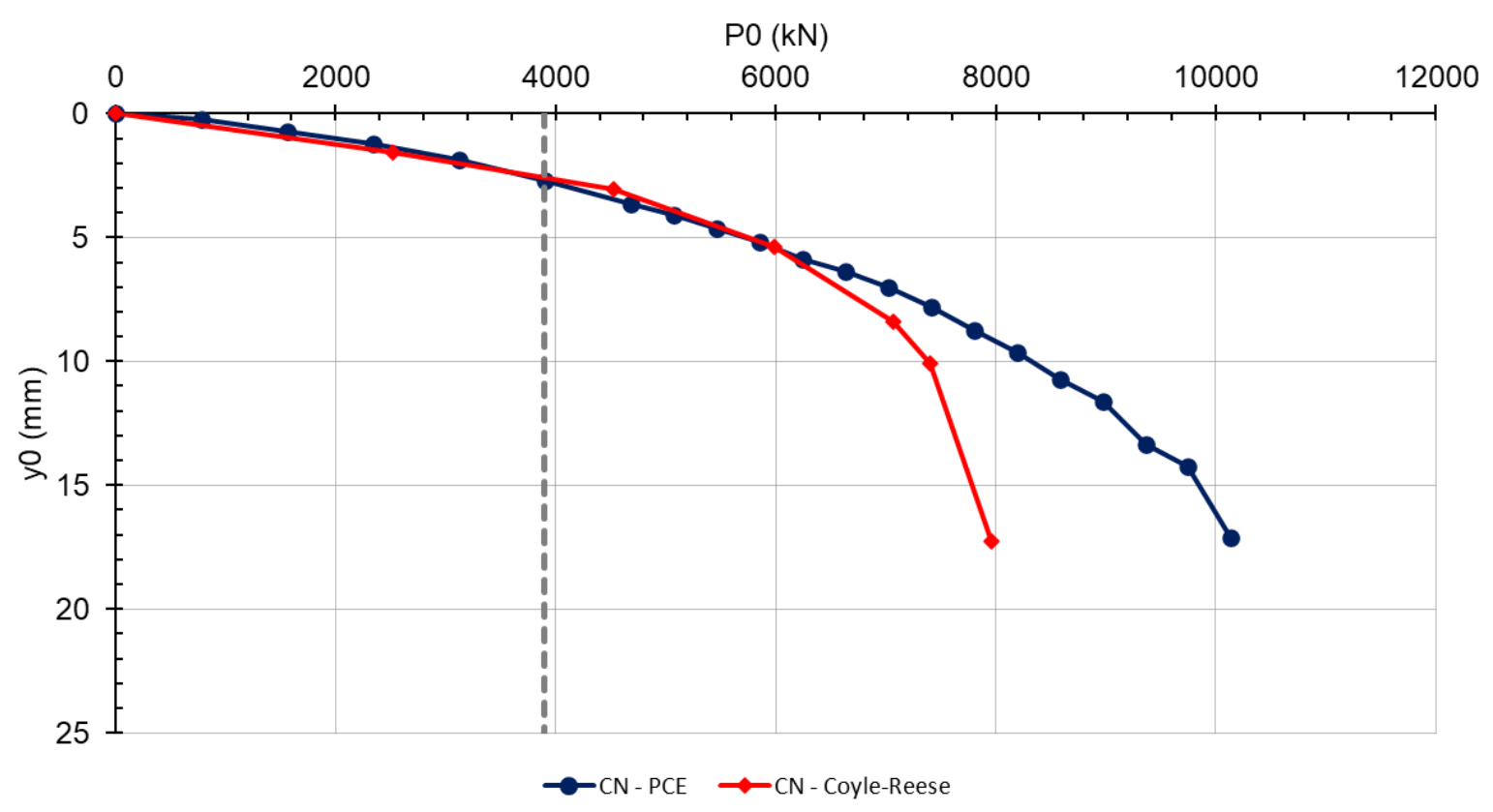

Figura 93: aplicação do modelo para o ensaio CN. 


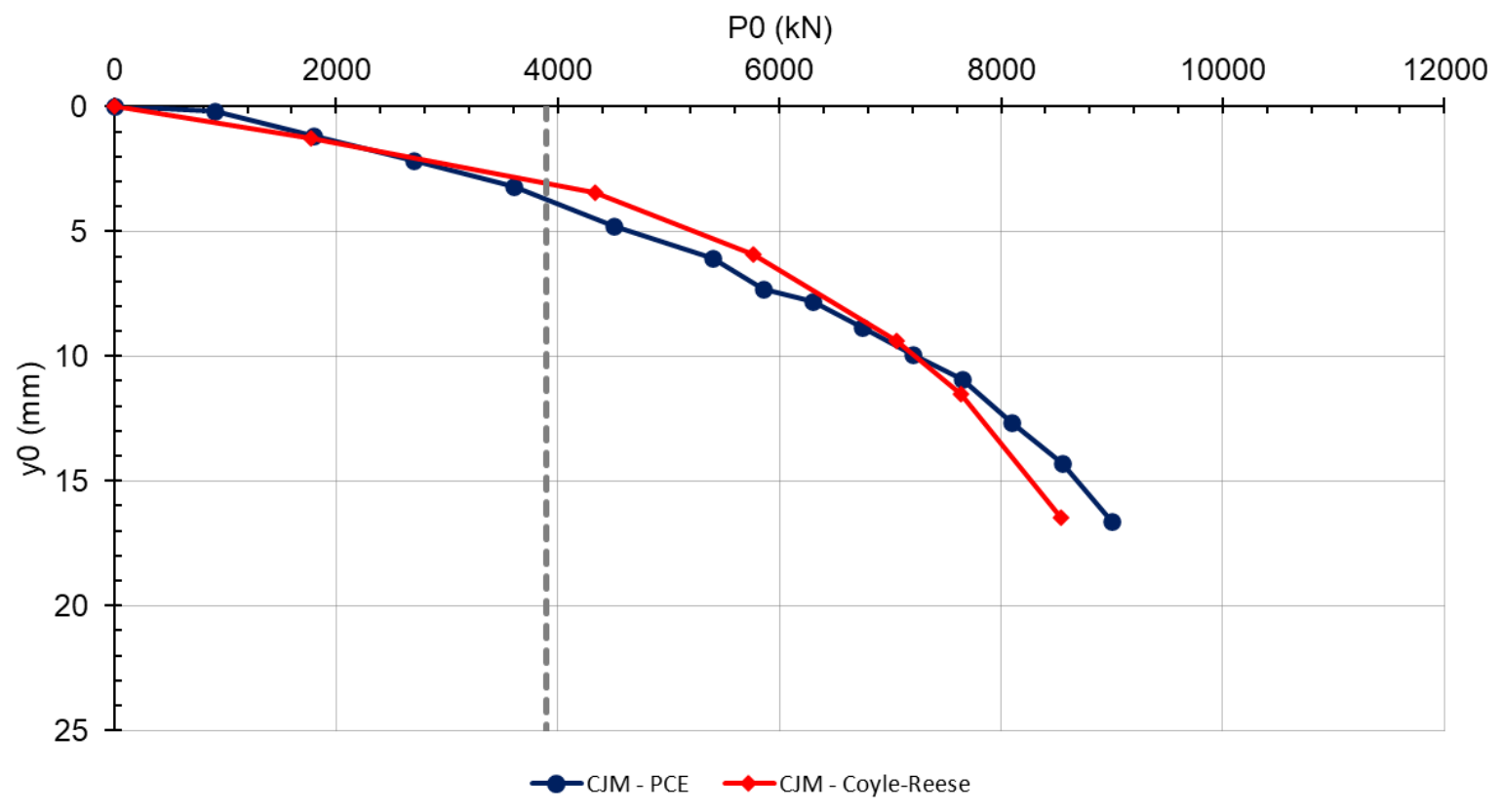

Figura 94: aplicação do modelo para o ensaio CJM.

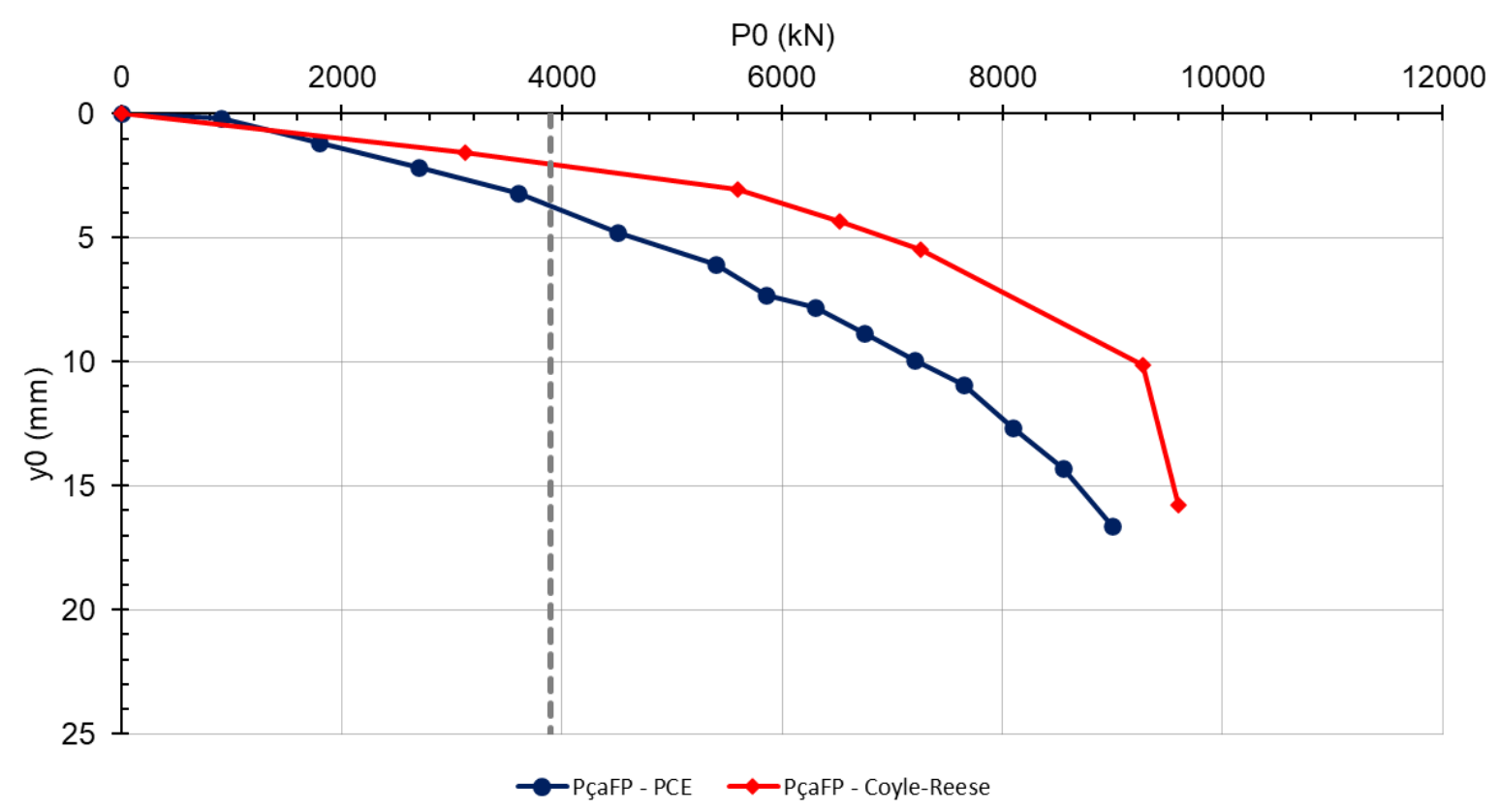

Figura 95: aplicação do modelo para o ensaio PçaFP. 


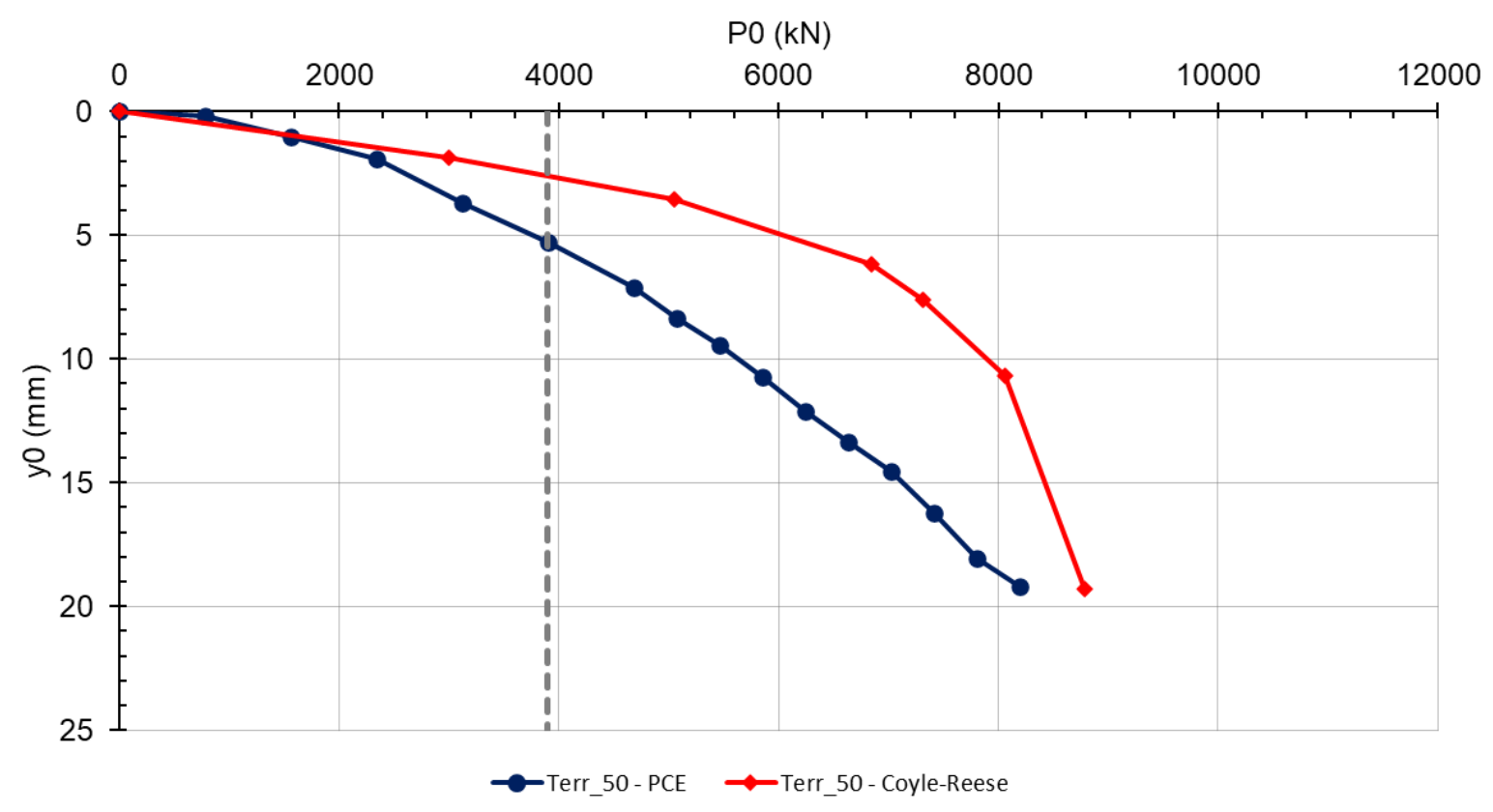

Figura 96: aplicação do modelo para o ensaio Terr_50.

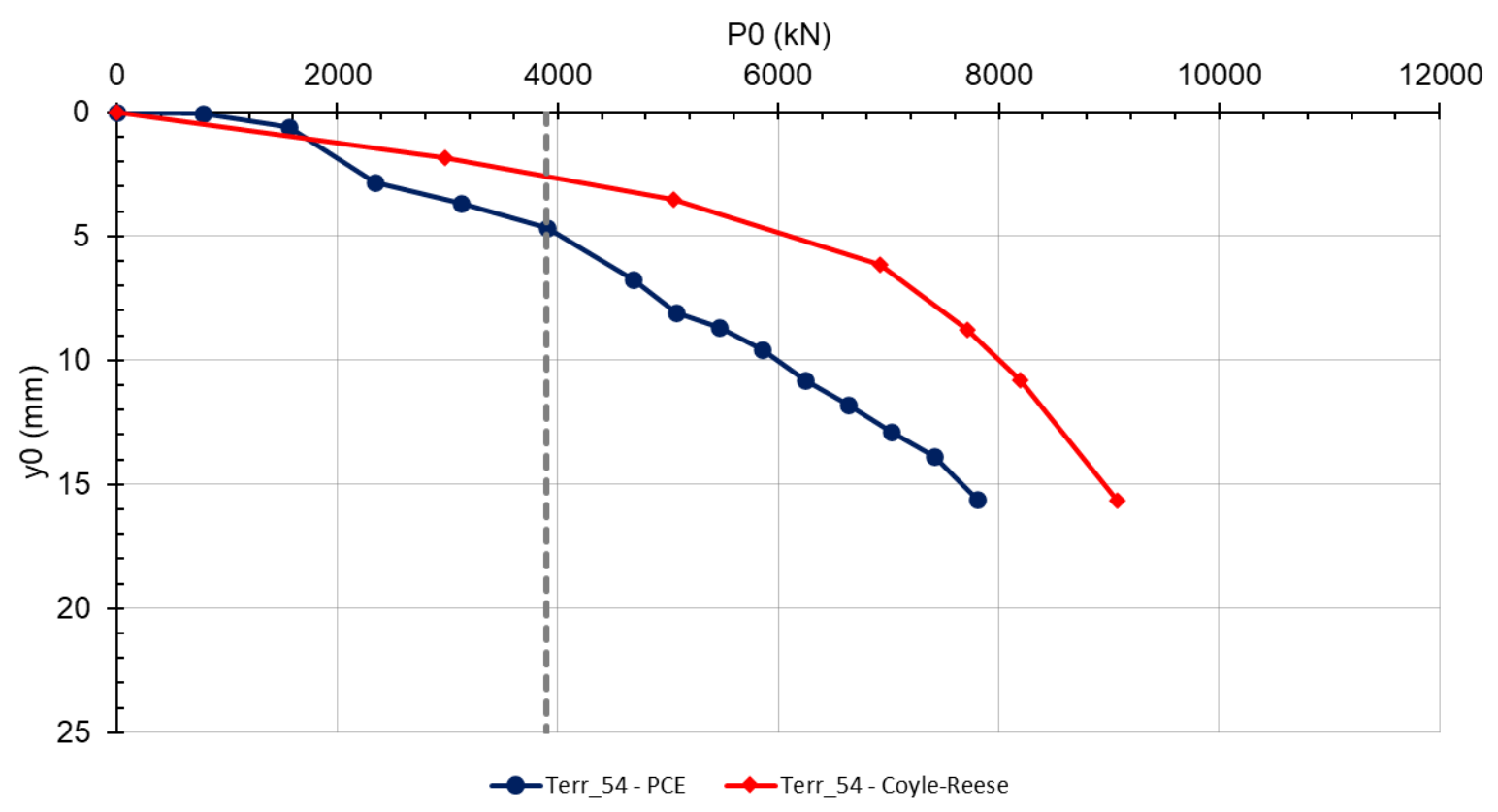

Figura 97: aplicação do modelo para o ensaio Terr_54. 


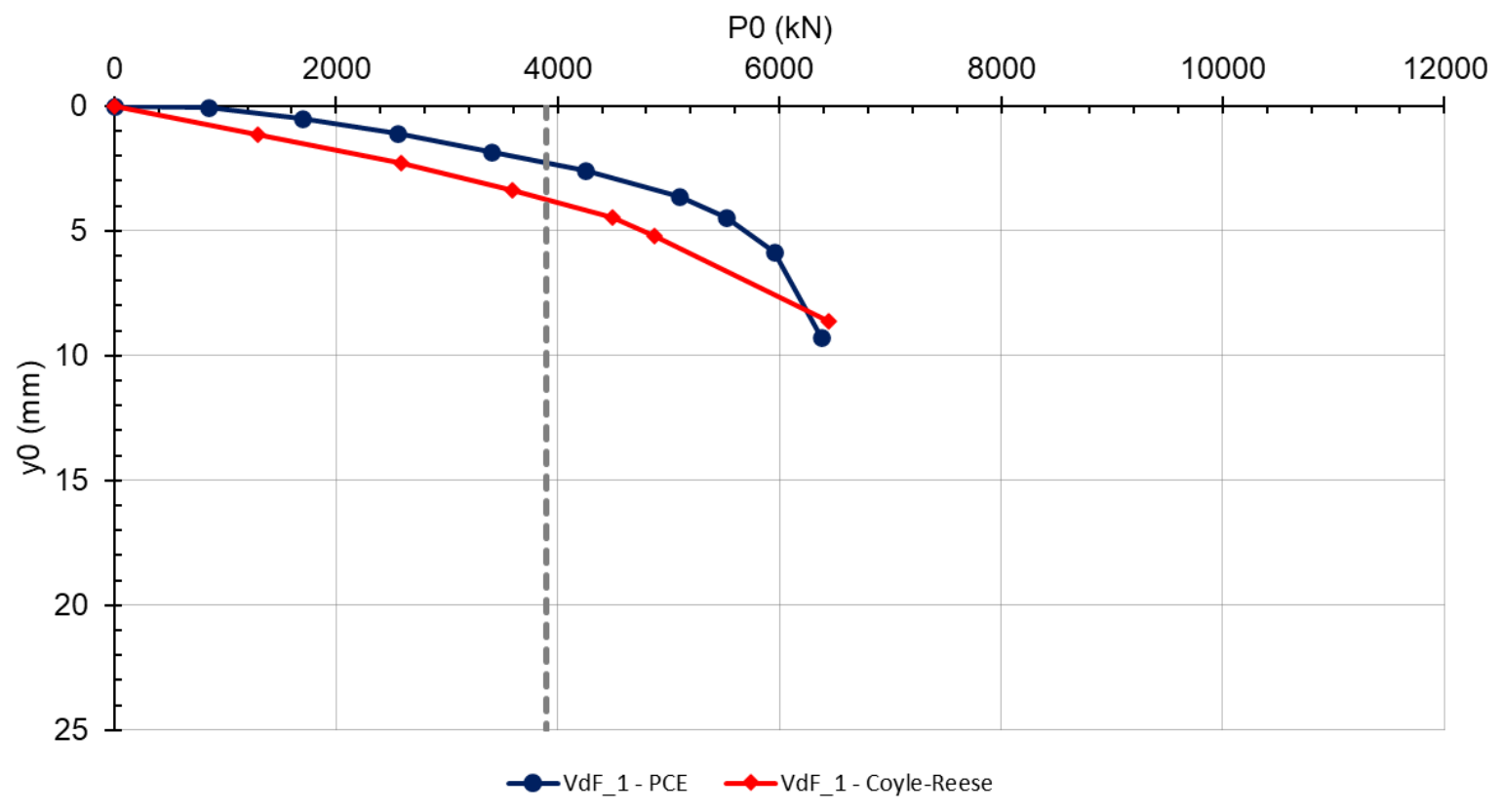

Figura 98: aplicação do modelo para o ensaio VdF_1.

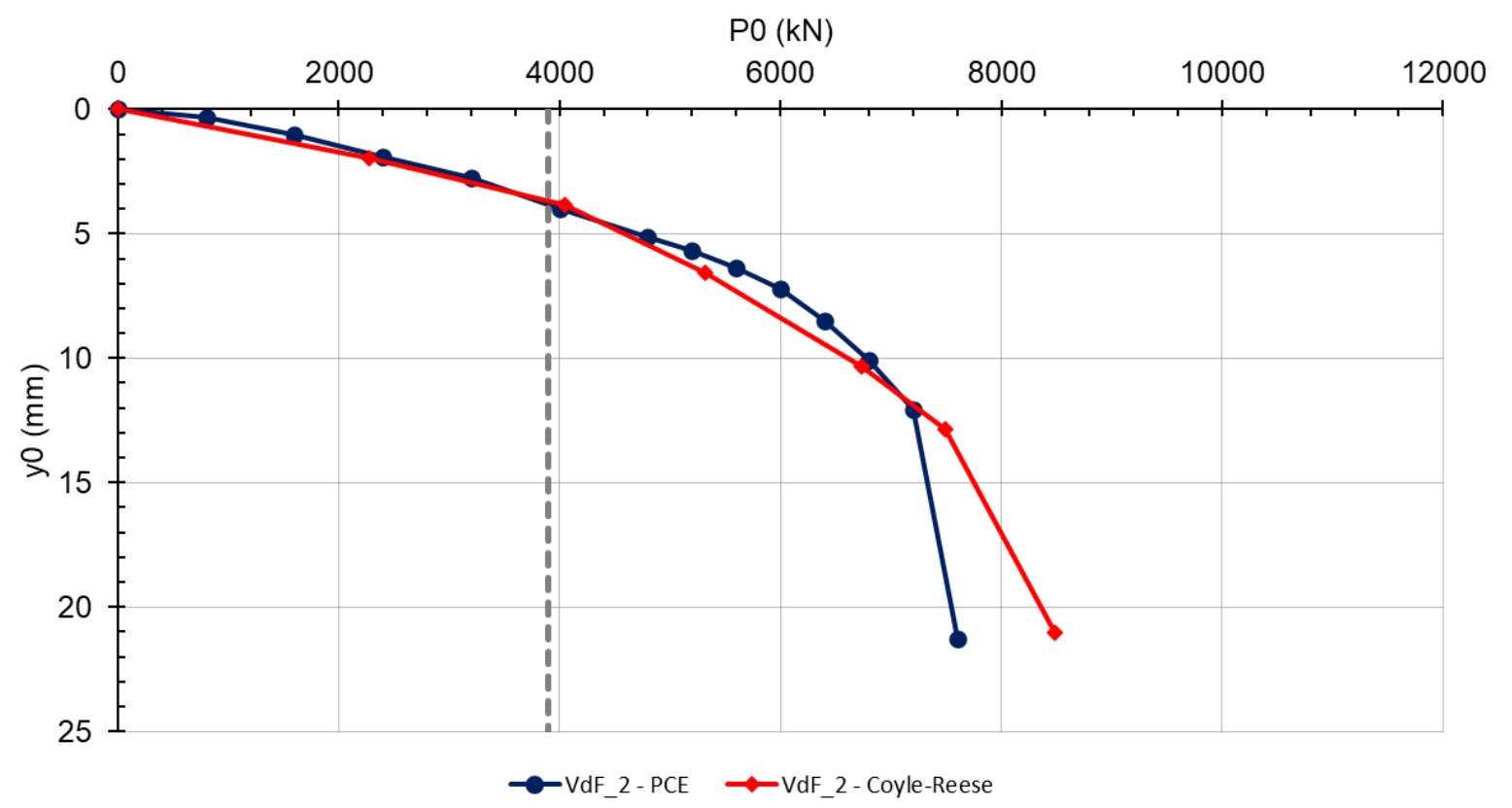

Figura 99: aplicação do modelo para o ensaio VdF_2. 


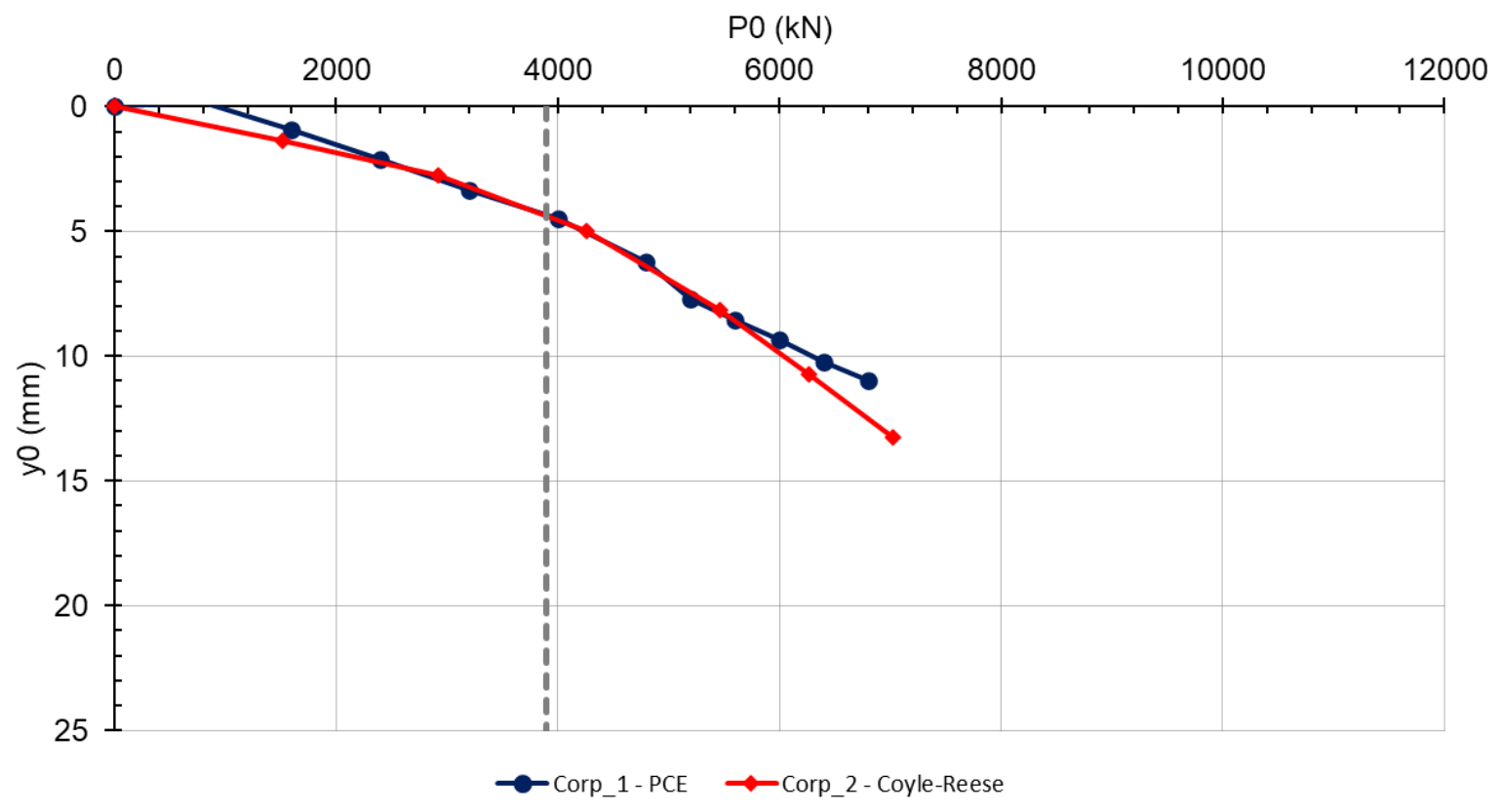

Figura 100: aplicação do modelo para o ensaio Corp_1.

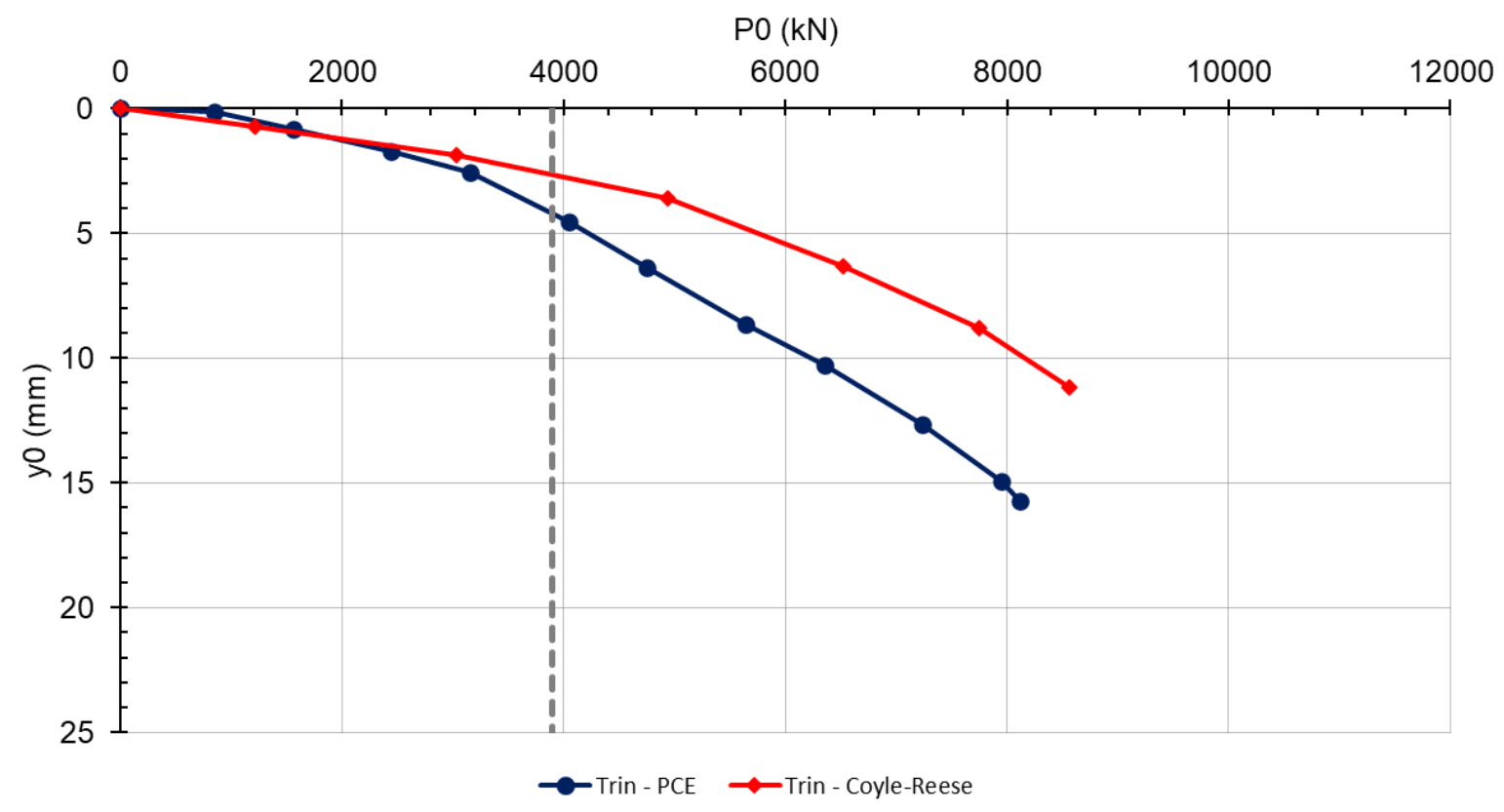

Figura 101: aplicação do modelo para o ensaio Trin. 


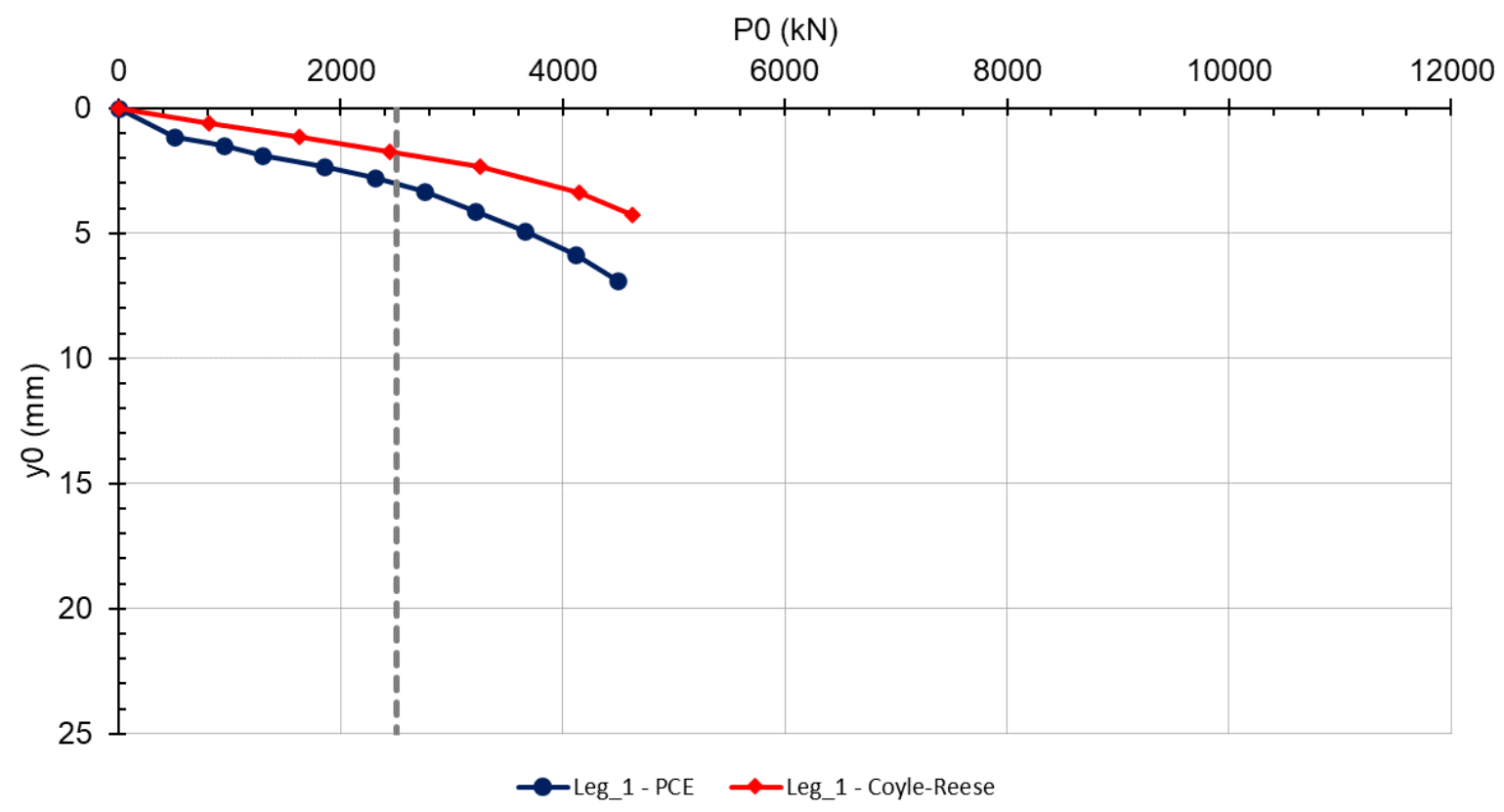

Figura 102: aplicação do modelo para o ensaio Leg_1.

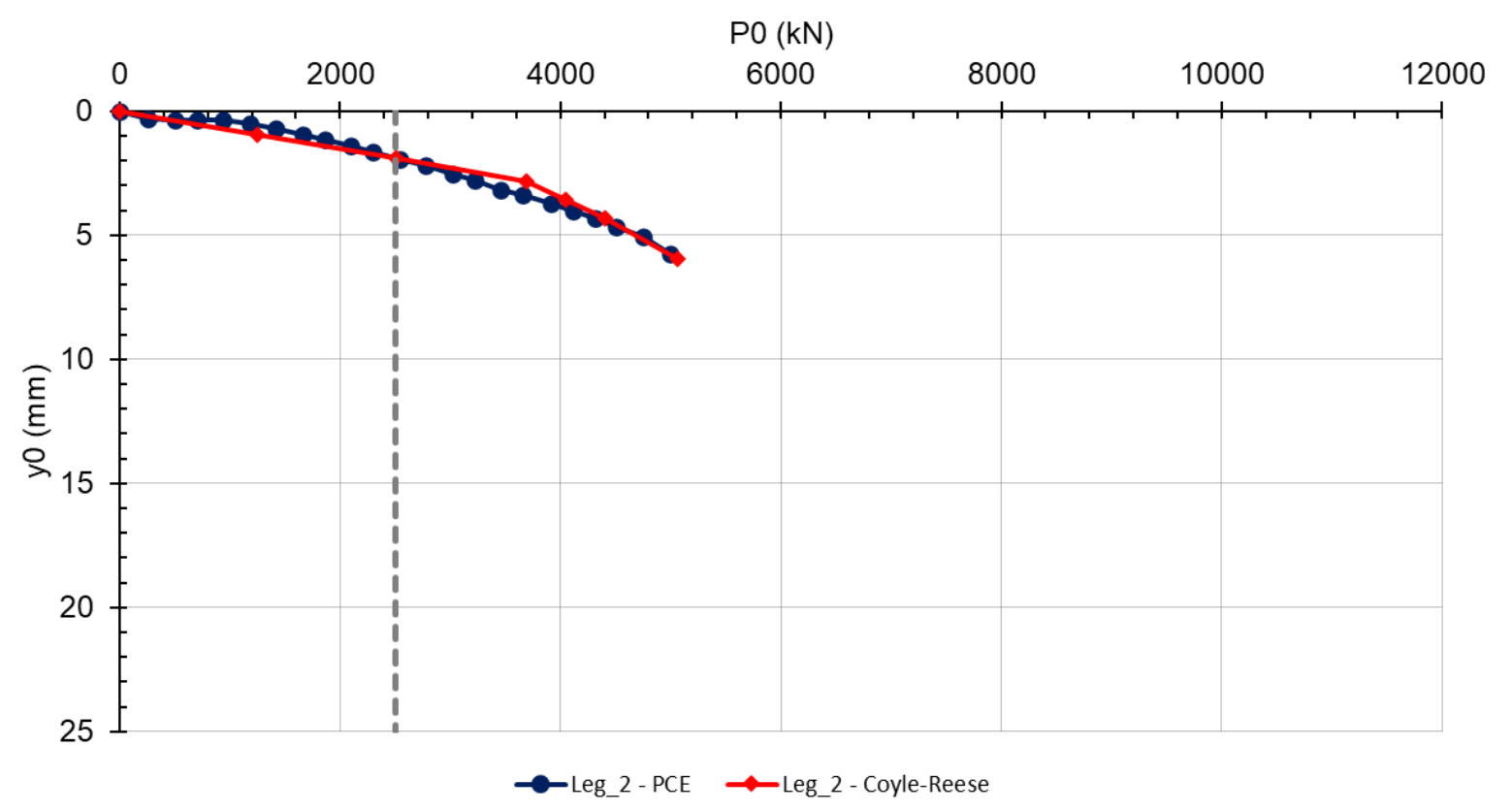

Figura 103: aplicação do modelo para o ensaio Leg_2. 


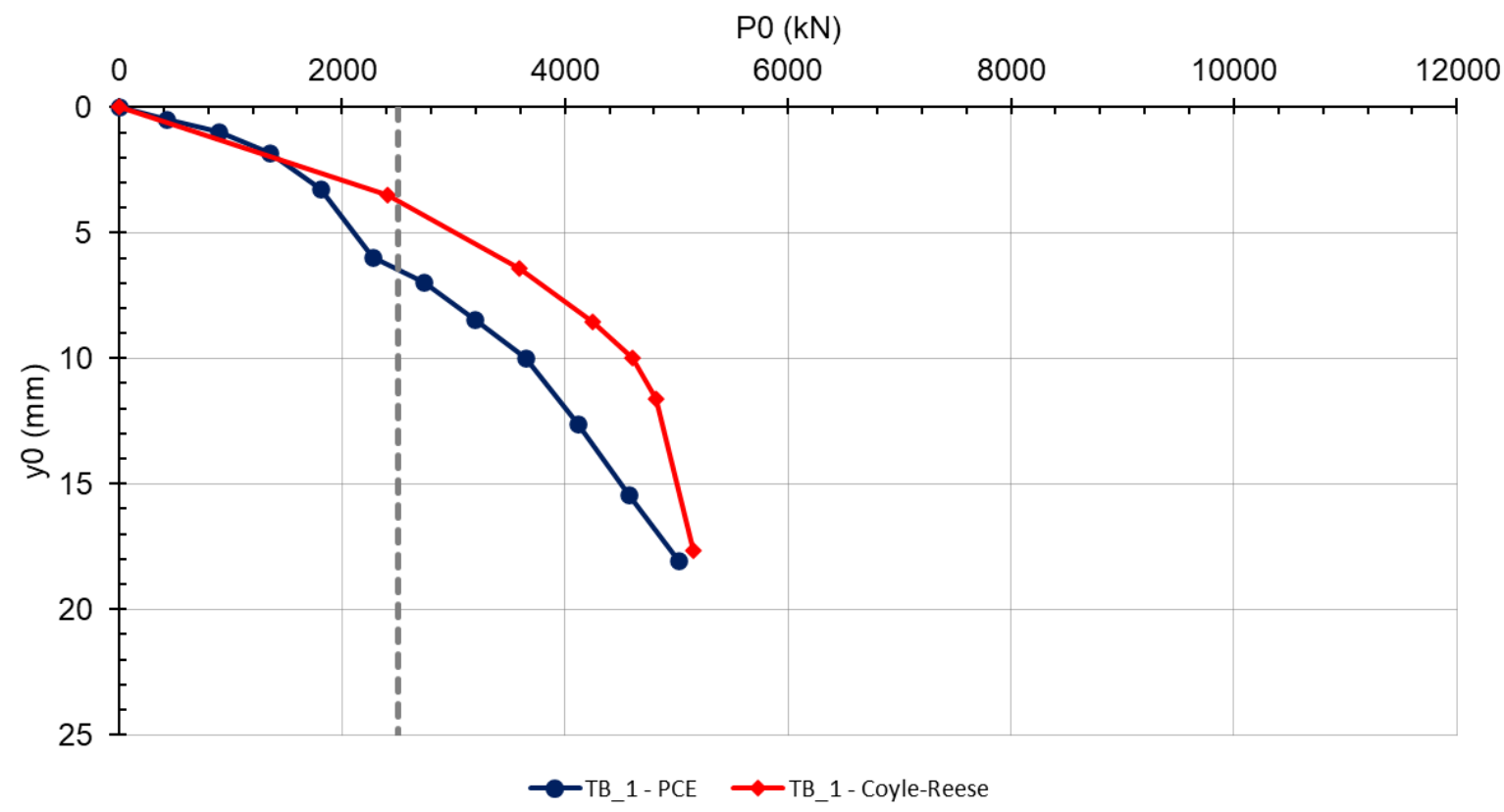

Figura 104: aplicação do modelo para o ensaio TB_1.

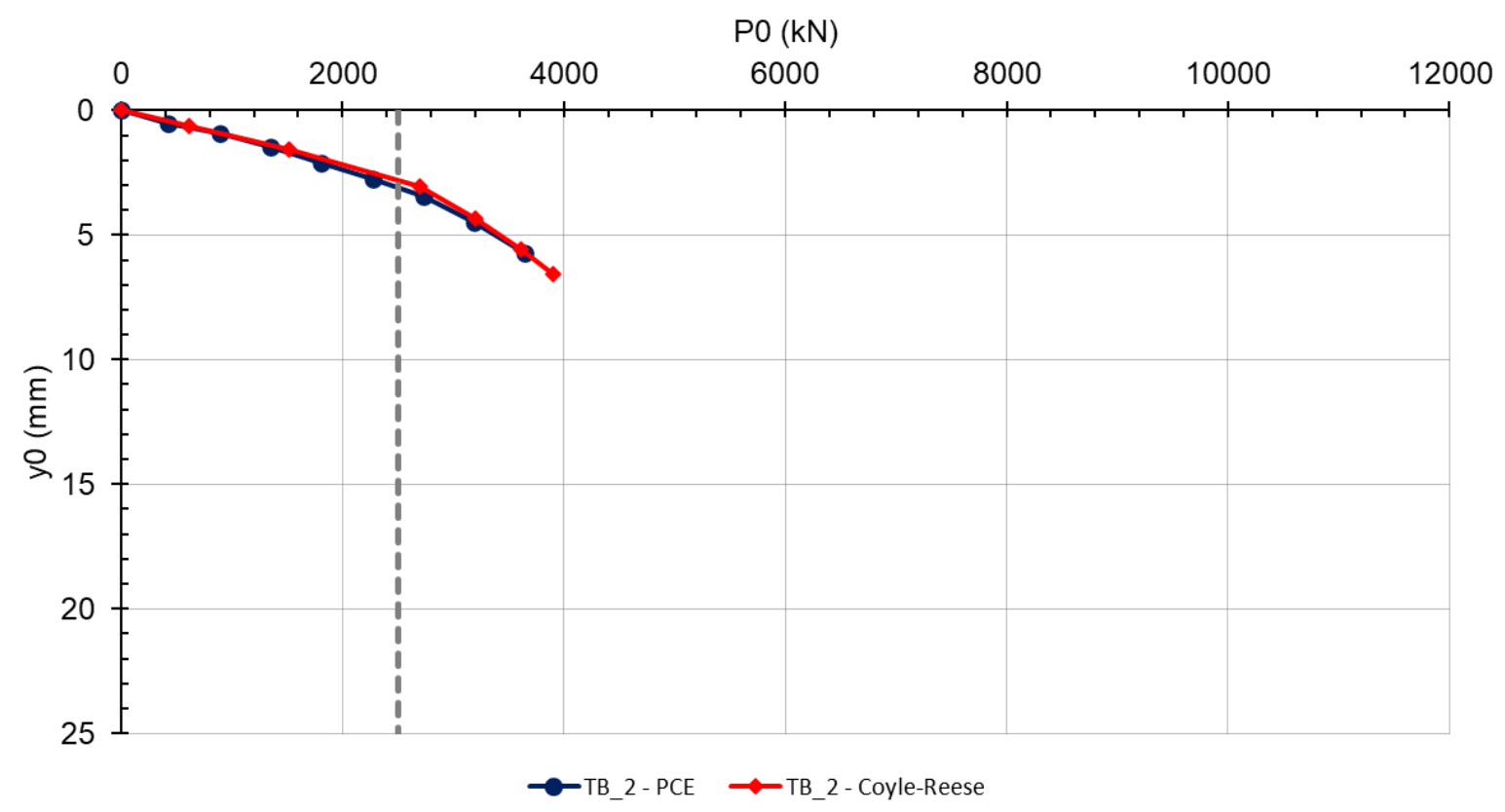

Figura 105: aplicação do modelo para o ensaio TB_2. 


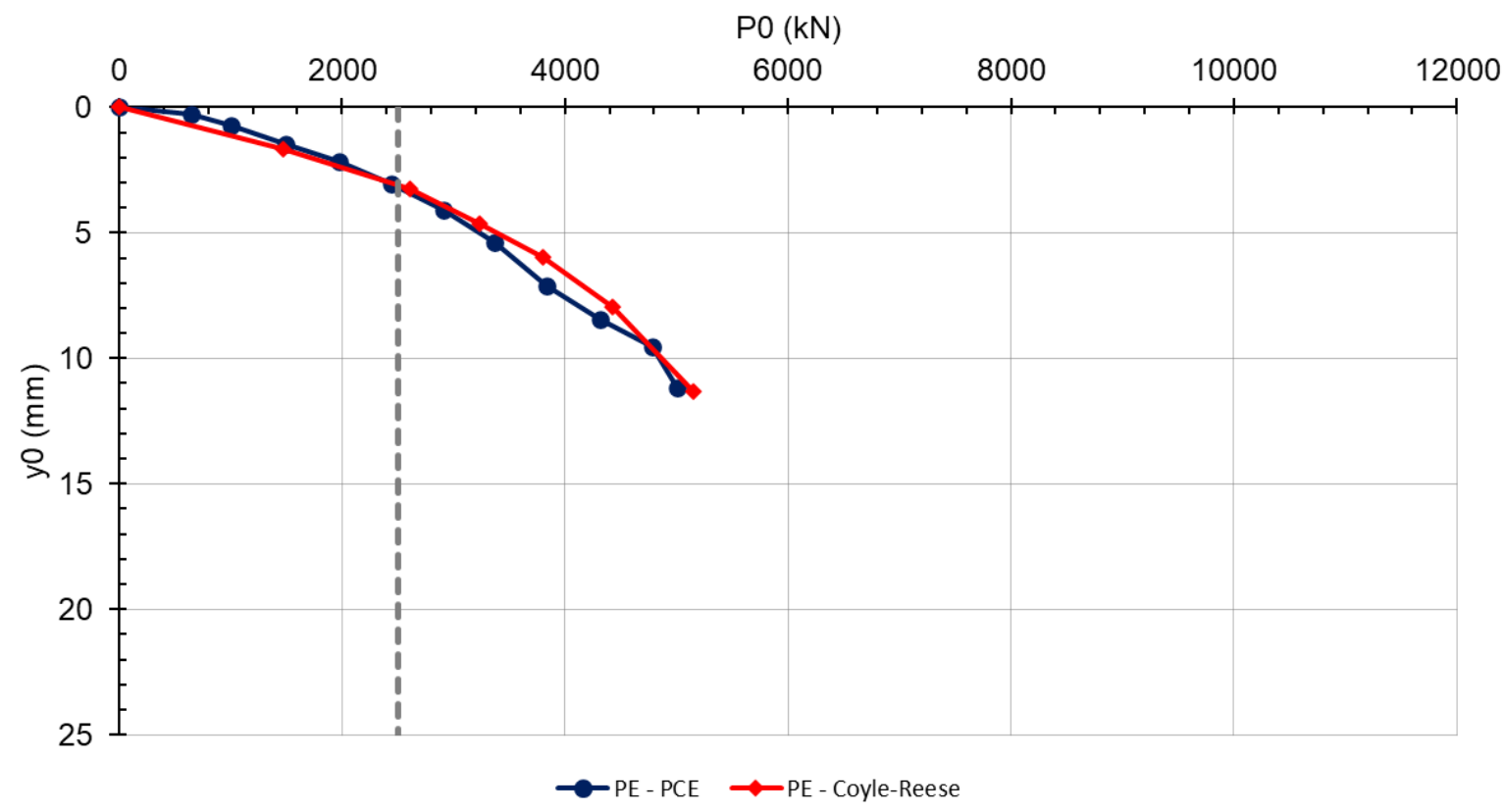

Figura 106: aplicação do modelo para o ensaio PE.

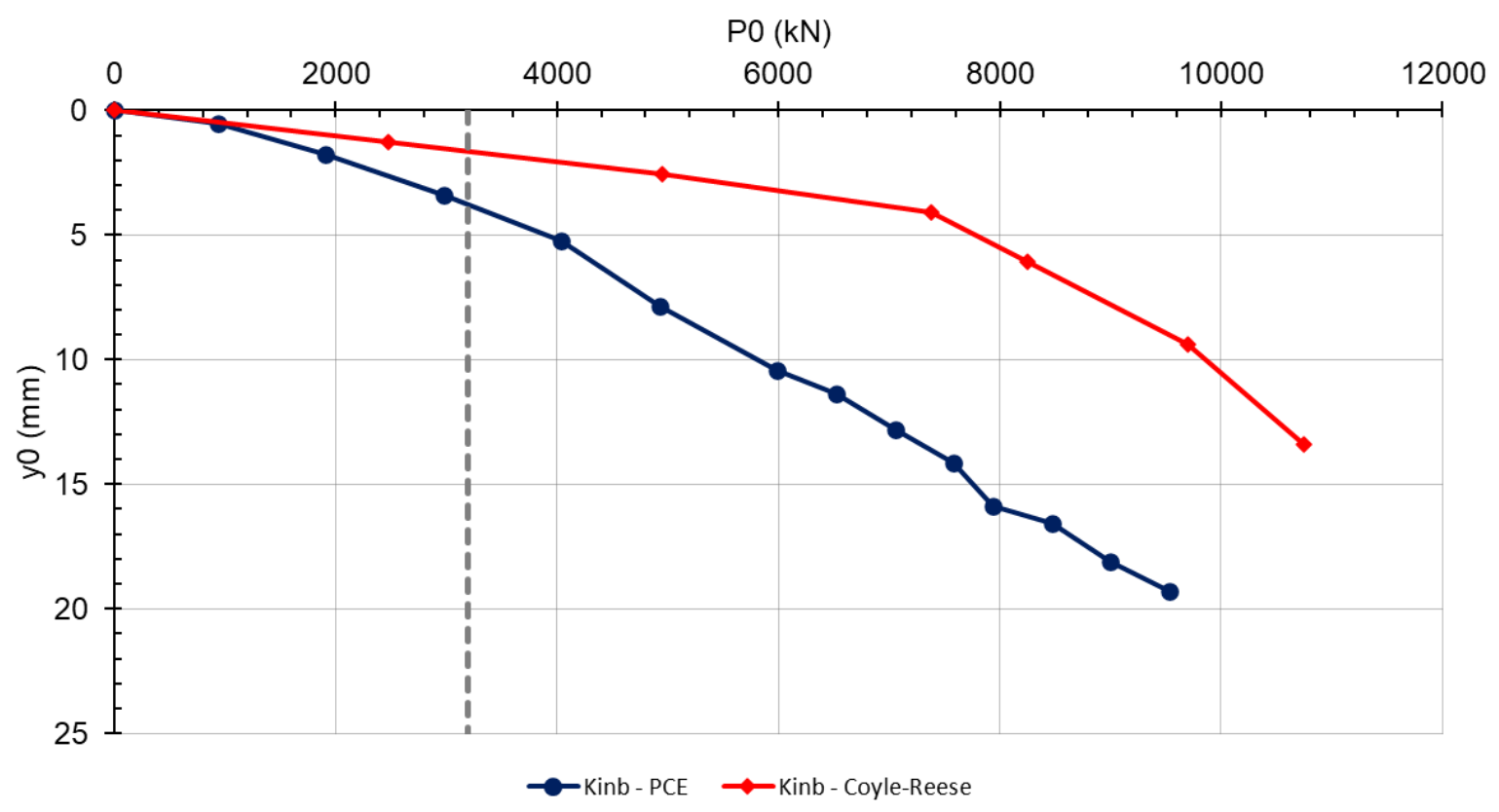

Figura 107: aplicação do modelo para o ensaio Kinb.

Observa-se que, utilizando os parâmetros obtidos nos itens 4.3 e 4.4, com poucas adaptações, os resultados apresentam razoável aderência na maioria dos casos. Os ensaios CJM, VdF_2, Corp_1, Leg_2, TB_2 e PE apresentaram boa aderência ao longo de quase todo o carregamento, com pequena diferença entre os deslocamentos estimados pelo modelo e medidos. Já PçaFP, Terr_50, Terr_54, Trin 
e Kinb apresentaram diferença significativa entre as curvas estimada pelo modelo e medida no ensaio. Para os demais ensaios, a aderência foi apenas razoável.

Observa-se que em nove dos quinze casos a curva obtida pelo modelo apresentou deslocamentos sensivelmente inferiores aos observados nos ensaios, o que é contra a segurança para a simulação de uma situação real de carregamento. $A$ estimativa da carga de ruptura, nessa análise, não é o principal objetivo - o maior interesse na aplicação do modelo é a estimativa dos deslocamentos da estaca na carga de trabalho. A Figura 108 ilustra as diferenças entre o valor do deslocamento na carga de trabalho estimado pelo modelo e medido no ensaio, para todos os casos analisados.

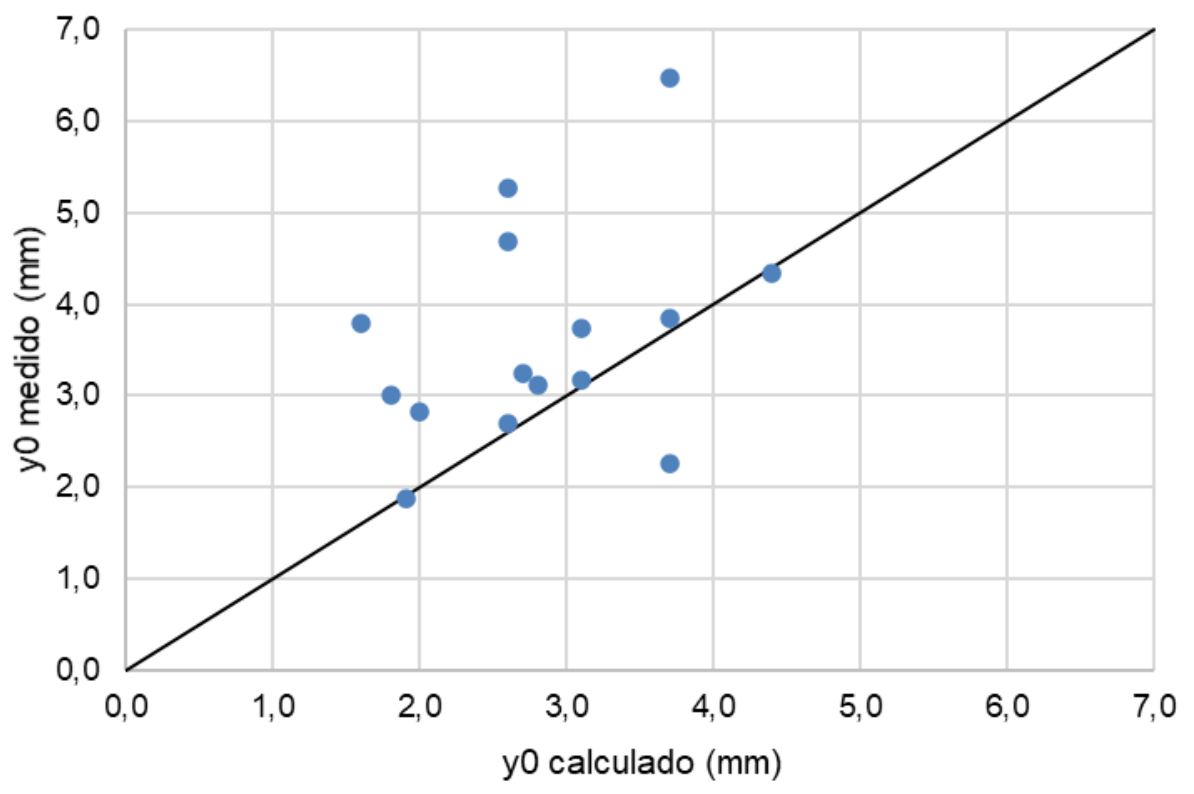

Figura 108: comparação entre os recalques na carga de trabalho estimados pelo modelo e medidos pelos ensaios.

\subsubsection{Aplicação do modelo com a adaptação dos parâmetros}

Com o intuito de diminuir as disparidades observadas e calibrar o modelo para que ele esteja mais próximo da situação real de carregamento da estaca, além de estar um pouco mais a favor da segurança, os parâmetros da Tabela 52 foram adaptados e as curvas estimadas pelo modelo, recalculadas. Os resultados dessa análise estão apresentados na Tabela 54 e nas Figuras 109 a 123. 
Tabela 54: parâmetros de Cambefort adaptados para a calibração do modelo de análise.

\begin{tabular}{|c|c|c|c|}
\hline Solo & $\boldsymbol{\alpha}$ & $\mathbf{f}_{\operatorname{máx}}(\mathbf{k P a})$ & $\mathbf{y} \mathbf{1}(\mathbf{m m})$ \\
\hline Areia compacta superficial & 4,0 & - & 5,0 \\
\hline Argila SFL & - & 30 & 2,5 \\
\hline Argila AT & - & 70 & 5,0 \\
\hline Areia/silte & 2,1 & - & 5,0 \\
\hline
\end{tabular}

Observou-se que a maneira mais eficiente para fazer com que as curvas calculadas pelo modelo se aproximassem das curvas reais medidas no ensaio foi a calibração do coeficiente $\mathrm{y}_{1}$, apesar de 0 valor de $5 \mathrm{~mm}$ adotado para a argila AT estar acima dos encontrados nas funções de transferência de carga do item 4.3.

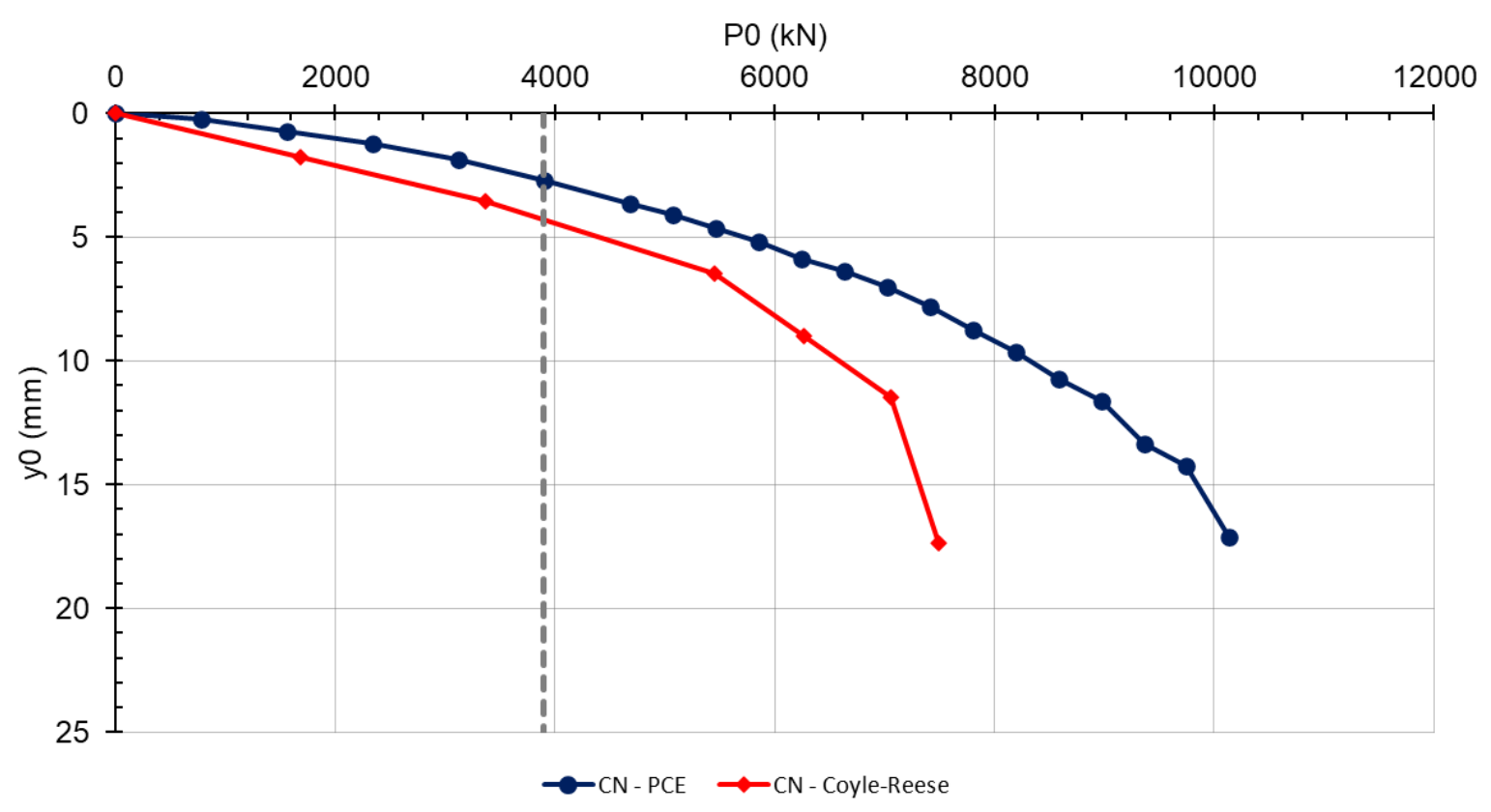

Figura 109: aplicação do modelo com os coeficientes adaptados para o ensaio CN. 


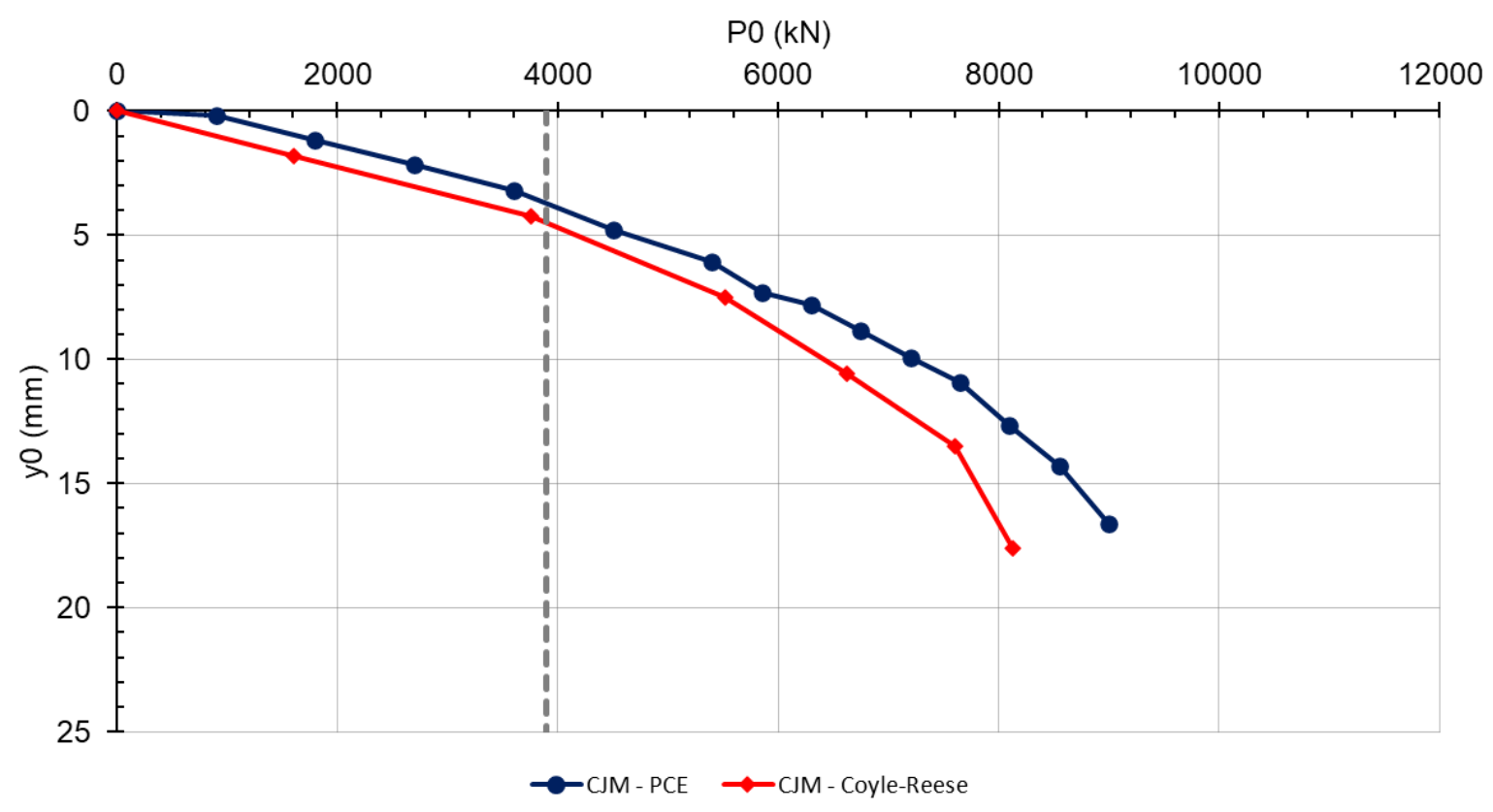

Figura 110: aplicação do modelo com os coeficientes adaptados para o ensaio CJM.

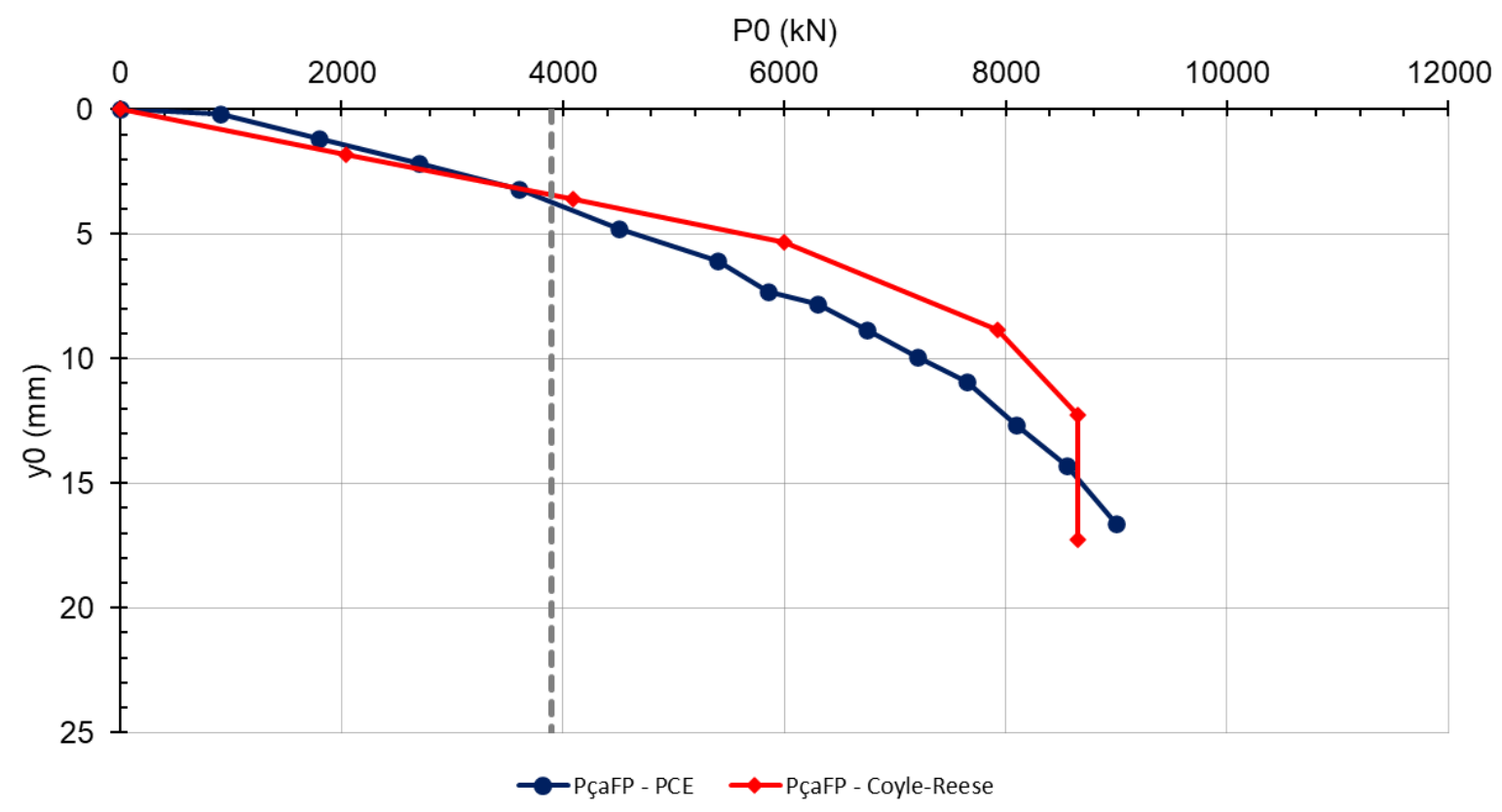

Figura 111: aplicação do modelo com os coeficientes adaptados para o ensaio PçaFP. 


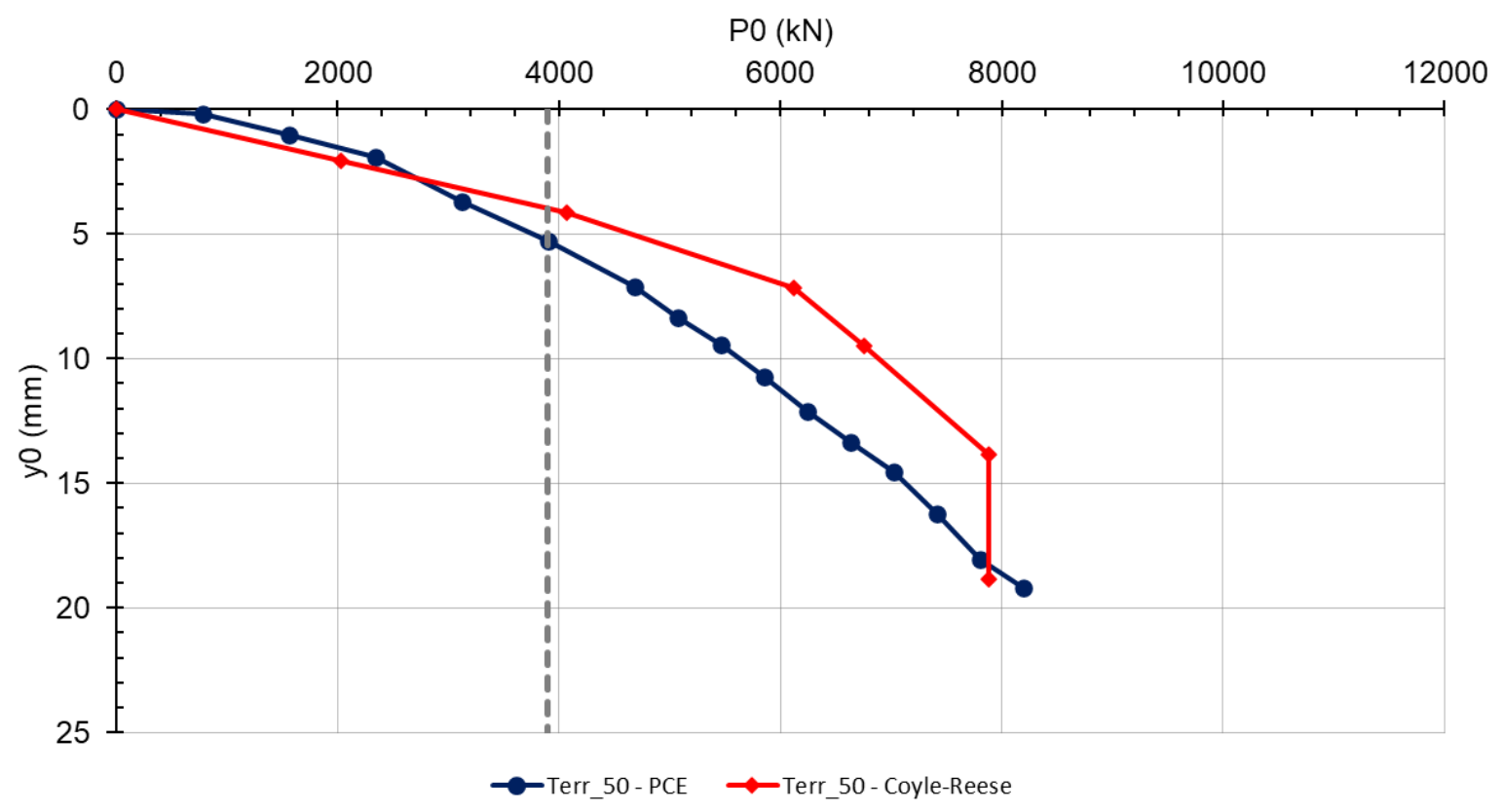

Figura 112: aplicação do modelo com os coeficientes adaptados para o ensaio Terr_50.

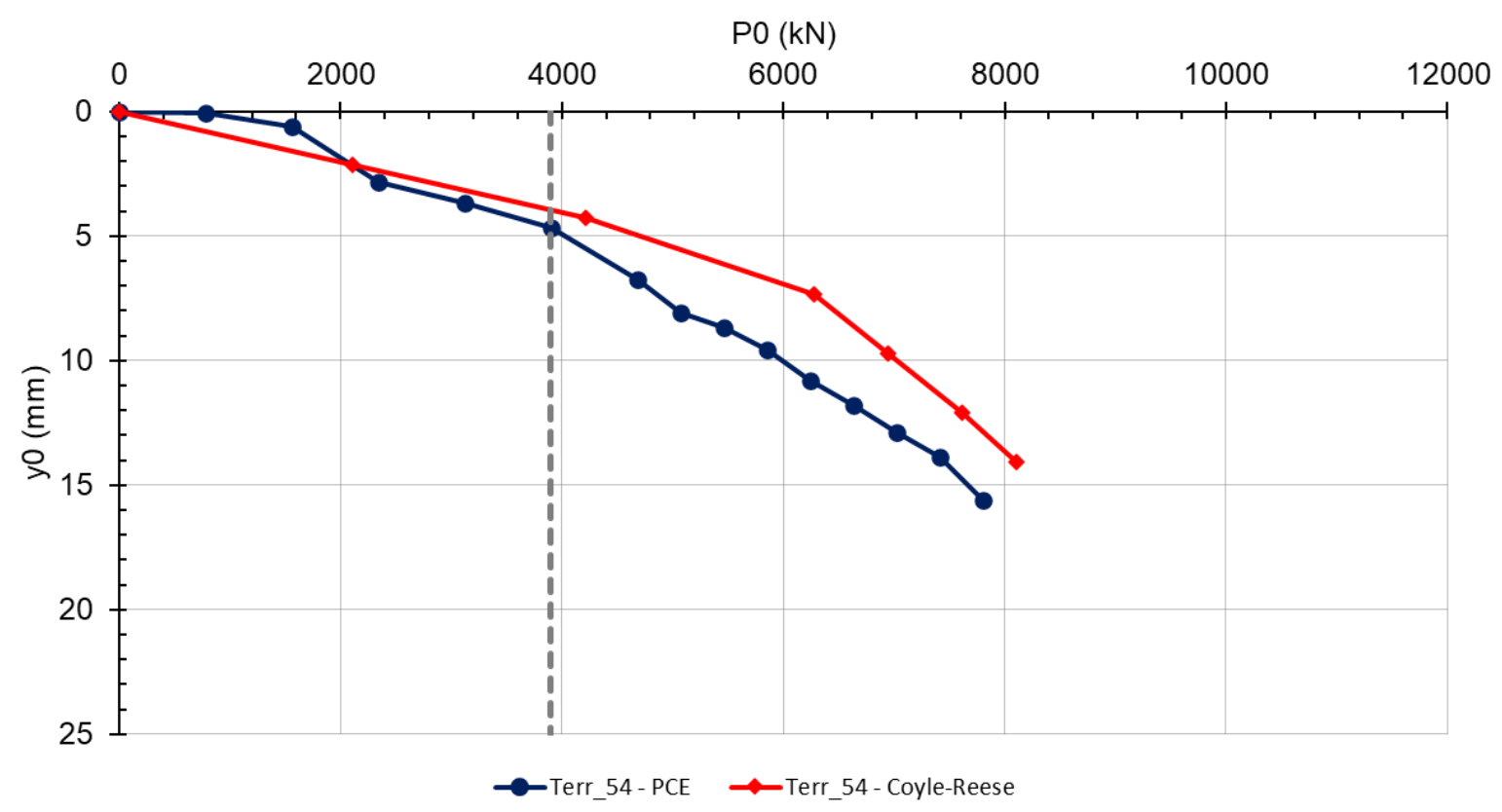

Figura 113: aplicação do modelo com os coeficientes adaptados para o ensaio Terr_54. 


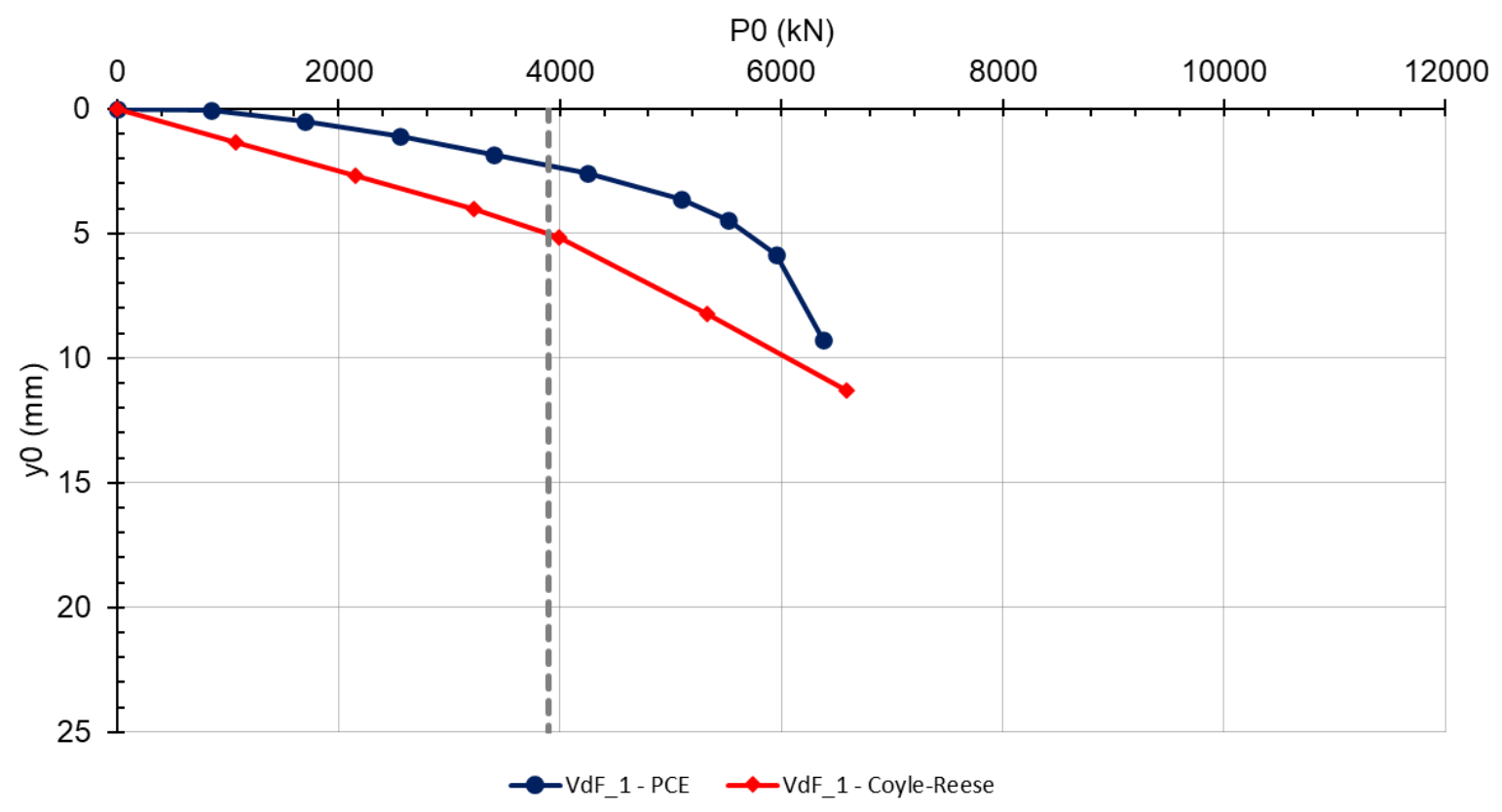

Figura 114: aplicação do modelo com os coeficientes adaptados para o ensaio VdF_1.

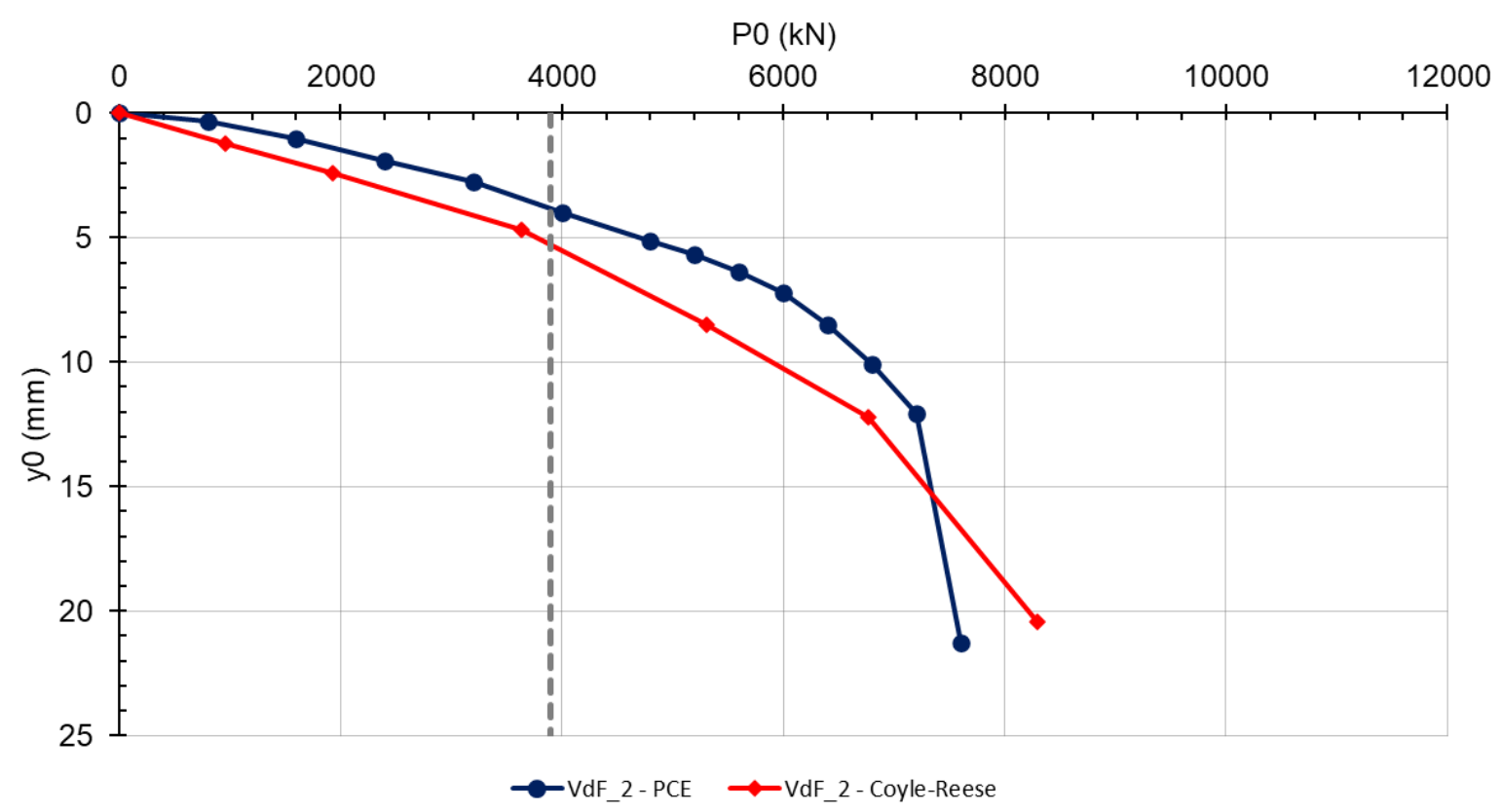

Figura 115: aplicação do modelo com os coeficientes adaptados para o ensaio VdF_2. 


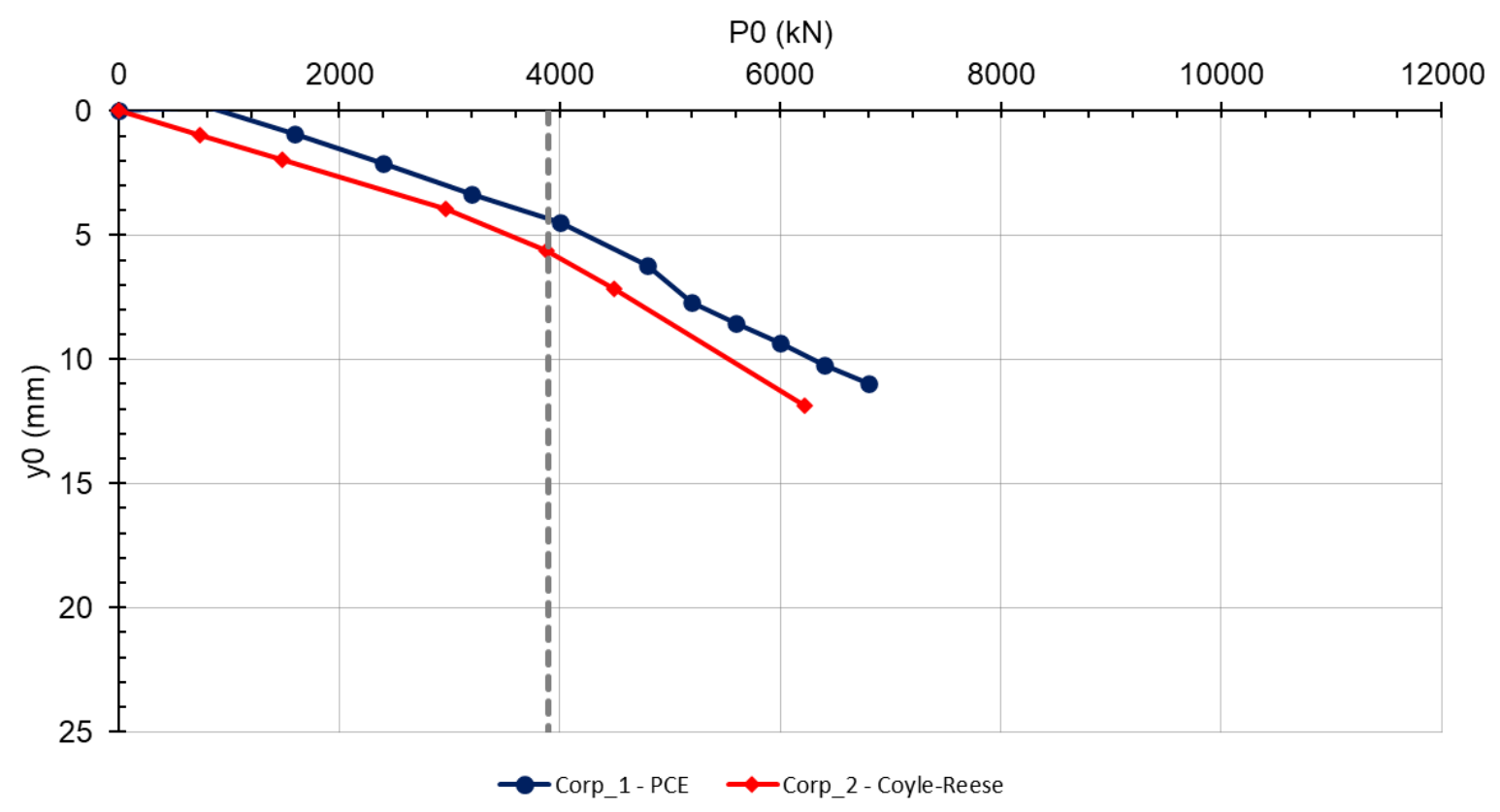

Figura 116: aplicação do modelo com os coeficientes adaptados para o ensaio Corp_1.

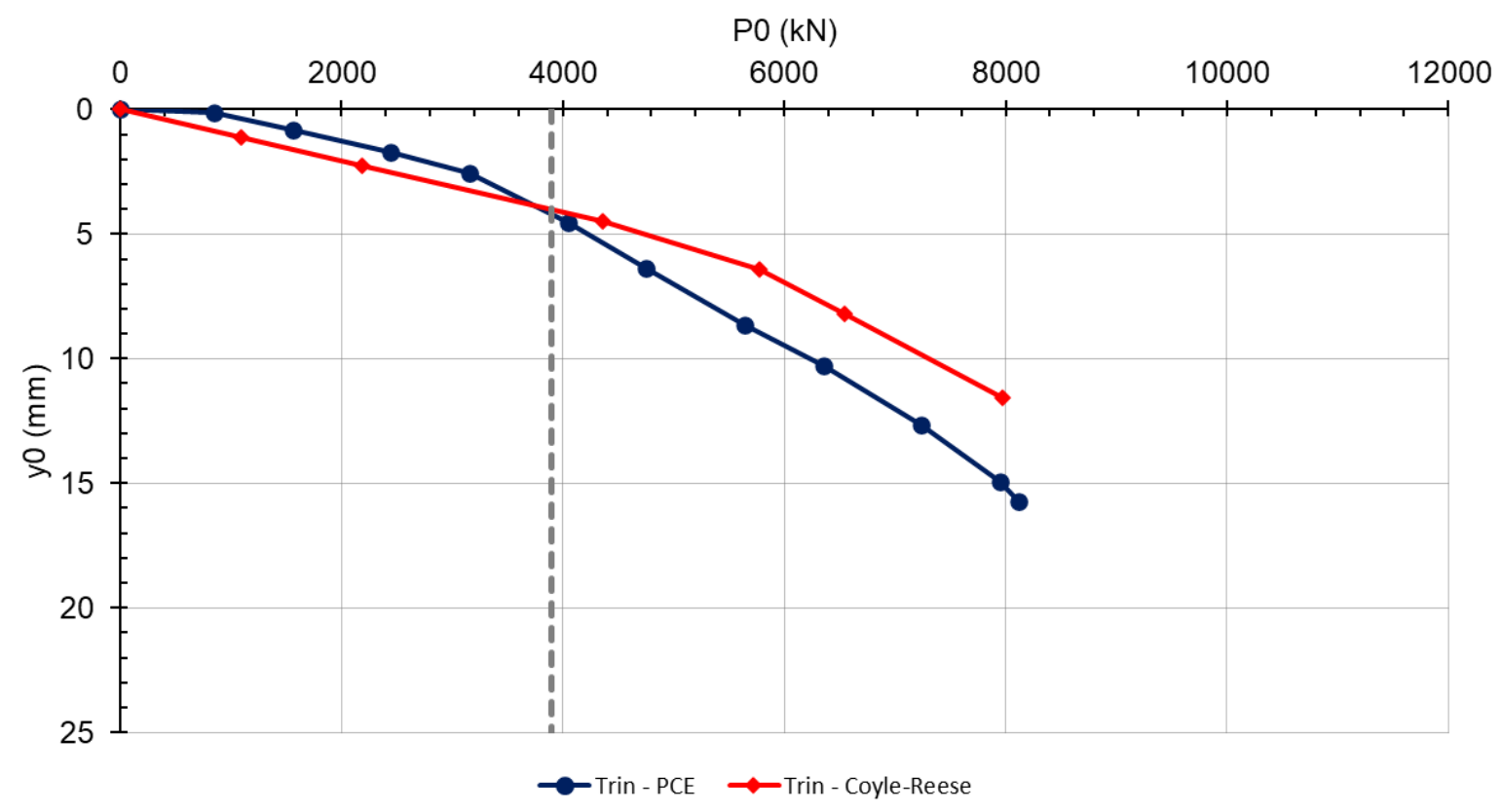

Figura 117: aplicação do modelo com os coeficientes adaptados para o ensaio Trin. 


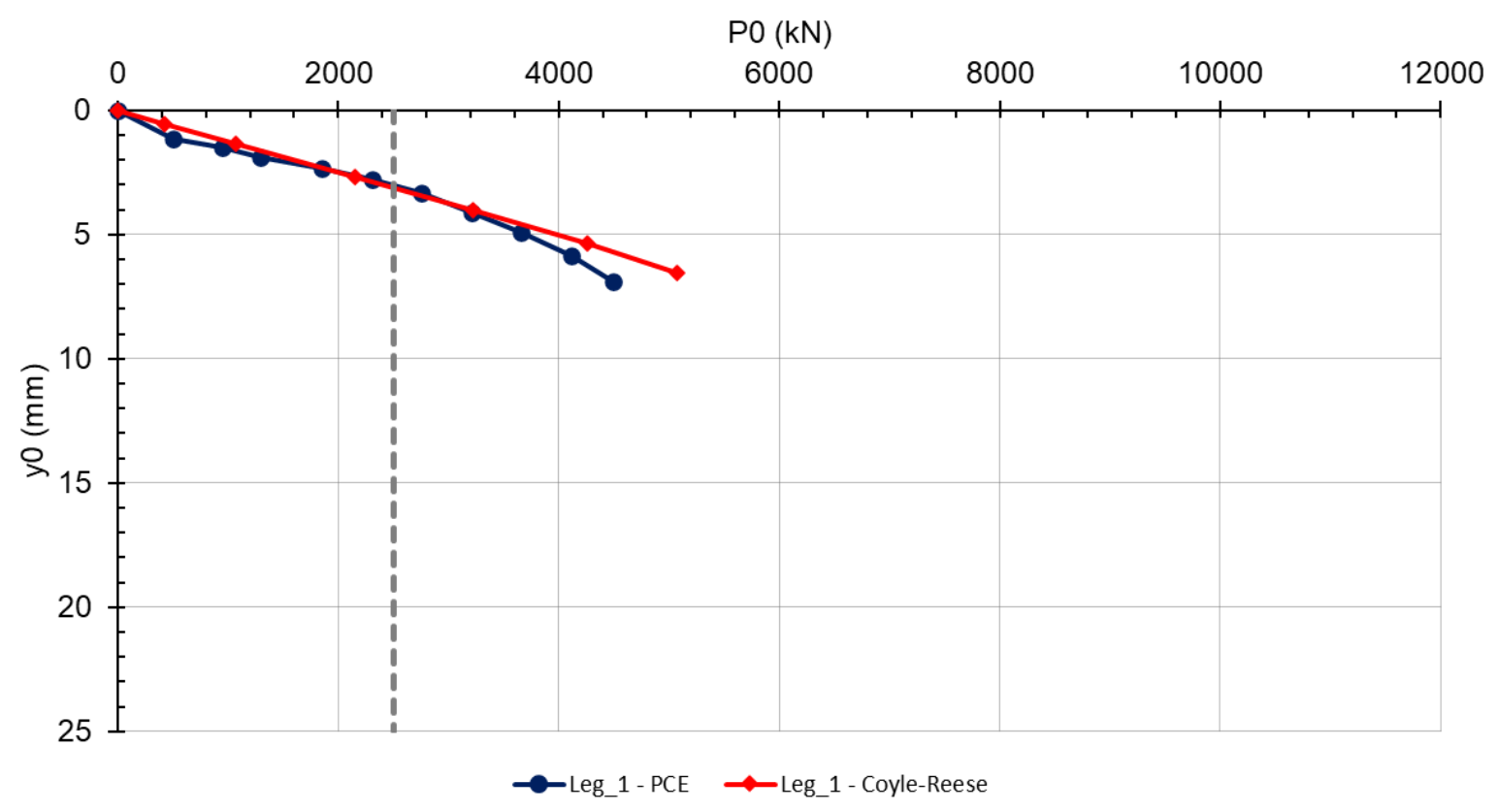

Figura 118: aplicação do modelo com os coeficientes adaptados para o ensaio Leg_1.

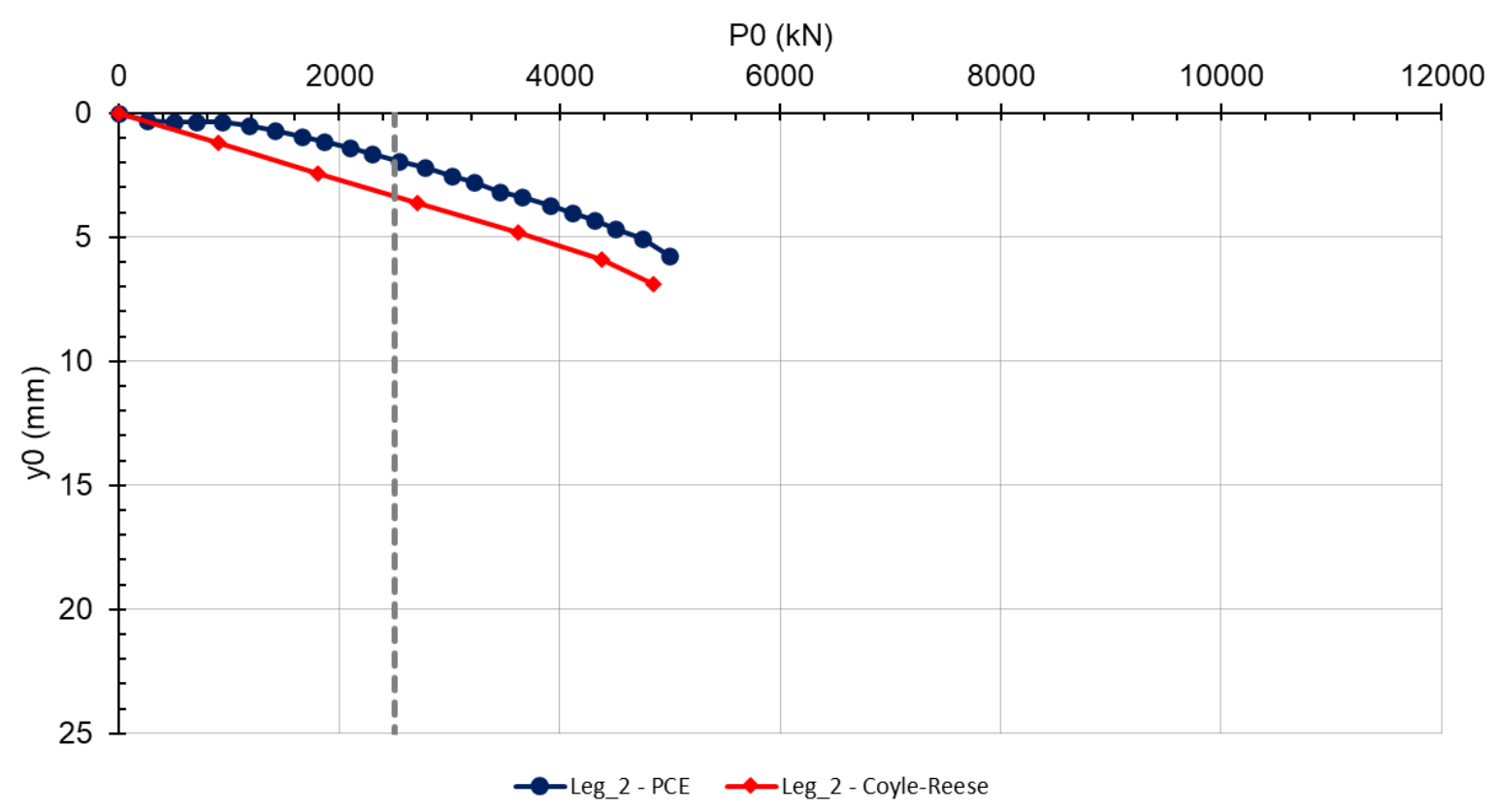

Figura 119: aplicação do modelo com os coeficientes adaptados para o ensaio Leg_2. 


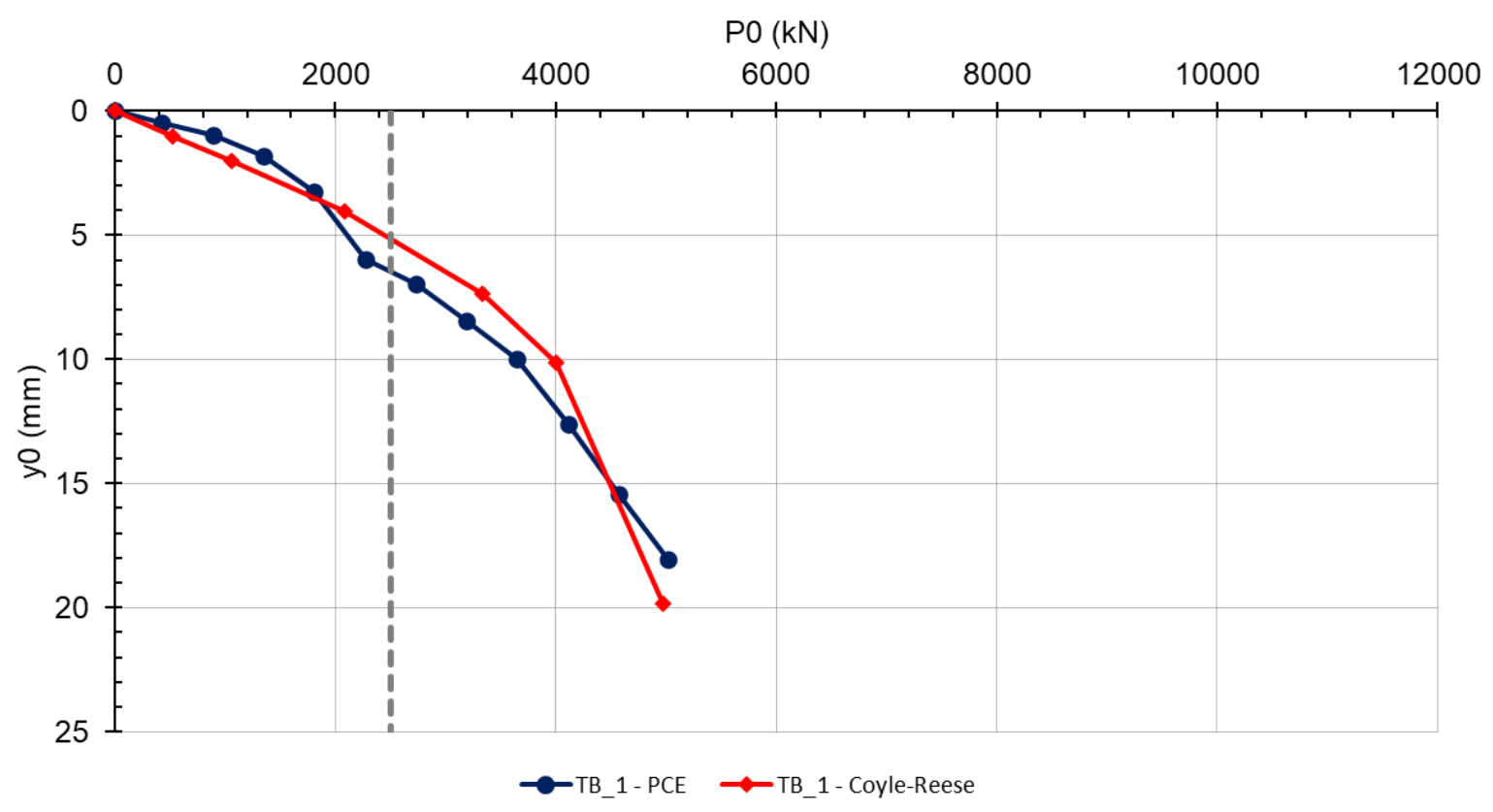

Figura 120: aplicação do modelo com os coeficientes adaptados para o ensaio TB_1.

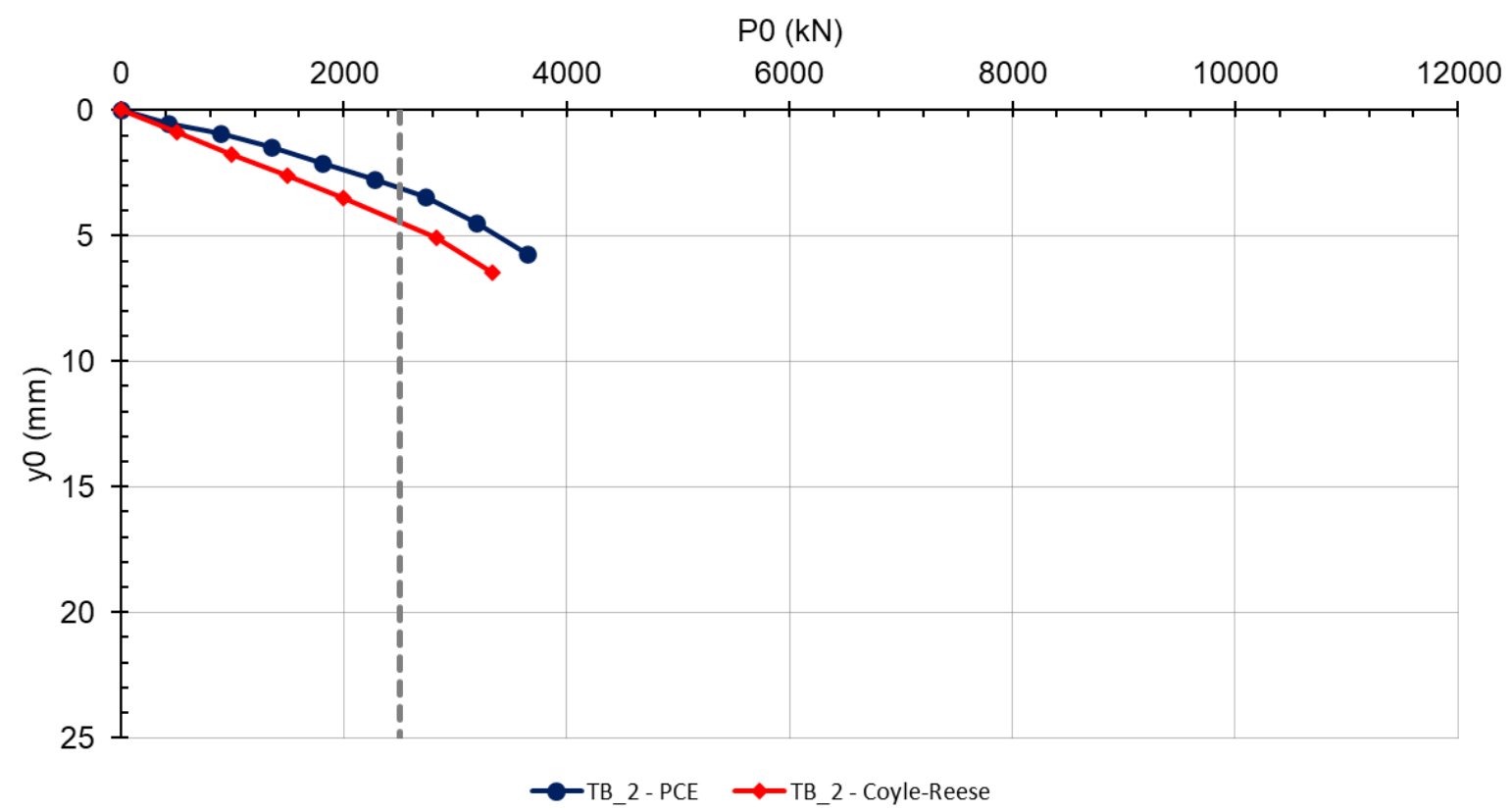

Figura 121: aplicação do modelo com os coeficientes adaptados para o ensaio TB_2. 


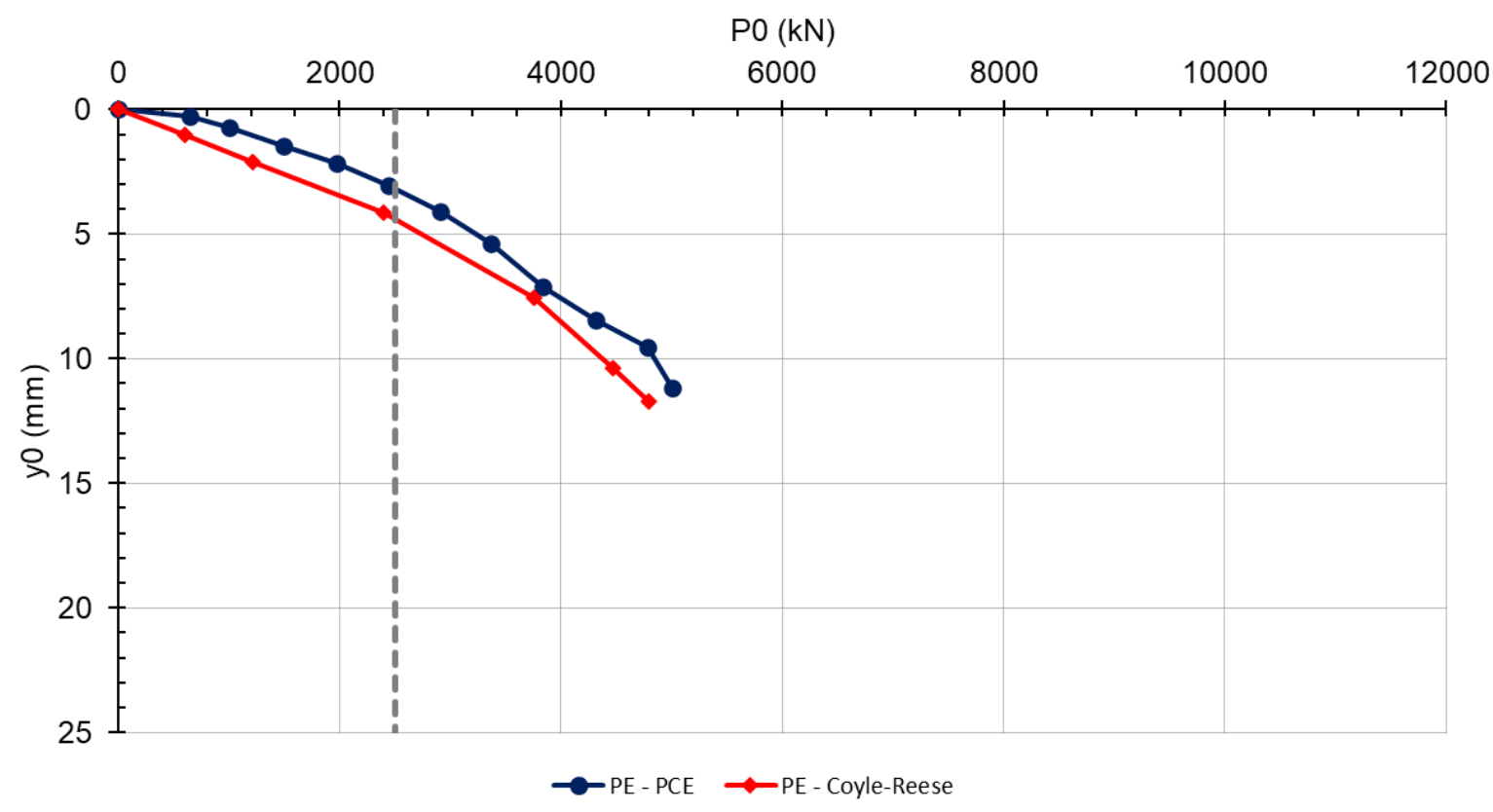

Figura 122: aplicação do modelo com os coeficientes adaptados para o ensaio PE.

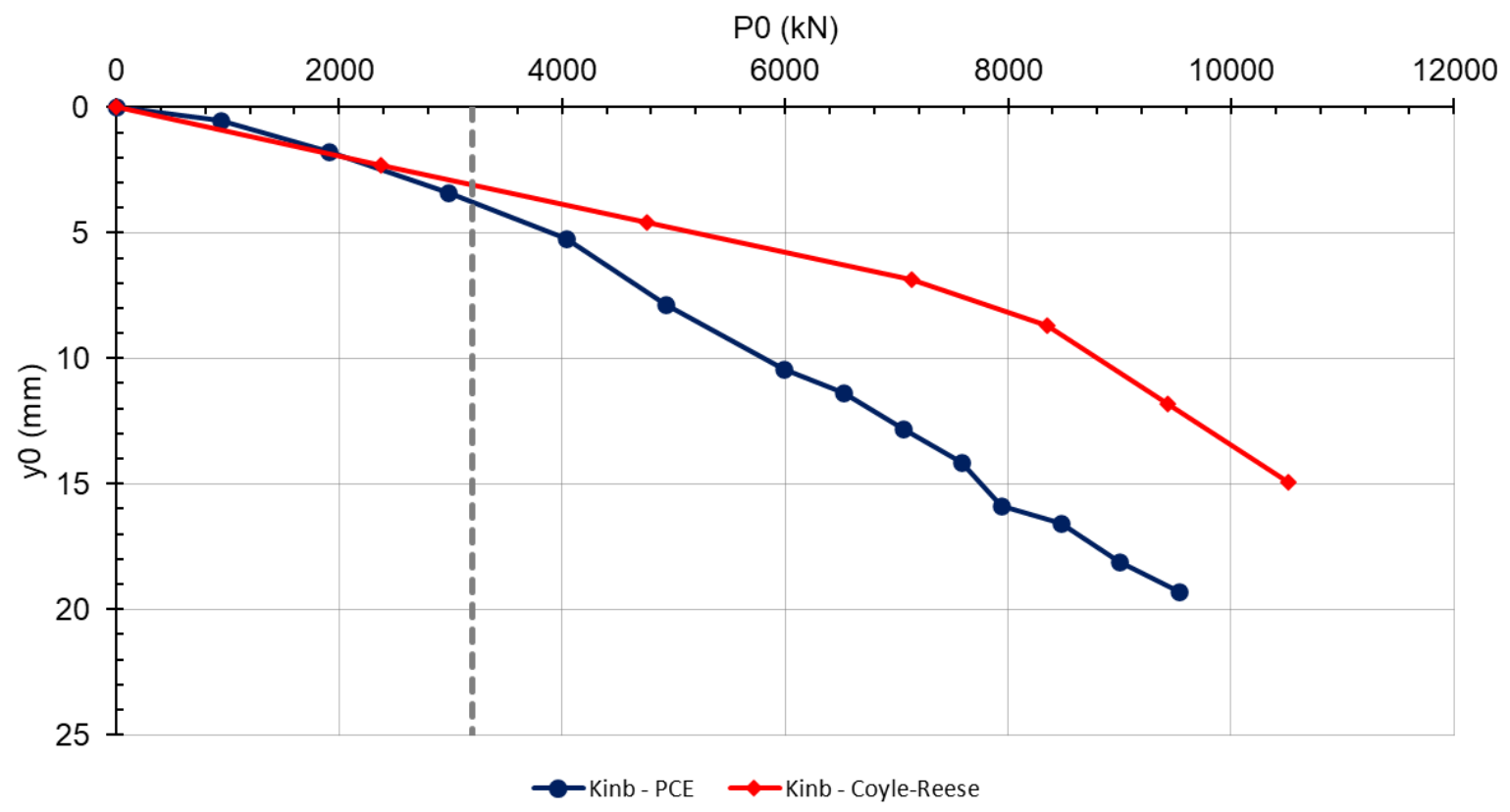

Figura 123: aplicação do modelo com os coeficientes adaptados para o ensaio Kinb.

Após a adaptação dos parâmetros, as curvas continuaram apresentando boa aderência, com um ligeiro "deslocamento" da maioria das curvas calculadas para baixo, em relação às medidas no ensaio - comportamento a favor da segurança, principalmente para a análise do deslocamento na carga de trabalho, como se pode 
observar na Figura 124. Alguns ensaios que apresentaram ótima aderência do início do ensaio até a carga de trabalho apresentaram comportamento bastante diferente a partir desse ponto, com deslocamentos bem menores do que os medidos no ensaioprincipalmente em PçaFP, Terr_50, Terr_54, Trin e Kinb. O ensaio Kinb, no entanto, pode ser considerado uma exceção neste trabalho, pois foi realizado no município da Praia Grande, e não em Santos - apesar de ainda estar na Baixada Santista, o perfil geotécnico típico da Praia Grande é um pouco diferente e apresenta maior predominância de camadas arenosas.

É interessante observar que as provas de carga TB_1 e TB_2, que foram realizadas em estacas diferentes de uma mesma obra, apresentaram comportamentos muito diferentes, e o modelo foi capaz de representar esses comportamentos com boa aderência, apenas com os dados das sondagens mais próximas das estacas ensaiadas.

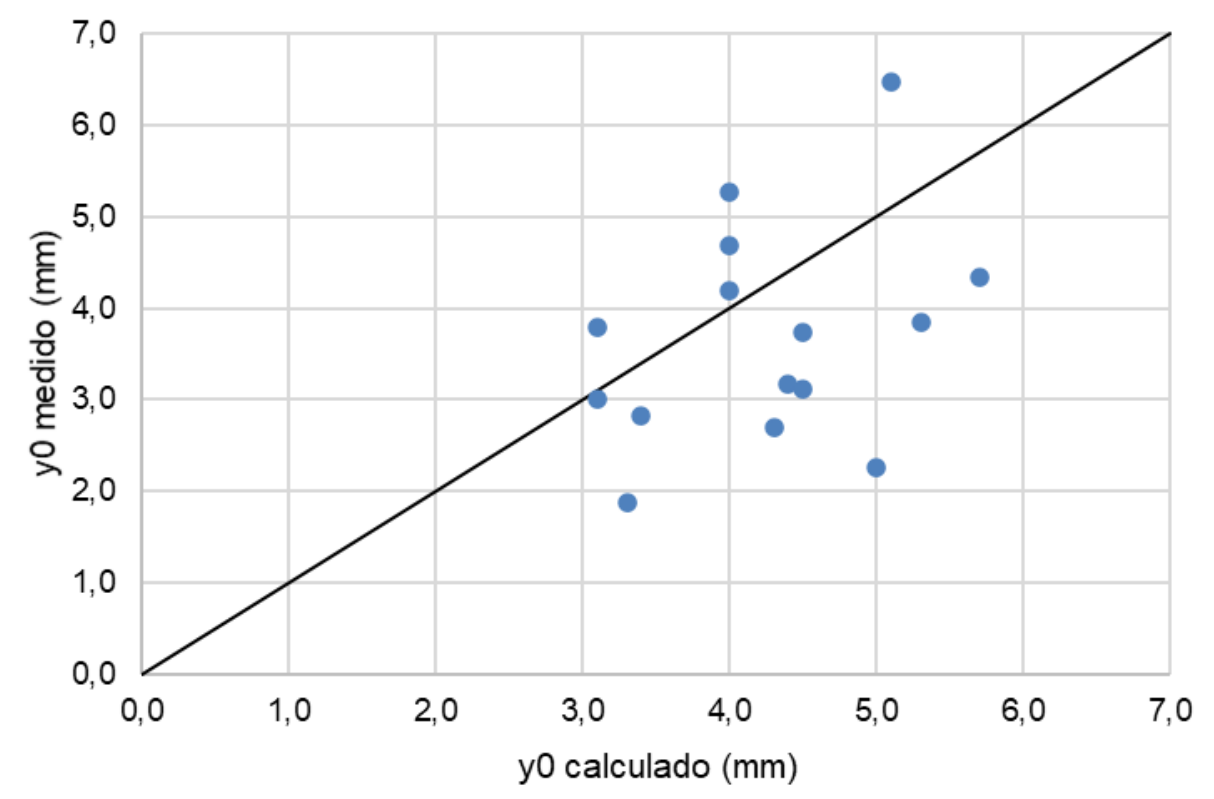

Figura 124: comparação entre os recalques na carga de trabalho estimados pelo modelo (com os parâmetros adaptados) e medidos pelos ensaios. 


\section{CONCLUSÕES}

\subsection{Sobre as estimativas de capacidade de carga por métodos semiempíricos}

A aplicação dos métodos semiempíricos consagrados com base no SPT para o cálculo de capacidade de carga dos estacões analisados neste trabalho confirmou que as estacas estavam superdimensionadas. A relação entre a carga máxima medida e a carga média estimada por 3 métodos semiempíricos foi de $80 \%$, sendo que em um caso esse valor chegou a $40 \%$. A razão principal desse comportamento reside no fato de a carga na ponta ter sido praticamente nula, ou seja, não foi mobilizada. Das seis estacas com instrumentação em profundidade, duas tinham strain gages próximos à ponta real da estaca, e esses indicaram deformações muito baixas, mesmo nos estágios finais de carregamento - e, consequentemente, a carga medida nesse nível era praticamente nula.

\subsection{Sobre as análises das provas de carga instrumentadas em profundidade}

A aplicação do Método do Módulo Tangente de Fellenius (1989) revelou valores do módulo de elasticidade do concreto variando na faixa de 19 a $33 \mathrm{GN}$, com média de $28 \mathrm{GN}$.

Para quatro ensaios instrumentados $-\mathrm{CN}, \mathrm{VdF}$ 2, Corp_1 e Trin - foi possível construir os diagramas de transferência de carga e as funções de transferência de carga (ou Relações de Cambefort) para o atrito lateral unitário. Porém, devido ao fato de a grande maioria dos ensaios analisados não ter atingido a ruptura geotécnica, só foi possível determinar satisfatoriamente os parâmetros da $1^{\underline{a}}$ Lei de Cambefort $f_{\text {máx }} \mathrm{e}$ y1 para alguns trechos entre strain gages. Os valores de $f_{\text {máx }}$ situaram-se, em geral, pouco acima dos valores usuais indicados na literatura técnica, com cifras de 45 a $50 \mathrm{kPa}$ para a areia compacta superficial; 12 a $45 \mathrm{kPa}$ para a argila SFL e 80 a $100 \mathrm{kPa}$ para a argila AT. Já os valores de $\mathrm{y}_{1}$, de 2 a $3 \mathrm{~mm}$ para a areia superficial (holocênica) e as argilas SFL, foram comparáveis aos da literatura, o mesmo não ocorrendo com a argila AT, com y 1 igual a $2 \mathrm{~mm}$, bem abaixo dos $5 \mathrm{~mm}$ indicados na literatura. 


\subsection{Sobre o efeito "estaca T"}

Quanto à análise do efeito "estaca T", sua possível influência foi observada apenas no ensaio Trin, no qual foi constatada diminuição do atrito lateral unitário da camada de argila SFL logo abaixo da areia compacta superficial. Como esse fenômeno foi observado em apenas um dos seis ensaios instrumentados, pode-se concluir, a princípio, que ele não é determinante na simulação das curvas cargarecalque no topo de estacas escavadas através do método Coyle-Reese (1966). Essa afirmação é corroborada pelo fato de que foi possível atingir razoável aderência entre as curvas teóricas e reais dos ensaios, principalmente nos trechos iniciais das curvas, como mostrado no item 4.5 .

\subsection{Sobre a adaptação dos coeficientes do método Falconi-Perez (2008) para estimar a capacidade de carga}

Um dos objetivos deste trabalho foi a adaptação do método semiempírico de cálculo de capacidade de carga Falconi-Perez (2008), desenvolvido originalmente para perfis metálicos cravados na Baixada Santista, para que pudesse ser utilizado para estacões nessa região.

Infelizmente, devido ao fato de a grande maioria dos ensaios analisados não ter atingido a ruptura geotécnica, não foi possível determinar satisfatoriamente os valores do atrito lateral na ruptura para o método ser utilizado para estacões. Além disso, para o cálculo da capacidade de carga de uma estaca, é imprescindível calcular sua resistência de ponta. Como se pode observar no item 4.3, para praticamente todos os ensaios, foi considerada carga zero na ponta das estacas - nem todos os ensaios instrumentados apresentavam strain gages próximos à ponta real da estaca e, quando apresentavam, mesmo nos estágios finais de carregamento, a deformação medida e, consequentemente, a carga calculada - nesse nível era muito baixa. Assim, não foi possível avaliar o cálculo da resistência de ponta dos estacões pelo método de Falconi-Perez (2008). Uma possibilidade era a utilização dos coeficientes originais do método para o cálculo de capacidade de carga da ponta da estaca, apresentados na Tabela 12, e adaptar apenas os parâmetros de capacidade de carga por atrito lateral a partir das análises feitas no item 4.4. Porém, como mencionado anteriormente, não 
haveria como aferir esse cálculo, pois não foram extraídos dados reais de resistência de ponta dos estacões a partir das provas de carga instrumentadas. Além disso, a resistência de ponta dos estacões é fortemente influenciada pelo método executivo de escavação, e é bastante diferente da resistência de ponta de uma estaca cravada, caso dos perfis metálicos para as quais o método Falconi-Perez (2008) foi concebido.

Assim, os parâmetros de cálculo de capacidade de carga por atrito lateral pelo método Falconi-Perez (2008) foram analisados e adaptados apenas para serem utilizados pelo método de Coyle-Reese (1966), com o objetivo de se obter o melhor ajuste entre as curvas carga-recalque medidas e calculadas pelo método, para cada prova de carga estática.

\subsection{Sobre o uso do método de Coyle-Reese (1966) para simular a curva carga- recalque do topo da estaca}

A simulação da curva carga-recalque do topo da estaca foi possível ajustando os parâmetros obtidos pelas provas de carga com instrumentação em profundidade e os coeficientes do método Falconi-Perez (2008), a partir da Tabela 52, com uma importante contribuição: a diferenciação do comportamento da areia compacta superficial em relação às areias e siltes em profundidade, conforme preconizado pelo método.

Observou-se que a calibração do parâmetro $\mathrm{y}_{1}$ foi a maneira mais eficiente para fazer com que as curvas calculadas pelo modelo se aproximassem das curvas reais medidas no ensaio. Adotou-se $2,5 \mathrm{~mm}$ para a argila SFL e $5 \mathrm{~mm}$ para as areias, siltes e a argila AT. A cifra de $5 \mathrm{~mm}$ para esses solos é consistente com dados da literatura técnica (Tabelas 2 e 3), mas não com os resultados das análises das provas de carga instrumentadas (Tabela 40).

Como resultado, observou-se que as curvas apresentaram, de maneira geral, uma boa aderência, principalmente no que diz respeito ao comportamento até a carga de trabalho. Como era esperado, para os estacões instrumentados os recalques associados às cargas de trabalho foram, em geral, superiores aos medidos, portanto,

a favor da segurança. Alguns ensaios que revelaram ótima aderência do trecho inicial até a carga de trabalho apresentaram comportamento bastante diferente a partir desse ponto, com deslocamentos bem menores do que os medidos no ensaio. É 
interessante observar que os ensaios TB_1 e TB_2, realizados em estacas diferentes de uma mesma obra, apresentaram comportamentos muito diferentes, e o modelo foi capaz de representar essa diferença de comportamento com boa aderência.

\subsection{Considerações finais}

O objetivo principal do trabalho foi a simulação da curva carga-recalque no topo de estacões na Baixada Santista, através do método de Coyle-Reese (1966), utilizando os coeficientes indicados na Tabela 54. Os resultados foram satisfatórios para a estimativa dos recalques na carga de trabalho das estacas, porém, não para a simulação do comportamento real da estaca ao longo de todo o carregamento, especialmente para a determinação da carga de ruptura. A adoção de $5 \mathrm{~mm}$ para o valor de $\mathrm{y}_{1}$ da areia compacta superficial, apesar de não ser coerente com algumas das conclusões das análises das provas de carga instrumentadas, apresentou melhores resultados para a simulação das curvas, principalmente para a estimativa do recalque na carga de trabalho, sendo a favor da segurança em relação à utilização de valores mais baixos de $\mathrm{y}_{1}$. A utilização do modelo apresentado neste trabalho, aliado a métodos semiempíricos de cálculo de capacidade de carga e à realização de provas de carga, pode ser ferramenta poderosa para analisar o comportamento real de estacas escavadas de grande diâmetro na Baixada Santista, quando submetidas a cargas axiais de compressão.

\subsection{Sugestões para trabalhos futuros}

a) a realização e análise de provas de carga instrumentadas em profundidade em estacões com diâmetros menores levadas até cargas mais elevadas, possivelmente até a ruptura geotécnica, para que sejam analisados efetivamente parâmetros de atrito lateral e resistência de ponta na ruptura;

b) a realização de provas de carga instrumentadas em profundidade com maior quantidade de instrumentos, como strain gages, ou ainda outros tipos, como extensômetros removíveis, para que se possa obter maior precisão nas medidas e analisar o comportamento de cada uma das camadas distintas de 
solo individualmente, e não de uma composição de camadas entre níveis de instrumentação;

c) a realização de provas de carga instrumentadas com níveis adicionais de instrumentação junto ao topo da primeira camada de argila SFL, imediatamente abaixo da camada de areia compacta superficial, para análise da possível influência do efeito "estaca T" nas estacas; $e$

d) a aplicação do modelo apresentado neste trabalho para simulação do comportamento dos estacões na Baixada Santista ainda na fase de projeto e, posteriormente, comparação da curva teórica simulada pelo modelo com a curva real obtida por prova de carga estática, e validação e/ou adaptação dos parâmetros da Tabela 54. 


\section{REFERÊNCIAS BIBLIOGRÁFICAS}

ACERVO ZF \& Engenheiros Associados S/S. 2019/2020.

ALBUQUERQUE, P.J.R. Estacas escavadas, hélice contínua e ômega: estudo do comportamento à compressão em solo residual de diabásio, através de provas de carga instrumentadas em profundidade. 2001. 297p. Tese (Doutorado) - Escola Politécnica da Universidade de São Paulo. São Paulo.

ALMEIDA, L.R.; MASET, V.L. Estudo dos critérios técnico-econômico e logísticos do projeto de fundações por estacas escavadas com fluido estabilizante na Baixada Santista. 2014. 78p. Trabalho de Formatura - Escola Politécnica da Universidade de São Paulo. São Paulo.

AOKI, N.; ANGELINO, C.N. Fundações Profundas na Baixada Santista. In: Solos do litoral de São Paulo. São Paulo: ABMS, 1994. p. 155-177.

AOKI, N.; VELLOSO, D.A. Um método aproximado para estimativa da capacidade de carga de estacas. In: Pan-American Conference on Soil Mechanics and Foundation Engineering. 1975. p. 377.

ASSOCIAÇÃO BRASILEIRA DE NORMAS TÉCNICAS. NBR 6122: Projeto e execução de fundações. Rio de Janeiro, 2019.

ASSOCIAÇÃO BRASILEIRA DE NORMAS TÉCNICAS. NBR 6122: Projeto e execução de fundações. Rio de Janeiro, 2010.

ASSOCIAÇÃO BRASILEIRA DE NORMAS TÉCNICAS. NBR 12131: Estacas - Prova de carga estática - Método de ensaio. Rio de Janeiro, 2006.

BRASFOND. Tecnologia e Inovação em Engenharia Geotécnica. Catálogo técnico e institucional. São Paulo, 2018. 60 p.

CAMBEFORT, $H$. Essai sur le Comportement en terrain homogène des pieux isoles et des groupes de pieux. Annales de I'Institut du Batiment et des Travaux Public, n. 204, 1964.

CASSAN, M. Les essais in situ en mécanique des sols. Eyrolles, 1988.

CINTRA, J.C.A.; AOKI, N. Fundações por estacas - projeto geotécnico. São Paulo: Oficina de Textos, 2010. 
COYLE, H. M.; REESE, L.C. Load transfer for axially loaded piles in clay. Journal of the Soil Mechanics and Foundations Division, v. 92, n. 2, p. 1-26, 1966.

DÉCOURT, L. Análise e projeto de fundações profundas - Estacas. In: FALCONI, F. F. et al. Fundações: teoria e prática. 3. ed. São Paulo: Pini, 2016.

DÉCOURT, L.; QUARESMA, A.R. Capacidade de carga de estacas a partir de valores de SPT. In: Congresso Brasileiro de Mecânica dos Solos e Engenharia de Fundações. 1978. p. 45-53.

DIAS, M.S. Análise do comportamento de edifícios apoiados em fundação direta no bairro da Ponta da Praia na cidade de Santos. Dissertação (Mestrado em Engenharia Geotécnica) - Escola Politécnica, Universidade de São Paulo, São Paulo, 2010.

FALCONI, F.F.; PEREZ, W. Prova de carga estática instrumentada em estaca metálica de seção decrescente com a profundidade na Baixada Santista análise de desempenho e critérios de dimensionamento. In: Congresso LusoBrasileiro de Geotecnia, 3, Coimbra, 2008. v. 4, p. 147-154.

FALCONI, F.F.; PEREZ, W. Estacas metálicas com seção variável ao longo da profundidade. In: IX Seminário de Engenharia Geotécnica do Rio Grande do Sul, ljuí, 2007.14p.

FELLENIUS, B. H. Tangent modulus of piles determined from strain data. The American Society of Civil Engineers, ASCE, Geotechnical Engineering Division, 1989 Foundation Congress, F. H. Kulhawy, Editor, Vol. 1, pp. $500-510$.

GOLOMBEK, S. et al. Para uma orientação ao projeto da Estrutura de fundação de obras na Baixada Santista. Ciclo de Palestras realizadas no Instituto de Engenharia, Divisão Técnica de Estruturas, São Paulo, 1965.

GUSMÃO, A.D. et al. Otimização de Fundações com Estacas de Perfis Laminados. XIII COBRAMSEG, p. 1161-1165, 2006.

LAM, C.; JEFFERIS, S. A. Performance of bored piles constructed using polymer fluids: lessons from European experience. Journal of Performance of Constructed Facilities, v. 30, n. 2, p. 04015024, 2016. 
MAFFEI, C.E.M.; GONÇALVES, H.H.S.; PIMENTA, P. de M. Renivelamento do Edifício Núncio Malzoni com 2,2을 de desaprumo. Geotecnia, Lisboa, n. 106, p. 133-161, 2006.

MASET, V.L.; MASSAD, F. Prova de carga estática instrumentada em estacão na Baixada Santista - análise dos resultados. In: Congresso Brasileiro de Mecânica dos Solos e Engenharia Geotécnica, XIX. 2018.

MASSAD, F. Solos marinhos da Baixada Santista: características e propriedades geotécnicas. 1. ed. São Paulo: Oficina de Textos, 2009-a. 247 p.

MASSAD, F. Comportamento de estacas metálicas na Baixada Santista: Instrumentação e Modelação. In: Engenharia de Fundações: Passado recente e perspectivas. Livro em homenagem ao prof. Nelson Aoki. 1. ed. São Carlos: Suprema Gráfica e Editora Ltda, 2009-b, v. 1, p. 105-116.

MASSAD, F. Obras de Terra. 1. ed. São Paulo: Oficina de Textos, 2003. v. 1. 170p.

MASSAD, F. Baixada Santista: Implicações da História Geológica no Projeto de Fundações. Solos e Rochas, 1999, v. 22, n.1, p. 3-49.

MASSAD, F. Pile Analysis Taking into Account Soil Stiffness and Residual Stresses. In: 10th Panamerican Conference on Soil Mechanics and Foundation Engineering. Guadalajara, México, 1995, v.2. p.1199-1210.

MASSAD, F. Sobre a Interpretação de Provas de Carga em Estacas, Considerando a Reversão do Atrito Lateral e a Carga Residual na Ponta. Solos e Rochas, São Paulo, 1992, v. 15, n.2.

MASSAD, F. O Atrito Lateral em Estacas Flutuantes nos Sedimentos Quaternários da Baixada Santista, à Luz da História Geológica. In: IX COBRAMSEF, Salvador, 1990.

MASSAD, F. Notes on the interpretation of failure load from routine pile load tests. Solos e Rochas, 1986, v. 9, n. 1, p. 33-38. 
MASSAD, F. As argilas quaternárias da Baixada Santista: características e propriedades geotécnicas. 1985. 250p. Tese de livre-docência apresentada à Escola Politécnica da Universidade de São Paulo. São Paulo.

MASSAD, F.; LAZO, G. Método gráfico para interpretar a curva cargarecalque de provas de carga verticais em estacas rígidas ou curtas. In: Congresso Brasileiro de Mecânica dos Solos e Engenharia de Fundações, 11. 1998, v.3, p. 1407-1414.

NIYAMA, S. et al. Verificação de desempenho. In: FALCONI, F. F. et al. Fundações: teoria e prática. 3. ed. São Paulo: Pini, 2016.

SAES, J.L. Execução de fundações profundas - Estacas escavadas com lama bentonítica. In: FALCONI, F. F. et al. Fundações: teoria e prática. 3. ed. São Paulo: Pini, 2016.

SUGUIO, K.; MARTIN, L. Geologia do Quaternário. In: Solos do litoral de São Paulo. São Paulo: ABMS, 1994. p. 69-97.

SUGUIO, K.; MARTIN, L. Formações quaternárias marinhas do litoral paulista e sul fluminense. In: International Symposium on Coastal Evolution in the Quaternary. 1978. 55p.

TEIXEIRA, A.H. Fundações Rasas na Baixada Santista. In: Solos do litoral de São Paulo. São Paulo: ABMS, 1994. p. 137-153.

TEIXEIRA, A.H. Capacidade de carga de estacas pré-moldadas em concreto nos sedimentos quaternários da Baixada Santista. In: Simpósio sobre depósitos quaternários das baixadas litorâneas brasileiras: origem, características geotécnicas e experiências de obras. São Paulo: ABMS, 1988, v.2, p. 5.1-5.25.

TEIXEIRA, A.H. Caso de un edifício en que la camada de arcilla (Santos) e encontraba inusitadamente preconsolidada. In: 1st Panamerican Conference on Soil Mechanics and Foundation Engineering. Vol. I, p. 201-215. México, 1959.

TEIXEIRA, A.H. Condiciones tipicas del subsuelo y problemas de asiento em Santos, Brasil. In: 1st Panamerican Conference on Soil Mechanics and Foundation Engineering. Vol. I. México, 1959. 
VARGAS, M. A Baixada Santista. Suas bases físicas. Revista USP, São Paulo, n.41, p. 18-27, 1999.

VARGAS, M. História dos Conhecimentos Geotécnicos: Parte 2 - Baixada Litorânea. In: Solos do litoral de São Paulo. São Paulo: ABMS, 1994. p. 17-39. 
ANEXO I - DADOS DAS PROVAS DE CARGA ESTÁTICA 
I.1. Conselheiro Nébias (CN)

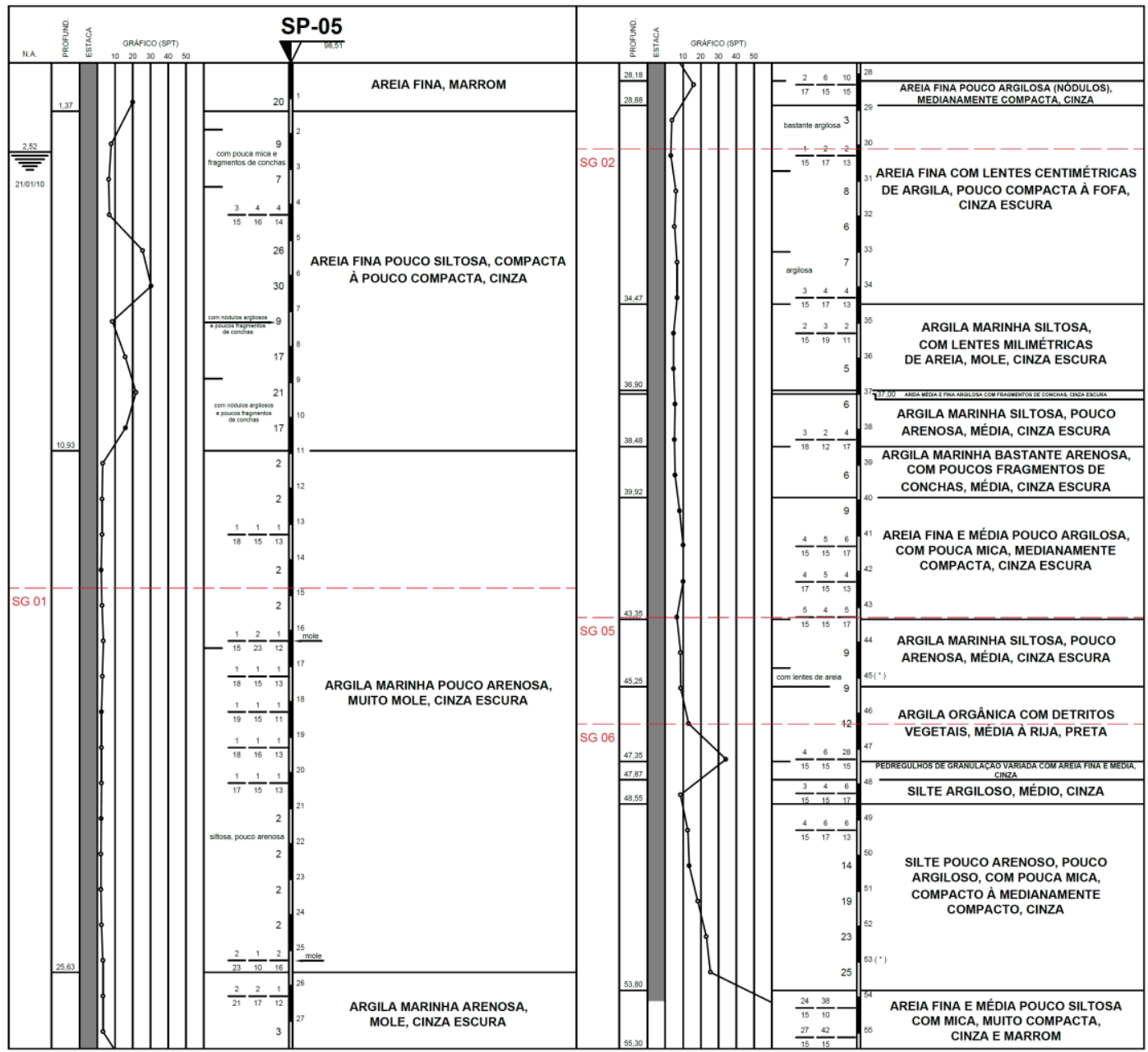

Figura 1-1: perfil SP-05, próximo à prova de carga $\mathrm{CN}$.

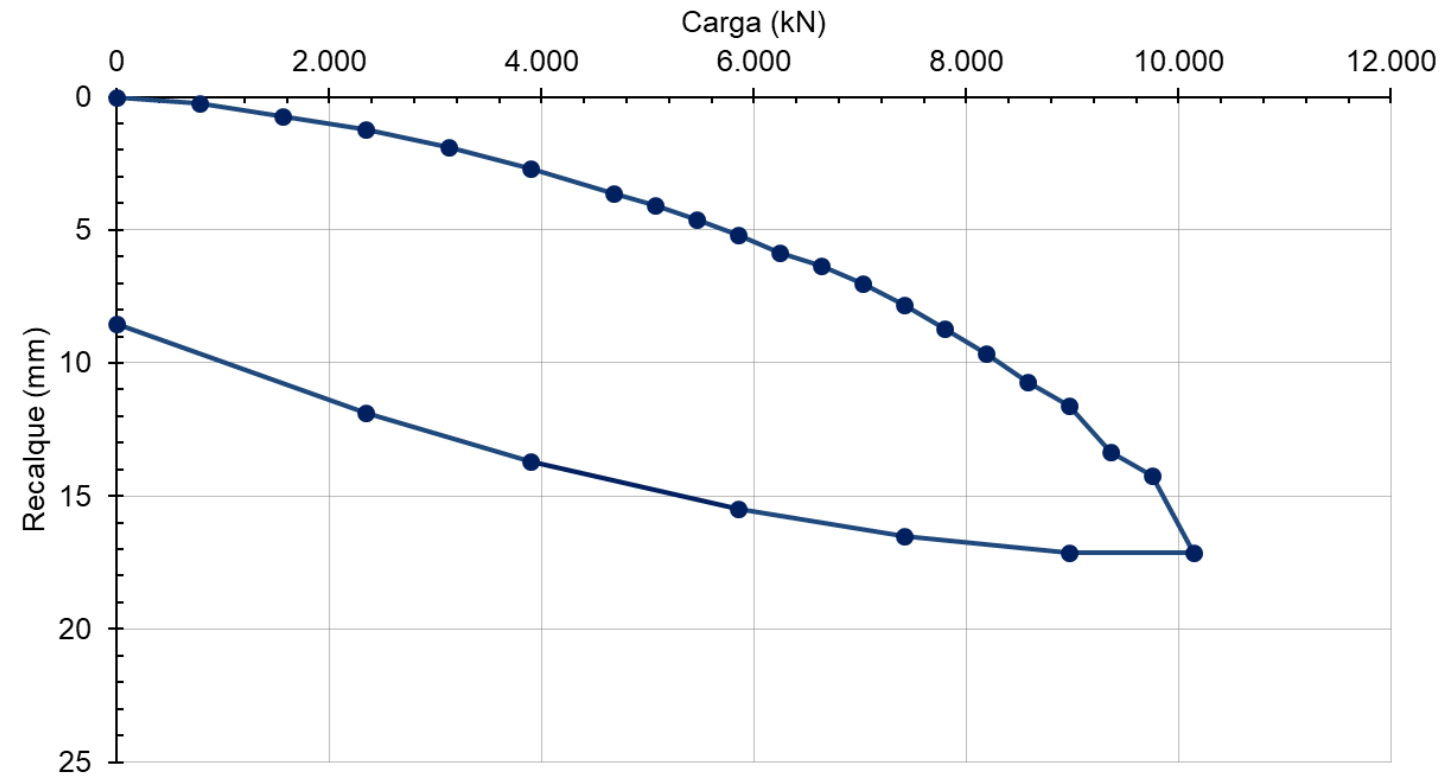

Figura I-2: curva carga-recalque da prova de carga $\mathrm{CN}$. 


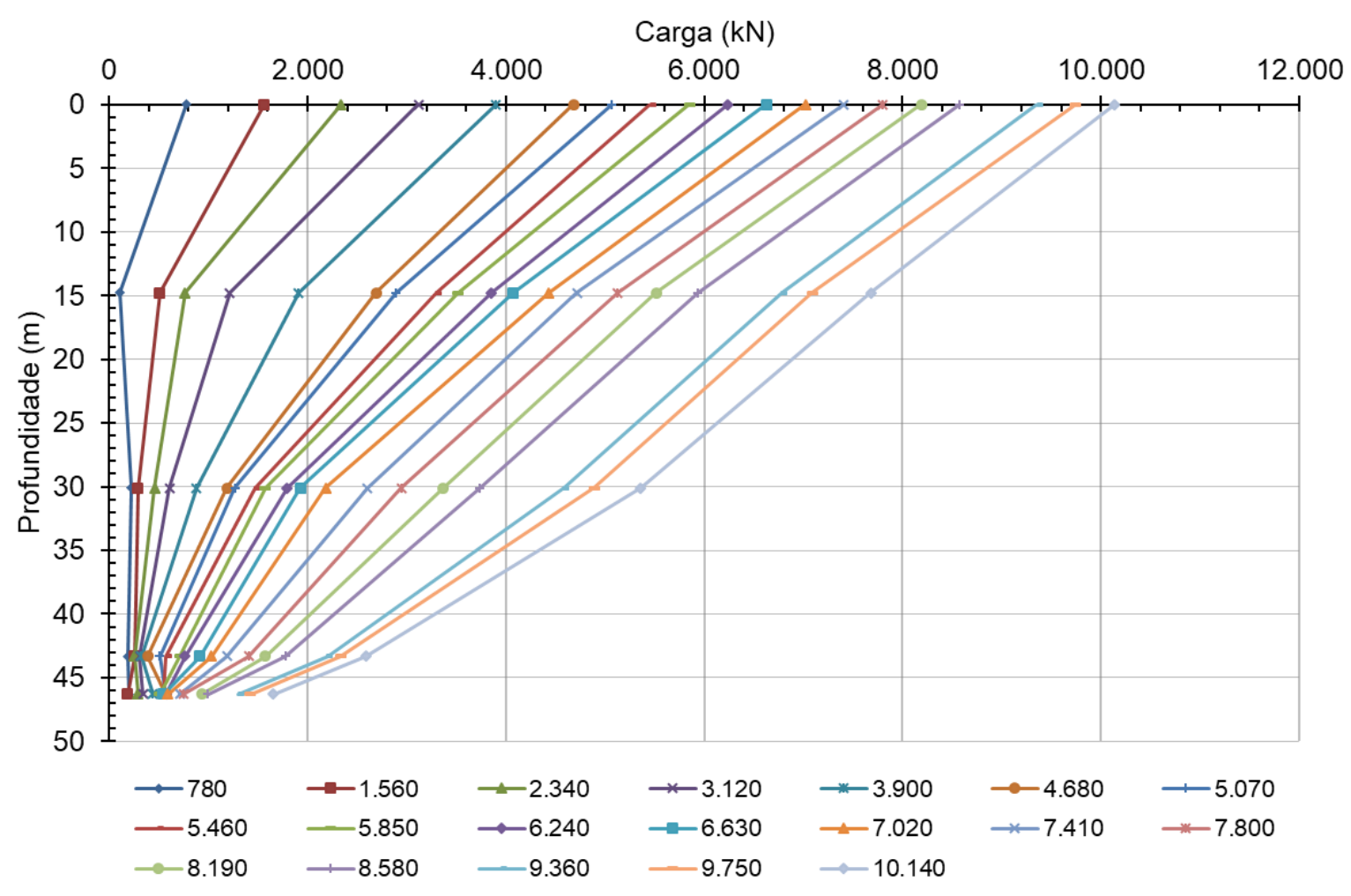

Figura l-3: diagramas de transferência de carga em profundidade do ensaio $\mathrm{CN}$ (conforme fornecido pelo executor). 
I.2. Coronel Joaquim Montenegro (CJM)

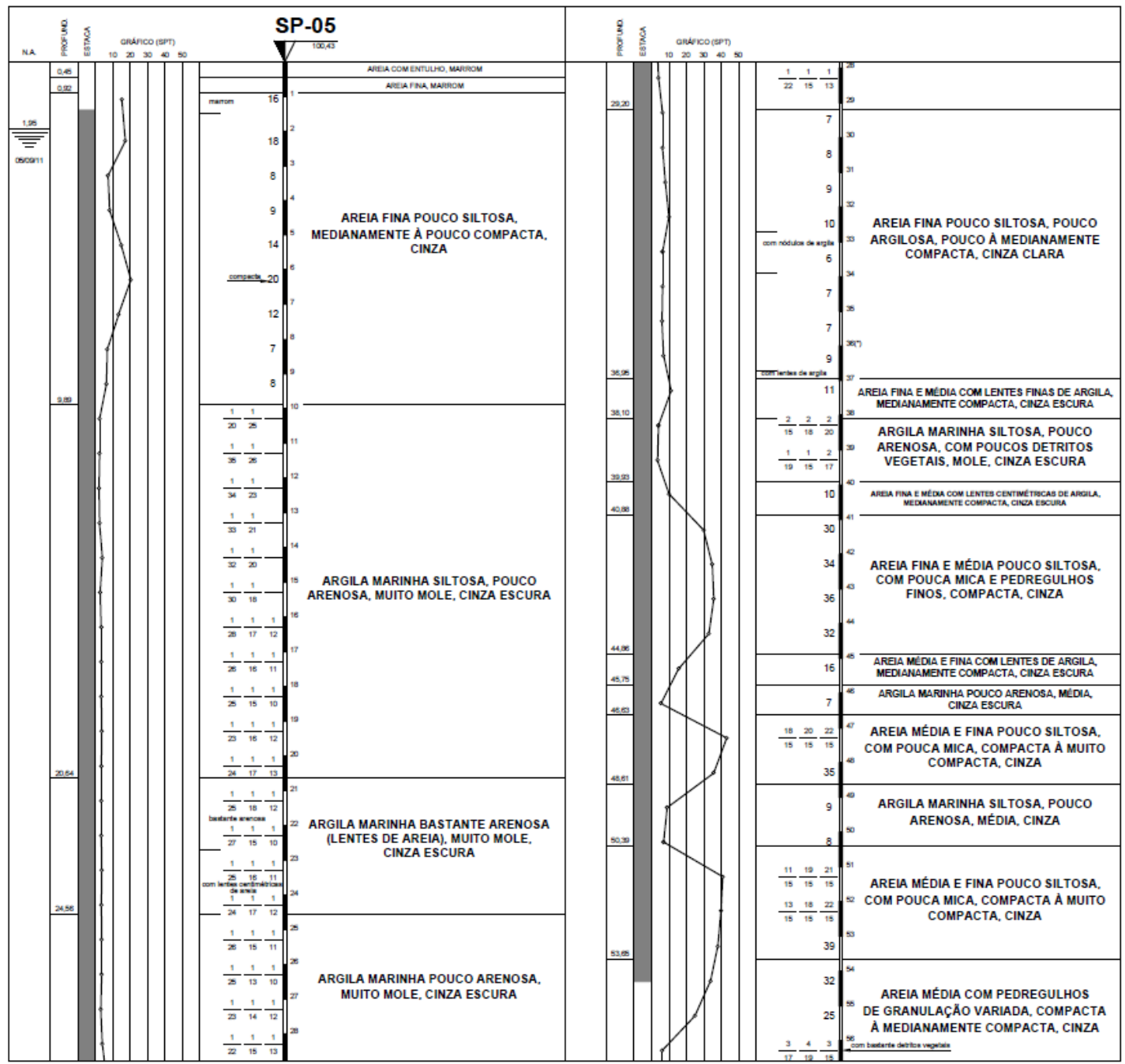

Figura l-4: perfil SP-05, próximo à prova de carga CJM.

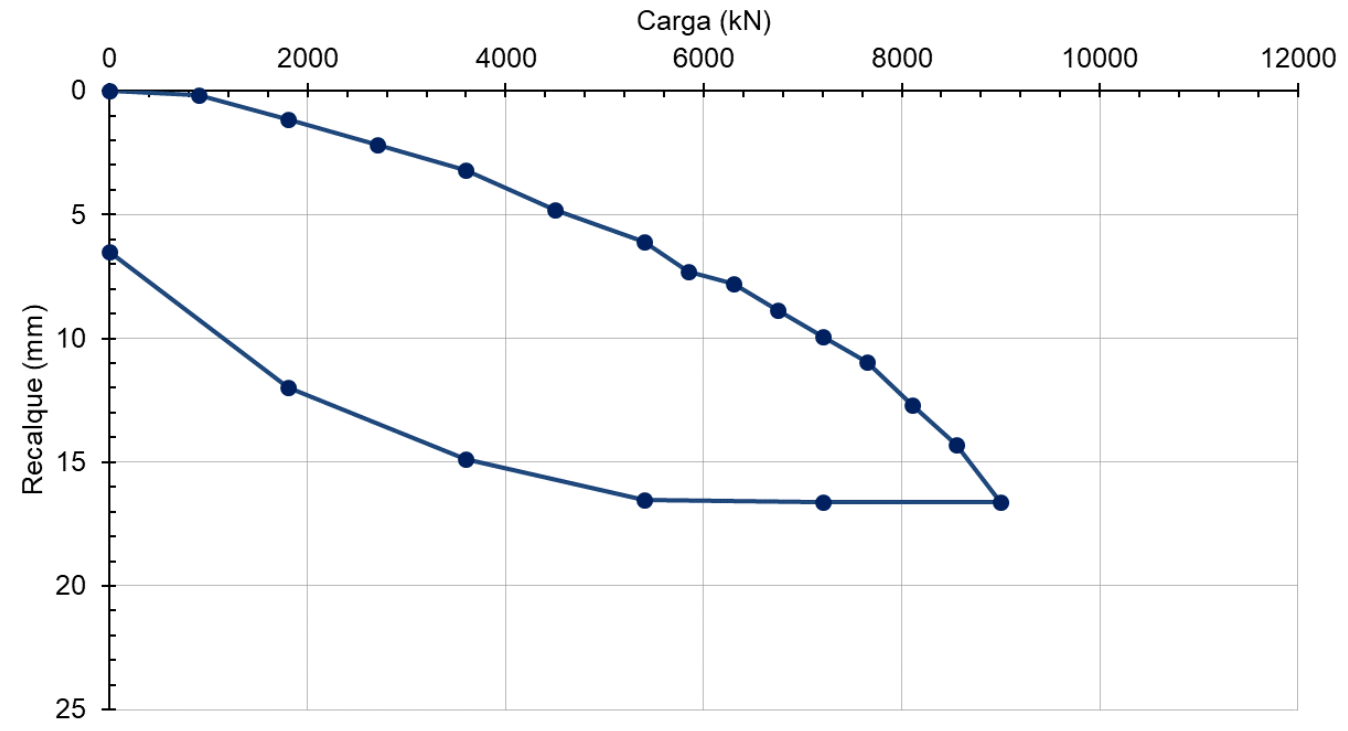

Figura 1-5: curva carga-recalque da prova de carga CJM. 
I.3. Praça Fernandes Pacheco (PçaFP)

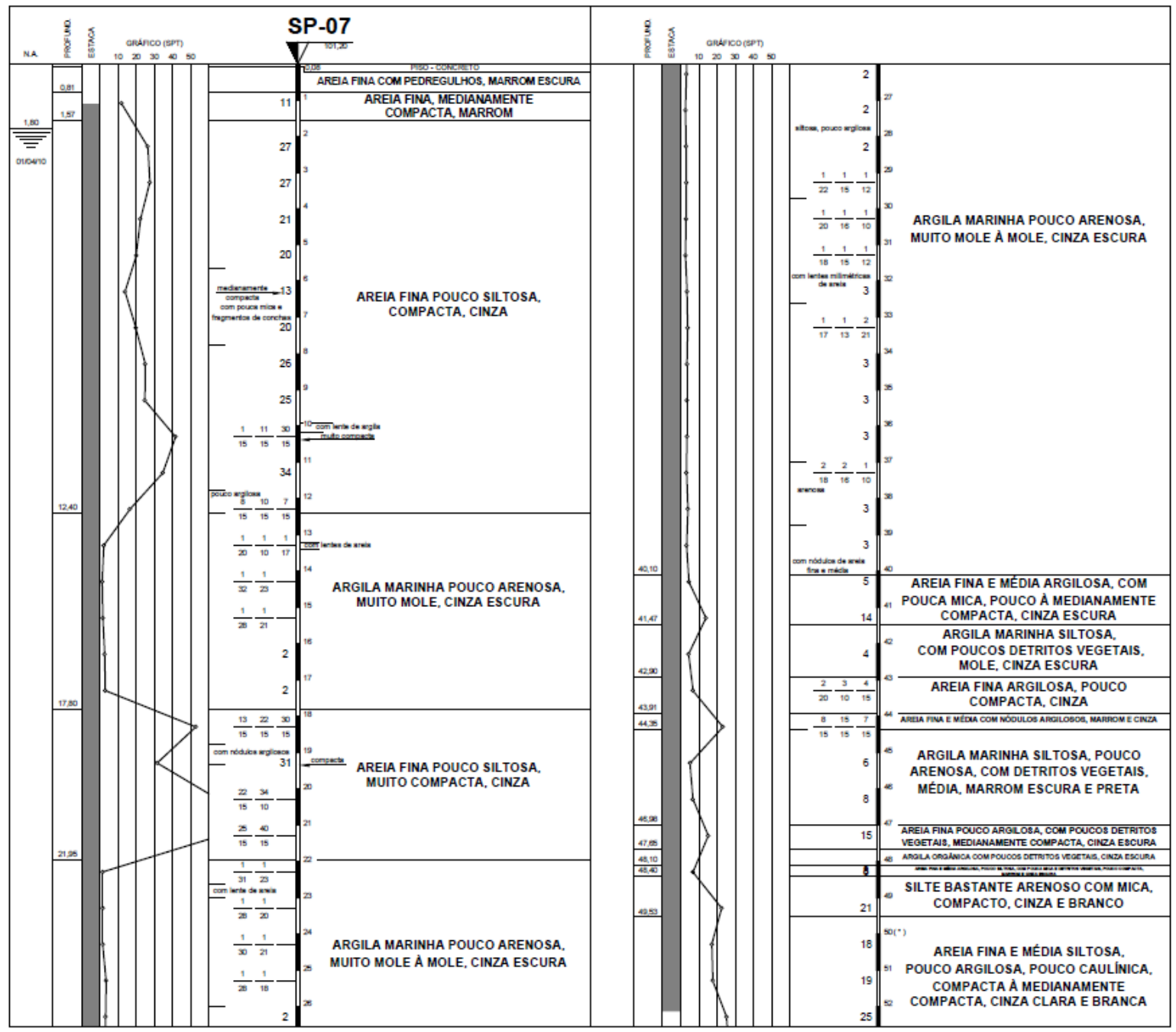

Figura I-6: perfil SP-07, próximo à prova de carga PçaFP.

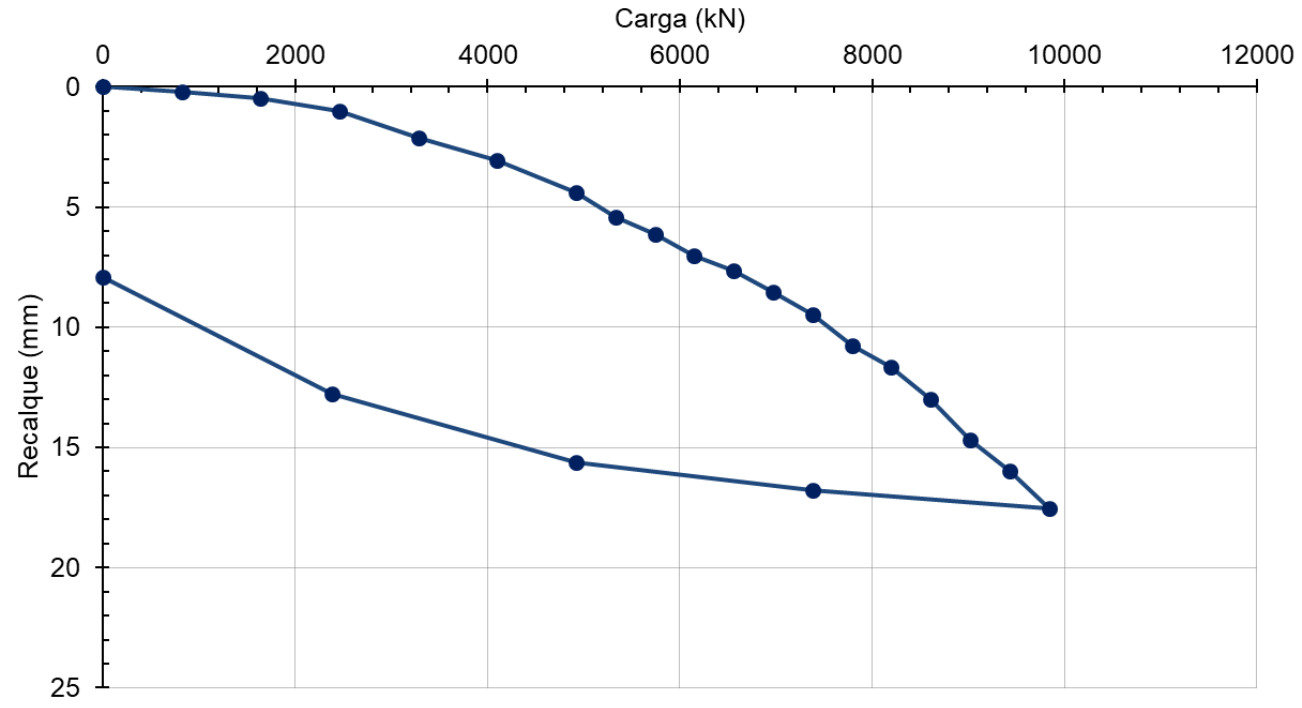

Figura 1-7: curva carga-recalque da prova de carga PçaFP. 
I.4. Terrazas Residence (Terr_50 e Terr_54)

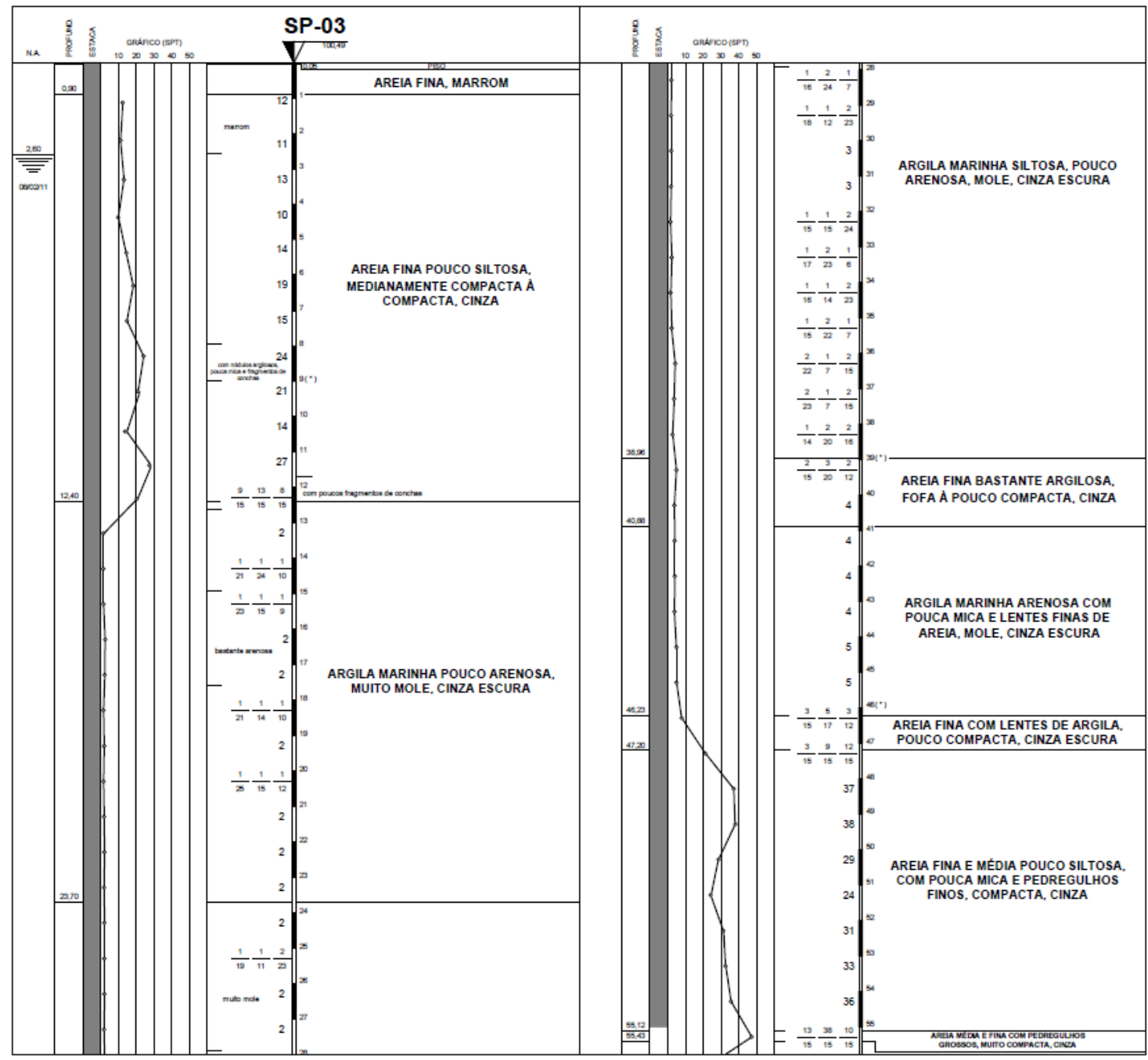

Figura I-8: perfil SP-03, próximo à prova de carga Terr_50.

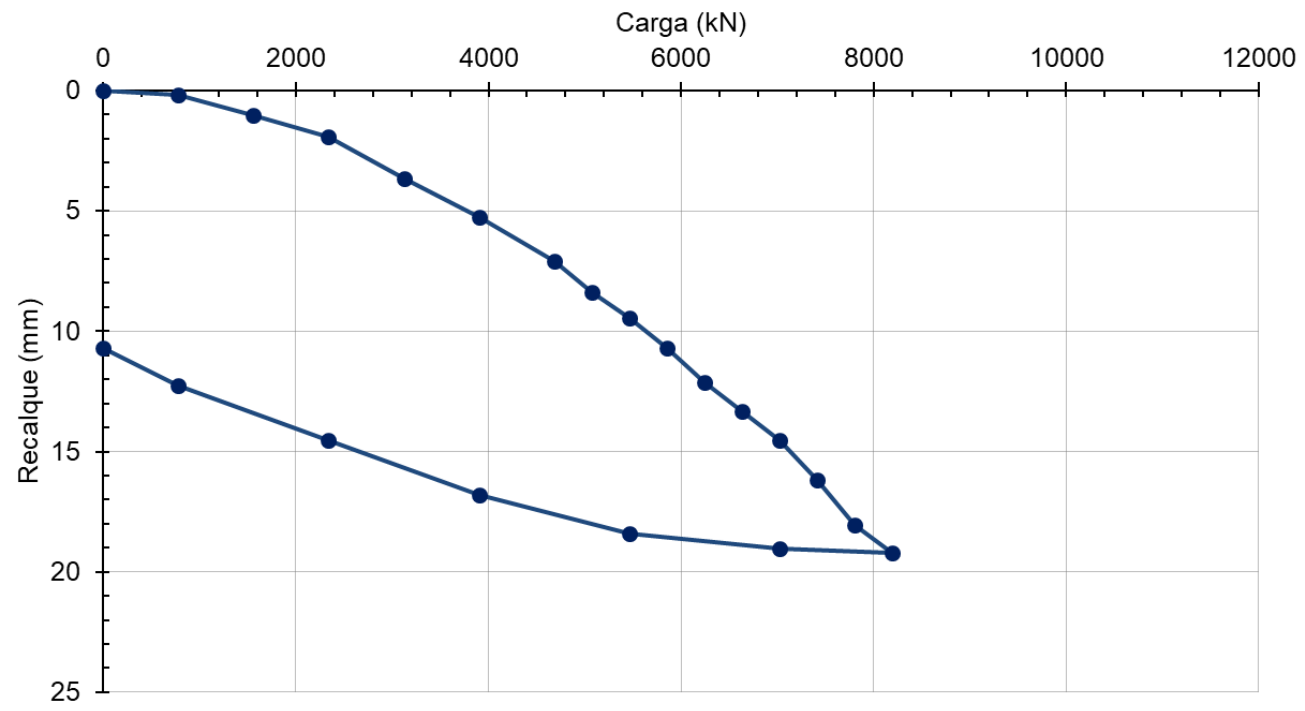

Figura I-9: curva carga-recalque da prova de carga Terr_50. 


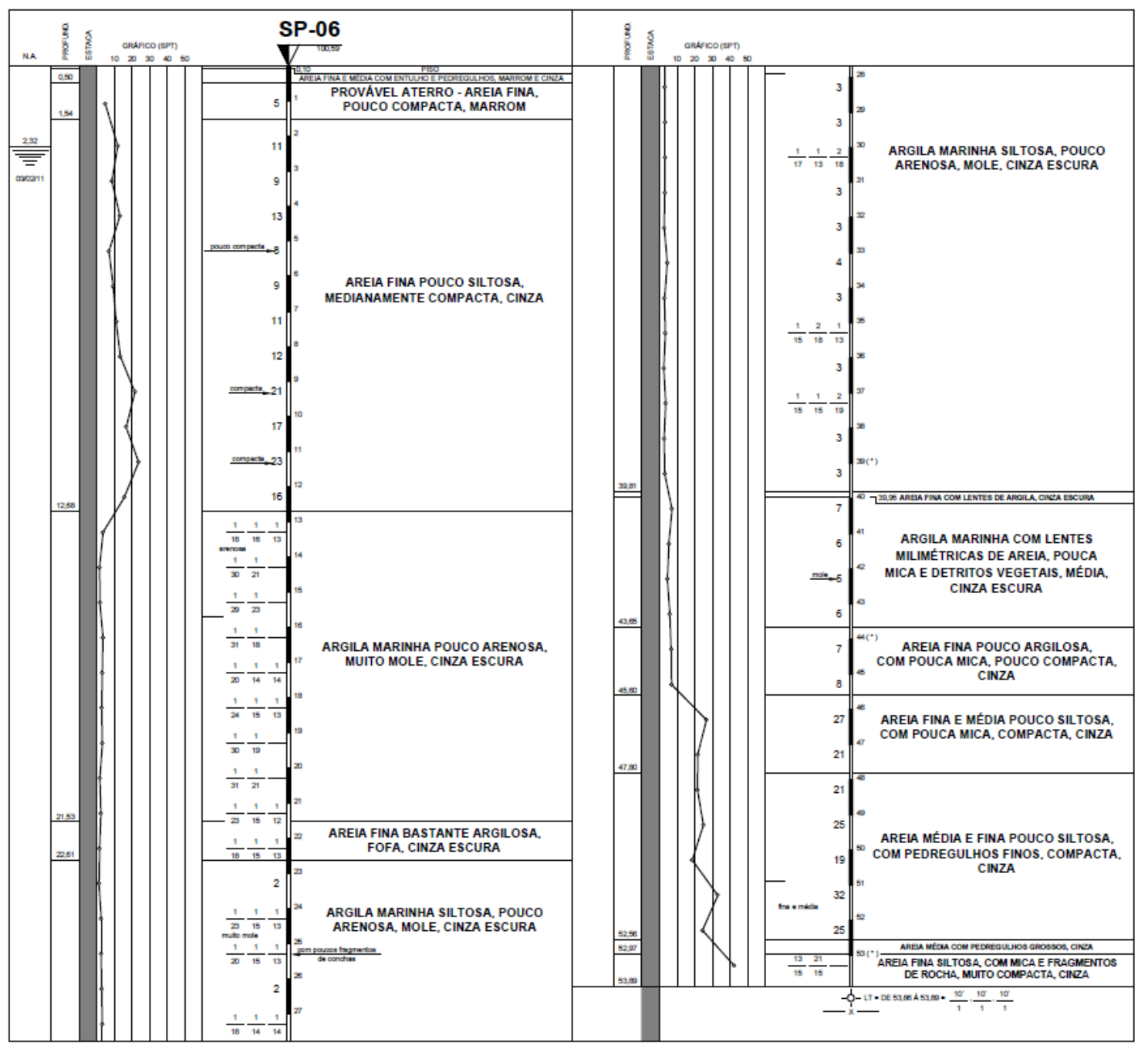

Figura I-10: perfil SP-06, próximo à prova de carga Terr_54.

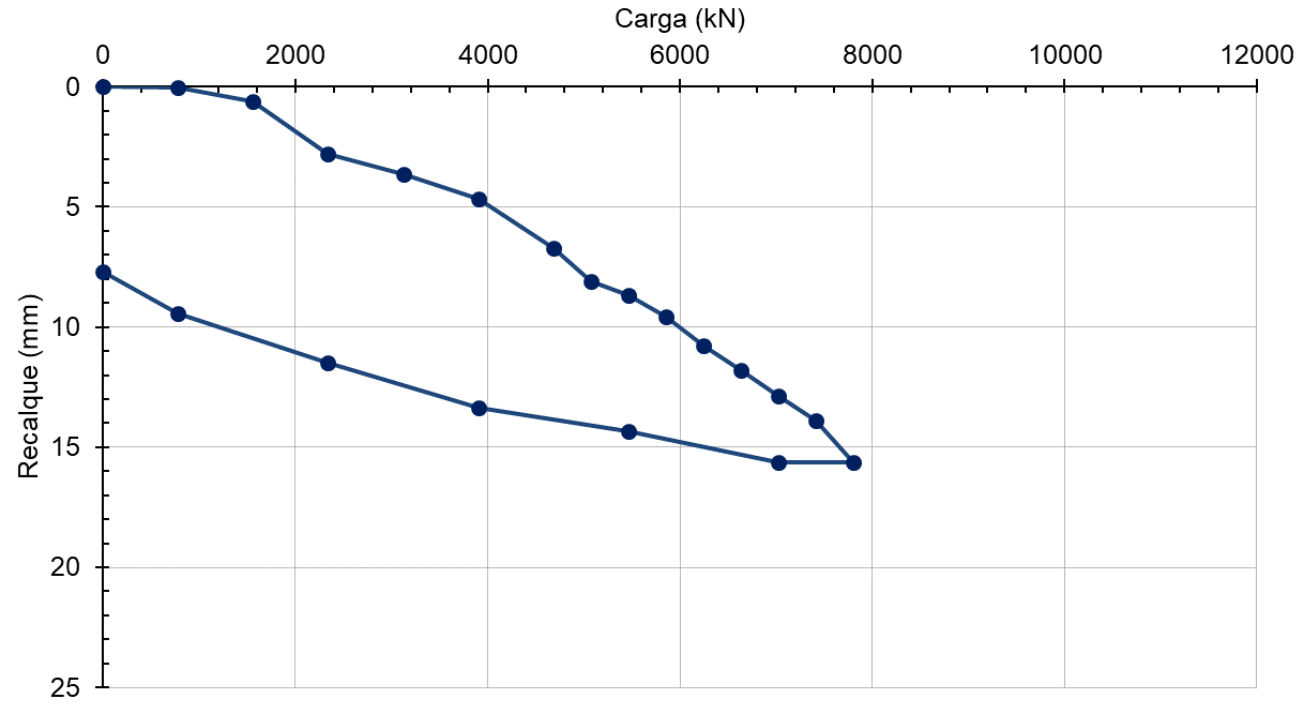

Figura I-11: curva carga-recalque da prova de carga Terr_54. 
I.5. Ville de France (VdF_1 e VdF_2)

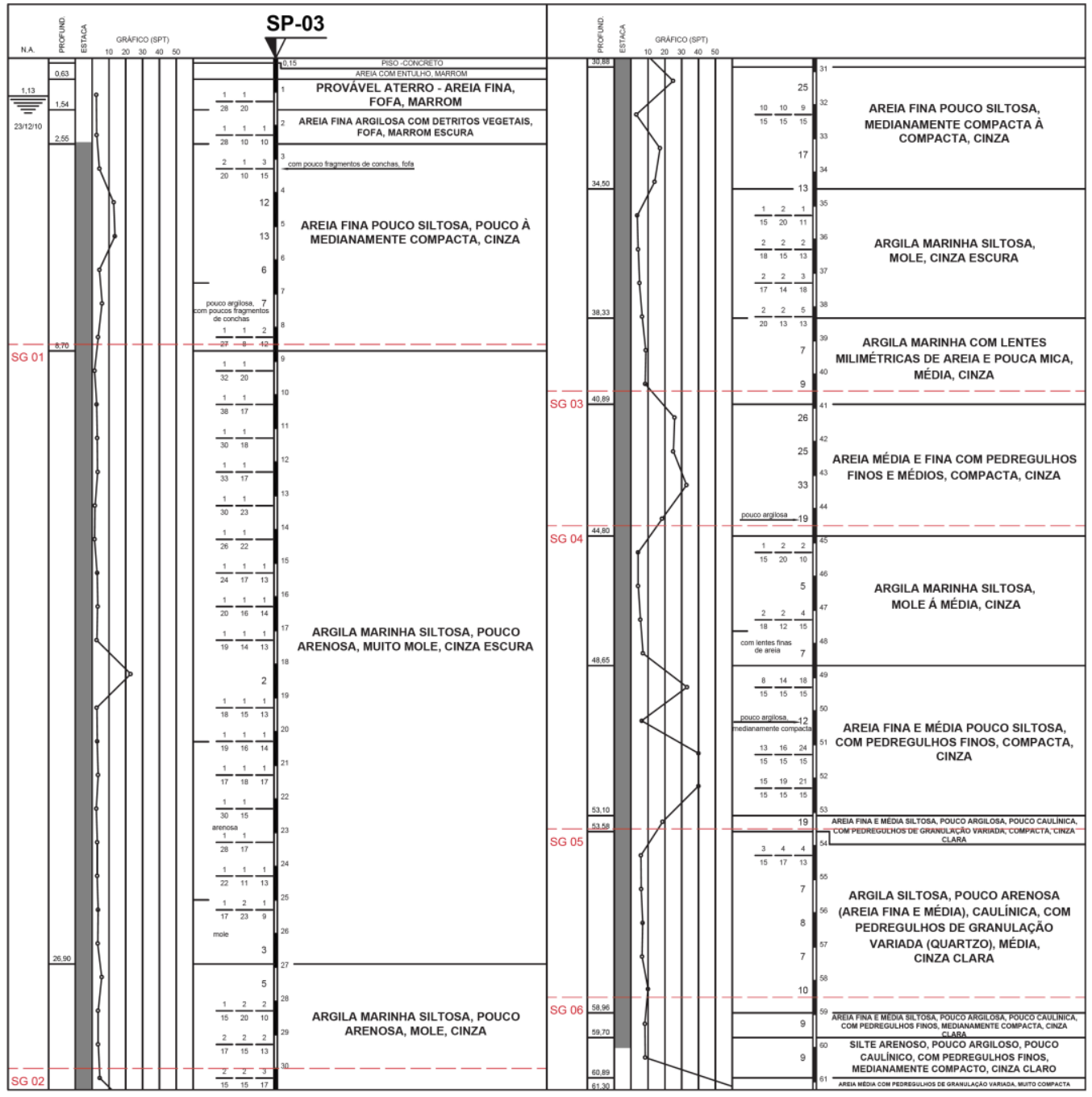

Figura I-12: perfil SP-03, próximo à prova de carga VdF_1.

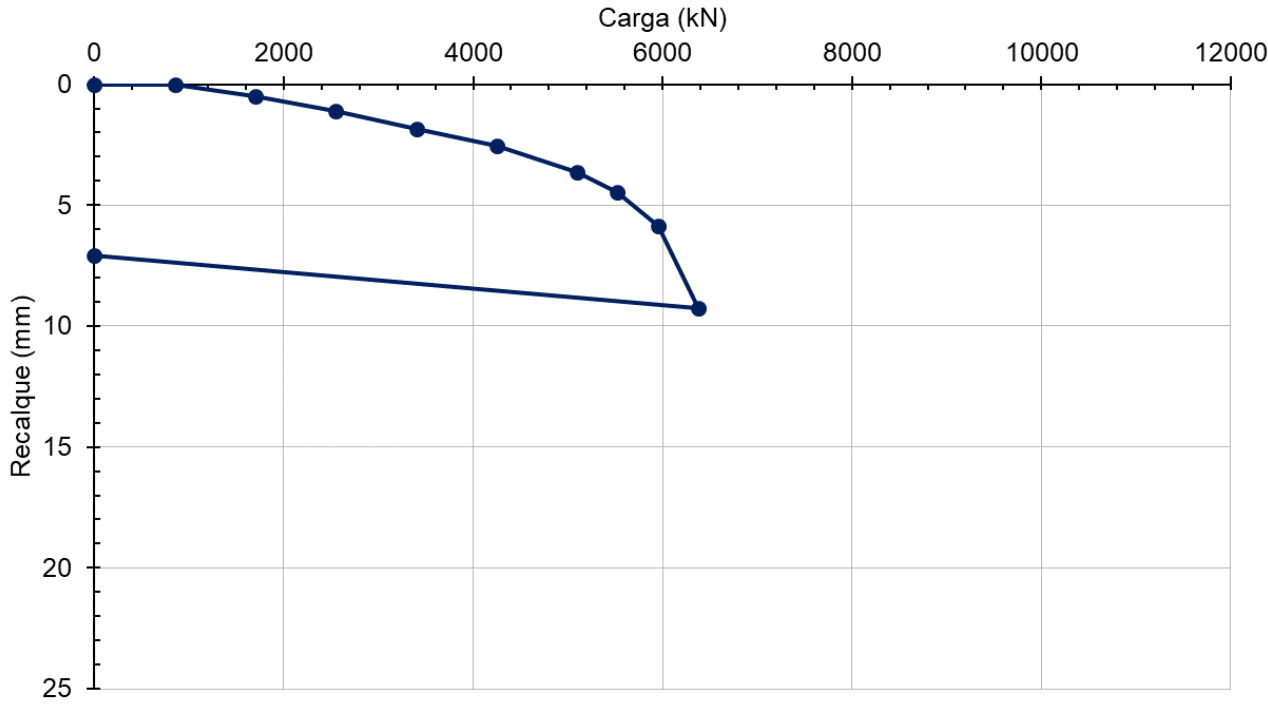

Figura I-13: curva carga-recalque da prova de carga VdF_1. 


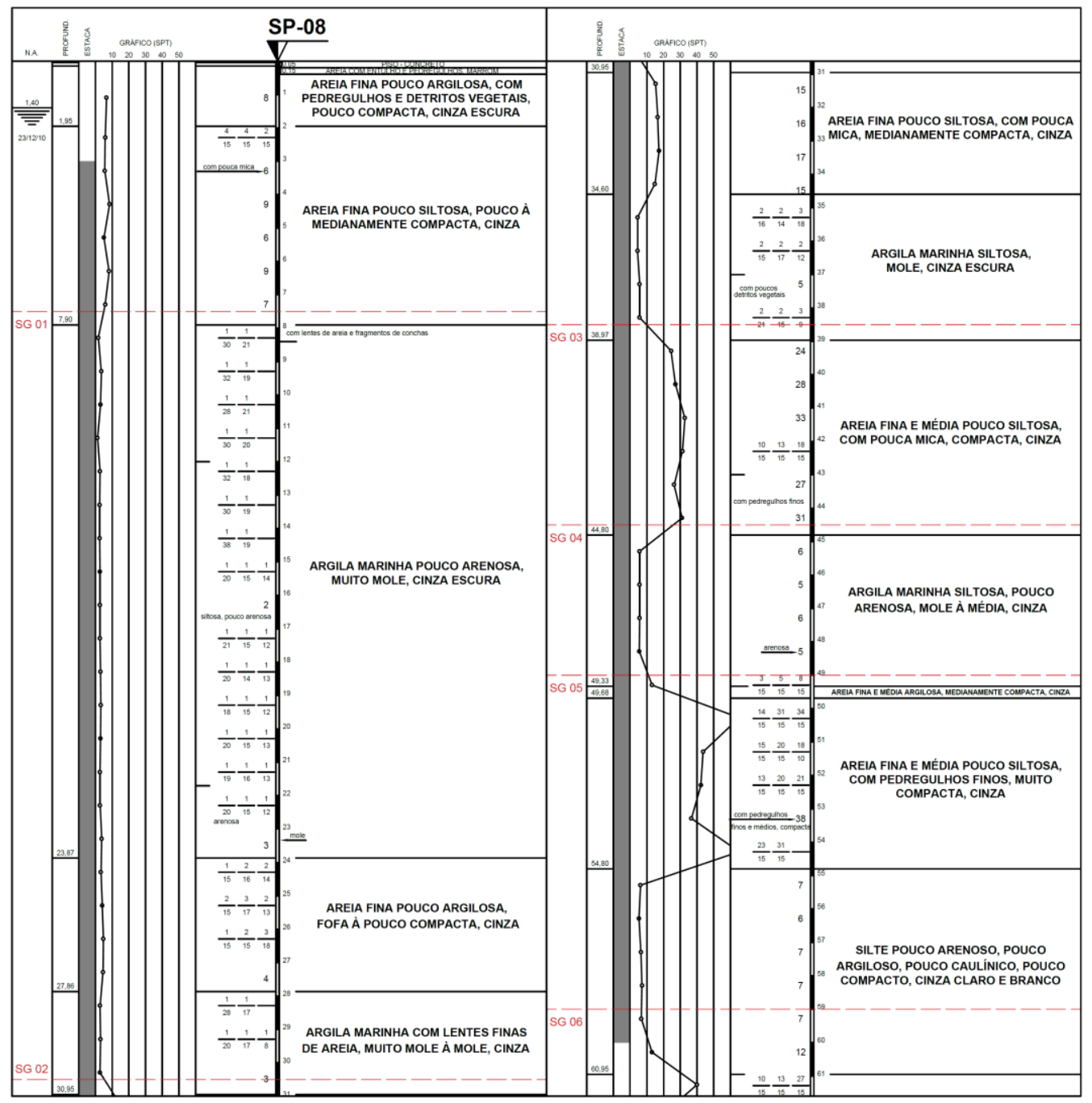

Figura I-14: perfil SP-08, próximo à prova de carga VdF_2.

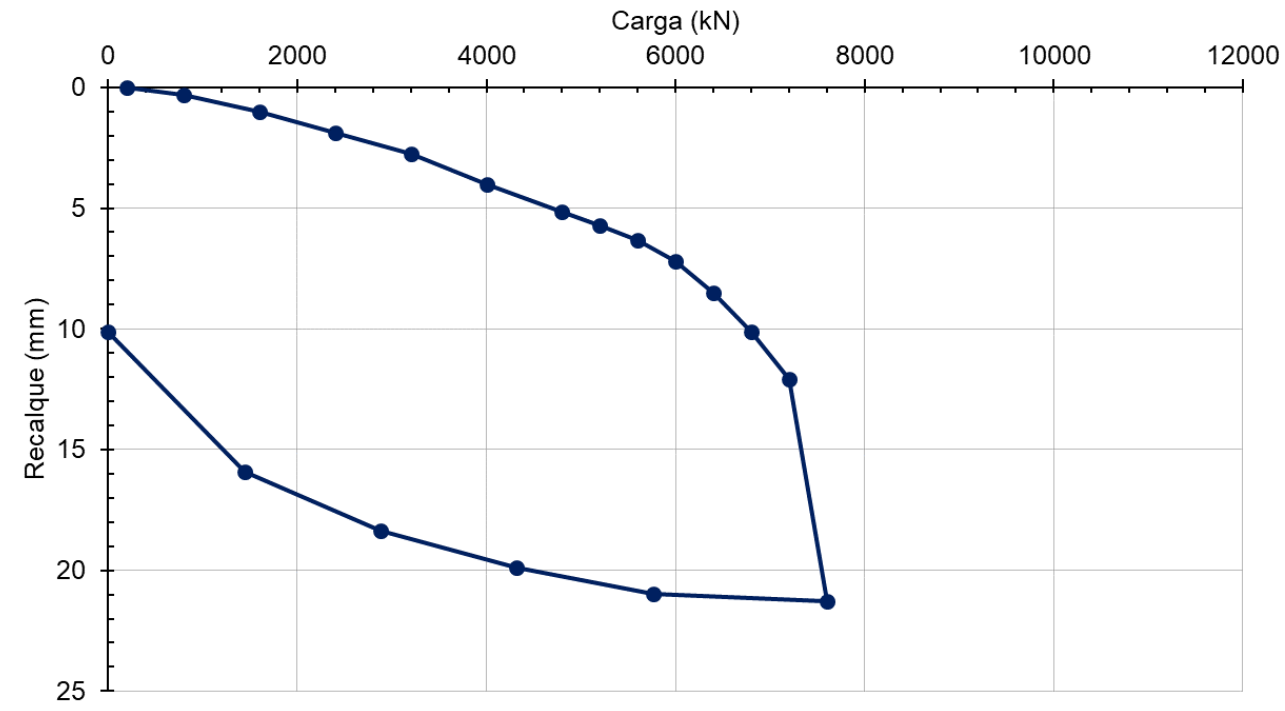

Figura l-15: curva carga-recalque da prova de carga VdF_2. 


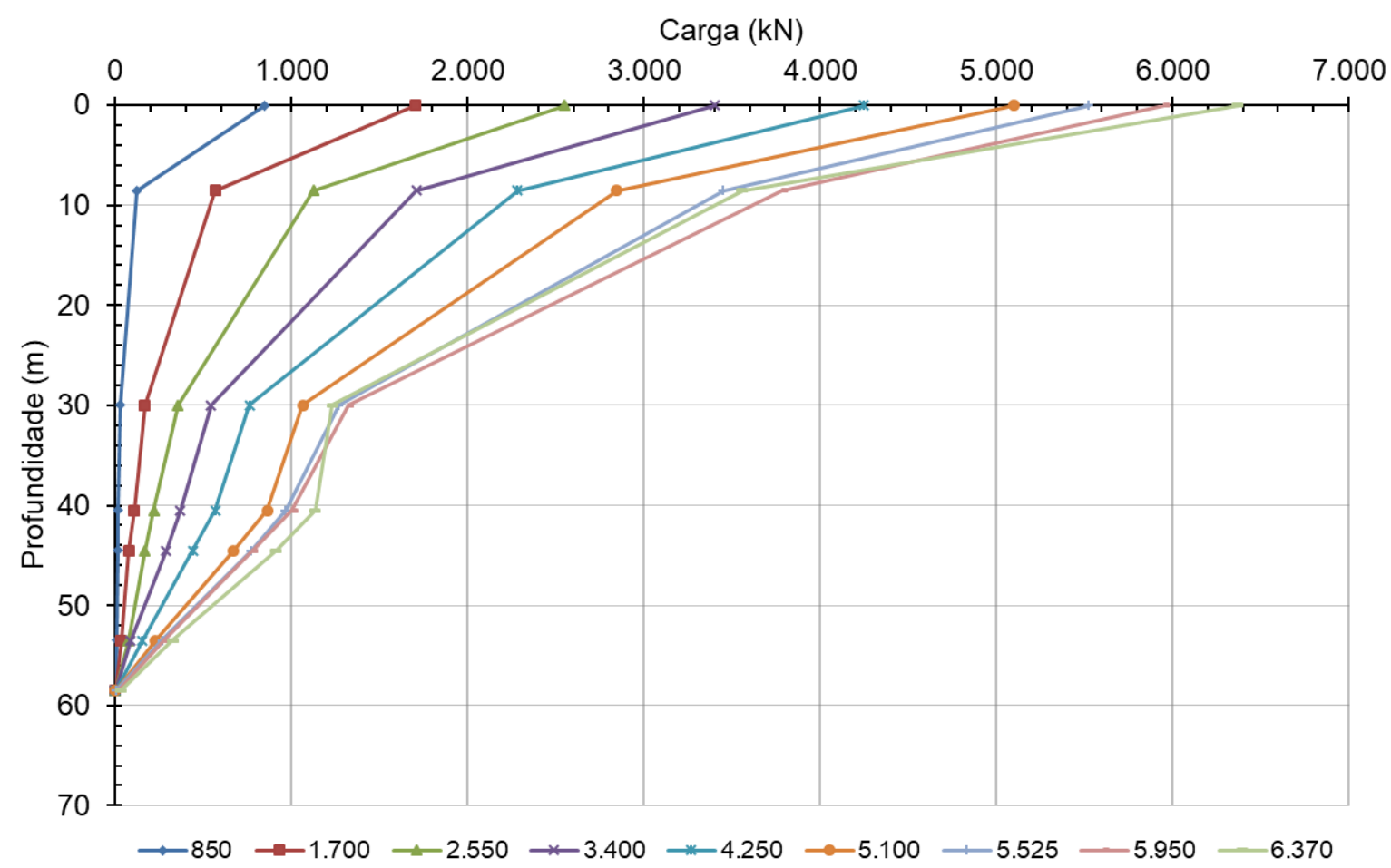

Figura l-16: diagramas de transferência de carga em profundidade do ensaio VdF_1 (conforme fornecido pelo executor).

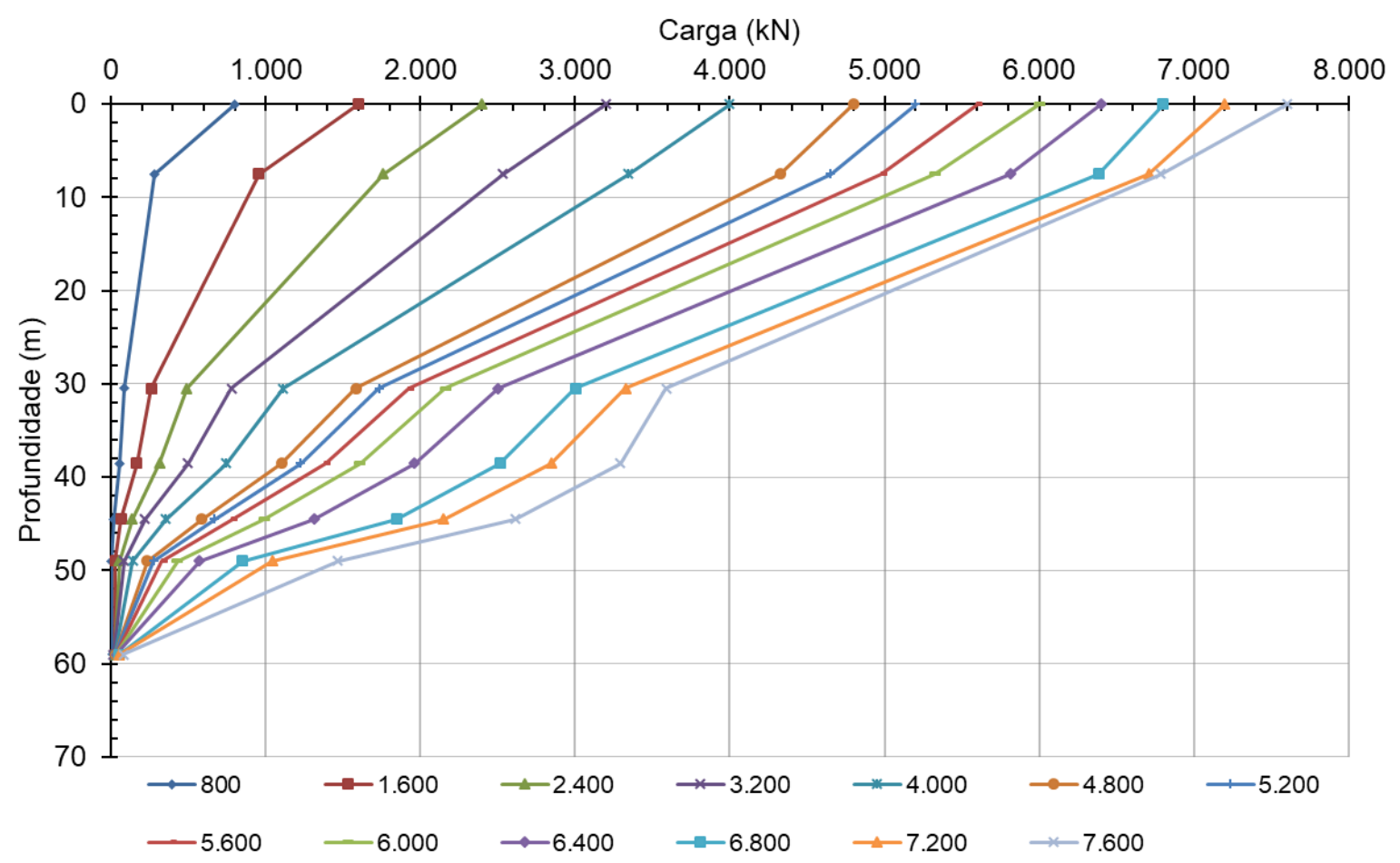

Figura 1-17: diagramas de transferência de carga em profundidade do ensaio VdF_2 (conforme fornecido pelo executor). 
I.6. Corporate (Corp_1 e Corp_2)

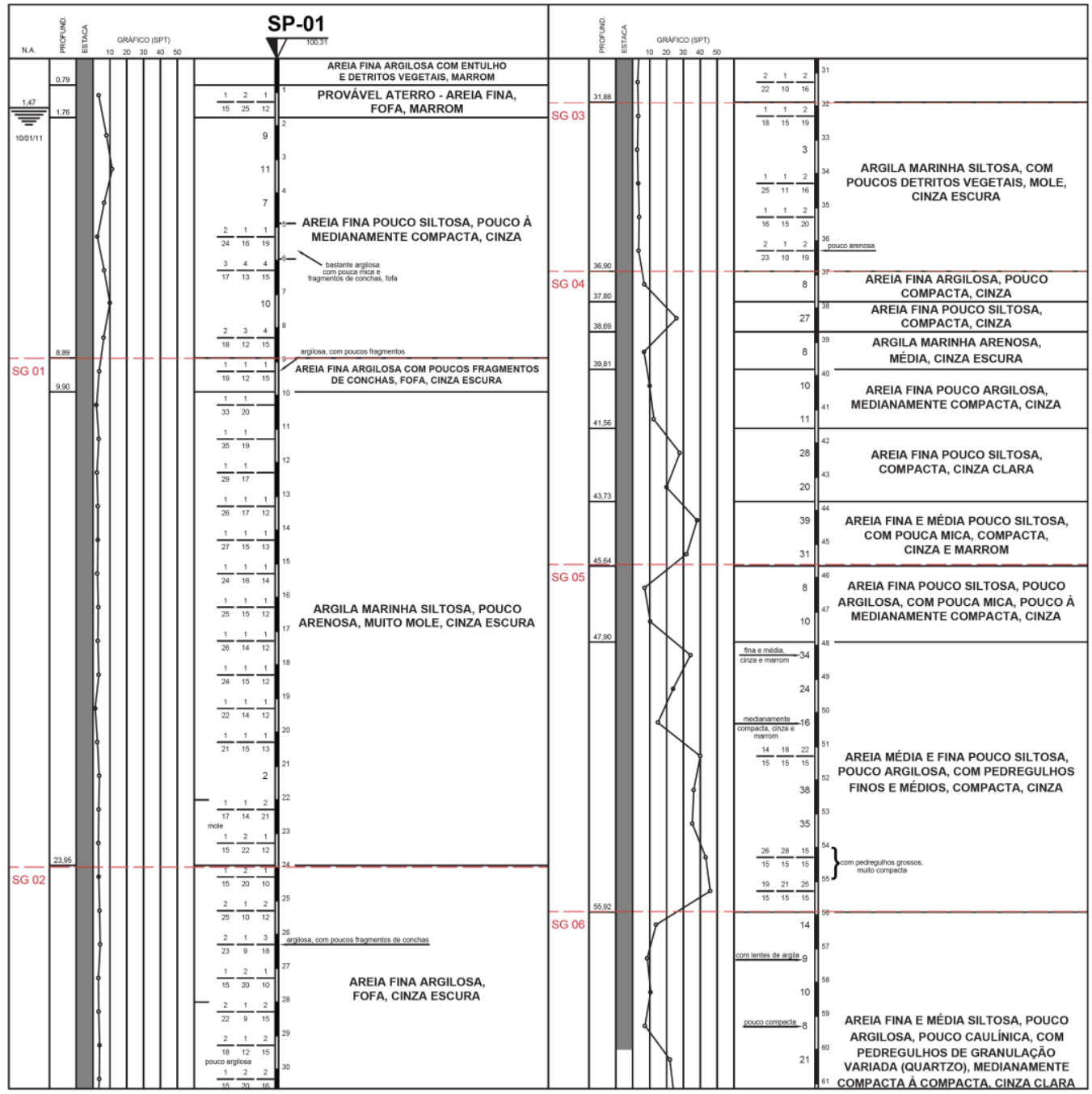

Figura l-18: perfil SP-01, próximo às provas de carga Corp_1 e Corp_2.

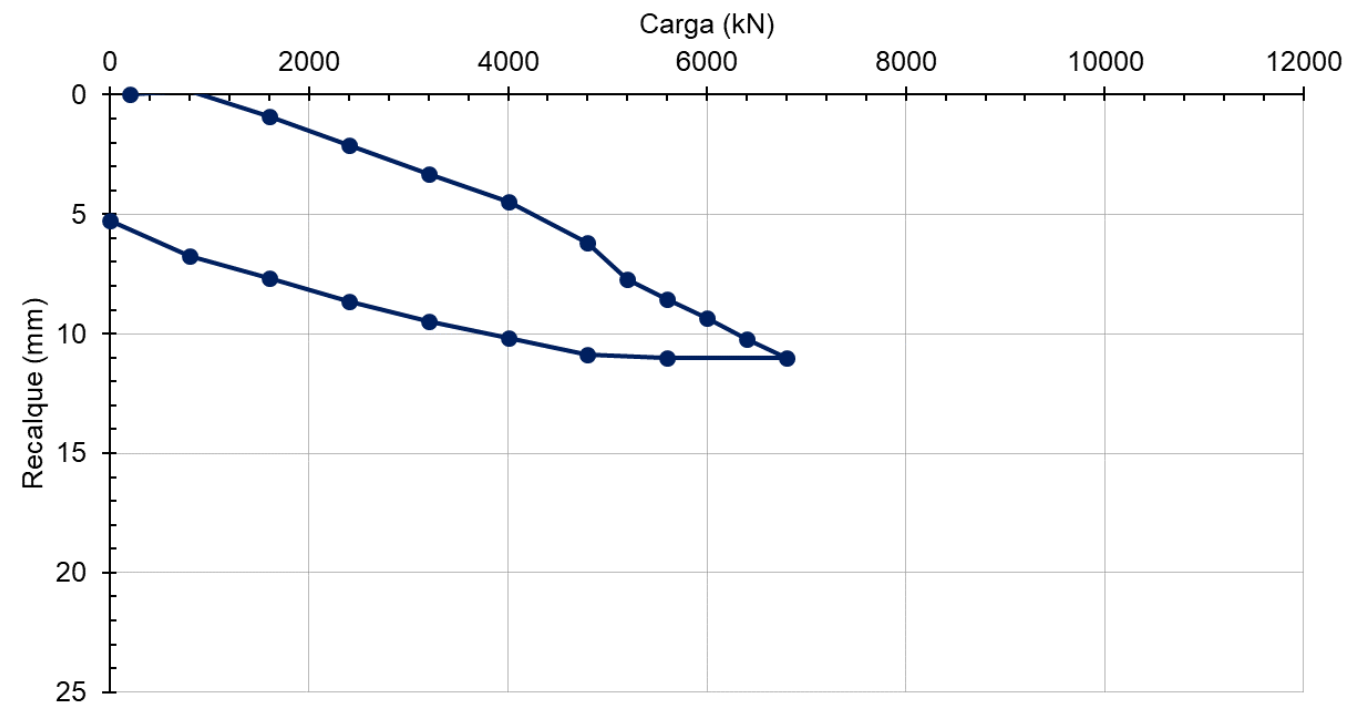

Figura l-19: curva carga-recalque da prova de carga Corp_1. 


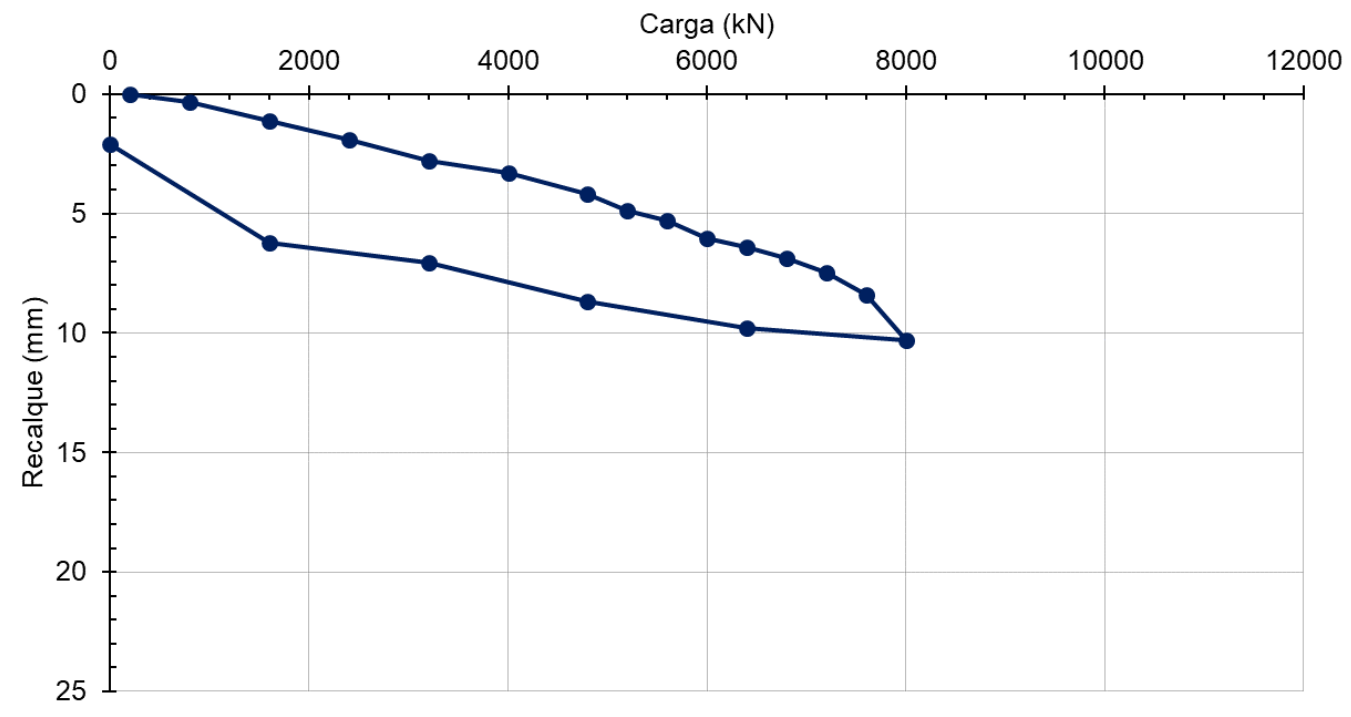

Figura I-20: curva carga-recalque da prova de carga Corp_2.

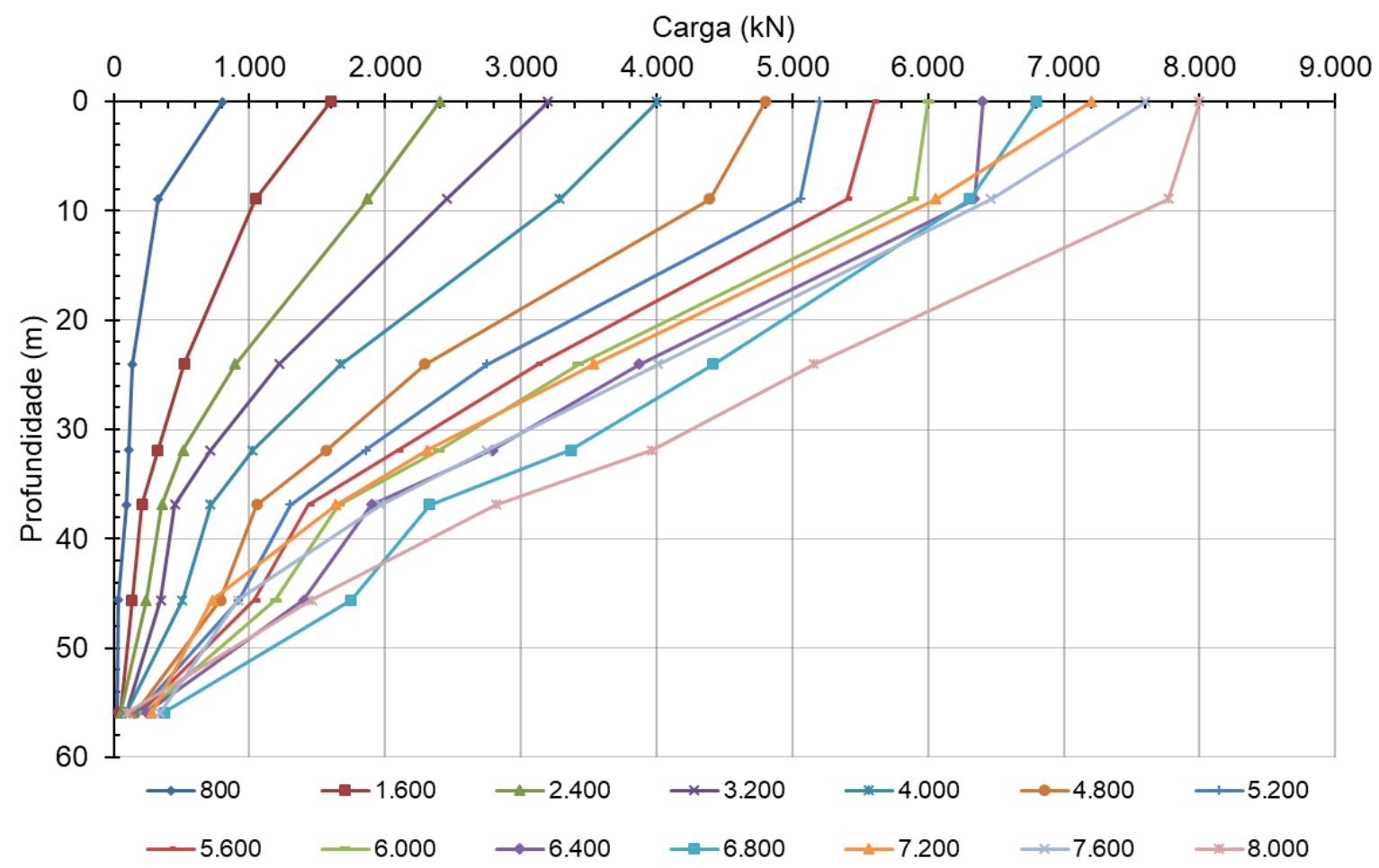

Figura I-21: diagramas de transferência de carga em profundidade do ensaio Corp_1 (conforme fornecido pelo executor). 


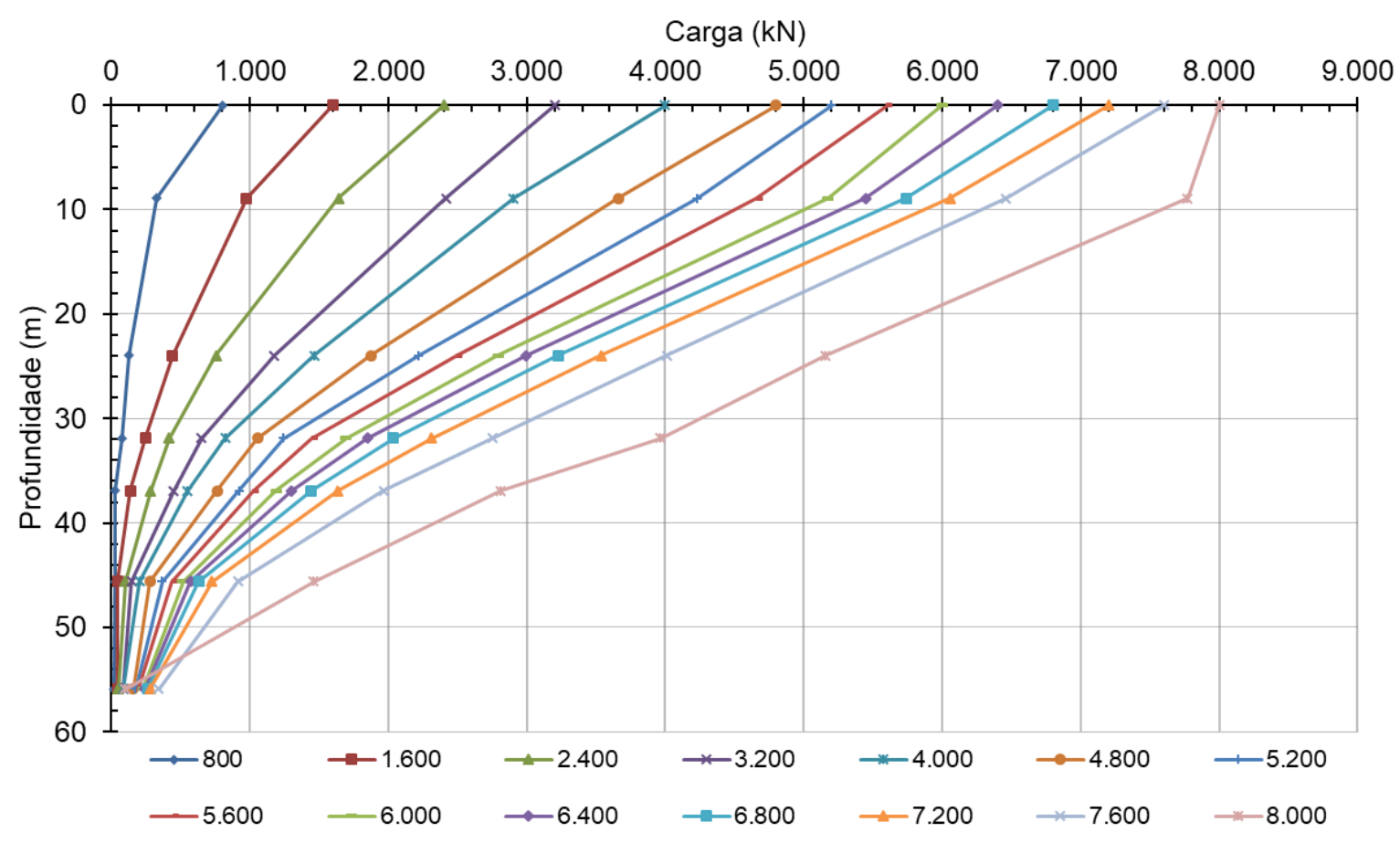

Figura I-22: diagramas de transferência de carga em profundidade do ensaio Corp_2 (conforme fornecido pelo executor). 
I.7. Rua Barão de Paranapiacaba (Trin)

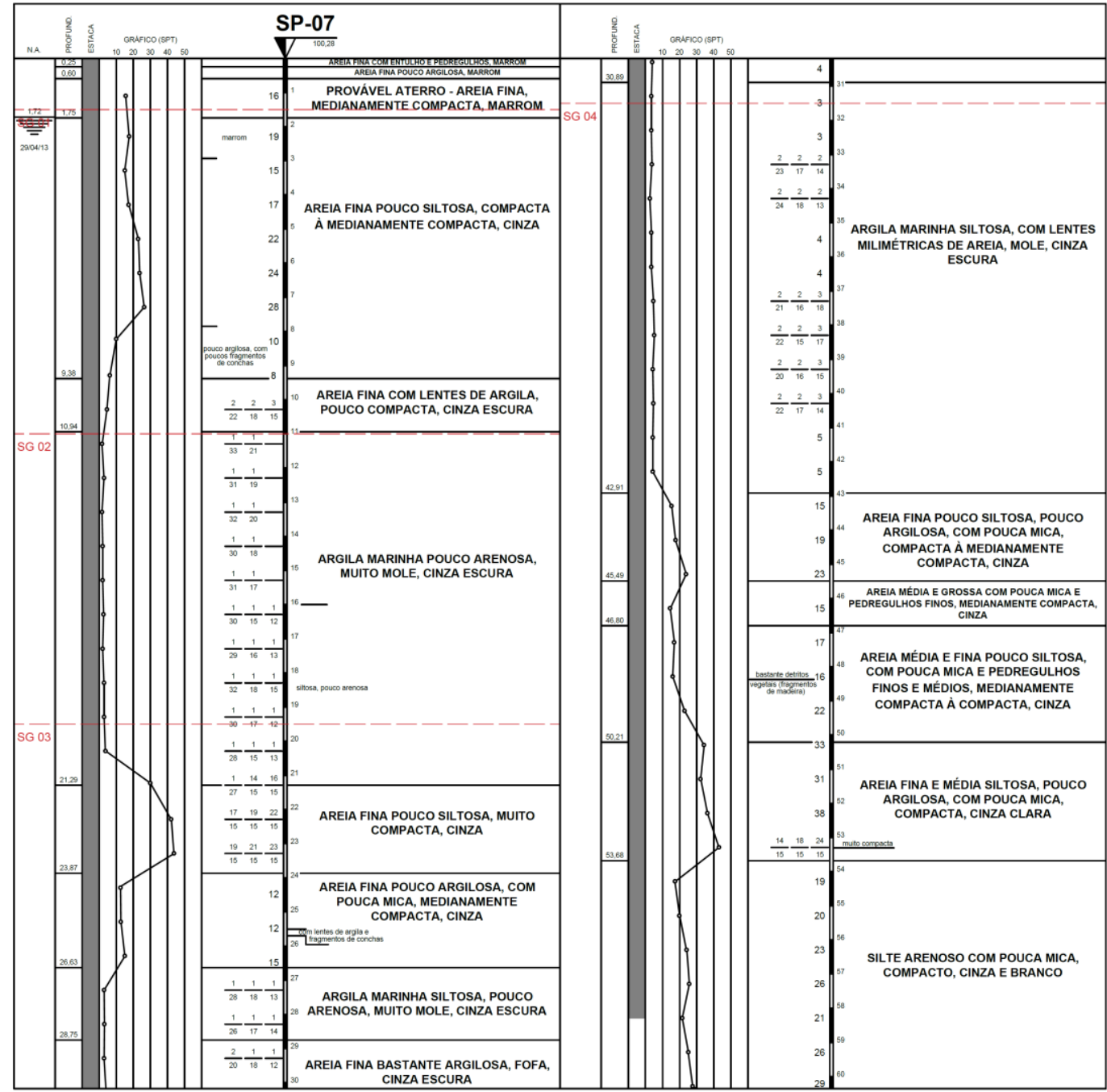

Figura l-23: perfil SP-07, próximo à prova de carga Trin.

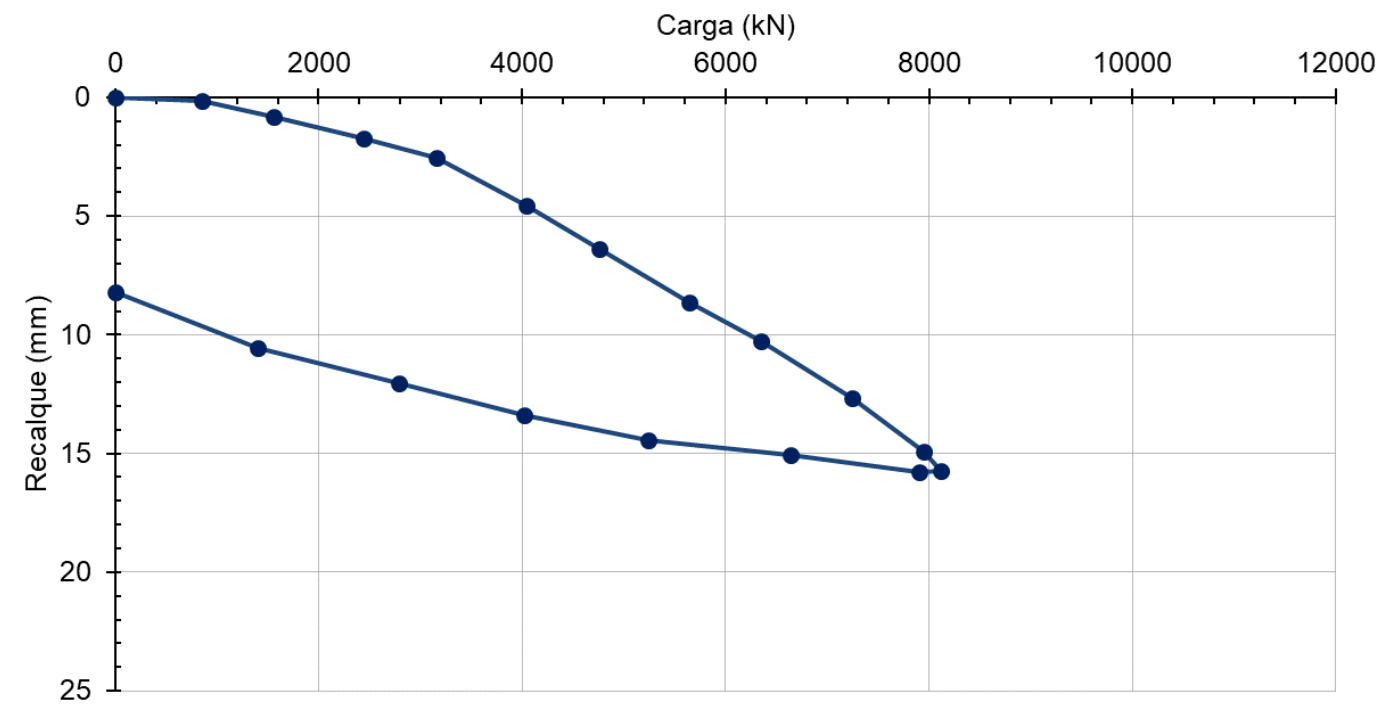

Figura I-24: curva carga-recalque da prova de carga Trin. 
I.8. Legend/Clube Sírio (Leg_1 e Leg_2)

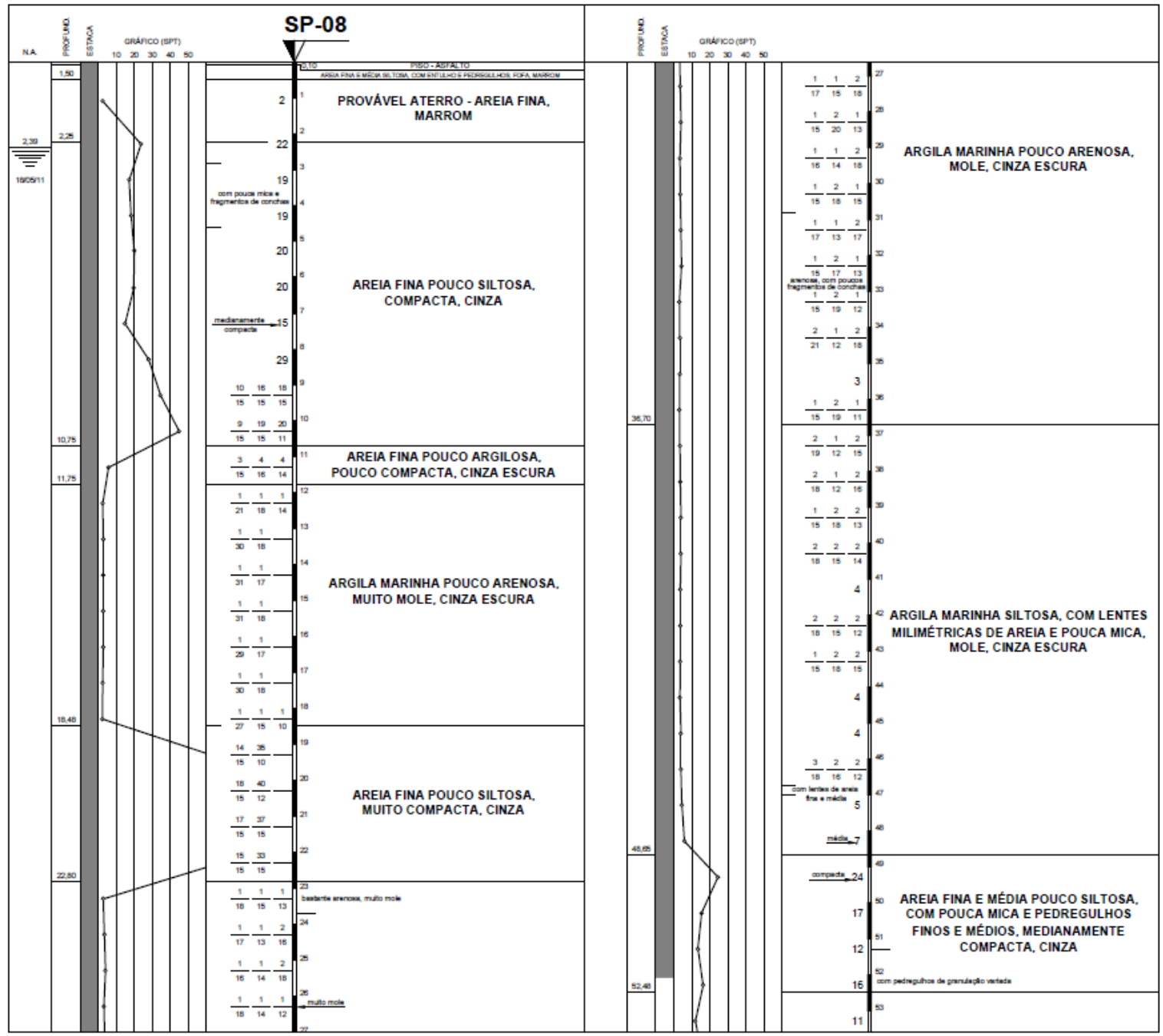

Figura I-25: perfil SP-08, próximo à prova de carga Leg_1.

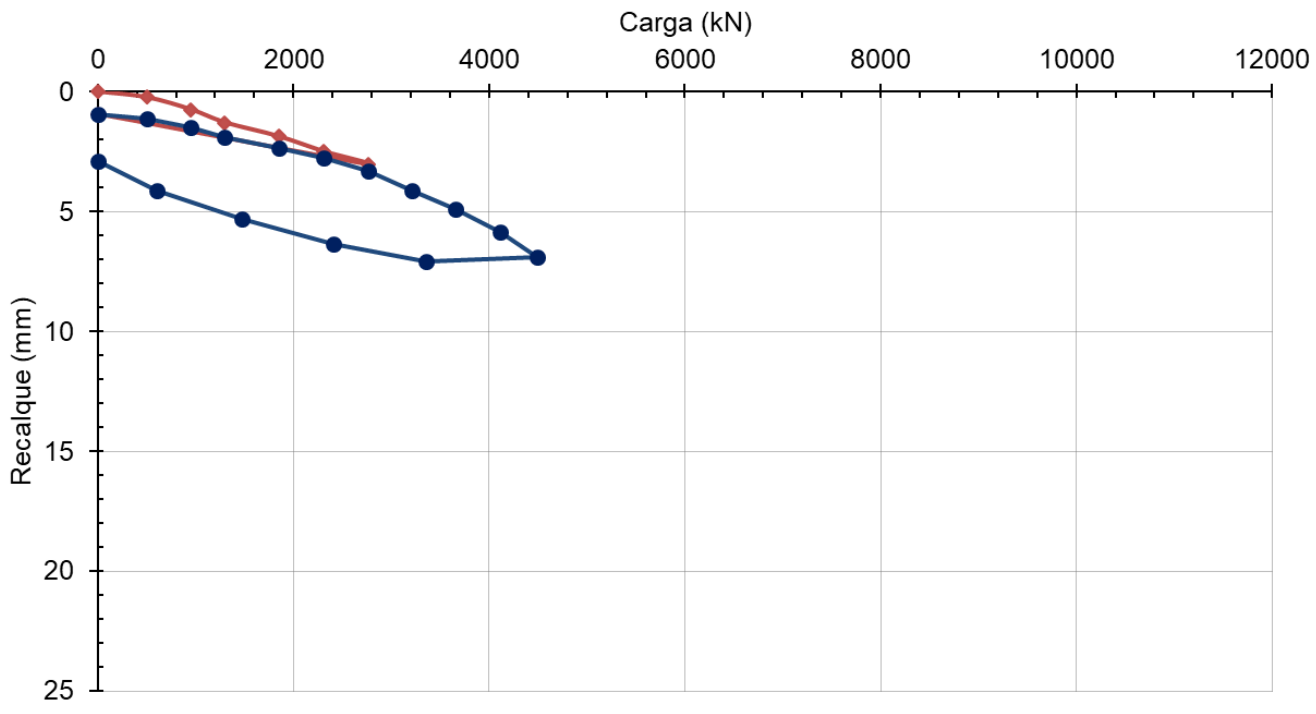

Figura I-26: curva carga-recalque da prova de carga Leg_1. 


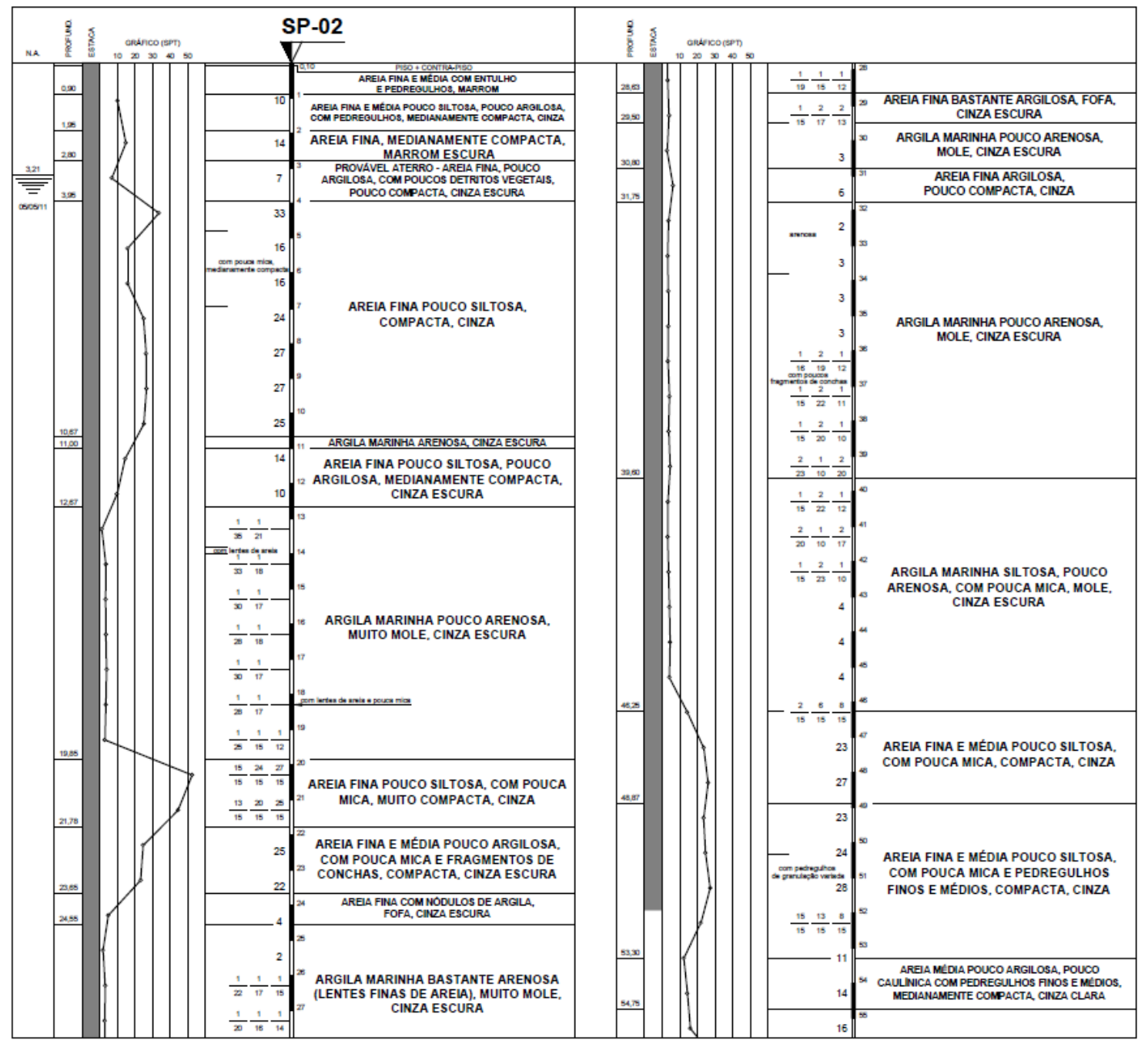

Figura I-27: perfil SP-02, próximo à prova de carga Leg_2.

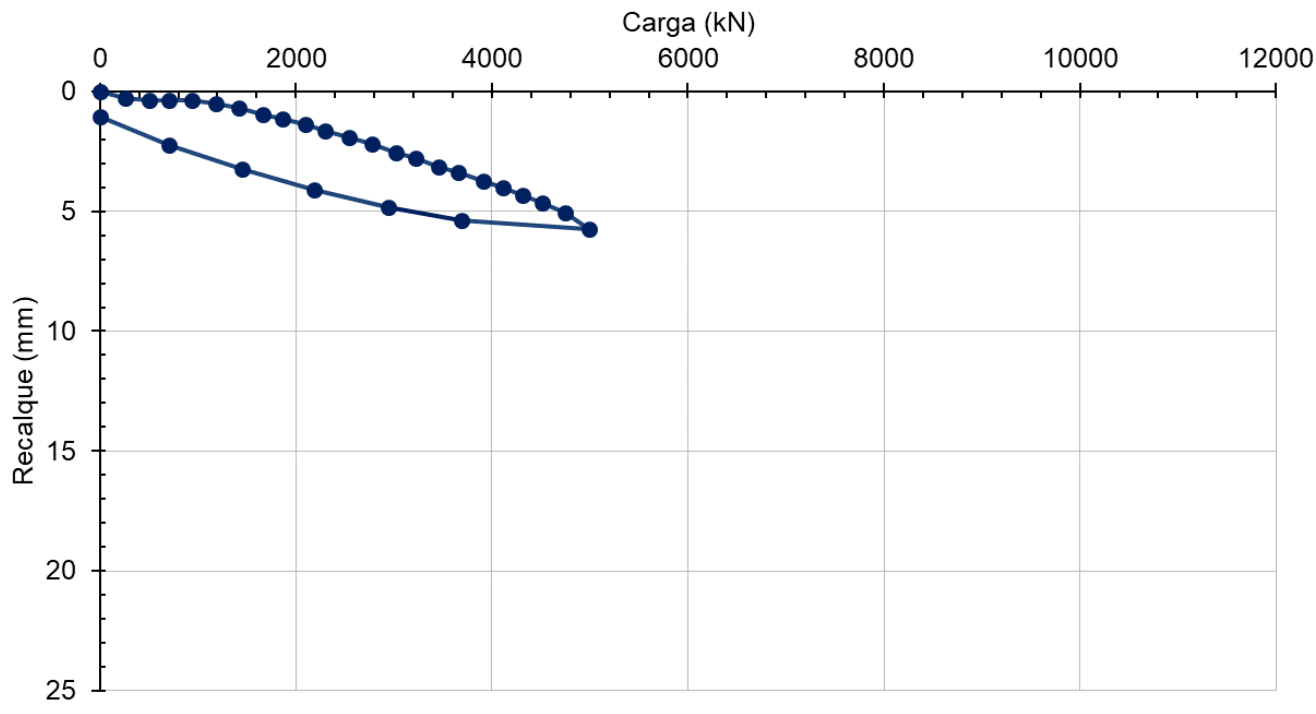

Figura I-28: curva carga-recalque da prova de carga Leg_2. 
I.9. The Blue/Pinhal (TB_1 e TB_2)

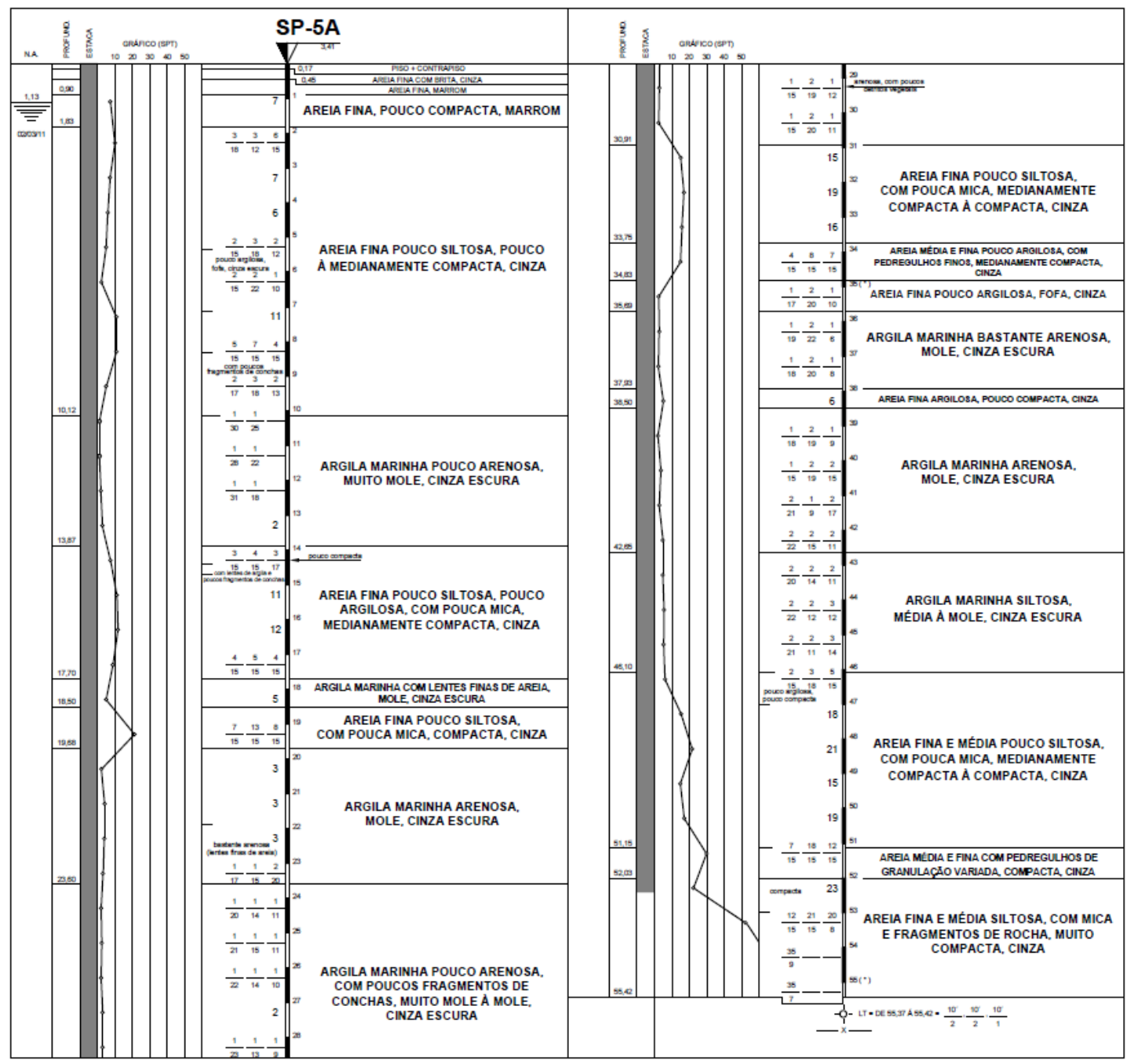

Figura l-29: perfil SP-5A, próximo à prova de carga TB_1.

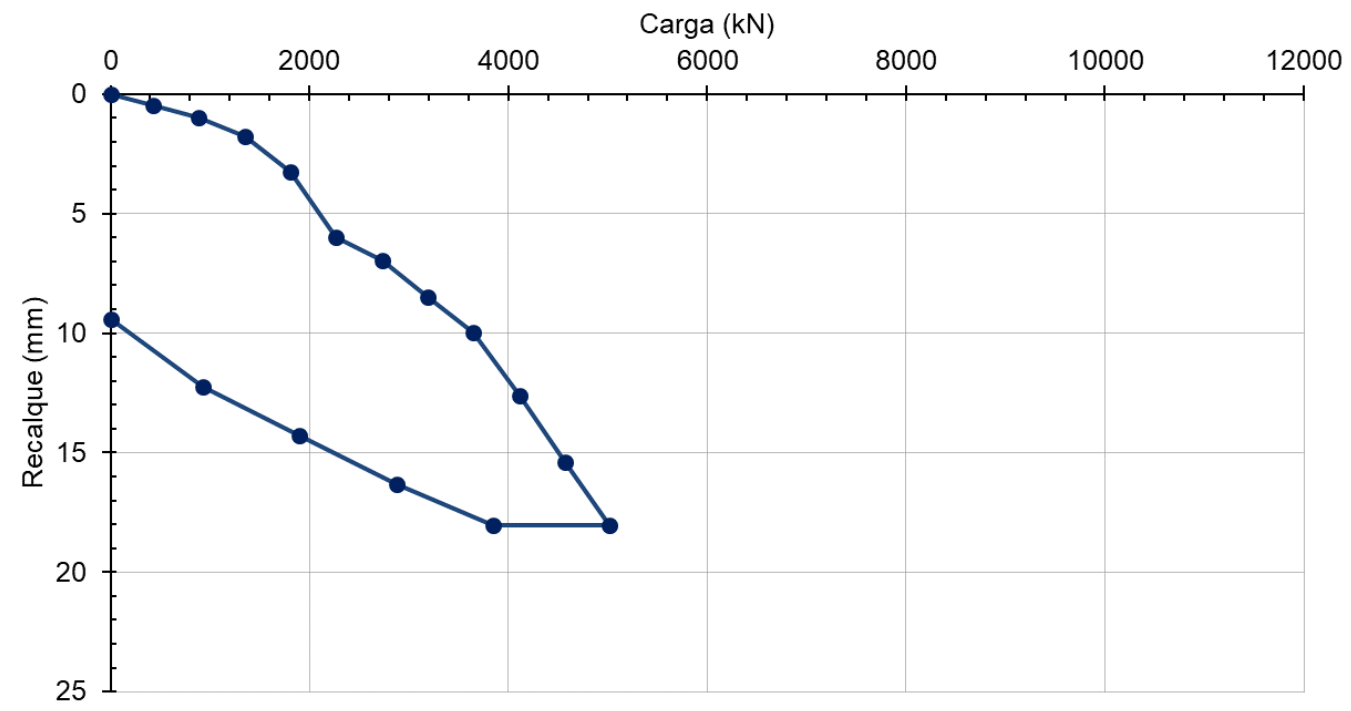

Figura I-30: curva carga-recalque da prova de carga TB_1. 


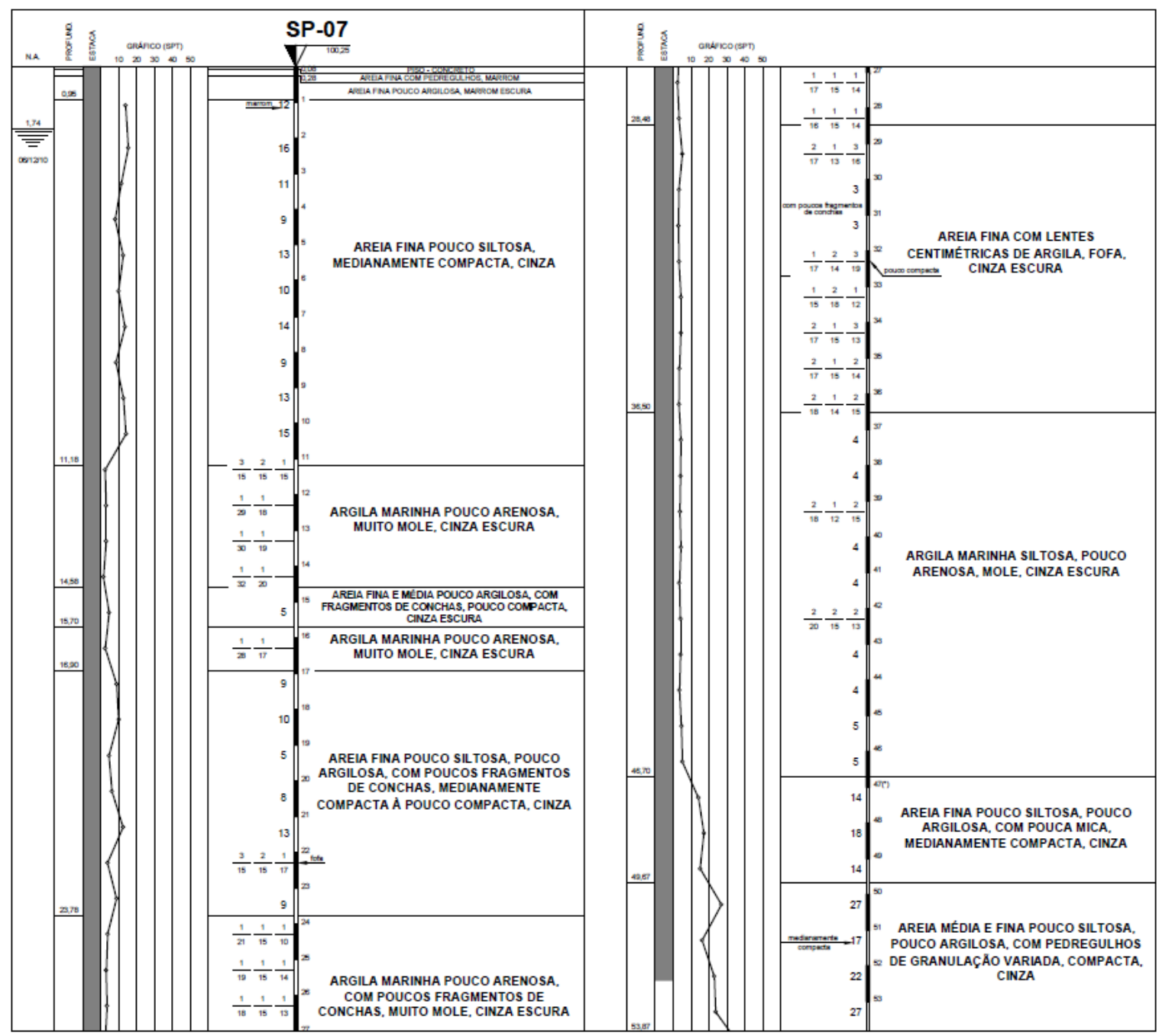

Figura I-31: perfil SP-07, próximo à prova de carga TB_2.

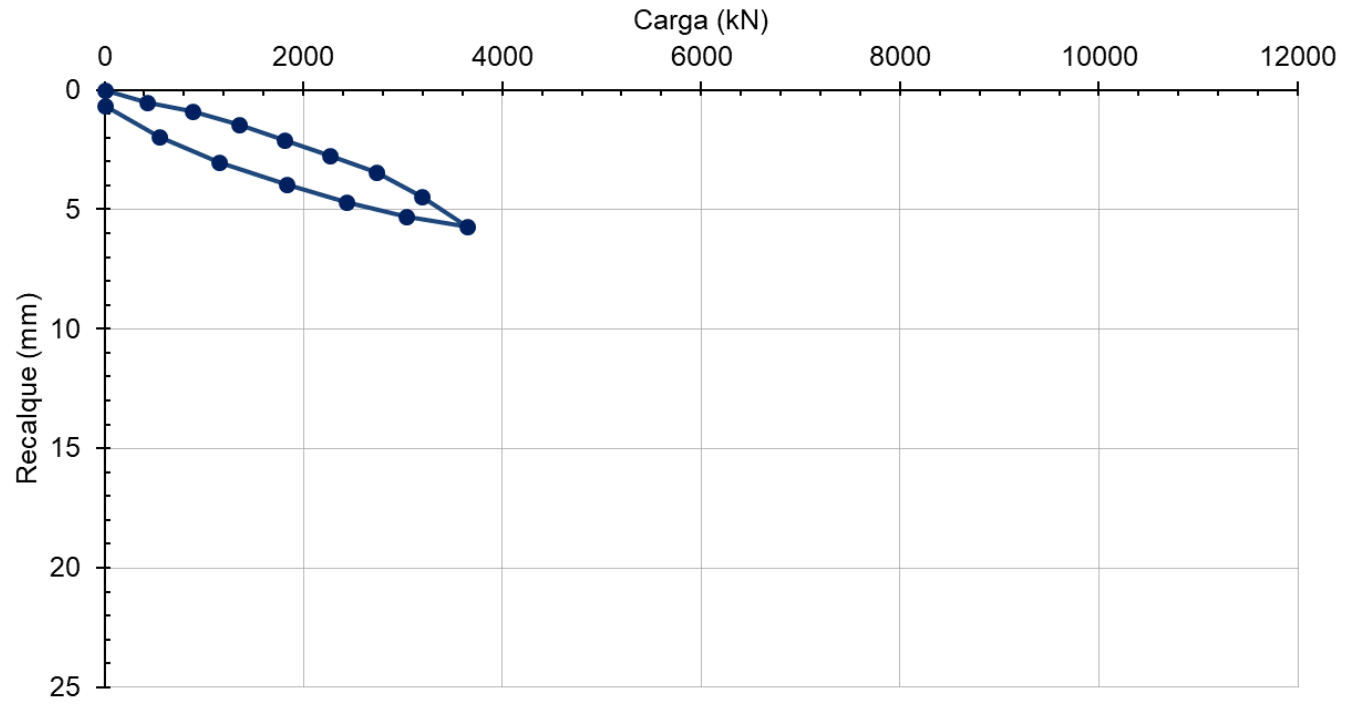

Figura I-32: curva carga-recalque da prova de carga TB_2. 
I.10. Rua Pernambuco (PE)

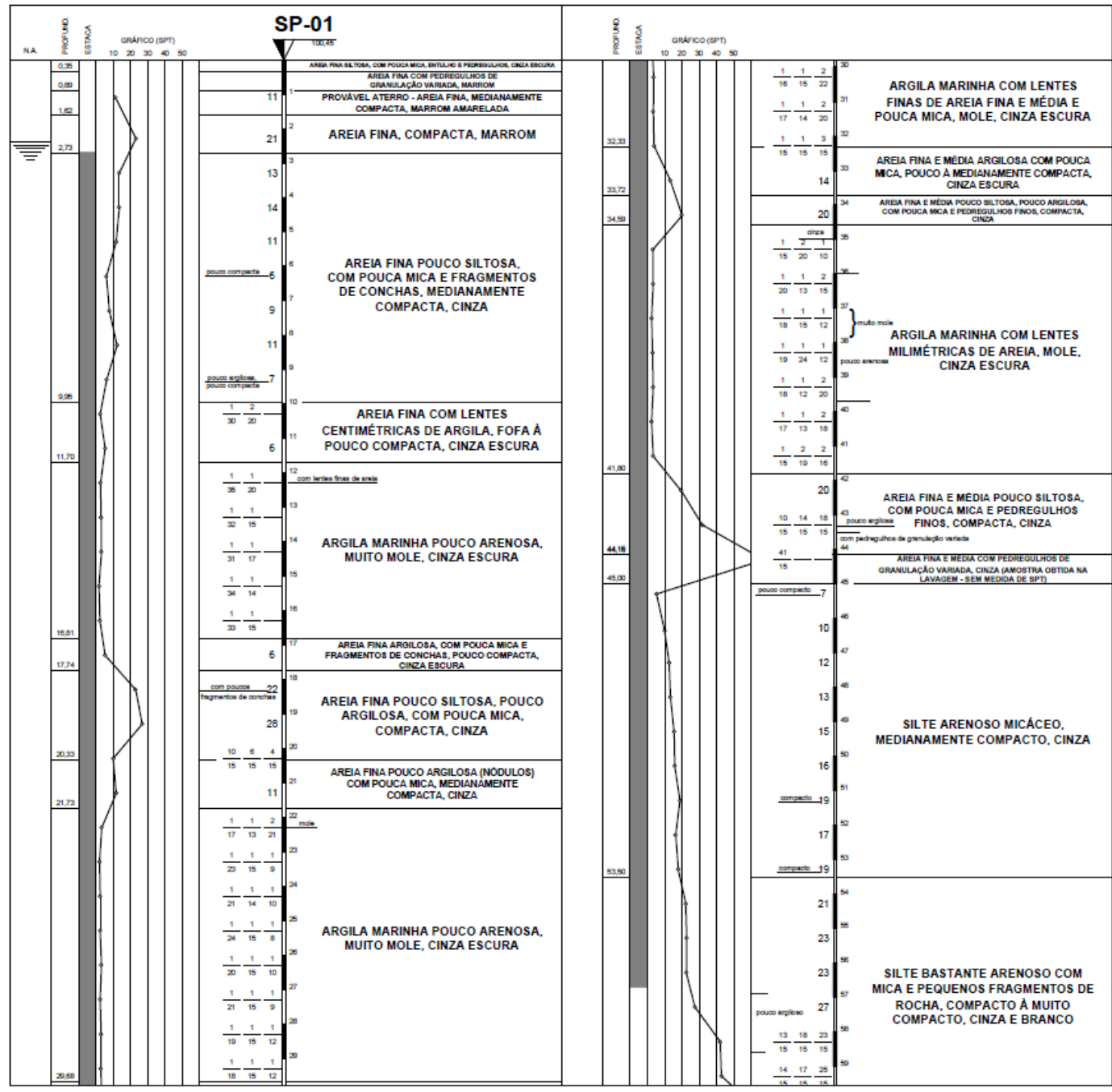

Figura l-33: perfil SP-01+01 $\mathrm{A}$, próximo à prova de carga $\mathrm{PE}$.

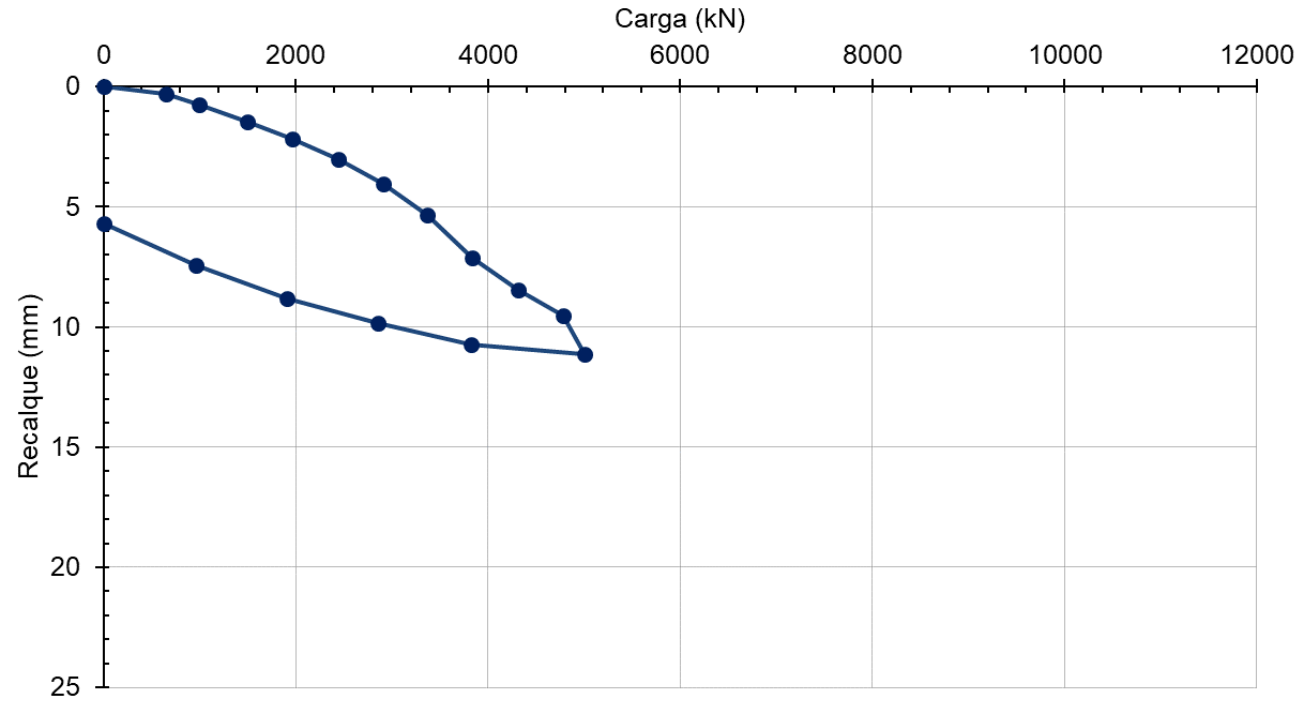

Figura I-34: curva carga-recalque da prova de carga PE. 
I.11. Rua Luiz Antonio de Andrade Vieira (Kinb)

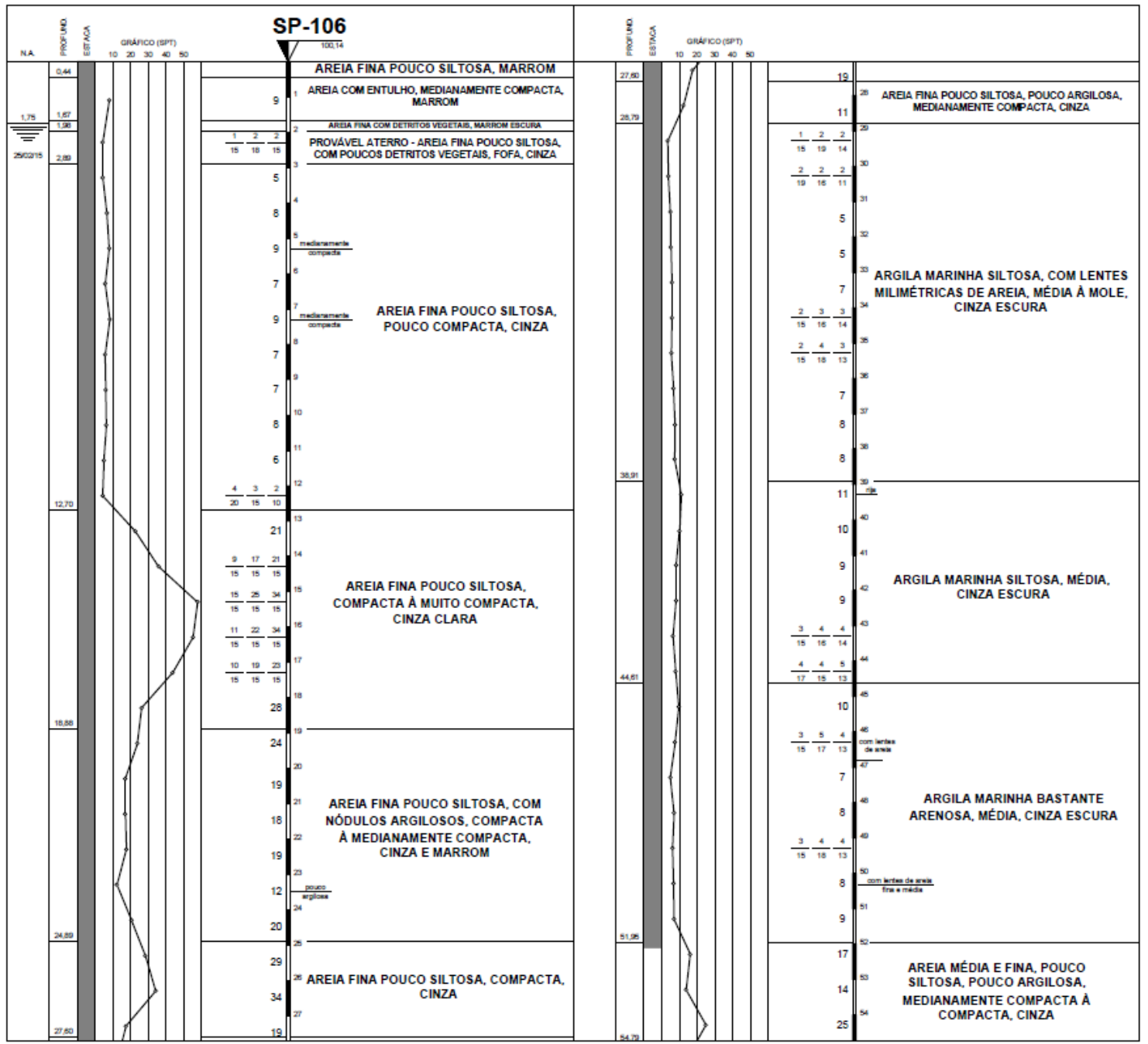

Figura I-35: perfil SP-106, próximo à prova de carga Kinb.

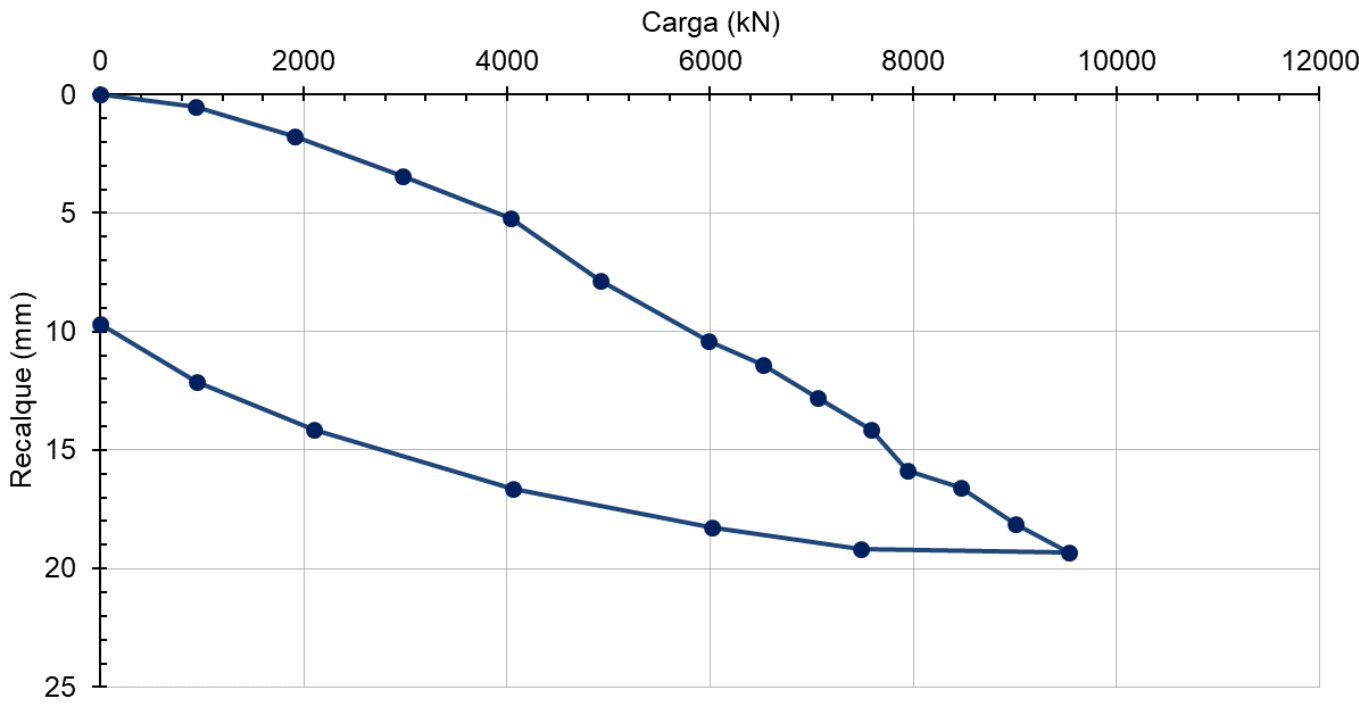

Figura I-36: curva carga-recalque da prova de carga Kinb. 